\title{
Repeatability of on-road routes and a comparison of on-road routes to the federal test procedure
}

\author{
J. Axel Radermacher \\ West Virginia University
}

Follow this and additional works at: https://researchrepository.wvu.edu/etd

\section{Recommended Citation}

Radermacher, J. Axel, "Repeatability of on-road routes and a comparison of on-road routes to the federal test procedure" (2004). Graduate Theses, Dissertations, and Problem Reports. 1454.

https://researchrepository.wvu.edu/etd/1454

This Thesis is protected by copyright and/or related rights. It has been brought to you by the The Research Repository @ WVU with permission from the rights-holder(s). You are free to use this Thesis in any way that is permitted by the copyright and related rights legislation that applies to your use. For other uses you must obtain permission from the rights-holder(s) directly, unless additional rights are indicated by a Creative Commons license in the record and/ or on the work itself. This Thesis has been accepted for inclusion in WVU Graduate Theses, Dissertations, and Problem Reports collection by an authorized administrator of The Research Repository @ WVU. For more information, please contact researchrepository@mail.wvu.edu. 


\title{
Repeatability of On-Road Routes and a Comparison of On-Road Routes to the Federal Test Procedure
}

\author{
J. Axel Radermacher \\ Thesis submitted to the \\ College of Engineering and Mineral Resources \\ at West Virginia University \\ in partial fulfillment of the requirements \\ for the degree of \\ Master of Science \\ in \\ Mechanical Engineering
}

Nigel N. Clark, Ph.D., Chair

Gregory J. Thompson, Ph.D.

Mridul Gautam, Ph.D.

Daniel K. Carder, MSME

Department of Mechanical and Aerospace Engineering

Morgantown, West Virginia

2004

Keywords: Emissions, On-road Emissions, Heavy-Duty Vehicle Emissions, Routes Copyright 2004 J. Axel Radermacher 


\section{Abstract \\ REPEATABILITY OF ON-ROAD ROUTES AND A COMPARISON OF ON-ROAD ROUTES TO THE FEDERAL TEST PROCEDURE}

By J. Axel Radermacher

Current testing methods are often unrepresentative of real world use, causing mobile source emissions inventories to be inaccurate. Emissions inventories account for emissions produced by vehicles and stationary sources for a given area. Heavy-duty vehicle data for emissions inventories are usually taken from the federal certification test. This test often does not correspond with in-use emissions. To accurately account for inuse emissions, data must be gathered from in-use testing.

West Virginia University has developed a Mobile Emissions Measurement System that recorded vehicle behavior, engine behavior, and exhaust emissions behavior during in-use testing. This system was used to obtain data from numerous vehicles over specified on-road routes. A study was conducted on on-road route repeatability. A methodology for finding repeatability had to be established, and factors influencing repeatability were identified. It was found that routes and drivers significantly influenced repeatability, and that further study of a larger sample group needs to be conducted before specific conclusions could be drawn about the influences of the vehicle on repeatability.

A further study was conducted on how well the on-road routes compare to the federal emissions test. Engine behavior for on road testing was binned and compared to the federal certification test. It was found that routes that contained substantial portions of urban traffic were more representative of the federal test procedure than routes with mostly freeway driving. 


\section{Acknowledgements}

There are numerous people who deserve thanks for aiding me during my graduate student career. Thank you Nigel Clark, for your guidance, support, and attitude as well as for the opportunity to complete a graduate degree. Thank you Gregory Thompson, for your efficiency and dedication in carrying out the work necessary to complete our research. Thank you Mridul Gautum, for leading this project and teaching me engineering and dedication. Thank you Daniel Carder, Wesley Riddle, Ron Jarrett, and numerous graduate students (especially John Gibble) for making the project successful and helping me with my work. Thank you Tom Spencer, Richard Atkinson, and Andy Pertl for your assistance and interesting conversation.

Thank you Karen, Astrid, Uschi and Fred, and Reinhard and Paula for your support, encouragement, and tolerance while I was completing my graduate studies and throughout my life. Thank you for teaching me ethics and morals that make me the person I am today.

Thank you Kassie, for tolerating the long days and late nights and for always supporting me regardless of my decisions. 


\section{Table of Contents}

Repeatability of On-Road Routes and a Comparison of On-Road Routes to the Federal

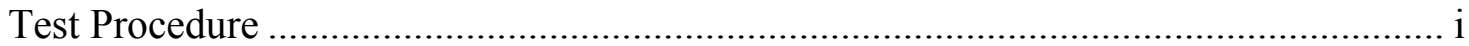

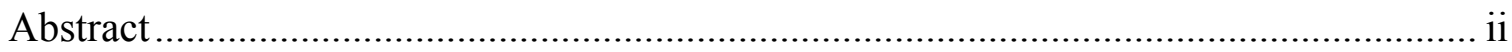

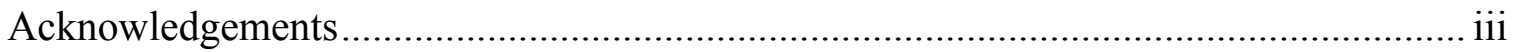

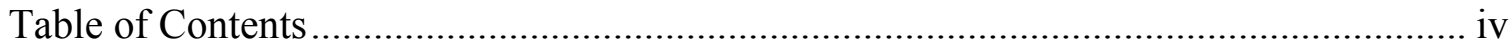

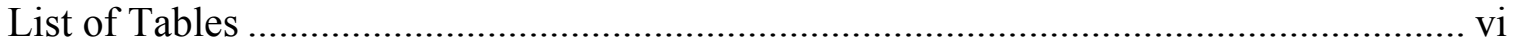

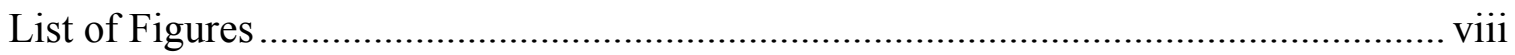

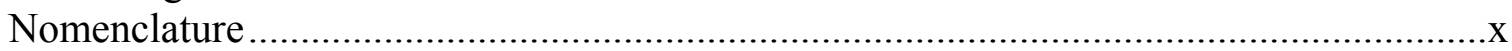

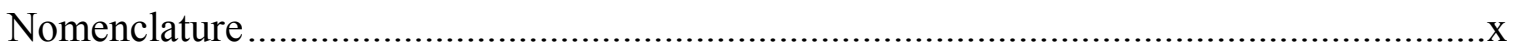

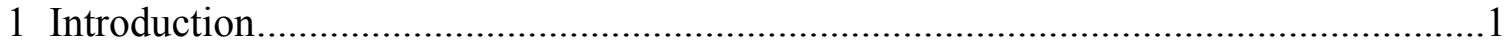

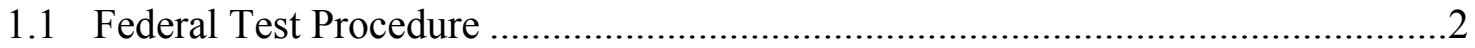

1.2 Emissions Inventory.....................................................................................

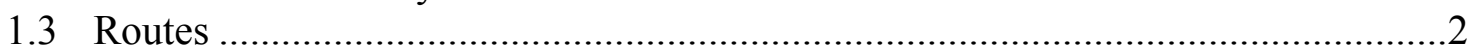

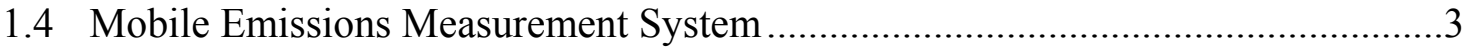

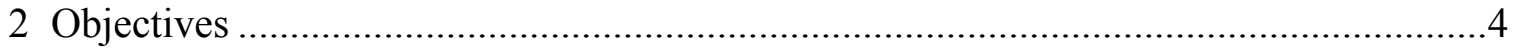

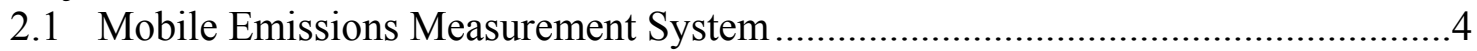

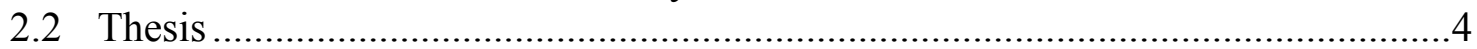

3 Literature Review ..........................................................................................

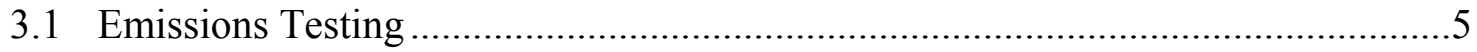

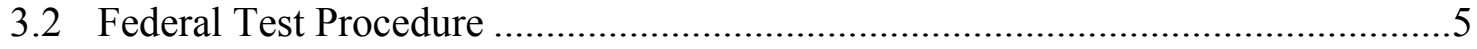

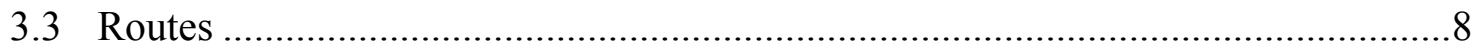

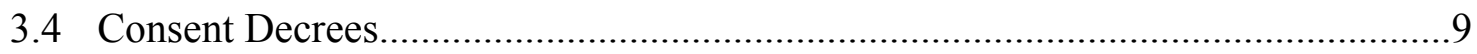

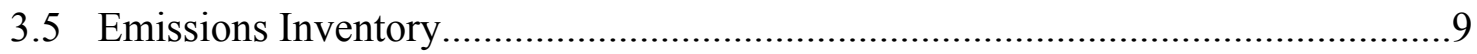

3.6 On-Road Emissions Measurement System .................................................11

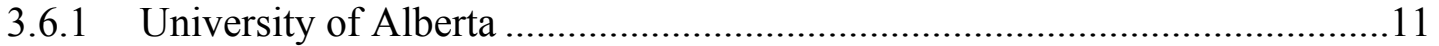

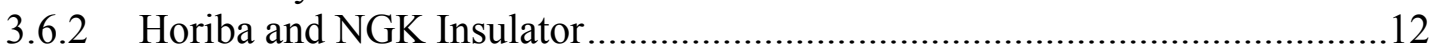

3.6.3 Technical Research Center of Finland ...................................................... 12

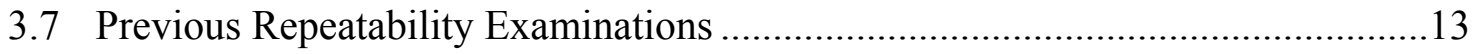

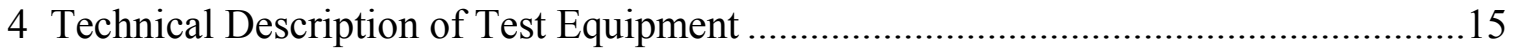

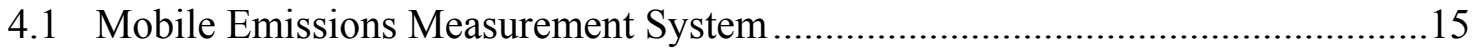

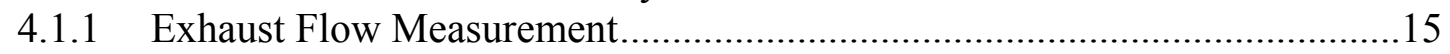

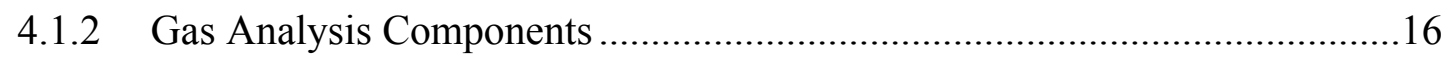

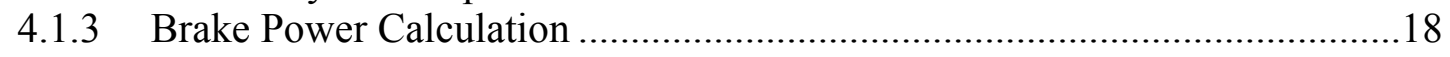

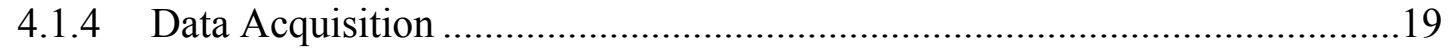

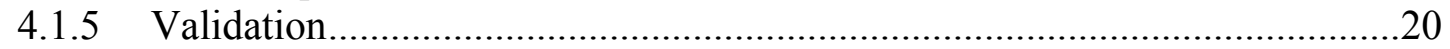

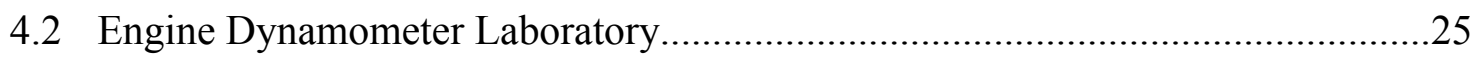

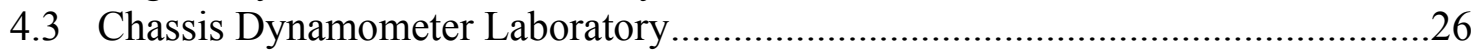

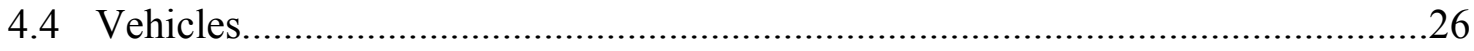

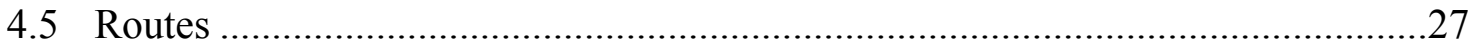

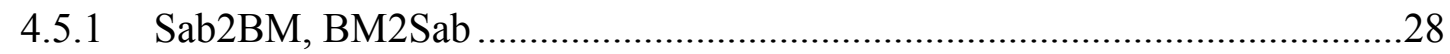

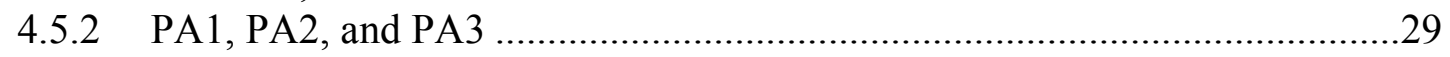

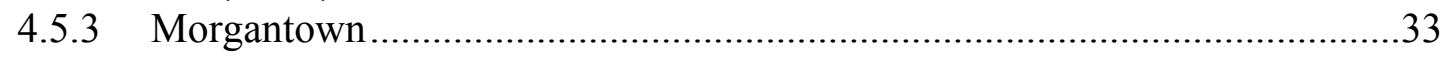

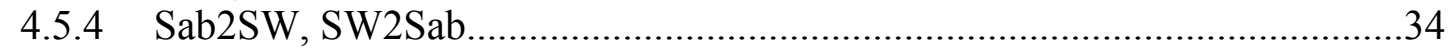

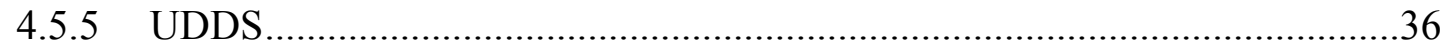




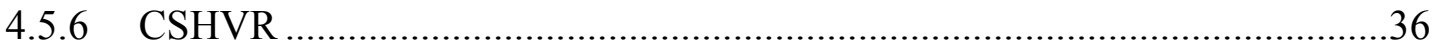

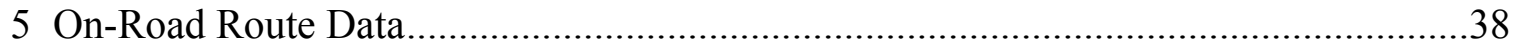

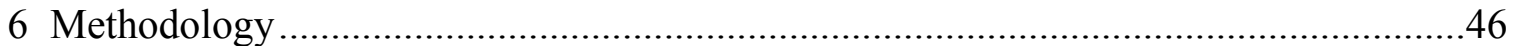

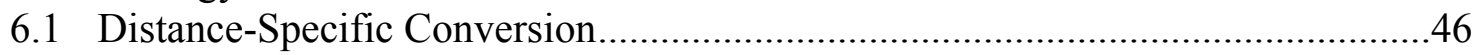

6.2 Multiple Dimension Linear Regression Analysis ..................................................46

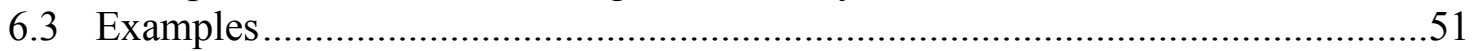

7 Repeatability of Current Testing Methods.................................................................53

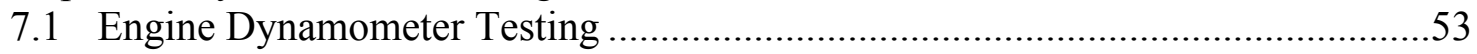

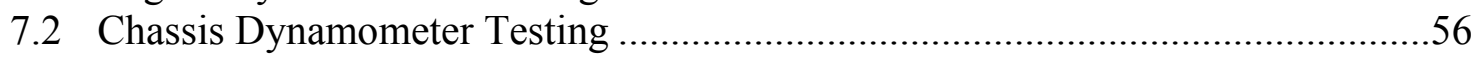

8 Repeatability of Vehicular Behavior and Emissions ....................................................60

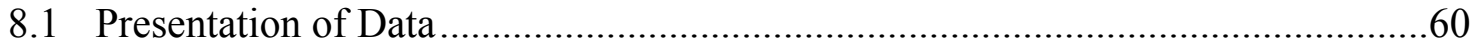

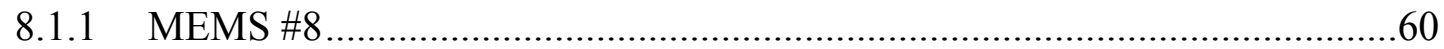

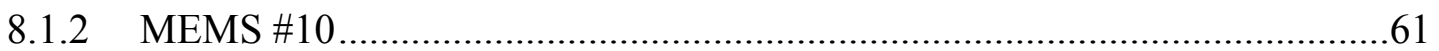

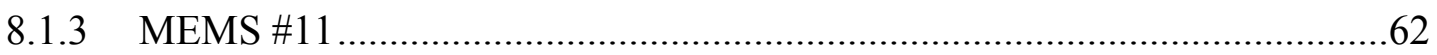

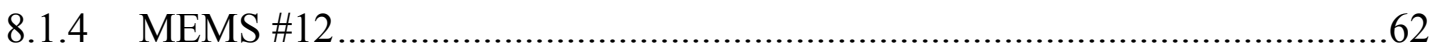

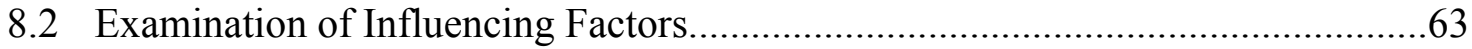

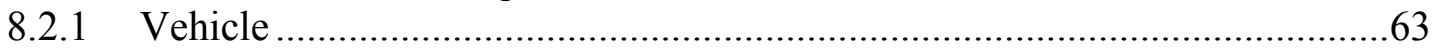

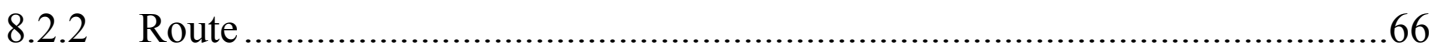

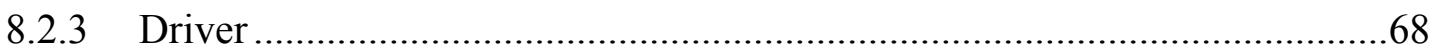

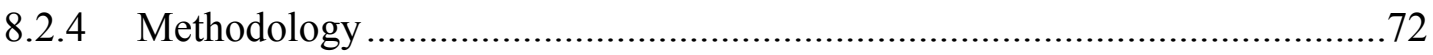

9 Examination of MEMS Routes with Respect to FTP …………………....................79

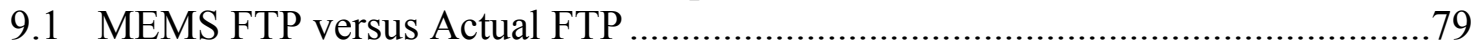

9.2 Methodology for FTP/On-Road Route Comparison.............................................82

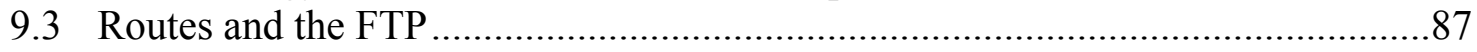

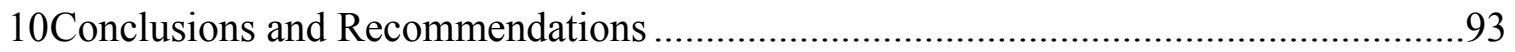

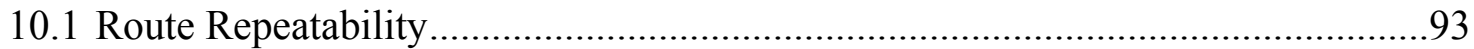

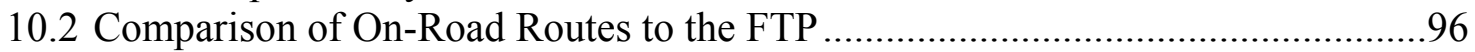

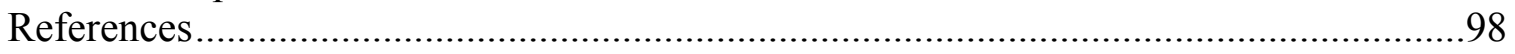

Appendix A: Not-to-Exceed Zone Description ..............................................................101

Appendix B: Converting Data to Distance-Based Program ……………........................103

Appendix C: 3-Dimensional Linear Regression Program ..............................................104

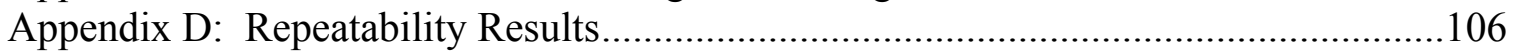

Appendix E: Speed/Load Distribution Program ............................................................109

Appendix F: COV\% and Coefficient of Repeatability Comparison.................................111 


\section{List of Tables}

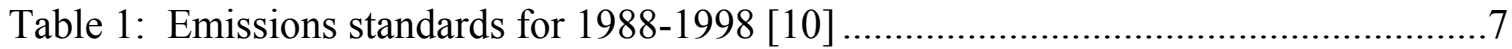

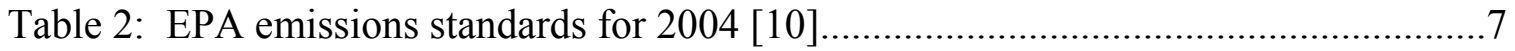

Table 3: EPA emissions standards for 2007 .............................................................. 7

Table 4: FTP validation criteria for speed, torque, and power [3] ................................

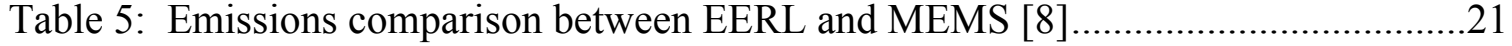

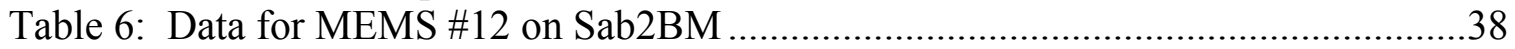

Table 7: Coefficients of repeatability for time-specific data of MEMS \#12 on

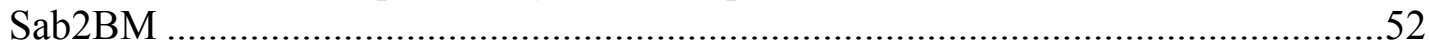

Table 8: Coefficients of repeatability for distance-specific data of MEMS \#12 on

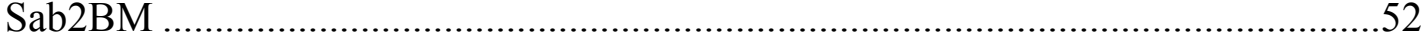

Table 9: Total trip energy, $\mathrm{CO}_{2}$ emissions, and $\mathrm{NO}_{\mathrm{x}}$ emissions for MEMS \#12 on

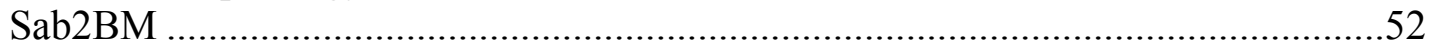

Table 10: Coefficients of repeatability for MEMS \#8 dynamometer testing over the

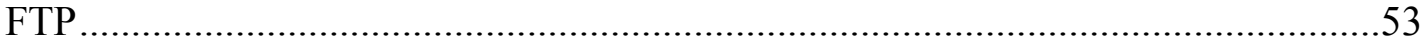

Table 11: Total energy and brake-specific emissions values for MEMS \#8 engine

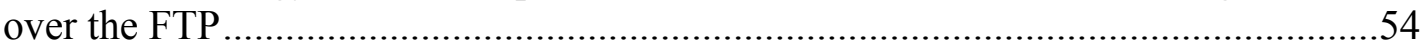

Table 12: Coefficients of repeatability for MEMS \#12 over the FTP ............................54

Table 13: Total energy and brake-specific emissions values for MEMS \#12 engine

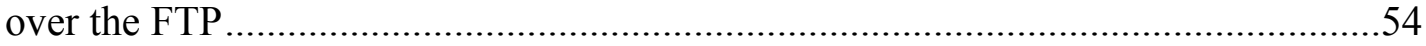

Table 14: Coefficients of repeatability for the dynamometer controlled Sab2BM

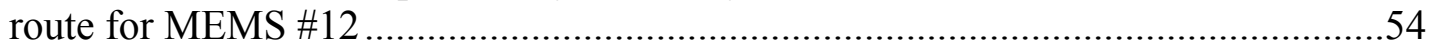

Table 15: Total energy and brake-specific emissions values for MEMS \#12 engine

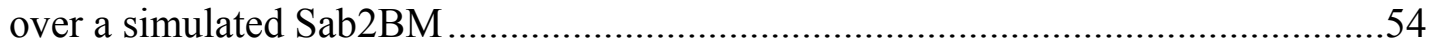

Table 16: Coefficients of repeatability for MEMS \#8 using MEMS data over the FTP.

Table 17: Total energy and brake-specific emissions values for MEMS \#8 engine

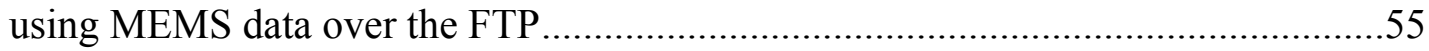

Table 18: Coefficients of repeatability for MEMS \#12 over the FTP using MEMS

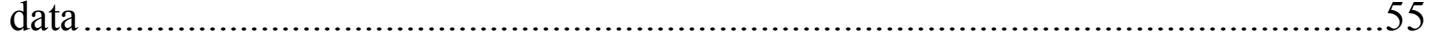

Table 19: Total energy and brake-specific emissions values for the MEMS \#12 engine over the FTP using MEMS data ..........................................................55

Table 20: Coefficients of repeatability for the MEMS \#12 engine over an in-cell

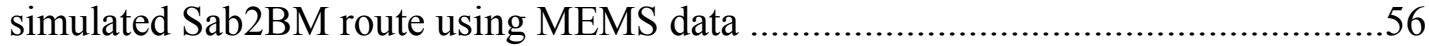

Table 21: Total energy and brake-specific emissions values for the MEMS \#12 engine over an in-cell simulated Sab2BM route using MEMS data.........................56

Table 22: Coefficients of repeatability for the Ford tractor over the UDDS ...................57

Table 23: Total energy and brake-specific emissions values for the Ford tractor over

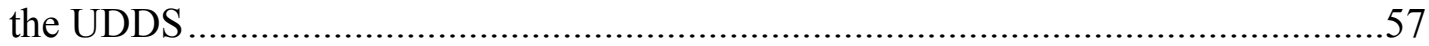

Table 24: Coefficients of repeatability values for the Sterling tractor over the CSHVR

Table 25: Total energy and brake-specific emissions values for the Sterling tractor

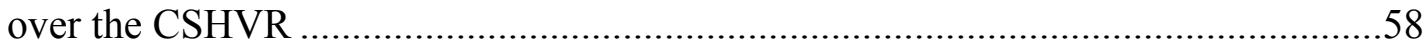

Table 26: Coefficients of repeatability for MEMS \#8 ...............................................60

Table 27: Average and COV\% values for total trip data for MEMS \#8. 
Table 28: Coefficients of repeatability for MEMS \#10 ............................................61

Table 29: Average and COV\% values for total trip data for MEMS \#10......................61

Table 30: Coefficients of repeatability for MEMS \#11 .............................................62

Table 31: Average and COV\% values for total trip data for MEMS \#11 ........................62

Table 32: Coefficients of repeatability for MEMS \#12 ............................................62

Table 33: Average and COV\% values for total trip data for MEMS $\# 12 \ldots \ldots \ldots \ldots \ldots \ldots \ldots . . . .63$

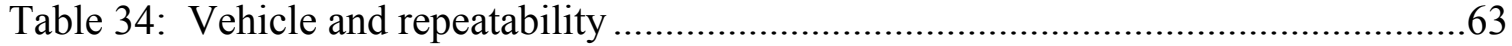

Table 35: Coefficients of repeatability for MEMS \#10 vs. MEMS \#11 over two

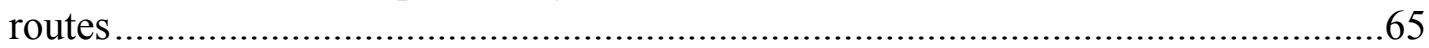

Table 36: Coefficients of repeatability for MEMS \#8 vs. MEMS \#12 over two routes...65

Table 37: Coefficients of repeatability for MEMS \#8, MEMS \#10, MEMS \#11, and

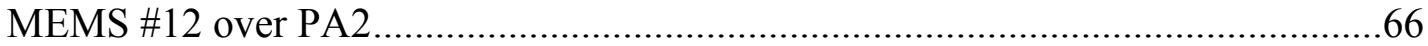

Table 38: Comparison of route repeatability ..........................................................66

Table 39: Coefficients of repeatability for MEMS \#8 over Sab2BM for three and

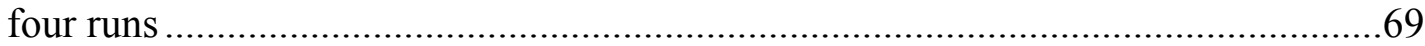

Table 40: Coefficients of repeatability for MEMS \#12 over BM2Sab...........................70

Table 41: Coefficients of repeatability for MEMS \#8 over Sab2SW ..............................70

Table 42: Effects of multiple runs on coefficient of repeatability ...................................76

Table 43: Variances between MEMS \#8 and MEMS \#12 for each examined

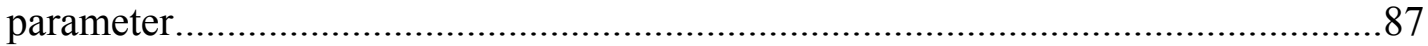

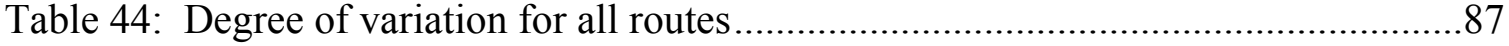

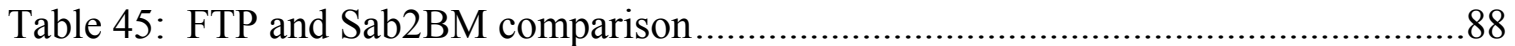

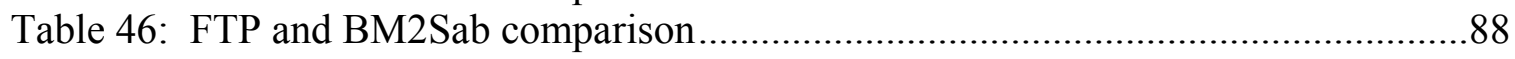

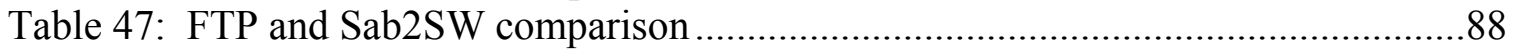

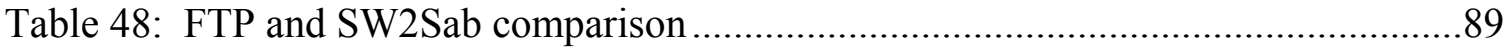

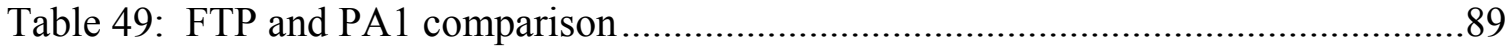

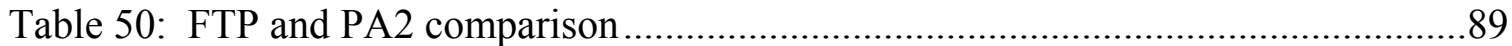

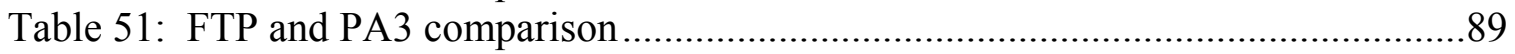

Table 52: Percent idle time for on-road routes and the FTP .....................................90

Table 53: Percent time spent at greater than $95 \%$ load for on-road routes and the

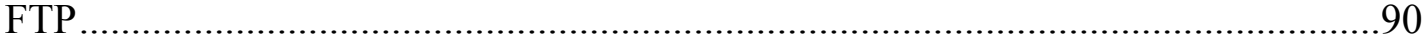

Table 54: Percent time spent over 105\% engine speed for on-road routes and the

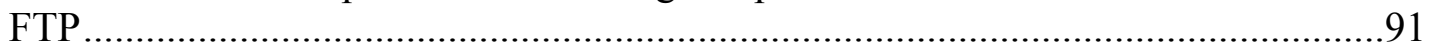

Table 55: Repeatability analysis of MEMS vehicle over Morgantown route. ...............106

Table 56: Repeatability analysis of MEMS vehicle over Sab2BM route......................106

Table 57: Repeatability analysis of MEMS vehicle over BM2Sab route.....................107

Table 58: Repeatability analysis of MEMS vehicle over Sab2SW route......................107

Table 59: Repeatability analysis of MEMS vehicle over SW2Sab route......................107

Table 60: Repeatability analysis of MEMS vehicle over PA1 route.............................108

Table 61: Repeatability analysis of MEMS vehicle over PA2 route.............................108

Table 62: Repeatability analysis of MEMS vehicle over PA3 route. ........................... 108 


\section{List of Figures}

Figure 1: Engine speeds for the FTP [3] ..............................................................6

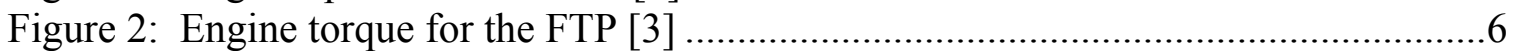

Figure 3: MEMS exhaust flow tube with Annubar and pressure transducer unit [8] .......16

Figure 4: Schematic of MEMS sampling system [8] ..................................................18

Figure 5: MEMS gas analyzer and data acquisition system [8]....................................20

Figure 6: Mass emissions rates of $\mathrm{CO}_{2}$ over a steady-state dynamometer test cycle -

MEMS results and laboratory results [8] ...........................................................21

Figure 7: Mass emissions rates of $\mathrm{NO}_{\mathrm{x}}$ over a steady-state dynamometer test cycle -

MEMS results and laboratory results [8] .............................................................22

Figure 8: Mass emissions rates of $\mathrm{CO}_{2}$ over the FTP transient test cycle-MEMS results and laboratory results $[8] \ldots \ldots \ldots \ldots \ldots \ldots \ldots \ldots \ldots \ldots \ldots \ldots \ldots \ldots \ldots \ldots \ldots \ldots \ldots \ldots \ldots \ldots \ldots \ldots \ldots . .22$

Figure 9: Mass emissions rates of $\mathrm{NO}_{\mathrm{x}}$ over the FTP transient test cycle - MEMS

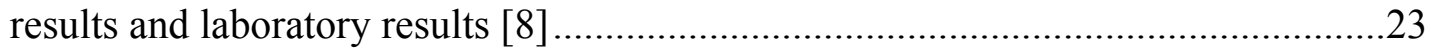

Figure 10: Mass emissions rates of $\mathrm{CO}_{2}$ over a simulated on-road transient test cycle

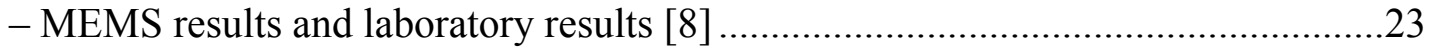

Figure 11: Mass emissions rates of $\mathrm{NO}_{\mathrm{x}}$ over a simulated on-road transient test cycle - MEMS results and laboratory results [8] .........................................................24

Figure 12: Continuous engine speed from MEMS data and in-cell data over the FTP ....24

Figure 13: Continuous engine torque from MEMS data and in-cell data over the FTP ...25

Figure 14: Map of Bruceton Mills route [8] ..............................................................28

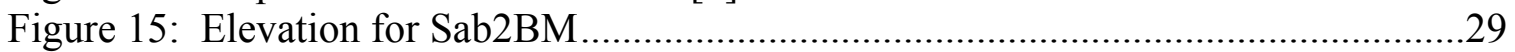

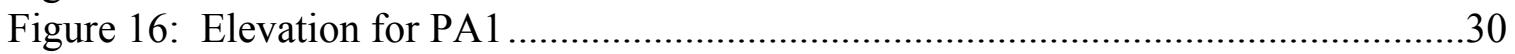

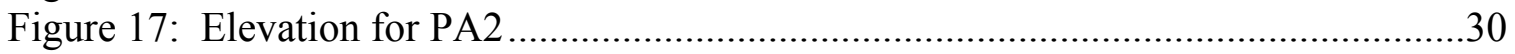

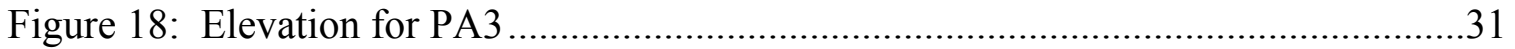

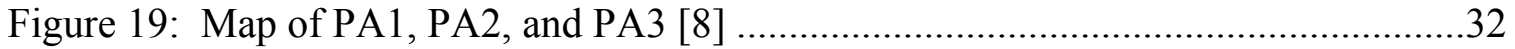

Figure 20: The map of Morgantown route [8] ..........................................................33

Figure 21: Elevation for the Morgantown route ...........................................................

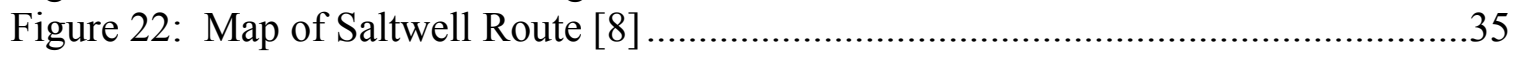

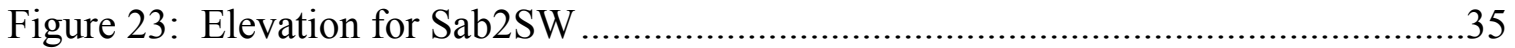

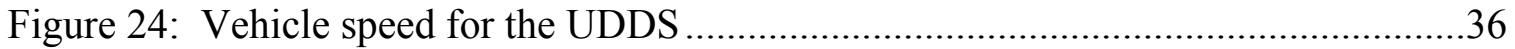

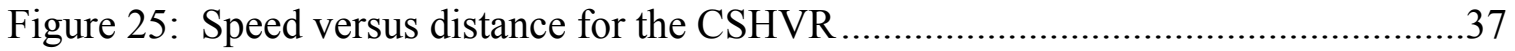

Figure 26: Speed versus time for the CSHVR ……….................................................

Figure 27: Time-based speed data for MEMS \#12 on Sab2BM........................................39

Figure 28: Distance-based vehicle speed data for MEMS \#12 on Sab2BM......................40

Figure 29: Distance-based elapsed time data for MEMS \#12 on Sab2BM .......................40

Figure 30: Distance-based gear ratio data for MEMS \#12 on Sab2BM ............................41

Figure 31: Distance-based engine speed data for MEMS \#12 on Sab2BM ......................42

Figure 32: Distance-based engine torque data for MEMS \#12 on Sab2BM .....................42

Figure 33: Distance-based engine power data for MEMS \#12 on Sab2BM.......................43

Figure 34: Distance-based $\mathrm{CO}_{2}$ emissions data for MEMS \#12 on Sab2BM....................44

Figure 35: Distance-based $\mathrm{NO}_{\mathrm{x}}$ emissions data for MEMS \#12 on Sab2BM ...................44

Figure 36: Distance-based NTE zone activity for MEMS \#12 on Sab2BM......................45

Figure 37: Detail of vehicle speed with instantaneous COV\% for MEMS \#12 over Sab2BM 
Figure 38: Vehicle speed as a function of distance for two repeat runs of MEMS \#8 on Sab2BM

Figure 39: Vehicle speed as a function of time for two repeat of MEMS \#8 on

Sab2BM

Figure 40: Point plotted in three-dimensional space with error and ideal values .............50

Figure 41: Three-dimensional plot of $\mathrm{NO}_{\mathrm{x}}$ data from three repeat runs of MEMS \#8

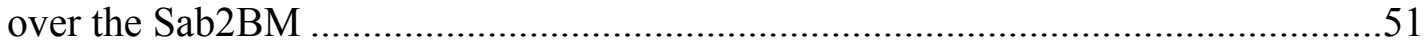

Figure 42: Detail of $\mathrm{CO}_{2}$ and power for the Sterling tractor test ..................................57

Figure 43: Detail of vehicle speed for the Sterling tractor over the CSHVR ...................58

Figure 44: Detail of hub power for the Sterling tractor over the CSHVR .......................59

Figure 45: Vehicle speed for four runs for MEMS \#8 over Sab2BM ...........................68

Figure 46: Engine torque for four runs for MEMS \#8 over Sab2BM ............................69

Figure 47: Detail of vehicle speed for MEMS \#10 and MEMS \#11 over PA1 ...............71

Figure 48: Detail of engine torque for MEMS \#10 and MEMS \#11 over PA1 ................72

Figure 49: Random points with a range of one and an offset of zero ..............................73

Figure 50: Random points with a range of one and an offset of two.............................74

Figure 51: Random points with a range of one and an offset of negative two ................74

Figure 52: The relationship of offset/range to coefficient of repeatability ......................75

Figure 53: Effects of multiple runs on coefficient of repeatability .................................76

Figure 54: Effects of discretization adjustments for MEMS \#12 over PA3 ....................77

Figure 55: Effects of discretization adjustments for MEMS \#12 over PA1 .....................78

Figure 56: Detail of time-based vehicle speed for MEMS \#12 over PA3 .......................78

Figure 57: FTP tested and defined percent speed and load set points for MEMS \#8 ......80

Figure 58: Detail of actual engine speed and torque for MEMS \#8 and FTP-defined set points

Figure 59: Rate of change of engine speed for actual and ideal engines over the FTP ....81

Figure 60: Rate of change of engine torque for actual and ideal engines over the FTP ...81

Figure 61: Speed and load for the FTP and Run 1 of Sab2SW for MEMS \#8 ................83

Figure 62: Percent engine speed distribution for Sab2BM and the FTP for MEMS \#8 ...84

Figure 63: Percent engine torque distribution for Sab2BM and the FTP for MEMS

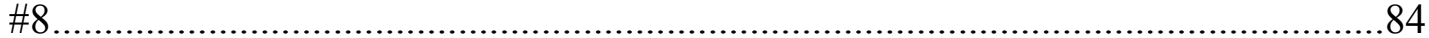

Figure 64: Bubble chart of speed and load distribution for Sab2BM and the FTP for MEMS \#8

Figure 65: Rate of Change in torque distribution for Sab2BM and FTP for MEMS \#8

Figure 66: Rate of change in engine speed distribution for MEMS \#8 over Sab2BM and the FTP

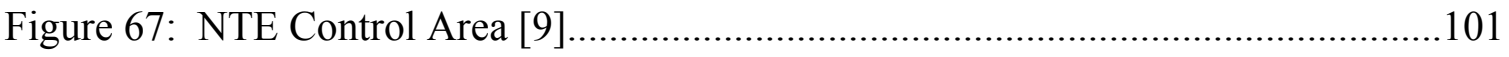

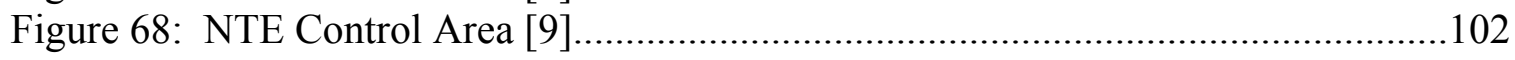

Figure 69: Comparison of COV\% for total trip energy (bhp-hr) and power coefficient of repeatability.

Figure 70: Comparison of $\mathrm{COV} \%$ for $\mathrm{CO}_{2}(\mathrm{~g} / \mathrm{mile})$ to $\mathrm{CO}_{2}$ coefficient of repeatability....

Figure 71: Comparison of COV\% for $\mathrm{NO}_{\mathrm{x}}(\mathrm{g} / \mathrm{mile})$ to $\mathrm{NO}_{\mathrm{x}}$ coefficient of repeatability..... 


\section{Nomenclature}

\begin{tabular}{|c|c|}
\hline $\mathrm{BM} 2 \mathrm{Sab}$ & Bruceton Mills to Sabraton \\
\hline CARB & California Air Resources Board \\
\hline CBD & Central Business District Driving Cycle \\
\hline CFR & Code of Federal Regulations \\
\hline $\mathrm{CNG}$ & Compressed Natural Gas \\
\hline $\mathrm{CO}$ & Carbon Monoxide \\
\hline $\mathrm{CO}_{2}$ & Carbon Dioxide \\
\hline $\mathrm{COV} \%$ & Coefficient of Variance Percent \\
\hline CSHVR & City Suburban Highway Vehicle Route \\
\hline CVS & Constant Volume Sampling \\
\hline DAS & Data Acquisition System \\
\hline ECU & Engine Control Unit \\
\hline EERL & Engine and Emissions Research Laboratory \\
\hline EPA & Environmental Protection Agency \\
\hline HFID & Heat Flame Ionization Detector \\
\hline FTP & Federal Test Procedure \\
\hline GVW & Gross Vehicle Weight \\
\hline GVWR & Gross Vehicle Weight Rating \\
\hline GPS & Global Positioning System \\
\hline $\mathrm{HC}$ & Hydrocarbons \\
\hline hp & Horsepower \\
\hline LPG & Liquefied Petroleum Gas \\
\hline LPM & Liters per Minute \\
\hline MEMS & Mobile Emissions Measurement System \\
\hline Motown & Morgantown (Route) \\
\hline MPH & Miles per Hour \\
\hline NDIR & Non-dispersive Infrared \\
\hline $\mathrm{NO}$ & Nitric Oxide \\
\hline $\mathrm{NO}_{\mathrm{x}}$ & Oxides of Nitrogen \\
\hline NIST & National Institute of Standards and Technology \\
\hline NTE & Not-to-Exceed \\
\hline $\mathrm{O}_{2}$ & Oxygen \\
\hline OEM & Original Equipment Manufacturer \\
\hline OREMS & On-Road Emissions Measurement System \\
\hline PA1 & PA Leg 1 (Route) \\
\hline PA2 & PA Leg 2 (Route) \\
\hline PA3 & PA Leg 3 (Route) \\
\hline PM & Particulate Matter \\
\hline ppm & Parts Per Million \\
\hline QC/QA & Quality Control, Quality Assurance \\
\hline RPM & Revolutions per Minute \\
\hline Sab2BM & Sabraton to Bruceton Mills (Route) \\
\hline Sab2SW & Sabraton to Saltwell (Route) \\
\hline $\mathrm{SBC}$ & Single Board Computer \\
\hline
\end{tabular}


SW2Sab Saltwell to Sabraton (Route)

S-HDDE Settling Heavy Duty Diesel Engine Manufacturers

TransLab Transportable Heavy-Duty Vehicle Emissions Testing Laboratory

UDDS Urban Dynamometer Driving Schedule

VMT Vehicle Miles Traveled

WVU West Virginia University

$\mathrm{ZrO}_{2} \quad$ Zirconium Oxide 


\section{Introduction}

Diesel engines are employed extensively in our society. They power trains, cars, trucks, pumps, construction equipment, generators and many other devices used regularly. Diesel engines are generally more efficient than comparable gasoline, natural gas, or propane engines and have lower life cycle costs. Diesel fuel fleets save over 30\% of fuel costs over similarly powered gasoline fleets [1]. While older diesel engines are associated with loud operation and visible soot, most modern engines have eliminated these problems. Diesel engines typically have lower carbon dioxide $\left(\mathrm{CO}_{2}\right)$, hydrocarbon (HC), and carbon monoxide (CO) emissions than comparable gasoline engines, but emit greater amounts of oxides of nitrogen $\left(\mathrm{NO}_{\mathrm{x}}\right)$ and particulate matter $(\mathrm{PM})$. However, none of these disadvantages outweighs dependence on diesel engines for the majority of our society. Therefore regulation is aimed toward minimizing the harmful effects of diesel engines while maintaining their usefulness.

$\mathrm{NO}_{\mathrm{x}}$ in the presence of $\mathrm{HC}$ and sunlight forms smog. Smog is responsible for reducing visibility in cities and is problematic for asthmatic individuals. PM from present day diesel engines contains varying amounts of carbon, sulfur, hydrogen, and other components. Primary and secondary PM cause visibility problems. Secondary PM forms in the atmosphere and consists of $\mathrm{SO}_{4}{ }^{2-}, \mathrm{NO}_{3}{ }^{-}$, and organic carbon which stems from $\mathrm{NO}_{\mathrm{x}}, \mathrm{SO}_{2}, \mathrm{NH}_{3}$, and $\mathrm{HC}$ emissions [1]. Each of these emissions is regulated and must be minimized by engine manufacturers.

Research has linked diesel engine exhaust to numerous health risks. Populationbased studies, some of which were adjusted for smoking, have shown that workers associated with diesel exhaust (truck drivers, railroad workers, heavy equipment operators) have increased rates of various cancers [2]. Several laboratory and field studies found non-cancer pulmonary, immunological, and respiratory effects, as well as biochemical and pathological alterations, presumably caused by diesel engine exhaust. These included dizziness; lightheadedness; eye, nose, and throat irritation; nausea; cough;

phlegm; wheezing; aggravation and/or development of asthma and allergies; airway inflammation and obstruction; and chronic bronchitis [2]. Further research is examining health effects specific to modern engines in greater depth. 


\subsection{Federal Test Procedure}

The federal test procedure (FTP) is the United States federal standard test for heavy-duty engine emissions certification [3]. Unlike cars that are certified over the FTP75 chassis dynamometer cycle, heavy-duty vehicle engines are certified independent from any vehicle. The test is a 1200 second long cycle that includes set engine speeds and loads and reports emissions in brake-specific units (g/bhp-hr). FTP certification data have been used to estimate emissions from mobile power plants. However, it is difficult to estimate vehicle miles traveled in relation to brake-specific power, causing FTP emissions data to be inadequate for emission inventories. The constraining parameters of the cycle limit its reflection of real-world emissions, potentially further reducing accuracy, making inventories inaccurate.

\subsection{Emissions Inventory}

Establishing an emissions inventory allows regulators to estimate health and environmental effects of known emissions sources. The United States Environmental Protection Agency (EPA) and the Air Resources Board of California (CARB) use several models. The MOBILE and PART models use FTP brake-specific data, while the inadequacy of the FTP data has led CARB to employ chassis dynamometer data to account for these emissions [4]. Knowledge of energy used per mile (bhp-hr/mile) and/or vehicles miles traveled (VMT) is used to infer gross emission production for a given vehicle.

\subsection{Routes}

For the purpose of this thesis, two types of routes were addressed. The primary study of this thesis examined on-road routes where the primary constraint was the path on which the vehicle traveled. Speed was limited by vehicle acceleration ability, speed limits, road conditions, traffic behavior, and traffic signals. Almost all other test conditions were unconstrained. WVU has tested a second type of route using chassis dynamometers. These routes differ from chassis dynamometer cycles by periods of 
unrestrained acceleration. Chassis dynamometer routes and cycles were discussed in brief for comparison purposes.

Routes have been suggested as alternatives to time-based cycles for vehicular emissions data. Cycles have been used extensively, but their usefulness in producing accurate emission inventories is questionable. While a cycle is arguably repeatable, one cannot insure that it accurately reflects the majority of vehicle miles driven. Studies have shown that comparative emissions data were influenced by the cycle over which the vehicle was tested [5].

A route eliminates some of the problems associated with cycles. Routes allow a vehicle to better reflect its in-use behavior during emissions tests. The chassis dynamometer route does this by allowing full power acceleration, which is characteristic of vehicles with low power-to-weight ratios. The on-road route, by nature, is fundamentally a reflection of in-use vehicle behavior. Because a route can more accurately reflect in-use vehicle behavior for a given engine/vehicle configuration, it is likely that routes would produce more accurate emission inventories. But while a route may reflect in-use vehicle behavior better, one can still not be certain that it is representative of actual in-use activity.

\subsection{Mobile Emissions Measurement System}

An on-road emissions measurement system (OREMS) is a device used for emissions testing over on-road routes and is used as a generic term in this thesis. WVU has created its own OREMS, dubbed the Mobile Emissions Measurement System (MEMS) $[6,7,8]$. MEMS was designed to meet the requirements of the Consent Decrees of the United States of America versus the settling heavy-duty engine manufacturers (S-HDDE) [9]. It is capable of measuring brake-specific and distancespecific mass emissions of $\mathrm{NO}_{\mathrm{x}}$ and $\mathrm{CO}_{2}$ over routes. MEMS data were used for the examination of routes for this thesis. 


\section{Objectives}

\subsection{Mobile Emissions Measurement System}

The purpose for MEMS was to obtain real world, on-road emissions data as defined by the Consent Decrees of the United States of America versus the six S-HDDE [9]. The Consent Decrees required the researching and constructing of on-road emissions measurement units that were able to provide reliable brake-specific mass emissions data over integrated routes and 30 second Not-to-Exceed (NTE) windows. A detailed description of the NTE zone can be found in Appendix A.

\subsection{Thesis}

The purpose of this thesis was to examine MEMS routes. Two analyses were conducted: on-road route repeatability and comparison of on-road routes to the FTP. In order to find a coefficient of repeatability, a methodology had to be established. A form of multidimensional linear regression was used to define repeatability. This methodology was first used to examine repeatability of in-cell engine tests and chassis dynamometer tests to establish a benchmark for later applications. Repeatability of on-road routes was then examined for several vehicles on all tested on-road routes and factors affecting repeatability were identified.

A comparison was made to find to what extent the MEMS routes vary from the FTP. Criteria had to be established, and each route was individually examined. Factors affecting the FTP representation of MEMS routes were identified, including engine torque and speed distribution, rate of change in torque, and rate of change in speed. 


\section{Literature Review}

\subsection{Emissions Testing}

Several means exist for emissions testing of engines and/or engine-chassis configurations. For each of these tests there are levels of accuracy and real world applicability; generally the more accurate tests have lower applicability while the more applicable tests are less accurate. These test methods, in order of most accurate to least accurate, include engine testing, chassis testing on routes, chassis testing on cycles, and on-road route testing.

\subsection{Federal Test Procedure}

The FTP engine dynamometer test is used for federal emissions certification of heavy-duty engines as defined in the CFR 40, Part 86, Subpart N [3]. Using the Monte Carlo simulation, the cycle was developed in the early 1970's from data collected in Los Angeles, CA and New York, NY. The study vehicles used to develop the cycle differed from most of today's heavy-duty vehicles in that they had lower power-to-weight ratios and that some vehicles were gasoline powered. The cycle does not represent either of the extremes of extended highway driving or constant start-and-stop city driving.

The 1200-second transient cycle is defined by engine speed and torque set points as percentages relative to respective defined maximums. One hundred percent torque is found at each speed by mapping the engine [3]. The engine full torque map is found by increasing engine speed at a rate of 8 revolutions per minute (RPM) per second while the engine is at "full rack" until the engine stops fueling. Zero percent torque is defined as zero brake torque. Zero percent speed is defined as idle, and $100 \%$ speed is defined as rated speed (manufacturer defined or calculated based on Code of Federal Regulations (CFR) procedure) [3]. Actual torques and speeds for a given engine are then found using the FTP-defined percent set points and the tested torque maximums from the lug curve as well as from the idle and rated speed. A graph of FTP speed is found in Figure 1, and load is found in Figure 2. The previous, current, and future emissions standards for heavy-duty vehicles can be found in Table 1, Table 2, and Table 3 respectively. In 2004 
manufacturers have two options. 2007 standards can be phased in based on percentage of sales; $25 \%$ in $2007,50 \%$ in $2008,75 \%$ in 2009 , and $100 \%$ in 2010 .

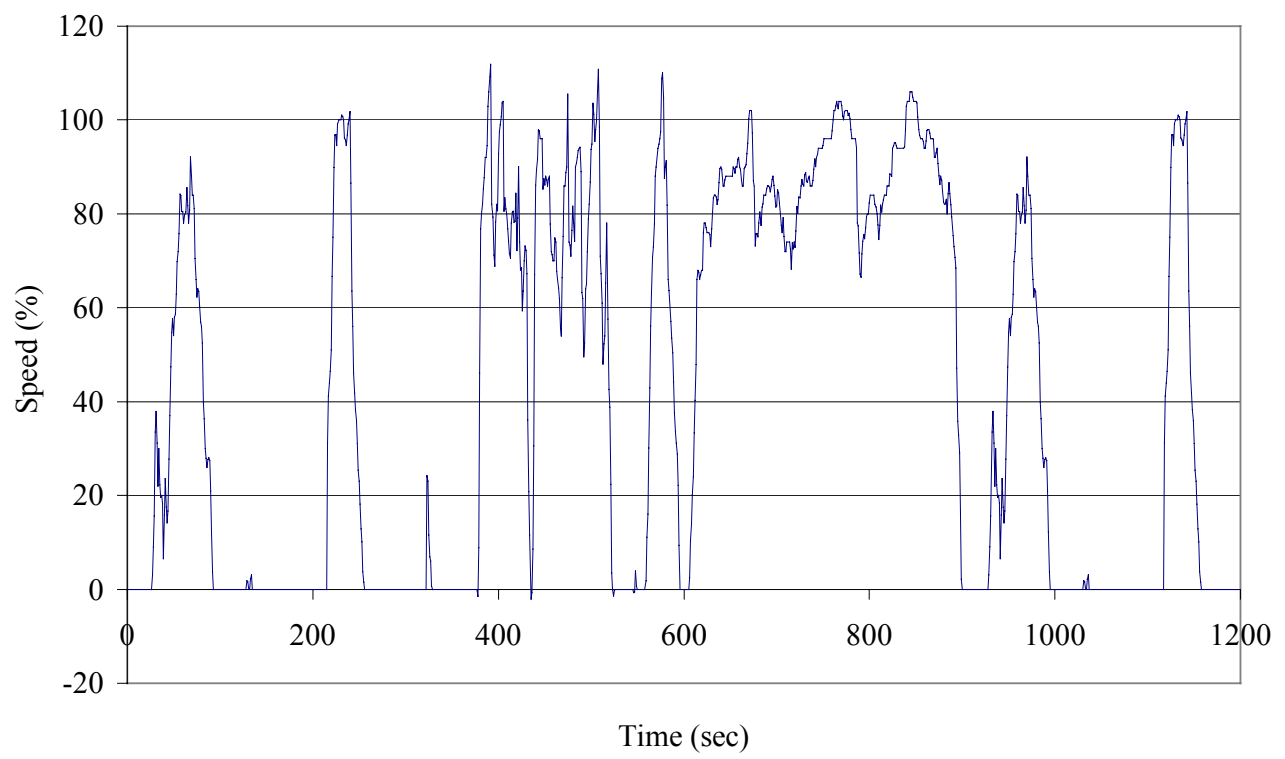

Figure 1: Engine speeds for the FTP [3]

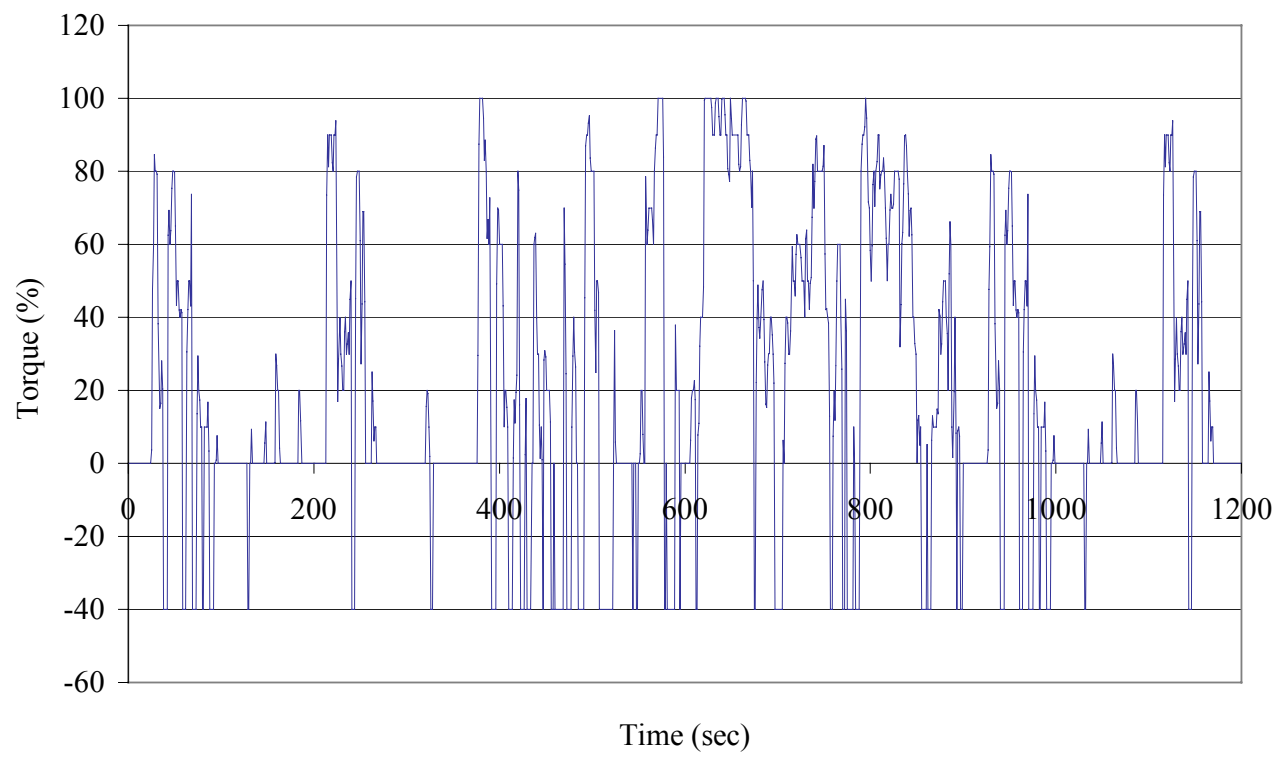

Figure 2: Engine torque for the FTP [3] 
Table 1: Emissions standards for 1988-1998 [10]

\begin{tabular}{|c|c|c|c|c|}
\hline Year & $\begin{array}{c}\text { HC } \\
(\mathrm{g} / \mathrm{bhp}-\mathrm{hr})\end{array}$ & $\begin{array}{c}\text { CO } \\
(\mathrm{g} / \mathrm{bhp}-\mathrm{hr})\end{array}$ & $\begin{array}{c}\mathbf{N O}_{\mathrm{x}} \\
(\mathrm{g} / \mathrm{bhp}-\mathrm{hr})\end{array}$ & $\begin{array}{c}\text { PM } \\
(\mathrm{g} / \mathrm{bhp}-\mathrm{hr})\end{array}$ \\
\hline 1988 & 1.3 & 15.5 & 10.7 & 0.6 \\
\hline 1990 & 1.3 & 15.5 & 6 & 0.6 \\
\hline 1991 & 1.3 & 15.5 & 5 & 0.25 \\
\hline 1994 & 1.3 & 15.5 & 5 & 0.1 \\
\hline 1998 & 1.3 & 15.5 & 4 & 0.1 \\
\hline
\end{tabular}

Table 2: EPA emissions standards for 2004 [10]

\begin{tabular}{|c|c|c|}
\hline Option & $\begin{array}{c}\text { NMHC + NO } \\
(\mathrm{g} / \mathrm{b} h \mathrm{p}-\mathrm{hr})\end{array}$ & $\begin{array}{c}\text { NMHC } \\
(\mathrm{g} / \mathrm{bhp}-\mathrm{hr})\end{array}$ \\
\hline 1 & 2.4 & $\mathrm{n} / \mathrm{a}$ \\
\hline 2 & 2.5 & 0.5 \\
\hline
\end{tabular}

Table 3: EPA emissions standards for 2007

\begin{tabular}{|c|c|c|}
\hline $\begin{array}{c}\text { NMHC } \\
\text { (g/bhp-hr })\end{array}$ & $\begin{array}{c}\text { NO }_{\mathbf{x}} \\
(\mathrm{g} / \mathrm{bh} \text {-hr })\end{array}$ & $\begin{array}{c}\text { PM } \\
(\mathrm{g} / \mathrm{bhp}-\mathrm{hr})\end{array}$ \\
\hline 0.14 & 0.20 & 0.01 \\
\hline
\end{tabular}

Certain validation criteria apply to the FTP [3]. As long as torque and speed are shifted together, the entire engine speed and torque data set may be advanced or delayed with respect to the reference values. Work must be calculated with negative torque values set to zero. Linear regression is then used to calculate validation statistics based on $1 \mathrm{~Hz}$ data for speed, torque, and power. Limits are set on least squares, y-intercept, and standard error values for engine speed, torque, and power. These limits can be found in the CFR [3]. Torque and power data points may be deleted under the following conditions:

- Wide open throttle and torque feedback $<$ torque reference

- Closed throttle, not at idle point, torque feedback $>$ torque reference

- Closed throttle, idle point, and torque feedback = curb idle transmission torque $(10 \mathrm{ft}-\mathrm{lb})$ 
Table 4: FTP validation criteria for speed, torque, and power [3]

\begin{tabular}{|c|c|c|c|}
\cline { 2 - 4 } \multicolumn{1}{c|}{} & Speed & Torque & BHP \\
\hline Standard error of Y on X & $100 \mathrm{rpm}$ & $\begin{array}{c}13 \% \text { of power map } \\
\text { maximum engine torque }\end{array}$ & $\begin{array}{c}\text { 8\% of power map maximum } \\
\text { brake horsepower (BHP) }\end{array}$ \\
\hline Slope of regression line & $\begin{array}{c}0.970 \text { to } \\
1.030\end{array}$ & $\begin{array}{c}0.83 \text { to } 1.03 \text { (hot) } 0.77 \\
\text { to } 1.03 \text { (cold) }\end{array}$ & $\begin{array}{c}0.89 \text { to } 1.03 \text { (hot) } \\
0.87 \text { to } 1.03 \text { (cold) }\end{array}$ \\
\hline Coefficient of determination, $\mathrm{r}^{2}$ & 0.9700 & 0.8800 (hot), 0.8500 (cold) & 0.9100 \\
\hline Y intercept of regression lin & $50 \rho \pi \mu$ & $15 \Phi \tau-\lambda \beta$ & 5.0 \\
\hline
\end{tabular}

\subsection{Routes}

A route is a path that a vehicle must follow where acceleration and speed are limited by vehicle design, driver, road and traffic conditions, weather, and legal speed limits. Two forms of routes were discussed in this work. The repeatability study for this thesis emphasizes on-road routes, but chassis dynamometer routes were examined to better understand the analysis. The on-road routes as discussed herein were set paths a vehicle followed on public roads where the limiting factors included driver psychology, road conditions, traffic patterns, traffic signals, weather conditions, vehicle power, and posted speed limits. For comparison purposes, a chassis dynamometer route was included. These routes differed from chassis dynamometer cycles by containing sections of unrestrained acceleration. This required the route to be a function of distance, whereas the cycle had speed set points as a function of time with no unrestrained acceleration.

Routes have potential benefits over conventional cycles for emission data inventories. Cycles define the speed of the vehicle at every point in time, thereby limiting acceleration. It was found that powerful vehicles could bias emissions by not applying full power while driving over a cycle, if the cycle accelerations were modest [5]. Drivers, as well as traffic, road, and weather conditions, can influence vehicle behavior and thereby emissions, but cycles cannot adequately see these effects. Also, comparative emissions vary depending on which cycle vehicles were tested.

Chassis dynamometer testing allows for the use of routes to establish a vehicle emissions inventory. Routes are a function of distance traveled and include portions of unrestrained acceleration until a set speed is obtained. This allows for a vehicle with higher power-to-weight ratio to complete the route in less time than a vehicle with lower 
power-to-weight ratio. Routes potentially have the added benefit of being feasible for more vehicles, because there are no direct limits on shifting or power-to-weight ratio.

\subsection{Consent Decrees}

The advent of electronically controlled fuel injection allowed manufacturers to vary injection timing of diesel engines with much greater flexibility than before. Early injection slightly improved fuel economy, while substantially increasing $\mathrm{NO}_{\mathrm{x}}$ production [11]. The EPA argued that engine manufacturers varied injection timing so that emissions were met over the FTP, but actual in-use emissions differed substantially [9]. The United States alleged in the Consent Decrees that the S-HDDE manufacturers did not adequately disclose these operating parameters and that these "defeat devices" failed to comply with the Clean Air Act [9].

In October 1998, the EPA, the United States Department of Justice, CARB, and the engine manufacturers Caterpillar, Cummins, Detroit Diesel, Volvo, Mack Trucks/Renault, and Navistar reached a settlement over high $\mathrm{NO}_{\mathrm{x}}$ emissions. The Consent Decrees set the following penalties for the engine manufacturers. Emissions standards for 2004 had to be met in October 2002, 15 months early. Manufacturers that were technologically unable to meet this requirement were allowed to pay nonconformance penalties. When rebuilt, existing engines had to be upgraded to be lower $\mathrm{NO}_{\mathrm{x}}$ emitters. The manufacturer had to add the necessary hardware and/or ECU programming to reduce $\mathrm{NO}_{\mathrm{x}}$, but was not allowed to charge for the additional cost. The

Supplemental Emissions Test had to be conducted with emissions limits equal to the FTP and NTE limits no greater than 1.25 times the FTP limits (with the exception of Navistar). Civil penalties and funding for pollution research had to be paid as well [10]. The funding for pollution research led to the MEMS project.

\subsection{Emissions Inventory}

Emissions inventory allows regulating bodies to estimate health and environmental effects of known emissions sources. To account for these emissions, the United States EPA and the Air Resources Board of California (CARB) use several models titled MOBILE5, PART5, and EMFAC. 
The MOBILE5 and PART5 models use brake-specific emissions data obtained during FTP certification testing and data about vehicle activity to estimate vehicle emissions. Conversion factors for energy consumed per distance (bhp-hr/mile) convert brake-specific emission data to distance-specific data. Vehicle miles traveled (VMT) then allow for estimations of gross emission production for a given vehicle. This can be seen in Equation 1. Note that the FTP was designed for emissions certification testing and was not intended to be used for emissions inventories.

$$
g=\left(\frac{g}{b h p-h r}\right)\left(\frac{l b s}{\text { gallon }}\right)\left(\frac{b h p-h r}{l b}\right)\left(\frac{\text { gallons }}{\text { mile }}\right)(V M T)
$$

Current in-use data on heavy-duty vehicle emissions are limited; therefore no true validation for the inventory models exists. Significant evidence suggests that sizeable gaps exist between predicted inventory levels and actual in-use emissions [12]. Current emissions standards require engine testing over the FTP, with emissions presented in brake-specific values. Conversion to distance-specific emission requires an average fuel economy from various cycles and conditions. This fuel economy reflects a cycle dependence that could inaccurately represent real-world use, particularly since use will vary by geography, driving conditions, and other factors for which it is difficult to account. Further evidence that in-use emissions vary substantially from predicted values was demonstrated by Weaver and Balam-Almanza [13], who conducted in-use testing of a garbage truck.

To improve emissions inventories, the FTP should reflect real-world engine and emissions behavior. This is hindered by the FTP procedure constraining test conditions to narrow windows of operation, such as intake temperature and pressures and exhaust backpressure [3]. This does not reflect the diversity of real-world environmental conditions, such as temperature and pressure fluctuations, blocked air filters or exhaust, and engine tampering. Furthermore, "off-cycle" injection timing has been incorporated into engine control strategies where in-use emissions would greatly differ from the FTP. Early injection produces more $\mathrm{NO}_{\mathrm{x}}$ but lower $\mathrm{PM}$ and fuel consumption. As injection timing is retarded, $\mathrm{NO}_{\mathrm{x}}$ emissions are reduced, but $\mathrm{PM}$ and fuel consumption are increased [11]. Due to the proprietary nature of engine control algorithms, it is 
impossible to estimate a priori the fraction of off-cycle operation. These factors lead to data collected during the FTP poorly representing actual in-use emissions.

These factors may be measured during chassis dynamometer testing. The chassis dynamometer allows for testing of engine, vehicle, and transmission combinations over specific cycles or routes. Most previous work was conducted over cycles that include speed-time relationships, which produce artificial limits on vehicle behavior. Routes have the potential to alleviate some of these shortcomings.

\subsection{On-Road Emissions Measurement System}

To measure emissions, OREMS have been used in the past in many configurations, including bag sampling, mini-dilution tunnels, and raw gas sampling. Most did not measure brake power, which prevented results from being presented in brake-specific units. A detailed examination of OREMS can be found in $[6,14]$.

MEMS eliminated some of the problems associated with many previous OREMS. Raw exhaust gas was sampled continuously while ECU data allowed for the inference of brake power. MEMS was designed to measure $\mathrm{CO}_{2}$ and $\mathrm{NO}_{\mathrm{x}}$ accurately from heavy-duty diesel vehicles and is described in Section 4.1. A detailed description of the designing and testing of MEMS can be found in [7, 8].

Past research that used OREMS over routes is discussed below.

\subsubsection{University of Alberta}

A yearlong University of Alberta study analyzed the effects of ambient temperature on automotive tailpipe emissions using an onboard measuring device. HC, $\mathrm{CO}, \mathrm{CO}_{2}, \mathrm{O}_{2}$, and $\mathrm{NO}_{\mathrm{x}}$ were reported in real-time. The study was conducted to develop models with one-, two-, and three-emissions factors and to examine their effectiveness in representing real world cumulative emissions. Repeated $17.4 \mathrm{~km}$ trips were made on an urban/suburban route using the same vehicle/driver configuration, with ambient temperatures varying from $-20^{\circ} \mathrm{C}$ to $+25^{\circ} \mathrm{C}$. No examination was done on repeatability, but the authors suggested that the greatest variance between runs was idle time, with speed and acceleration remaining mostly consistent [15].

Three trips were selected and examined in detail to "illustrate the capabilities and repeatability of the in-use measurement system" [16]. The intent was to analyze 
differences in driving patterns and emissions. The authors examined averages and standard deviations of speed, graphical depictions of acceleration versus speed, and percent power distribution. Emissions were examined for each run and the averages and standard deviations were presented. The authors concluded that repeated trips had anomalies that significantly affected emissions reporting. They made no attempt to define repeatability [16].

\subsubsection{Horiba and NGK Insulator}

Horiba and NGK Insulator conducted a study analyzing $\mathrm{NO}_{\mathrm{x}}$ emissions using an OREMS on a vehicle equipped with a $2.0 \mathrm{~L}$ diesel engine and an automatic transmission [17]. The vehicle was tested for one year over two routes that were tested daily, two

routes tested weekly, and other routes. The authors examined how humidity and/or temperature influenced $\mathrm{NO}_{\mathrm{x}}$ emissions and fuel economy. $\mathrm{NO}_{\mathrm{x}}$ emissions were found to decrease as humidity increased. Fuel economy was found to be worse in the summer and winter than in the spring and autumn. The authors concluded that the increased fuel consumption in the summer resulted from air conditioner usage, and that the increased fuel consumption in the winter resulted from the increased drag because of higher air density. The effects of fuel properties were not discussed. No attempts were made to examine directly repeatability for vehicle behavior or emissions [17].

\subsubsection{Technical Research Center of Finland}

A Finnish study was conducted to examine emissions of two gaseous heavy-duty engines using OREMS [18]. Two transit buses were tested: a stoichiometric LPG engine and a lean-burn $\mathrm{CNG}$. The vehicles were tested on two routes, and emissions values were compared to a diesel control vehicle. The Otaniemi route was $3.4 \mathrm{~km}$ long and included three 10-second stops. Efforts were made to make this route behave as a cycle by eliminating runs where red lights or traffic obstacles influenced the results. The 'line 23' route was $17.1 \mathrm{~km}$ long, with 10-second stops at each bus stop. This route was designed to reflect "real-life-driving conditions" and no attempts were made to keep this route as consistent as possible [18]. Emissions data were presented for $\mathrm{CO}, \mathrm{CO}_{2}$, and $\mathrm{NO}_{\mathrm{x}}$ as well as fuel consumption. No attempt was made to analyze route repeatability. 


\subsection{Previous Repeatability Examinations}

While no previous repeatability examinations have been performed for on-road routes, there exist several repeatability studies of chassis dynamometer vehicle behavior and/or emissions. McKain and Clark [19] examined methods for regression analysis of speed and torque data as quality control standards for WVU's Transportable Heavy-Duty Vehicle Emissions Testing Laboratories (TransLab). Noguchi et al. [20] examined the repeatability of an experienced and an inexperienced driver as well as the improvements of a robotic "driver." Traver et al. [21] examined emissions repeatability from six different heavy-duty chassis-testing laboratories.

McKain and Clark used a linear regression model to find a level of repeatability for the Central Business District Driving Cycle (CBD), the Five Peak Cycle, and the EPA Urban Dynamometer Driving Schedule (UDDS) for heavy-duty vehicles. The researchers examined repeatability of speed and power, and the effects of test vehicle weight, driver experience, and test cycle on regression. For all conditions, speed had much better correlation than power. They suggested that this stemmed from the driver being able to follow speed quite accurately using a computer display, but the driver needed to adjust power, often aggressively, to insure that the speed was met. The lower correlation of power was compounded by gearshifts, which required periods of zero power, then bursts of full power for the driver to shift properly while still meeting the trace. This shifting process caused only a small fluctuation in speed but drastic power variations [19].

McKain and Clark also examined the factors influencing repeatability. Vehicle weight had no substantial effect on repeatability, but driver behavior/experience had a significant influence. Experienced drivers produced better regression coefficients and standard errors. Inexperienced drivers were able to improve speed regression coefficients for consecutive runs, but they were unable to improve power regression coefficients. The test cycle employed also affected repeatability. Cycles with greater speeds allowed for less pedal dithering, improving power regression coefficients. Speed regression 
coefficients were found to vary little from cycle to cycle. The authors concluded that the method was effective for speed but unreliable for power [19].

Noguchi et al. [20] examined repeatability of an experienced test driver, an inexperienced test driver, and a robotic test driver. The following properties were examined: repeatability of accelerator pedal operation, repeatability of brake pedal operation, repeatability of intake manifold pressure, stability of intake manifold pressure, repeatability of driving speed, and traceability of driving speed. These were examined with an automatically and a manually shifted automobile over the Japan 10 mode. Methodology for measuring repeatability required calculating the variance of error. The robotic driver exhibited better repeatability than both human drivers under all conditions. For the manually shifted vehicle, the experienced driver had better repeatability for all parameters except stability of manifold pressure. There was no significant difference in repeatability between the experienced and inexperienced driver on the automatically shifted vehicle [20].

Traver et al. [21] used reproducibility and repeatability statistics when crosschecking six different chassis dynamometer laboratories. A heavy-duty vehicle was tested at each lab over the urban dynamometer schedule and over a steady-state cycle. The methodology for reducing the data used unitless reproducibility and repeatability indices, $\mathrm{h}$ and $\mathrm{k}$ respectively, as defined by the American Society for Testing and Materials. The reproducibility index refers to the laboratories' "ability to measure the same value in a standard test as other labs" [21]. The repeatability index refers to a laboratory's ability to produce consistent data when compared to the performance of the other laboratories studied. The authors found the data from the different laboratories to be consistent, with the exception of one laboratory that was considerably different from the rest. The methodology used was designed to crosscheck laboratories and appeared inappropriate for route comparison [21]. 


\section{Technical Description of Test Equipment}

\subsection{Mobile Emissions Measurement System}

While there have been many OREMS as discussed previously, this section's technical description refers only to MEMS. The MEMS system used to collect data presented in this thesis had several subsystems, including: an exhaust mass flow rate measurement system; an ECU interface system; an emissions gas sampling, conditioning, and analyzing system; a global positioning system (GPS); and a data acquisition system (DAS). MEMS was powered by an on-board generator for ease of installation, to avoid additional loading from an alternator-powered inverter, and to avoid the maintenance issues associated with batteries.

MEMS recorded emissions and reported with its highest level of accuracy in the NTE window. The NTE window is a zone defined by engine speed and torque. Load and power must be greater than $30 \%$ of their respective maximum values. Engine speed must be greater than $15 \%$ of the European Stationary Cycle (ESC) speed as calculated using Equation 2, where $n_{\mathrm{lo}}$ is the lowest engine speed where $50 \%$ of full power can be produced and $n_{h i}$ is the highest engine speed where $70 \%$ of full power can be produced. For exhaust emissions to be reported, the engine must have been operating within the NTE window for at least 30 seconds. If the engine operated in the NTE zone for 31 seconds, this would include two 30-second NTE windows. More detailed description of the NTE zone can be found in Appendix A.

\section{Equation 2}

$$
15 \% E S C=n_{l o}+0.15\left(n_{h i}-n_{l o}\right)
$$

\subsubsection{Exhaust Flow Measurement}

Exhaust gas flow rate was measured using a Dietrich Standard Annubar ${ }^{\mathrm{TM}}$, which is a multiple inlet differential pressure device [8]. The Annubar was incorporated into a pipe with a diameter generally matching that of the stock exhaust. For dual exhaust stacks, one branch was capped and the other was replaced with the Annubar flow tube. Flow tubes of several diameters were constructed to accommodate varying exhaust sizes. 
A Validyne P55D pressure transducer measured differential pressure over the Annubar, and an Omega PX203 measured absolute pressure in the flow tube. Temperature was measured before and after the Annubar for redundancy, using J-type thermocouples. This system was most accurate during turbulent flow, which existed in most of the NTE zone. The system was designed to produce minimal backpressure while being rugged and robust, with minimal effects from soot deposits [8]. The assembled flow measurement system is shown in Figure 3.

Moreover, the absolute and differential pressure transducers were periodically calibrated using a Heise PTE-1 pressure calibrator. During the data collection procedure, the intercepts were reset for the differential and absolute pressure sensors [8].

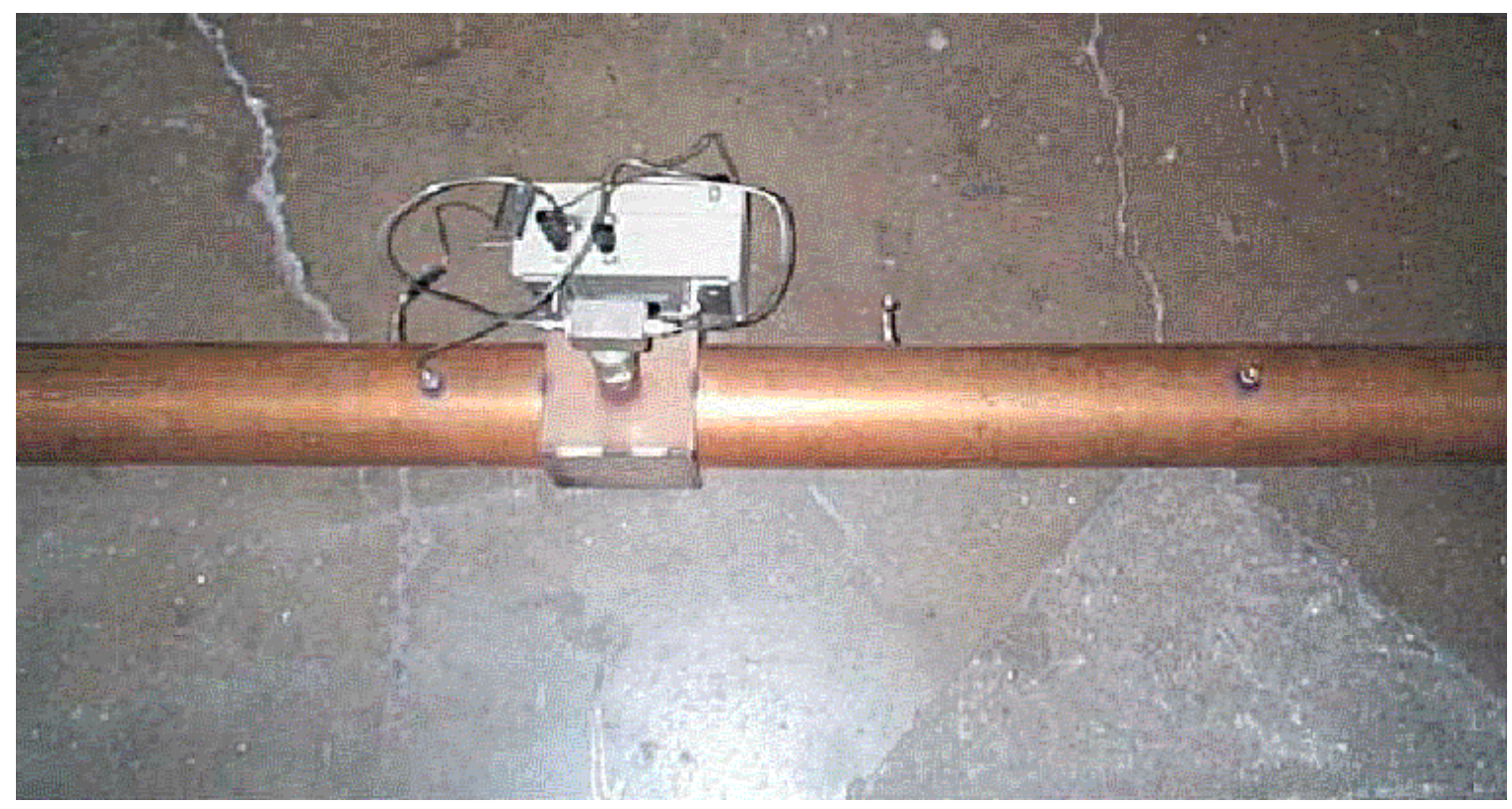

Figure 3: MEMS exhaust flow tube with Annubar and pressure transducer unit [8]

\subsubsection{Gas Analysis Components}

The sampling and conditioning system was designed to provide for a constant sample flow rate, minimize water interference, remove particulate matter, and maintain temperature. Samples were taken from the exhaust stream using a probe of 0.25 " stainless steel tubing designed in accordance with CFR 40 Part 89.412.96. A heated Teflon line transferred the sample from the probe to the MEMS unit. PM was removed from the sample using a Unique Products heated filter. The sample then passed through a 
$\mathrm{NO}_{2}$ to $\mathrm{NO}$ converter and was measured by a $\mathrm{ZrO}_{2}$ sensor. The sample was then pulled into a heated head Air Dimensions Inc. Dia-Vac ${ }^{\circledR}$ pump. The sample then passed through a custom designed Peltier chiller to remove moisture, reducing the outlet dew temperature to approximately $40^{\circ} \mathrm{F}$. A drain allowed for excess water to be removed from the system. Needle valves and a differential pressure transducer controlled the flow rate to the Horiba BE-140 (3.0 LPM) and the electrochemical NO cell (0.5 LPM) [8]. A schematic for the design can be seen in Figure 4.

$\mathrm{NO}_{\mathrm{x}}$ concentrations were primarily measured using a Horiba MEXA 120, which measures concentrations from $0-5000 \mathrm{ppm}$. The system incorporates a $\mathrm{ZrO}_{2}$ sensor approximately the size of an automotive oxygen sensor with remote electronics and display. Even though the device is marketed as a $\mathrm{NO}_{\mathrm{x}}$ analyzer, tests at WVU showed an $\sim 75 \%$ response to $\mathrm{NO}_{2}$ [22]. Therefore a $\mathrm{NO}_{2}$-to-NO converter was incorporated upstream from the sensor. An electrochemical $\mathrm{NO}$ cell was used for redundant $\mathrm{NO}_{\mathrm{x}}$ measurement, which was included downstream from the NO converter and the waterremoving sample chiller. The measurement range for the electrochemical NO cell was from 0-5000 ppm.

$\mathrm{CO}_{2}$ concentrations were measured using a Horiba BE-140AD analyzer. This non-dispersive infrared (NDIR) device directs broadband infrared light onto solid-state optical sensors. Narrow band pass filters insured that only light of the corresponding wavelength for the gas of interest reached the sensor. A chopper wheel turned by a stepper motor insured that light reached only one of the four optical sensors at a given time. The device was designed to reduce the effects of temperature and electrical noise. The Horiba BE-140AD was capable of measuring $\mathrm{CO}_{2}, \mathrm{CO}$, and $\mathrm{HC}$ concentrations. Diesel engines, however, generally produce $\mathrm{CO}$ and $\mathrm{HC}$ concentrations too low to obtain accurate data using the BE-140, but gasoline engines would produce measurable concentrations. 


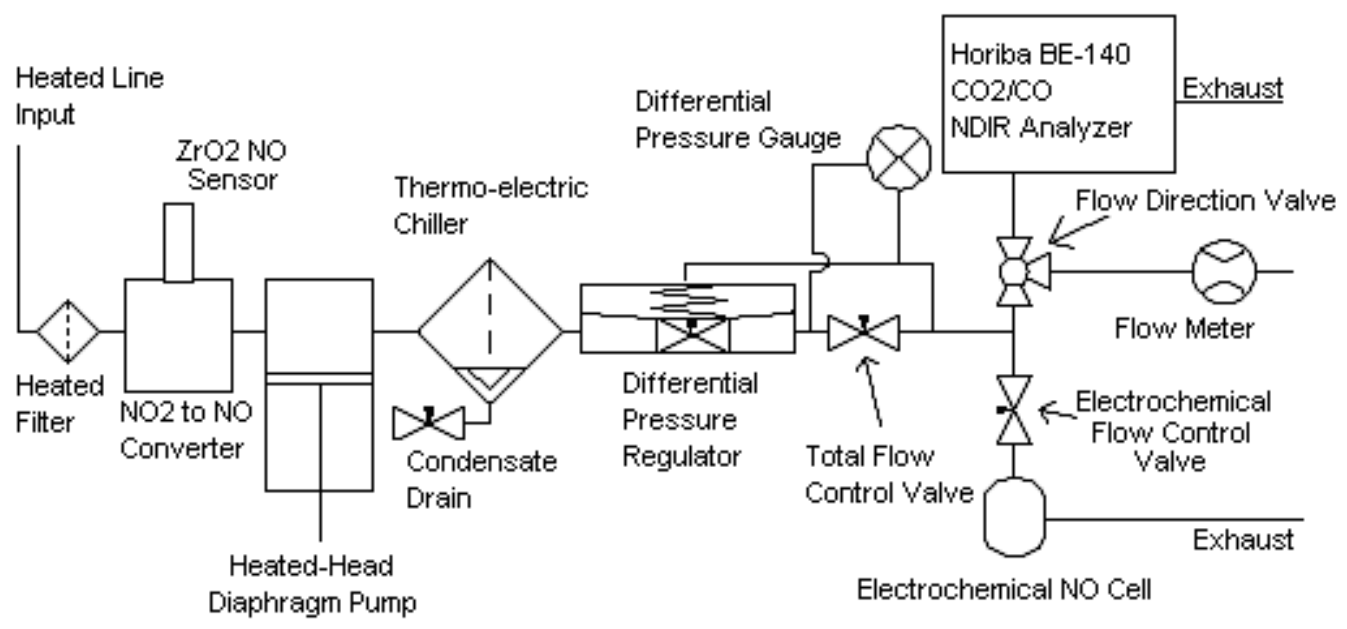

Figure 4: Schematic of MEMS sampling system [8]

The gas analyzers were calibrated using gas bottles with known concentrations and a Horiba SGD-710C gas divider. Gas concentrations were within $\pm 1 \%$ accuracy and were selected based on the range of exhaust concentrations of the vehicle. Calibration gas was sampled through a three-way valve located between the sampling probe and the heated line. Before each test, and at defined intervals, the Horiba BE-140 was calibrated at zero and span, and the electrochemical NO and the MEXA 120 were calibrated using a three-point calibration.

\subsubsection{Brake Power Calculation}

Brake-specific power had to be recorded to report emissions in brake-specific units. Engine power was calculated using publicly broadcast ECU speed and fueling. ECU reported engine speed was found to be accurate and reliable with average errors of less that $1 \%$ over the FTP [23]. Engine torque was calculated using engine fueling and known values found in the manufacturer's lug curve and a no-load curb idle [23].

Torque was inferred as follows. The manufacturer's lug curve provided a value for torque at $100 \%$ fueling. The no-load data gave the percent fueling necessary for the engine to overcome its frictional losses and parasitic accessory loading while producing no useful torque. One then inferred the output torque by linearly interpolating the percent fueling. Using a test engine in laboratory testing over the FTP with an engine dynamometer, it was found that the actual and inferred torque had a 5\% integrated difference over the FTP when the engine manufacturer's lug curve was used [23]. When 
a measured lug curve was used, the inferred and actual dynamometer tested torque values had a 1\% integrated difference over the FTP [23]. The torque calculations were such that the error significantly increased as torque decreased. This was compounded when the torque inference was done at high engine speeds where the fueling is cut. Since brakespecific emissions data were generally reported only in the NTE zone, this error was minimized [23].

Yet note that the manufacturer's lug curve may not match the actual torque curve exactly. Fuel properties vary in heating value, specific gravity, hydrogen to carbon ratio, viscosity, and other parameters that effect engine performance, engine calibration, and emissions [26,27]. This reduced the accuracy of the lug curve, causing error in the inference of torque. Some lug curves were also roughly discretized, further reducing accuracy. Also, manufacturers sometimes may switch engine maps under certain conditions such as: limiting torque in low gears, cutting fuel at high vehicle speeds, increasing torque when under cruise control or hill climbing, or any other operation that varies operation from the lug curve used to infer torque. These differences may affect fueling percent, causing errors associated with torque inference.

\subsubsection{Data Acquisition}

The MEMS DAS was housed in an aluminum box, which contained a single board computer (SBC), keyboard, mouse, flat panel LCD screen, and the Horiba MEXA 120 control panel. The Advantech PCM-9570/S single board computer (SBC) had an $850 \mathrm{MHz}$ Intel ${ }^{\circledR}$ processor and $256 \mathrm{MB}$ of RAM. A SC-2345 National Instruments signal conditioning system used National Instruments SCC series signal conditioners to condition the analog inputs. A National Instruments PCMCIA E-Series DAQ Card$6062 \mathrm{E}$ was used to read analog inputs, which provided 16 channels at 12 bits resolution. A Dearborn Group DPAIII/PC104 or serial Protocol Adapter was used to communicate engine information to the SBC. The DAS along with the gas analyzer unit are presented in Figure 5.

At the end of each run, the data were copied to a post-processing computer where examinations were done to insure quality and completeness. If a run contained data that invalidated the NTE brake-specific data, then the run was repeated. The data reduction 
created Excel files that contained instantaneous data at $5 \mathrm{~Hz}$. Data from these files were used for this thesis.

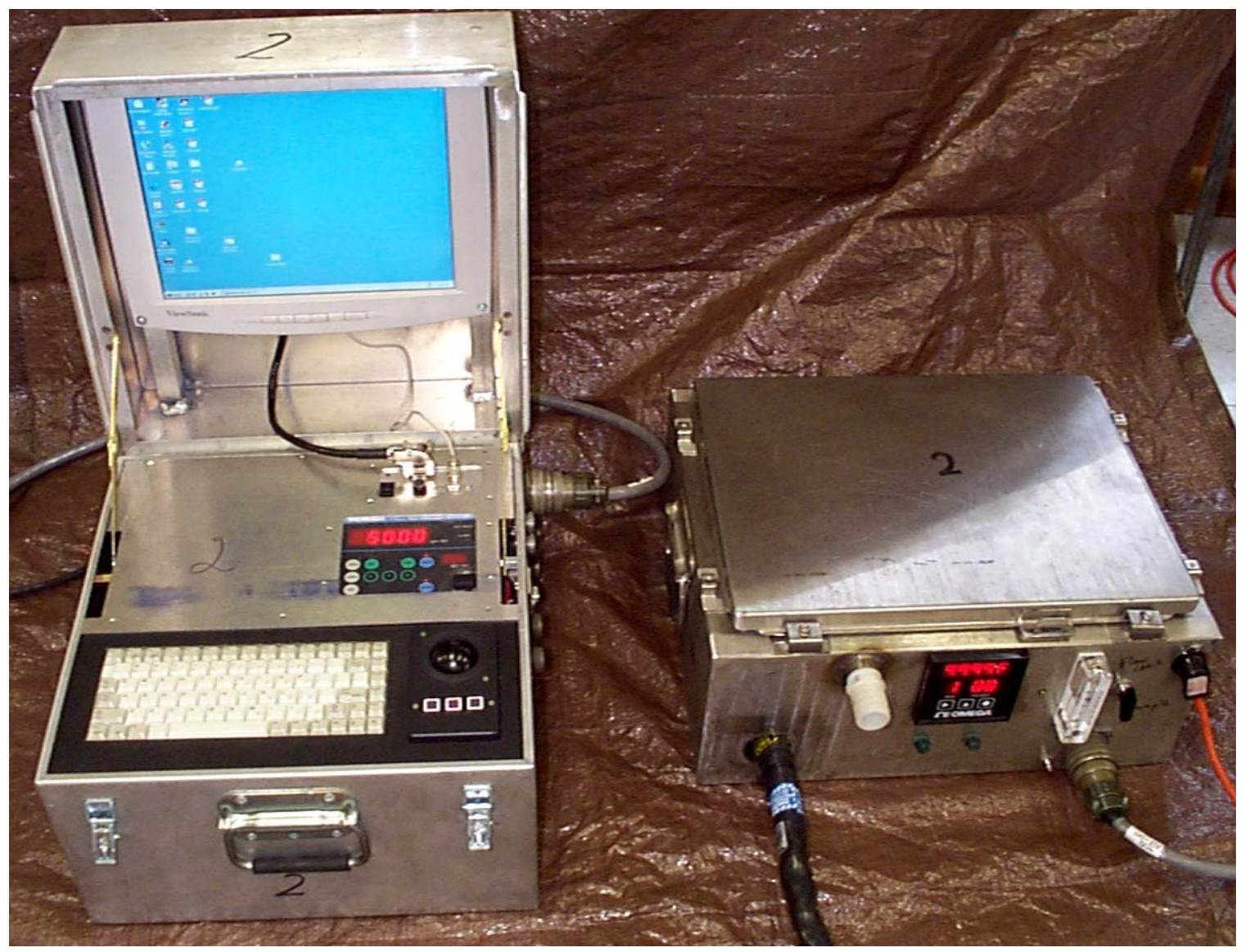

Figure 5: MEMS gas analyzer and data acquisition system [8]

\subsubsection{Validation}

Comparative tests were conducted to insure the accuracy of MEMS by testing an engine with the MEMS unit and WVU Engine Emissions Research Laboratory (EERL) in parallel. Three modes of operation were tested: steady-state operation with peak torque and peak power modes, transient operation that followed the speed-load schedule of the FTP, and a simulated on-road operation that was created from data taken from vehicle tests. The results shown here were taken from one of these validation tests. Figure 6, Figure 7, Figure 8, Figure 9, Figure 10, and Figure 11 show in-cell and MEMS emissions measurement comparison while Figure 12 and Figure 13 show speed and torque comparisons respectively. For this analysis MEMS inferred torque values accounted for the inertial torque loading whereas in-cell torque measurements did not. 
Table 5: Emissions comparison between EERL and MEMS [8]

\begin{tabular}{|c|c|c|c|c|c|c|c|}
\hline \multirow{2}{*}{\multicolumn{2}{|c|}{ Dynamometer Test Cycle }} & \multicolumn{2}{|c|}{$\begin{array}{c}\text { MEMS Mass } \\
\text { Emissions } \\
\text { Results (g/bhp } \\
\text { hr) }\end{array}$} & \multicolumn{2}{|c|}{$\begin{array}{c}\text { Laboratory } \\
\text { Mass } \\
\text { Emissions } \\
\text { Results (g/bhp } \\
\text { hr) }\end{array}$} & \multicolumn{2}{|c|}{$\begin{array}{c}\text { Percent } \\
\text { Difference }\end{array}$} \\
\hline & & $\mathbf{N O}_{\mathrm{x}}$ & $\mathrm{CO}_{2}$ & $\overline{\text { NO }_{x}}$ & $\mathrm{CO}_{2}$ & $\mathbf{N O}_{\mathrm{x}}$ & $\mathrm{CO}_{2}$ \\
\hline \multirow{2}{*}{ Steady-State Test Cycle } & Peak Torque & 5.26 & 477.6 & 5.29 & 421.4 & -0.4 & 13.3 \\
\hline & Peak Power & 5.56 & 462.2 & 5.94 & 436.0 & -6.4 & 6.0 \\
\hline \multicolumn{2}{|c|}{ FTP Transient Test Cycle } & 3.54 & 599.2 & 3.37 & 546.5 & 5.2 & 9.6 \\
\hline \multicolumn{2}{|c|}{ Simulated On-Road Test Cycle } & 5.73 & 476.1 & 5.60 & 456.9 & 2.3 & 4.2 \\
\hline
\end{tabular}

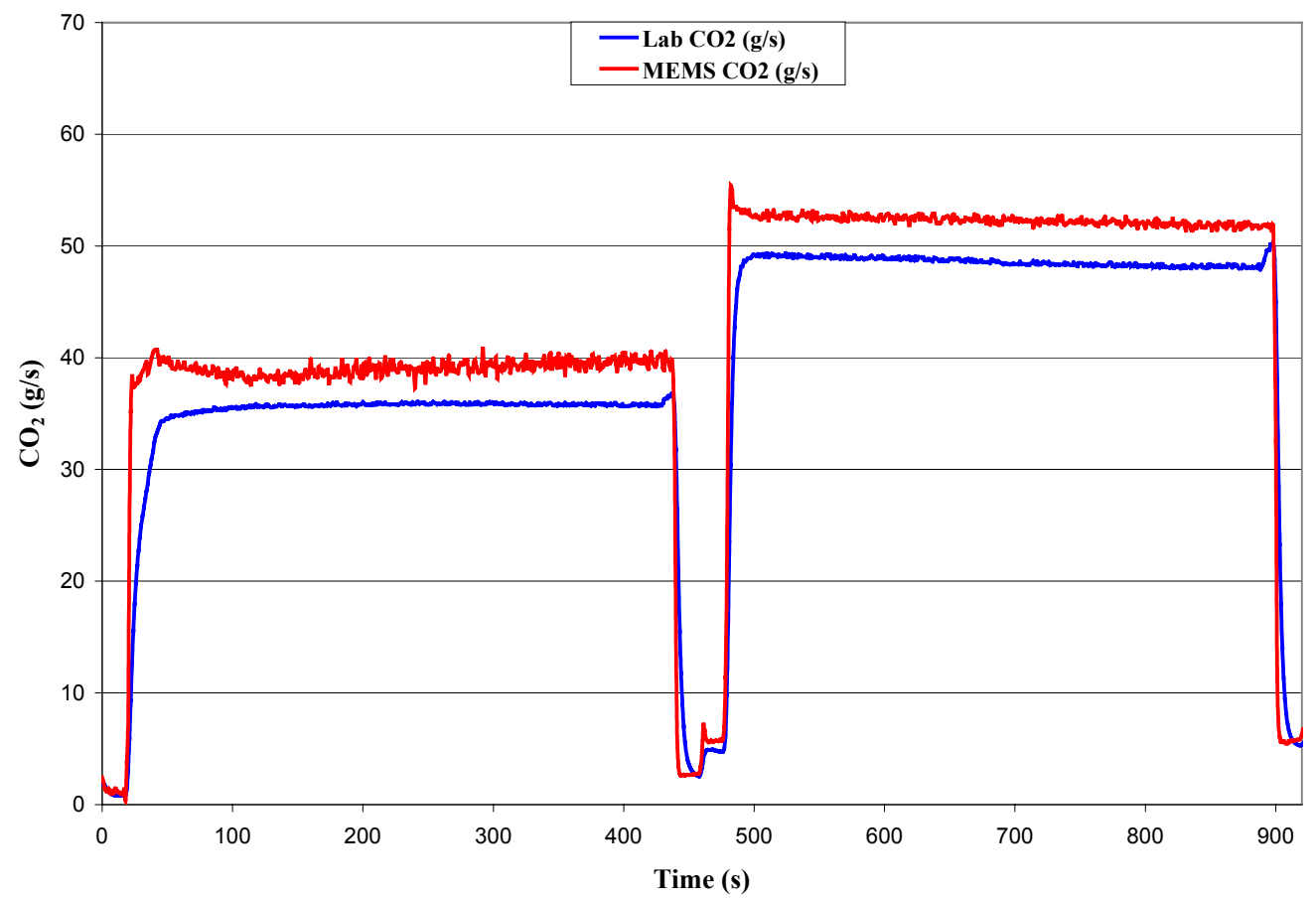

Figure 6: Mass emissions rates of $\mathrm{CO}_{2}$ over a steady-state dynamometer test cycle-MEMS results and laboratory results $[8]$ 


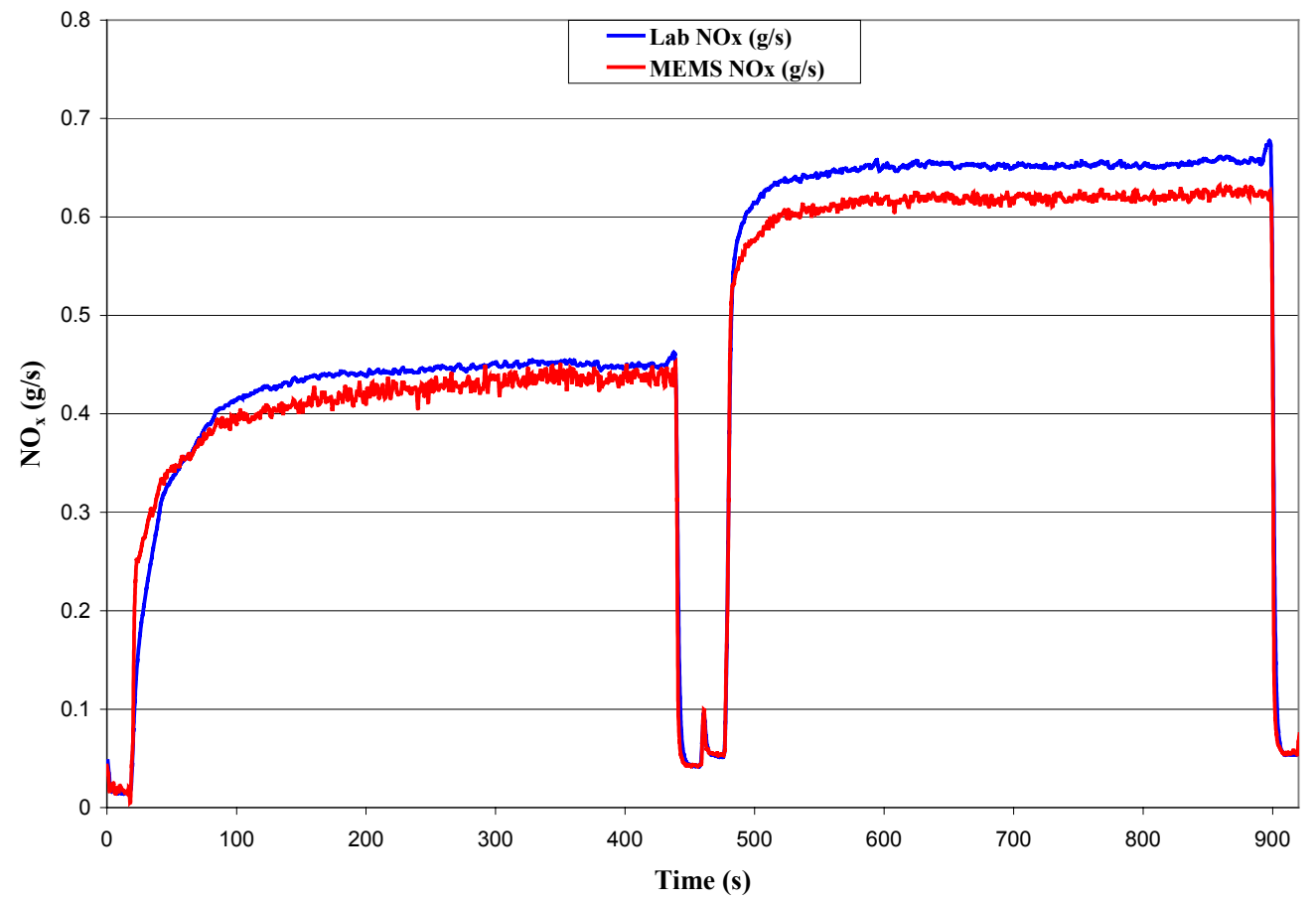

Figure 7: Mass emissions rates of $\mathrm{NO}_{\mathrm{x}}$ over a steady-state dynamometer test cycle - MEMS results and laboratory results $[8]$

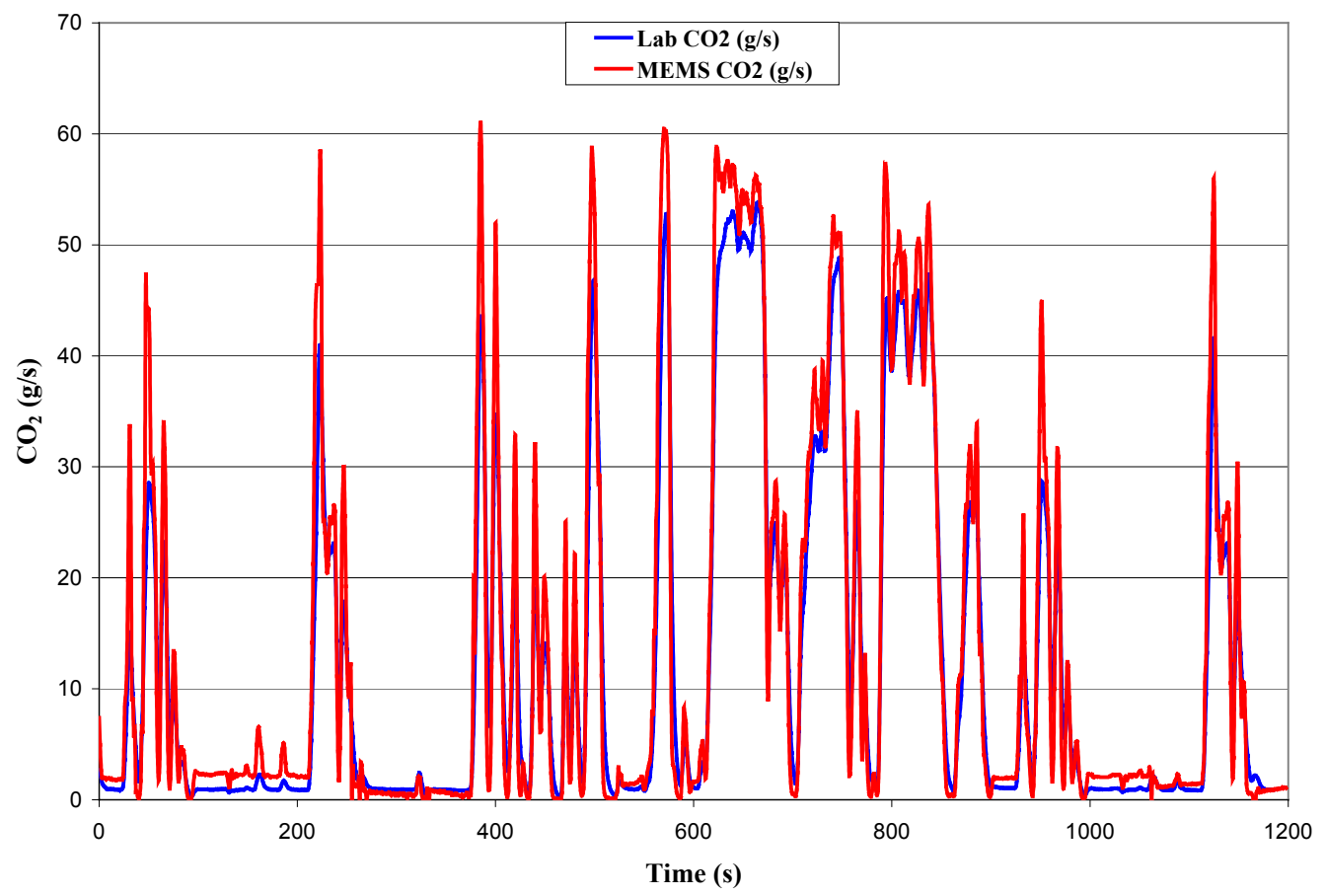

Figure 8: Mass emissions rates of $\mathrm{CO}_{2}$ over the FTP transient test cycle - MEMS results and laboratory results $[8]$ 


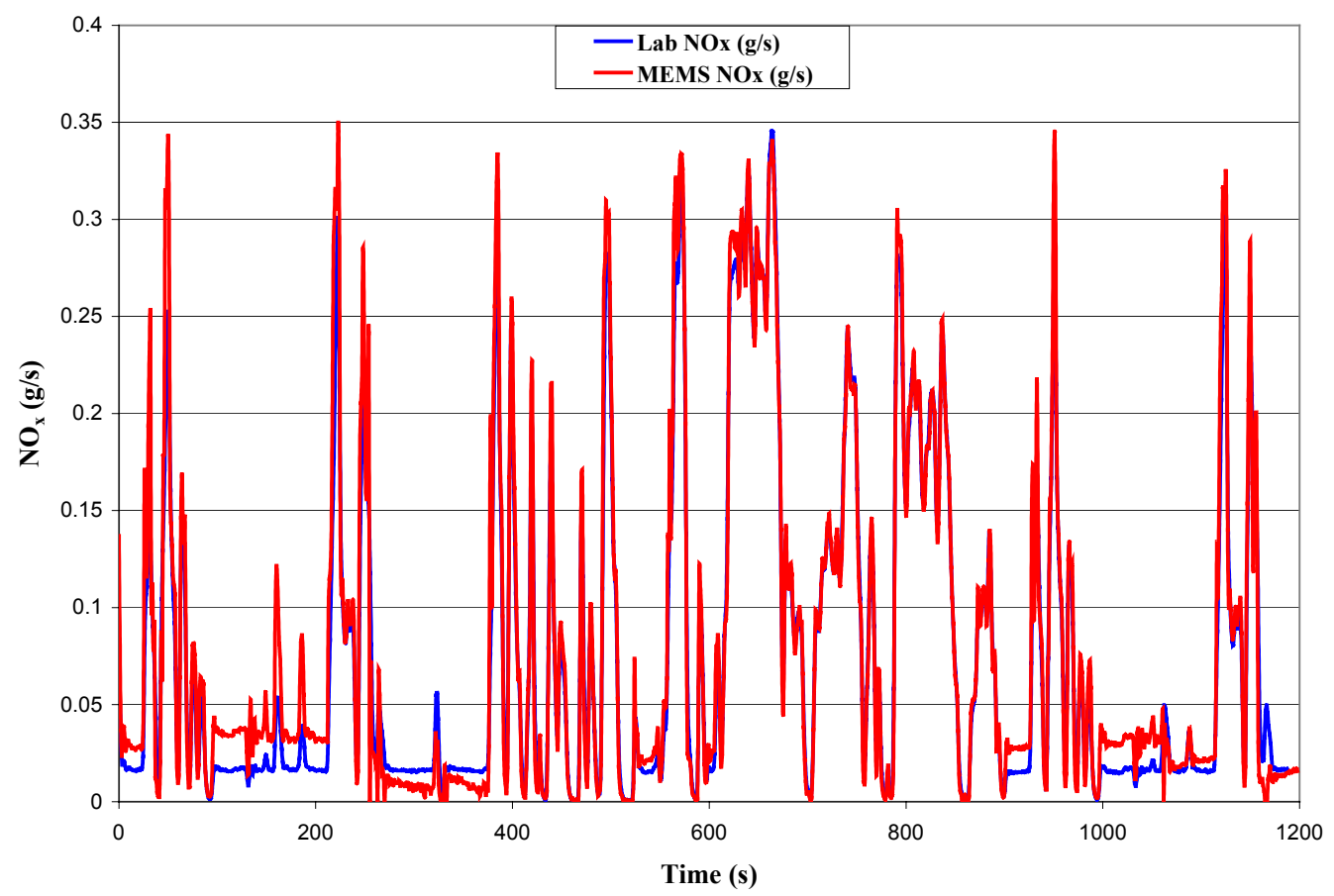

Figure 9: Mass emissions rates of $\mathrm{NO}_{\mathrm{x}}$ over the FTP transient test cycle - MEMS results and laboratory results $[8]$

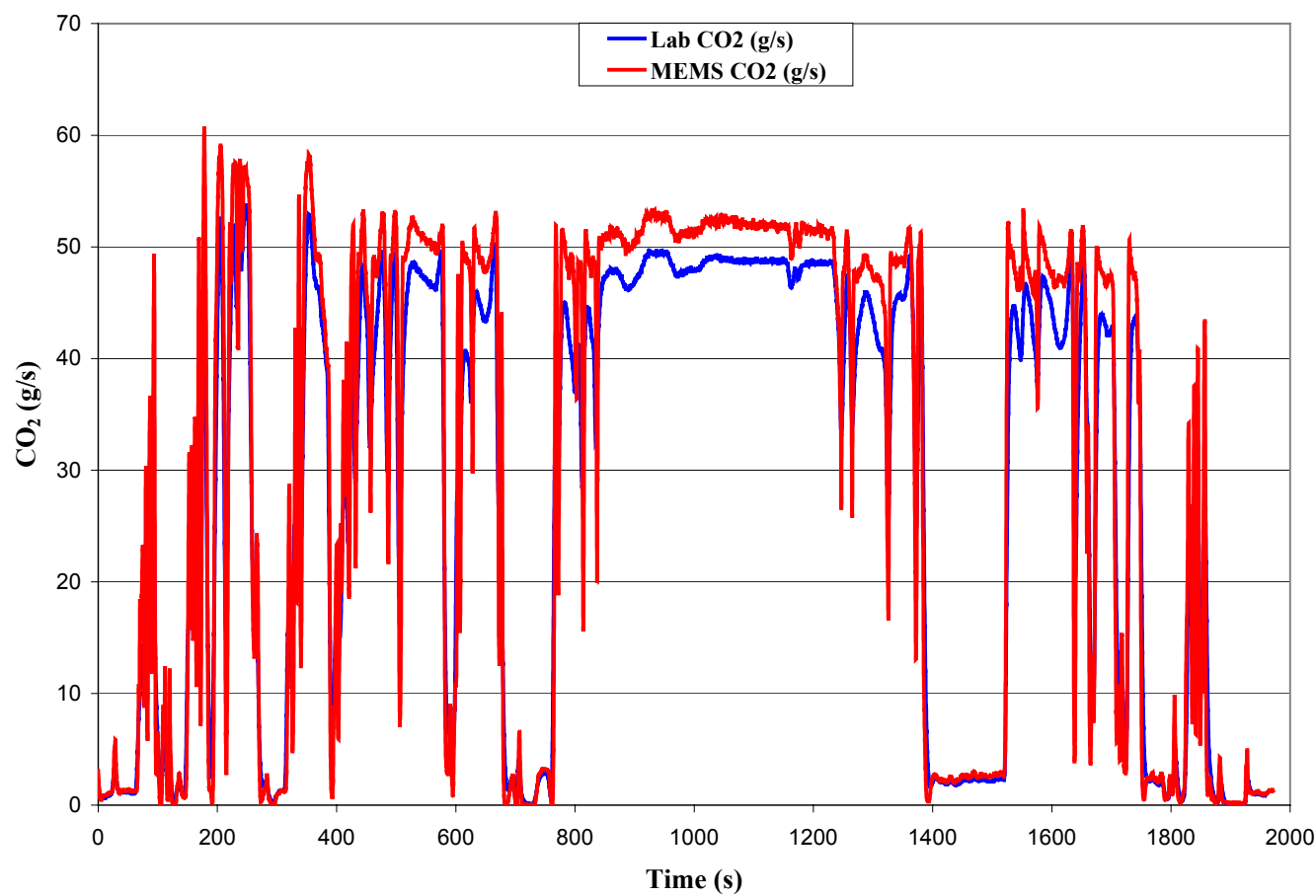

Figure 10: Mass emissions rates of $\mathrm{CO}_{2}$ over a simulated on-road transient test cycle - MEMS results and laboratory results $[8]$ 


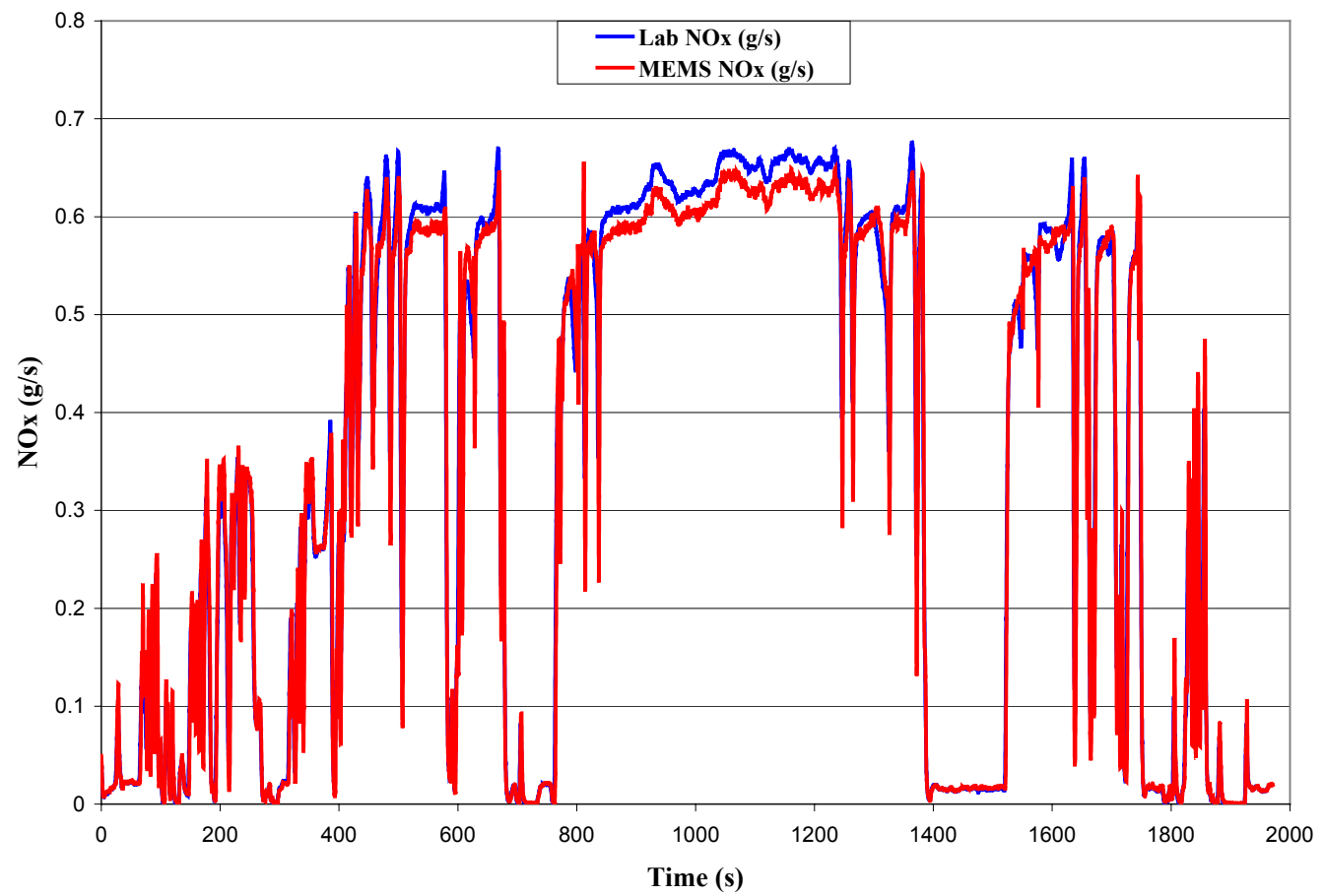

Figure 11: Mass emissions rates of $\mathrm{NO}_{\mathrm{x}}$ over a simulated on-road transient test cycle - MEMS results and laboratory results $[8]$

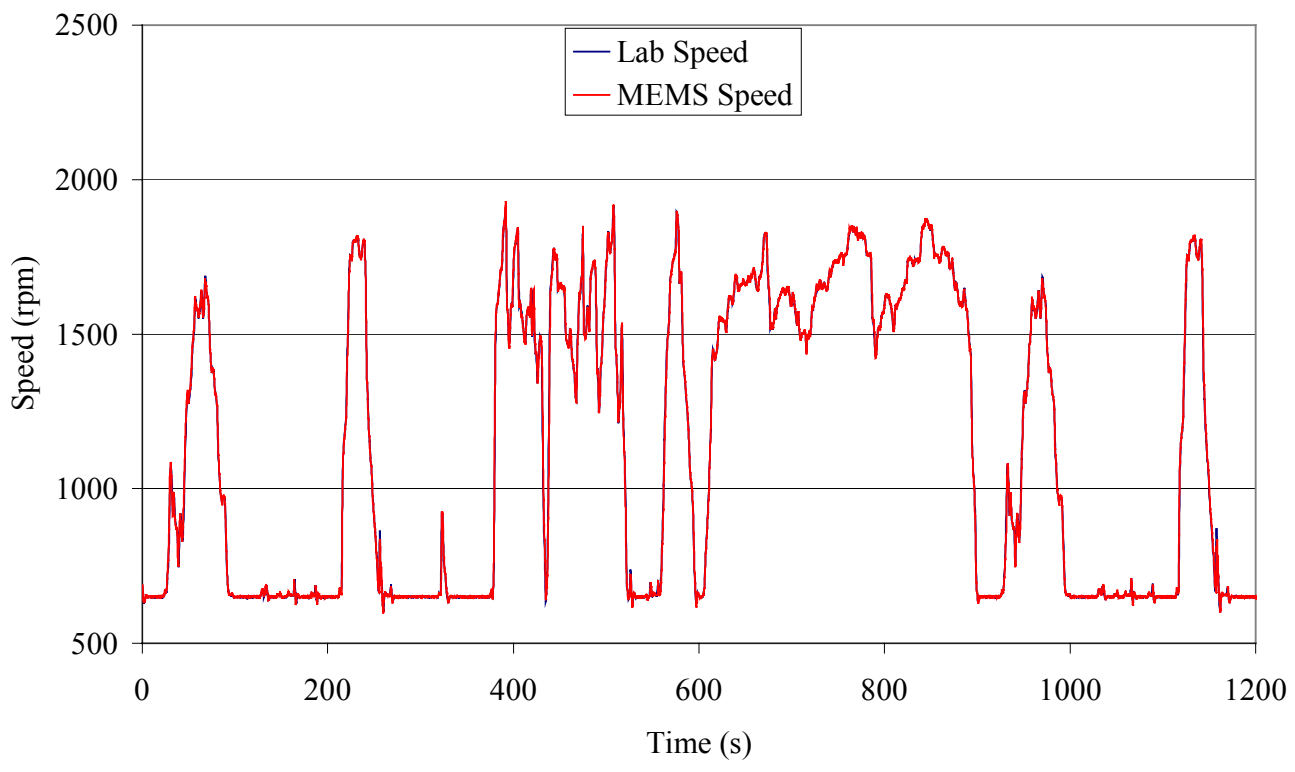

Figure 12: Continuous engine speed from MEMS data and in-cell data over the FTP 


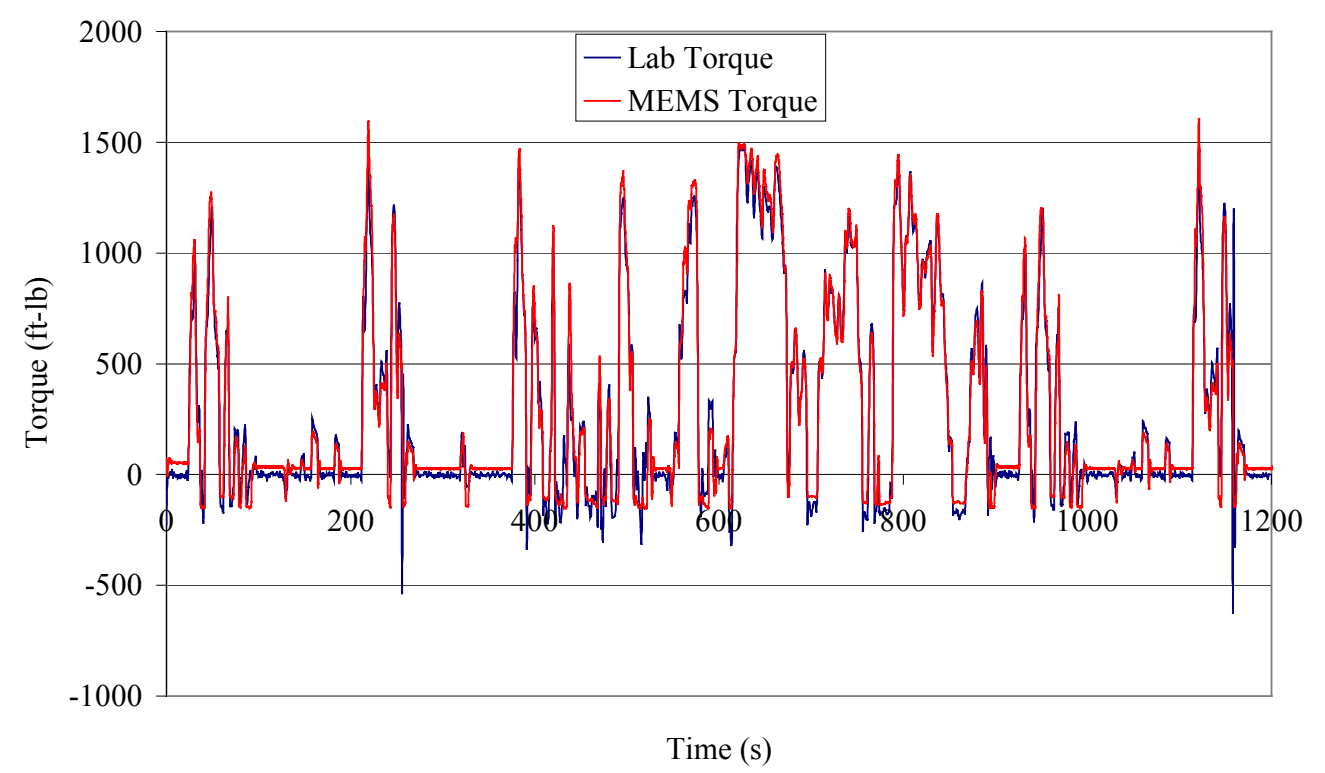

Figure 13: Continuous engine torque from MEMS data and in-cell data over the FTP

\subsection{Engine Dynamometer Laboratory}

Engine dynamometer tests were conducted at WVU's Engine and Emissions Research Laboratory. The laboratory meets all requirements as specified in the CFR 40, Part 86, Subpart N. A General Electric DYC-243 was connected to the engine via a driveshaft. The DYC-243 was capable of absorbing up to $550 \mathrm{hp}$ and motoring up to 500 hp. The exhaust gas was diluted in a full scale, constant volume sampling (CVS) tunnel. The dilution tunnel was constructed of stainless steel and was 18 inches in diameter and 40 feet long. HC were measured using a Rosemont Analytical Model 402 heated flame ionization detector (HFID). $\mathrm{NO}_{2}$ was converted to $\mathrm{NO}$ before being measured by a Rosemont Analytical Model 955 chemiluminescent analyzer. A Horiba AIA-210 NDIR measured $\mathrm{CO}_{2}$ and a Horiba AIA-210LE NDIR measured CO. Background and exhaust bags were collected for each test using $80 \mathrm{~L}$ Tedlar bags. The background bag allowed for the subtraction of ambient gases from total engine emissions, and the exhaust bag allowed for QC/QA of integrated samples. 


\subsection{Chassis Dynamometer Laboratory}

Chassis dynamometer data were collected using West Virginia University's Transportable Heavy-Duty Vehicle Emissions Testing Laboratories (TransLab). The laboratories featured a heavy-duty chassis dynamometer that used flywheels to simulate vehicle inertia and air-cooled eddy current power absorbers to simulate rolling resistance and wind drag. The vehicle rested on free spinning rollers, while power was taken from hub-mounted adaptors. $\mathrm{NO}_{\mathrm{x}}, \mathrm{CO}, \mathrm{CO}_{2}$, and $\mathrm{HC}$ emissions were recorded continuously using a full-scale dilution tunnel in accordance with the CFR 40, Part 86, Subpart N. These laboratories have collected extensive data on diesel and alternative fueled vehicles.

\subsection{Vehicles}

Vehicles that yielded data examined in this thesis are described below. The first four are MEMS vehicles and the last two were included for chassis dynamometer comparison purposes.

- MEMS \#8-A Volvo Class 8 tractor was tested, loaded to within $5 \%$ of GVWR, which was $80,000 \mathrm{lbs}$. It was powered by a $1998425 \mathrm{hp}$ engine. The tractor had a 10 speed unsynchronized manual transmission. The vehicle was laden using a flatbed trailer loaded with cement blocks and road barriers. The vehicle had approximately 453,000 miles at the start of testing.

- MEMS \#10-A Class 7 school bus was tested, powered by a $2001215 \mathrm{hp}$ engine. It had an automatic transmission and was loaded with bags of corn to within 5\% of its GVWR of $31,000 \mathrm{lbs}$. The vehicle belonged to the Monongalia County (WV) school system and was used predominantly for transporting students in rural/urban areas with minimal highway use. The vehicle had approximately 14,800 miles at the start of testing.

- MEMS \#11- Another class 7 school bus was tested, also powered by a 2001215 hp engine. It had an automatic transmission and was loaded with bags of corn to within $5 \%$ of its GVWR of 31,000 lbs. The vehicle belonged to the Monongalia County (WV) school system and was used predominantly for transporting students in rural/urban areas with minimal highway use. The vehicle had approximately 10,300 miles at the start of testing. 
- MEMS \#12-A Peterbilt Class 8 Tractor was tested, loaded to within $5 \%$ of GVWR, which was 80,000 lbs. It was powered by a $1996475 \mathrm{hp}$ engine. The tractor had an 18 speed unsynchronized manual transmission. The vehicle was purchased by WVU from Hunter's Truck Sales and Service, Inc., in Uniontown, PA. WVU had used the tractor occasionally for transport of emissions test equipment. The vehicle was laden using a flatbed trailer loaded with cement blocks and road barriers. The vehicle had approximately 385,700 miles at the start of testing.

- A Ford tractor truck powered by a 1996280 hp Cummins M11 280E with a 10speed manual transmission was tested on a chassis dynamometer with a test weight of 36,600 lbs. The vehicle had approximately 108,000 miles at the start of testing.

- A Sterling tractor with a 1998470 hp DDC Series 60 and a 10 speed manual transmission was tested on a chassis dynamometer. The test weight was 42,000 lbs. The vehicle had approximately 252,900 miles at the start of testing.

Upon receiving the vehicles, WVU visually examined each vehicle for non-OEM or modified parts, checked for engine fault codes, and performed a standard safety inspection. The service history was reviewed with the vehicle owner. Each vehicle was loaded to within 5\% of GVWR for the majority of the testing. Vehicles were tested using commercially available on-road diesel fuel.

\subsection{Routes}

MEMS was tested on four routes, three of which were divided into separate legs. These were Sabraton to the Saltwell exit on I-79 and back (Sab2SW, SW2Sab), Sabraton to the Bruceton Mills exit on I-68 and back (Sab2BM, BM2Sab), Morgantown (Motown), and Pittsburgh, which was separated into three legs (PA1, PA2, PA3). For comparison purposes a chassis dynamometer cycle and route were also examined. These are the UDDS for heavy-duty vehicles and the City Suburban Highway Vehicle Route (CSHVR) respectively [3, 5]. For all on-road routes, elevation was calculated from 
ambient pressure as recorded during an arbitrarily selected run. All elevations are shown relative to the starting point.

\subsubsection{Sab2BM, BM2Sab}

This route included an outbound and a return leg. The route started at the WVU's Sabraton testing facility (1462 Earl Core Rd. Morgantown, WV), which is a short distance from exit 4 on I-68 on urban roads. The route headed toward I-68 on the urban road through several traffic lights. The route continued eastbound on I-68 and included $5 \%$ grades. The turnaround point was at the truck stop at the Bruceton Mills exit, exit 23 off of I-68. The return trip was over the same route back to the WVU Sabraton facility. Interstate speeds were posted as $70 \mathrm{MPH}$. There is a mandatory truck stop/brake check before the $5 \%$ descent on the return trip. During the descent, trucks are limited to 50 MPH. The outbound leg was 20.4 miles in length and the return leg was 19.9 miles. The route can be seen on a map in Figure 14 and relative elevation for Sab2BM can be seen in Figure 15. BM2Sab followed the same contour in the reverse direction.

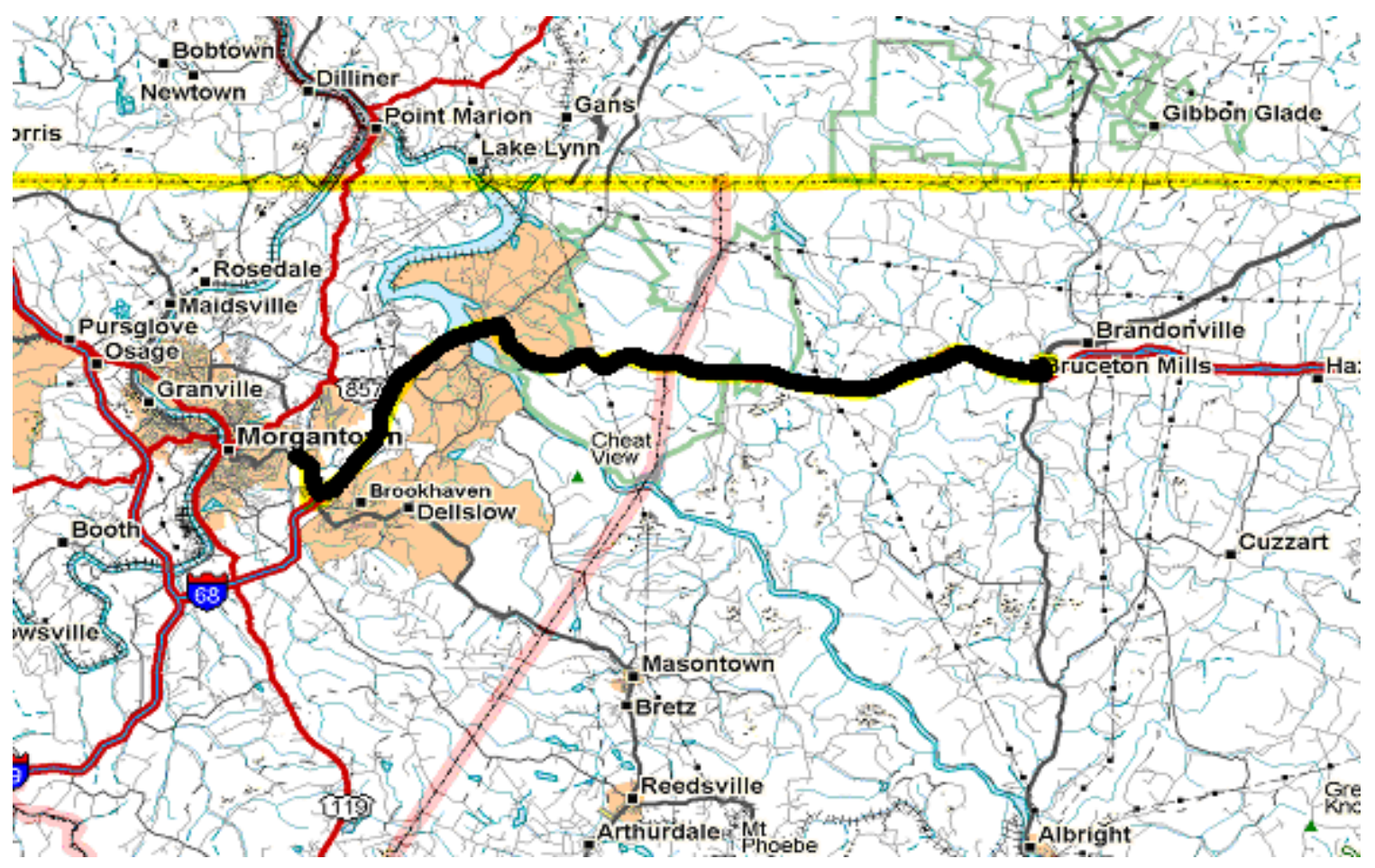

Figure 14: Map of Bruceton Mills route [8] 


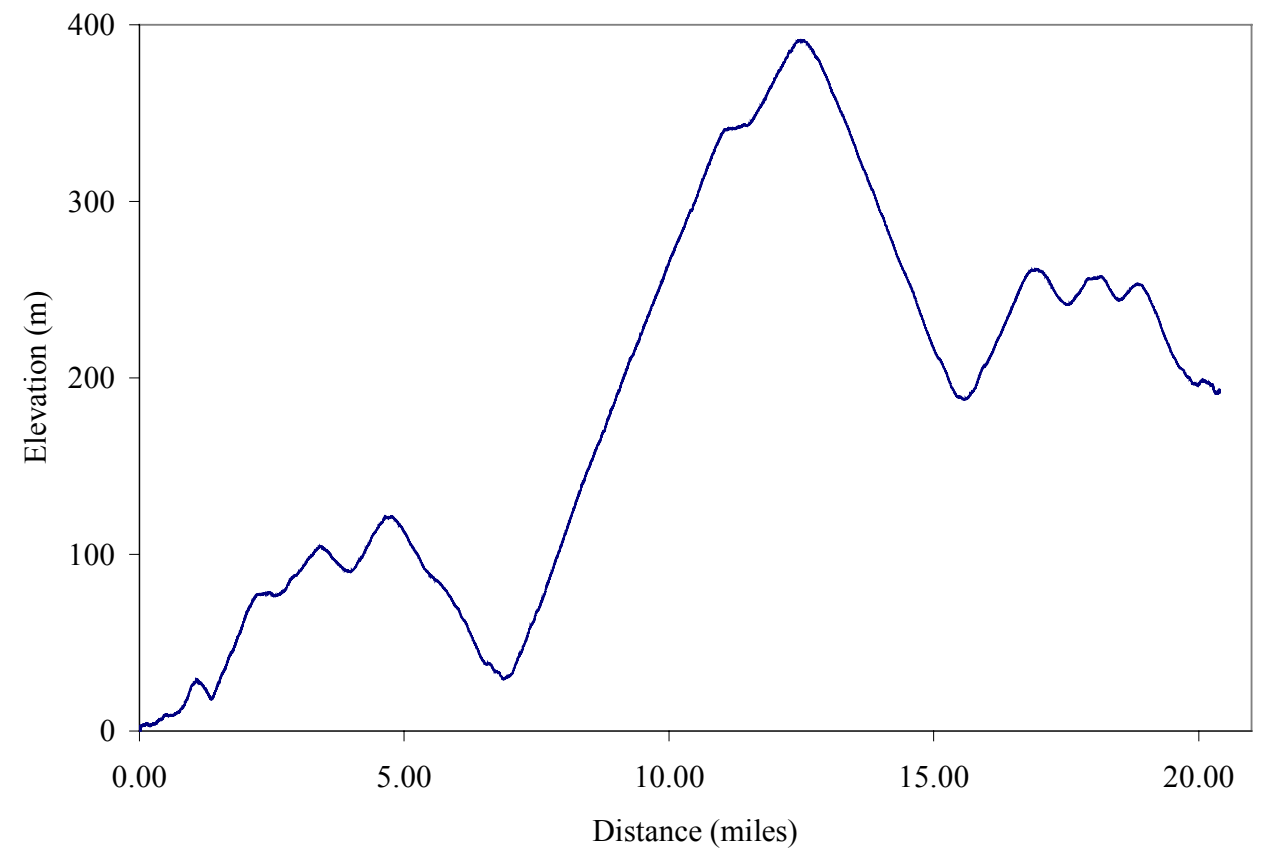

Figure 15: Elevation for Sab2BM

\subsubsection{PA1, PA2, and PA3}

This route started on the exit ramp of exit 19B off of I-70 in Pennsylvania. The route followed US Rt. 19 north through suburban areas toward Pittsburgh. The route continued through urban traffic then proceeded with freeway driving until it returned to West Virginia. A map of the full route can be seen in Figure 19. The route was divided into three legs signified as PA1, PA2, and PA3 with respective distances of 12.1, 23.2, and 51.8 miles. Relative elevation for each leg can be seen in Figure 16, Figure 17, and Figure 18. 


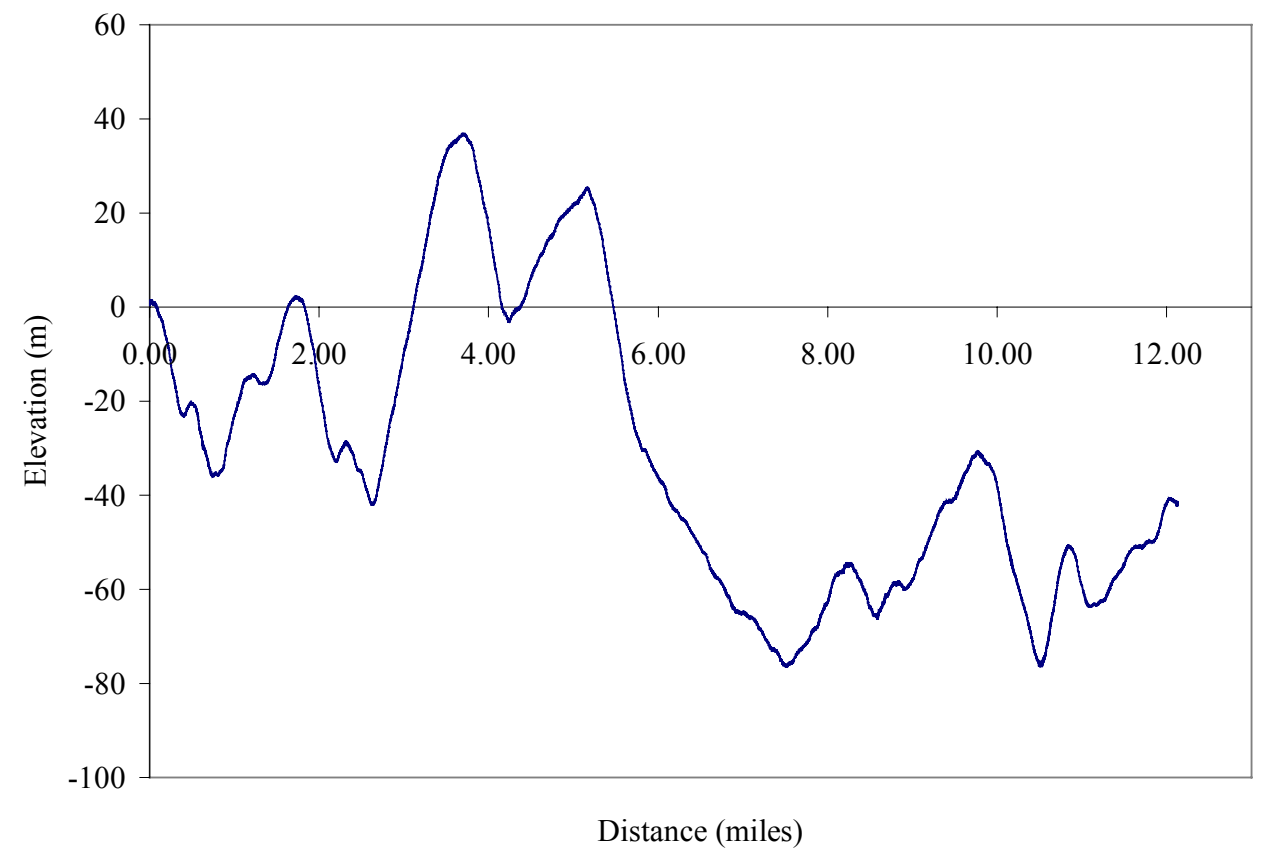

Figure 16: Elevation for PA1

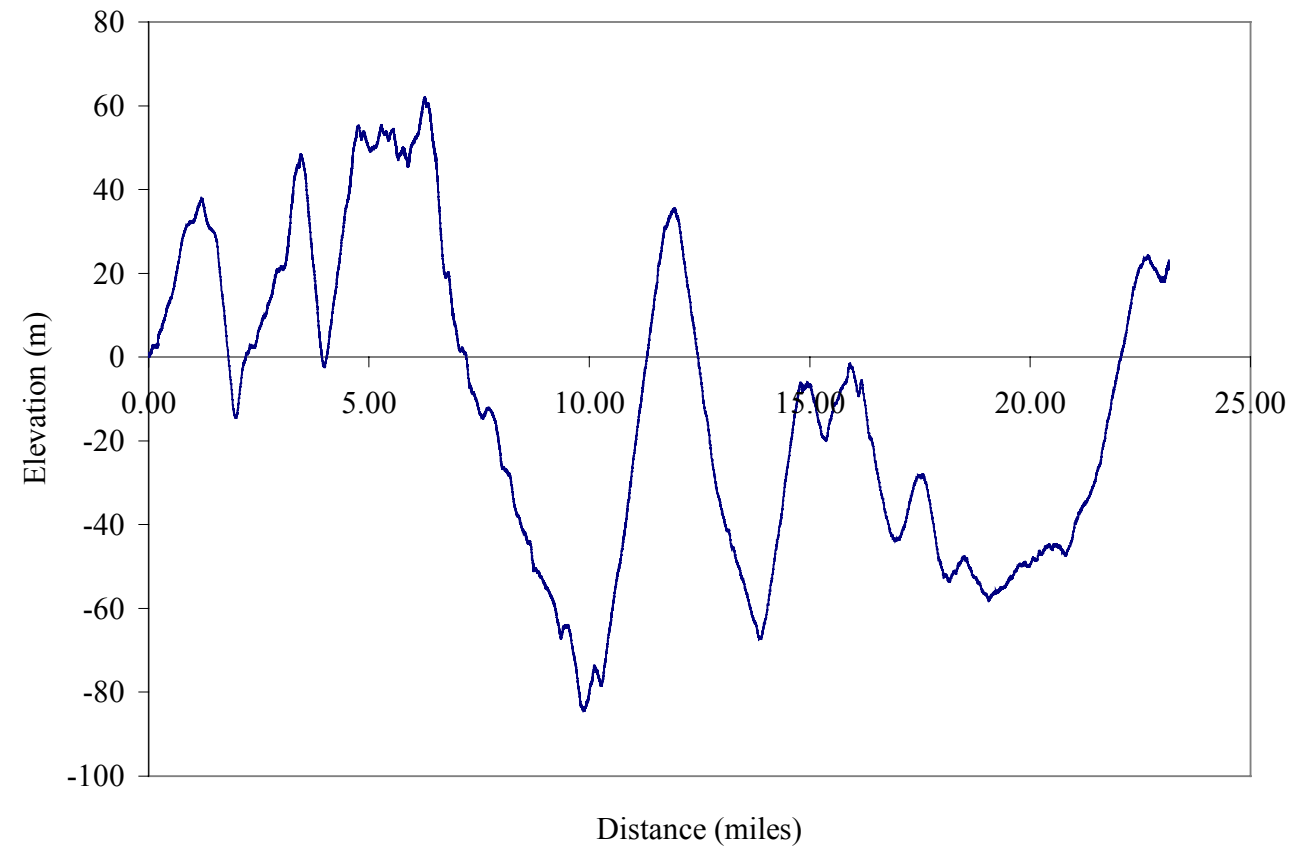

Figure 17: Elevation for PA2 


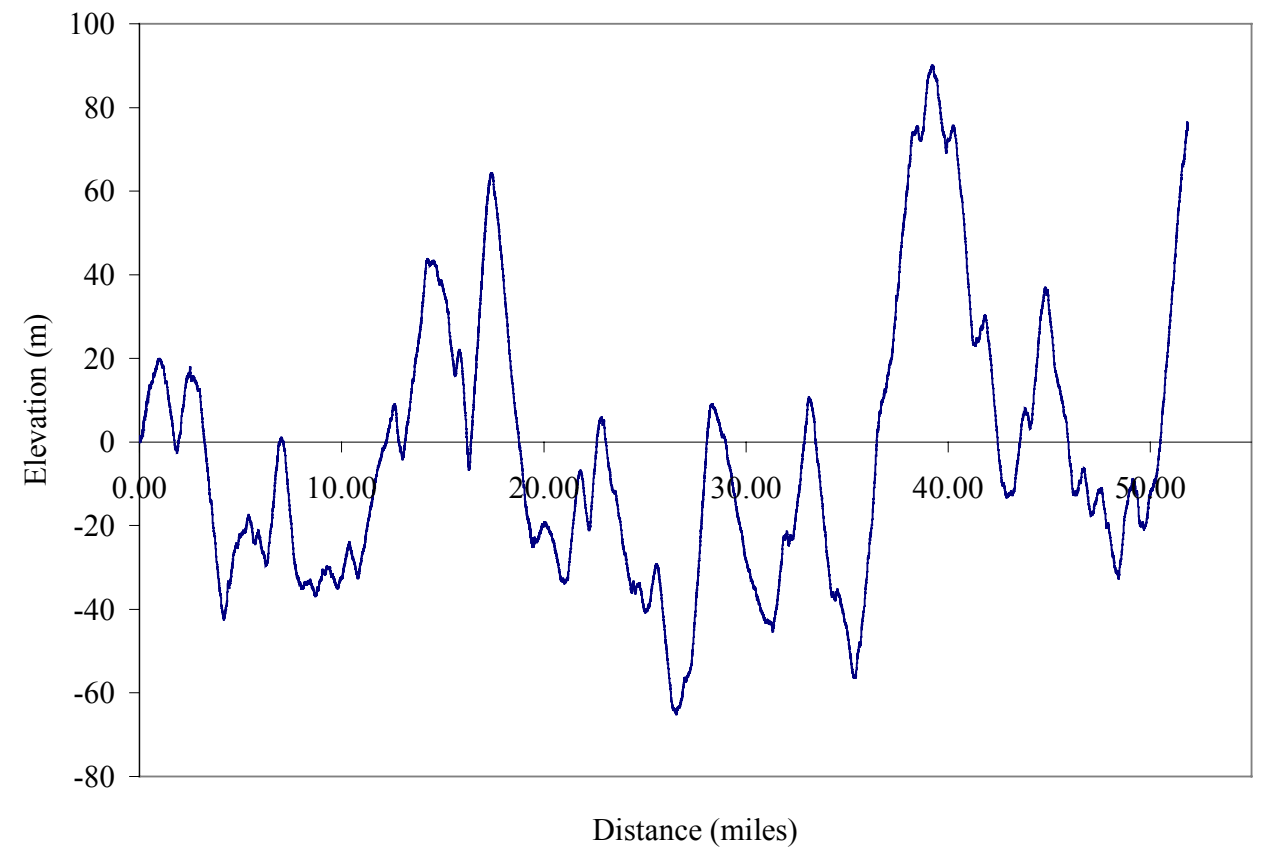

Figure 18: Elevation for PA3 


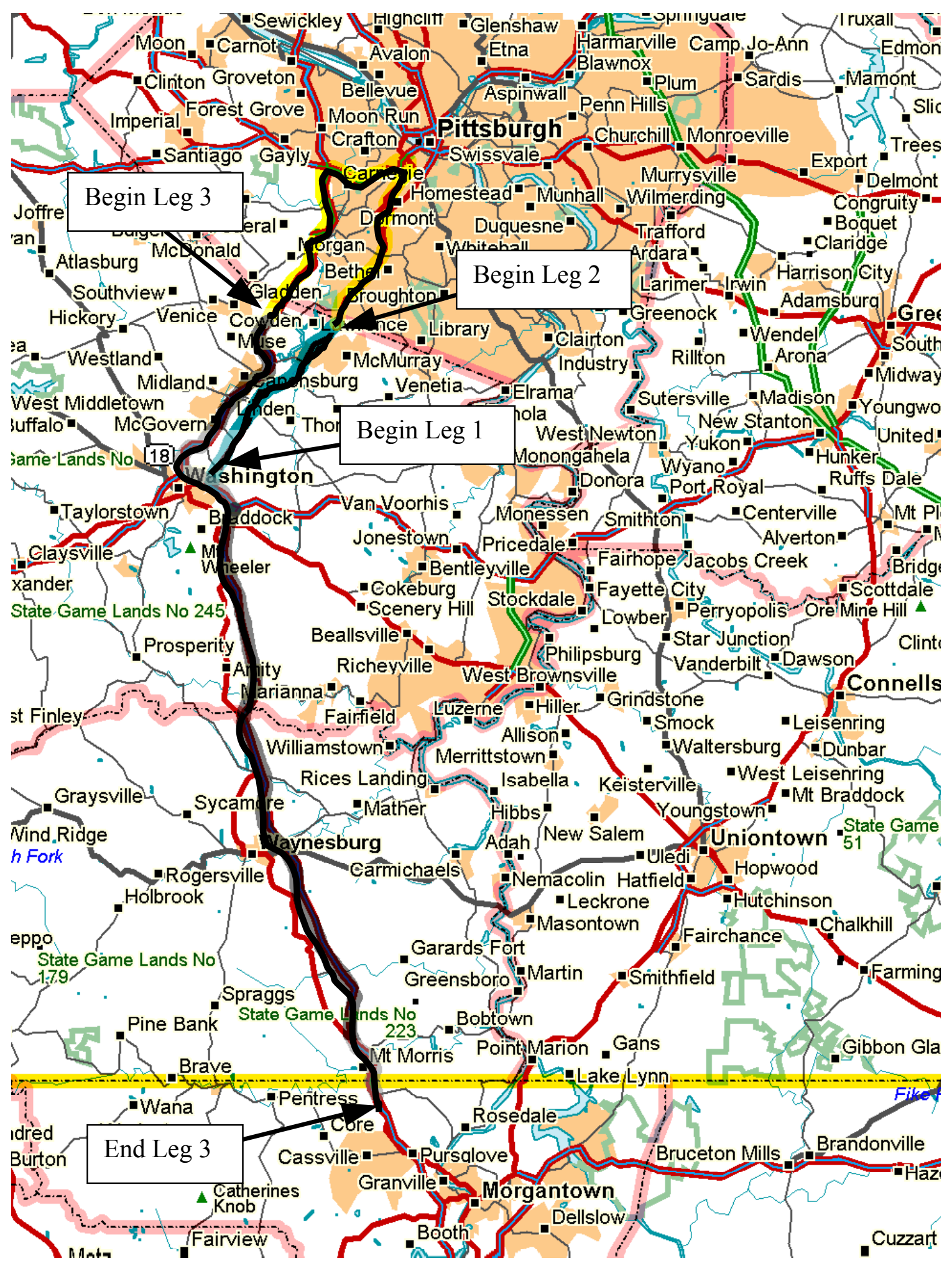

Figure 19: Map of PA1, PA2, and PA3 [8] 


\subsubsection{Morgantown}

The Morgantown route started at WVU's Sabraton Facility and proceeded on urban and suburban roads, consisting of two and four lanes, with posted speed limits of 35,40 , and $50 \mathrm{mph}$. The return journey was on I-79 and I-68, where the posted speed was $70 \mathrm{mph}$. Due to weight limit restrictions on the Star City bridge, set between MEMS Phase II and Phase III, vehicles over 60,000 GVW were not tested on this route. The route was 20.4 miles long and moved in a counter-clockwise direction on the map in Figure 20. Relative elevation for the Morgantown route can be seen in Figure 21. For this thesis the route has been abbreviated as "Motown." The erroneous difference in elevation between the beginning and end of route resulted from a change in ambient pressure or sensor drift. This change/drift was approximately 0.049 in $\mathrm{Hg}$ or $14 \mathrm{~m}$. This is $0.17 \%$ of the absolute pressure and is within the $0.25 \%$ accuracy range of the sensor.

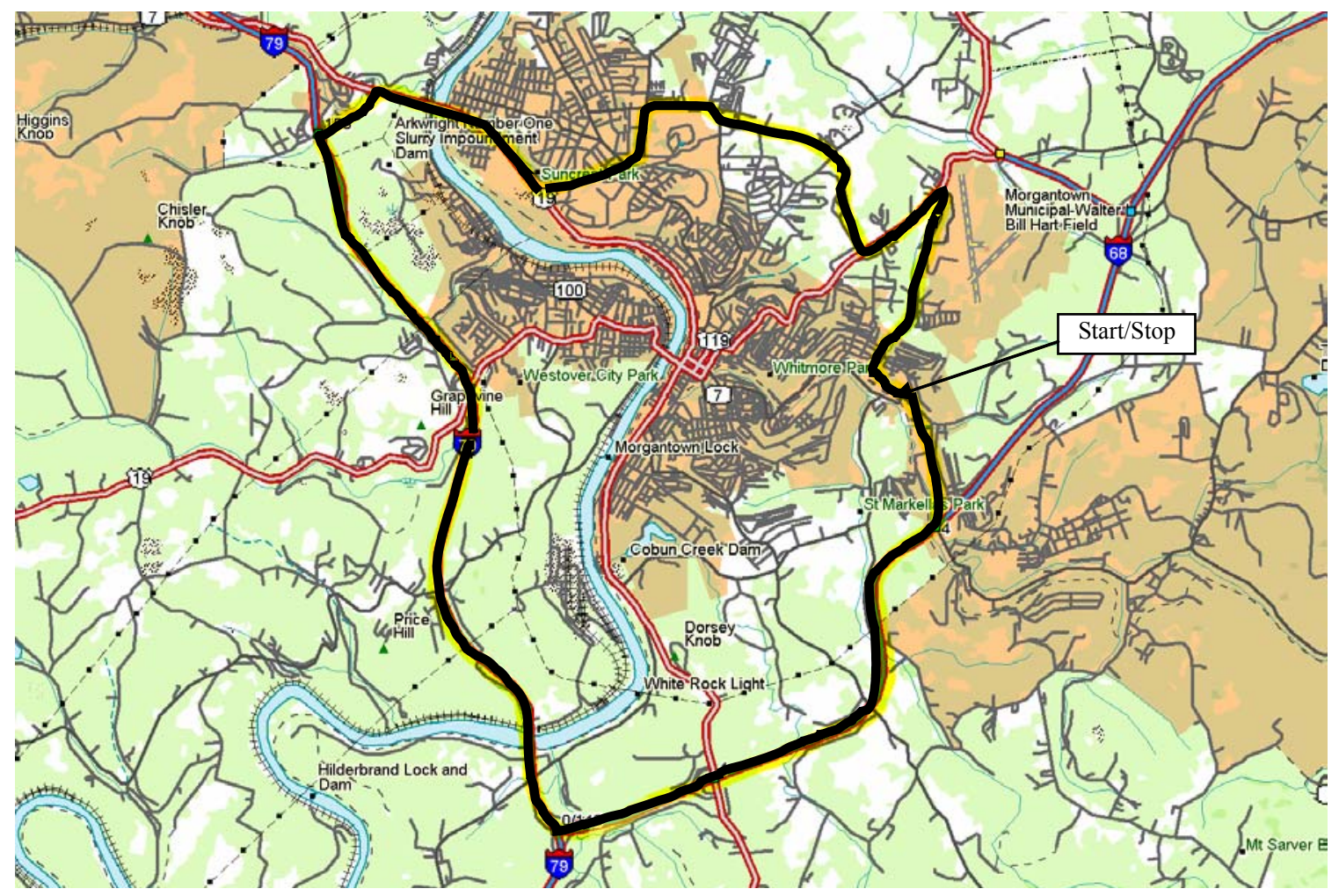

Figure 20: The map of Morgantown route [8] 


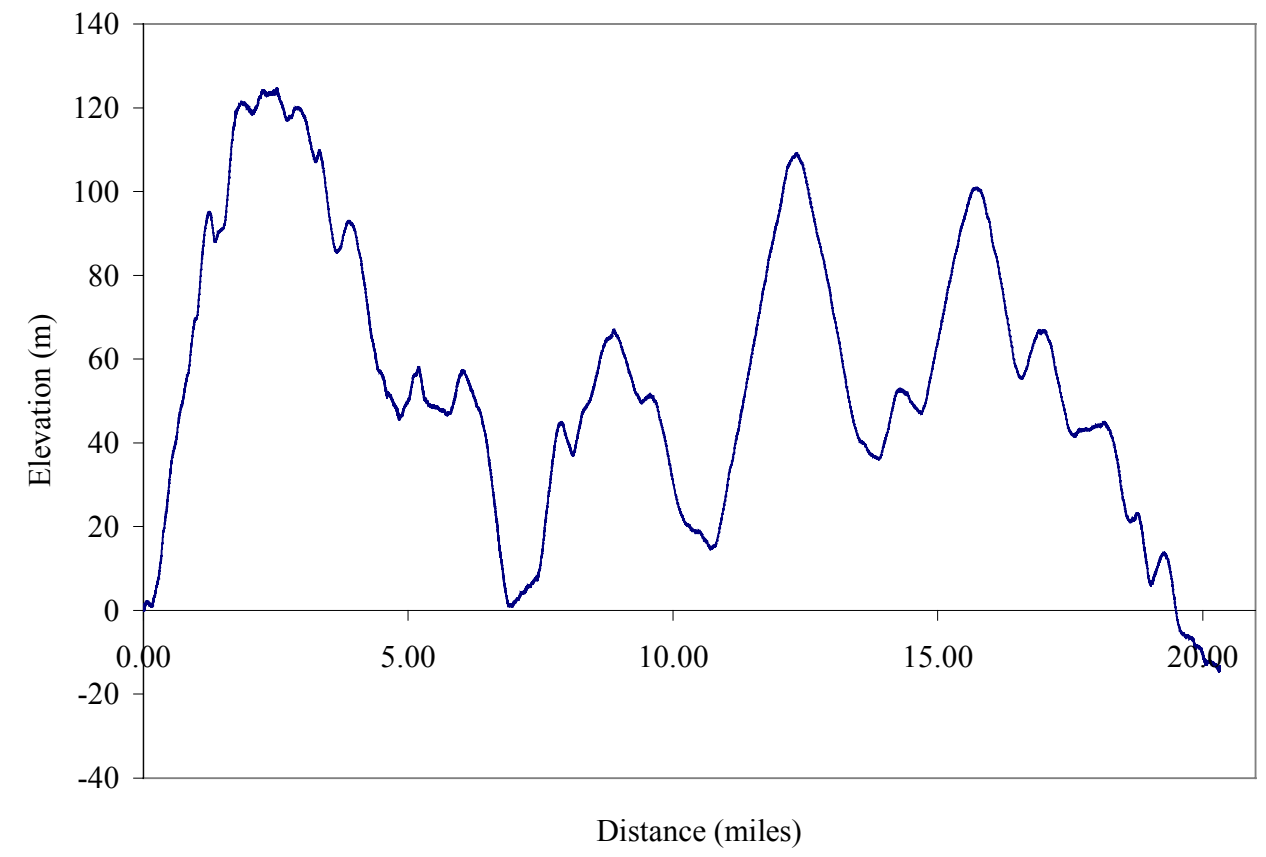

Figure 21: Elevation for the Morgantown route

\subsubsection{Sab2SW, SW2Sab}

This route originated at WVU's testing facility in Sabraton and proceeded to nearby I-68, heading west. It then headed south on I-79 until reaching the Saltwell exit where the first leg (Sab2SW) ended and the second leg (SW2Sab) began. Each leg was 29.5 miles. The posted speed limits were largely $70 \mathrm{mph}$. This route can be seen in Figure 22. The relative elevation for the Sab2SW can be seen in Figure 23. SW2Sab followed the same contour in the reverse direction. 


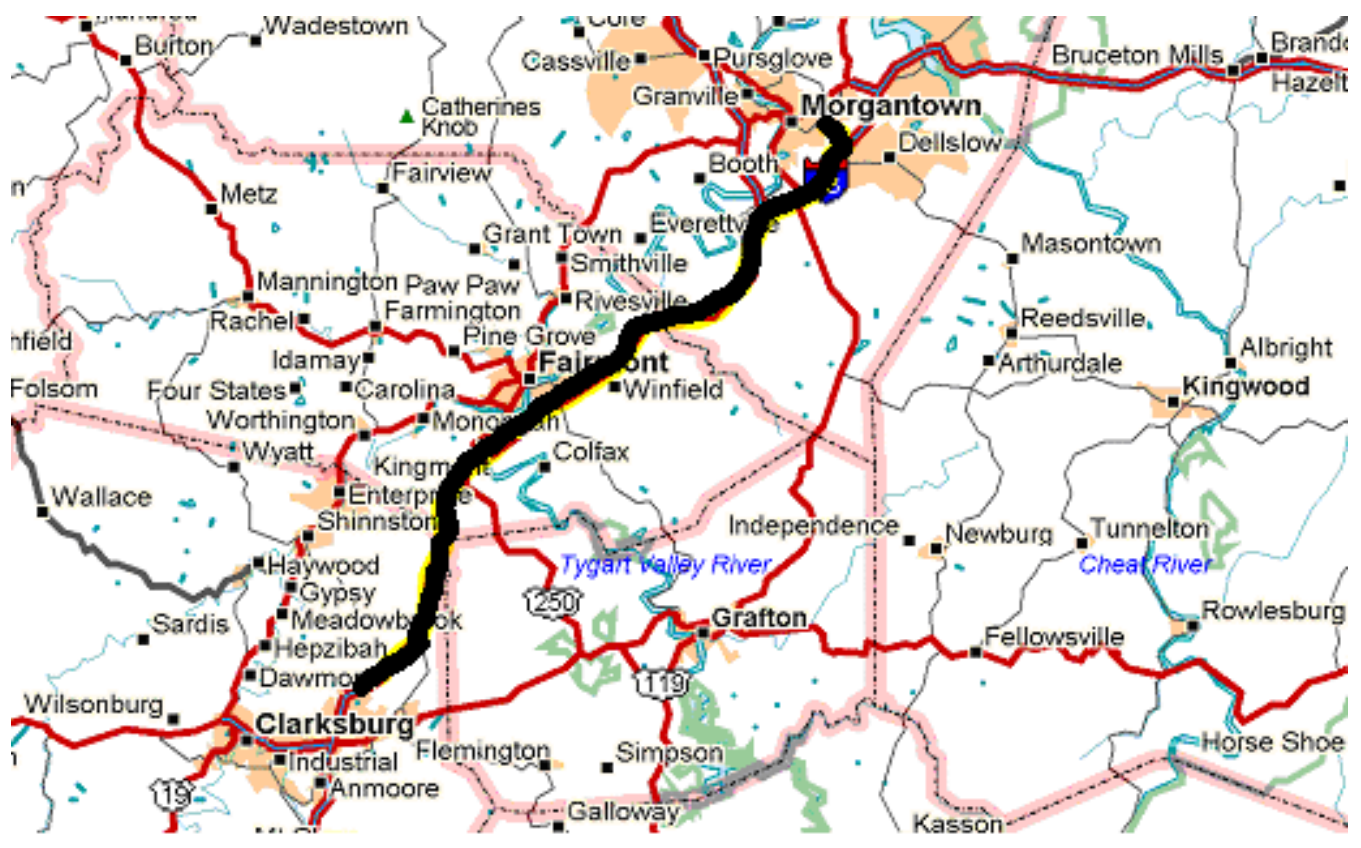

Figure 22: Map of Saltwell Route [8]

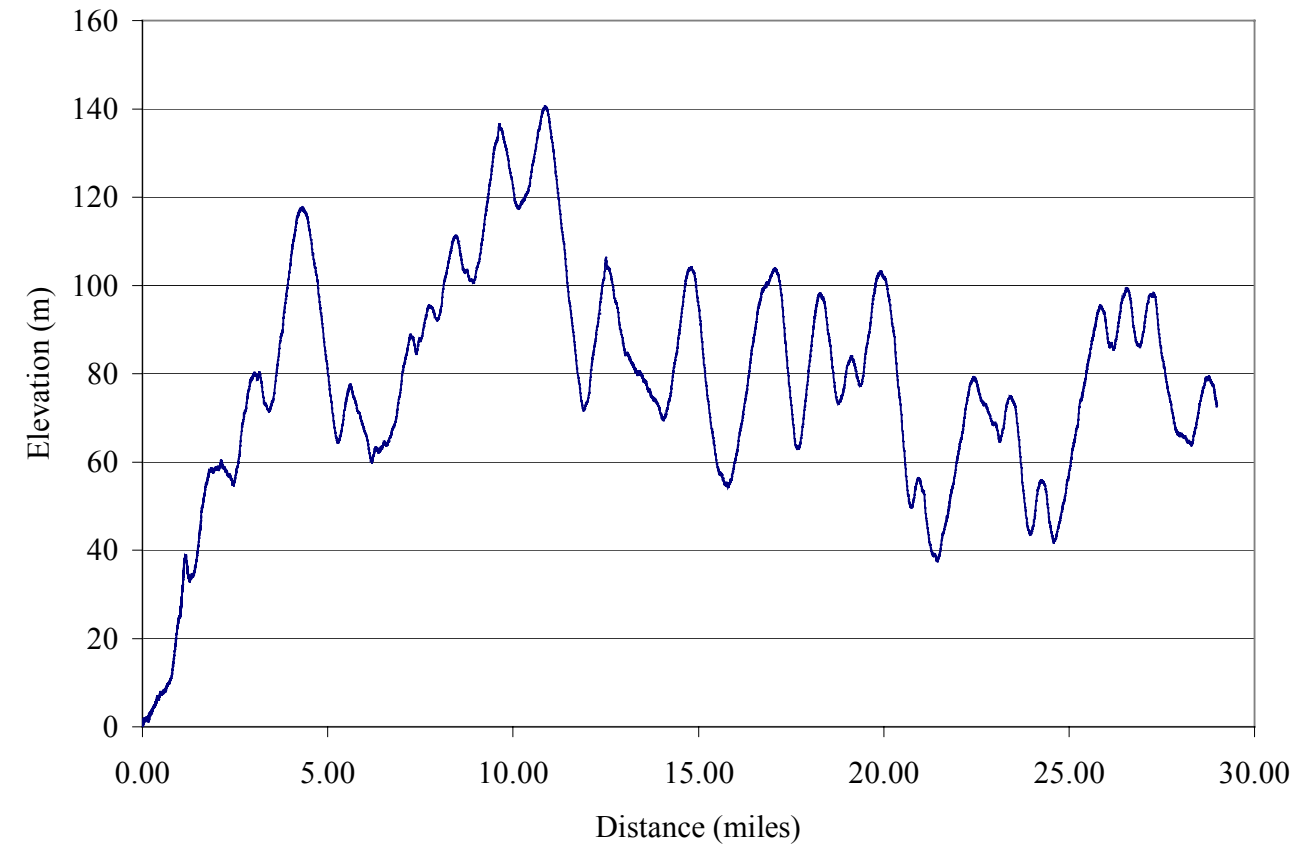

Figure 23: Elevation for Sab2SW 


\subsubsection{UDDS}

The Urban Dynamometer Driving Schedule as tested in this examination was a 1039 second long cycle that included nine stops and had a maximum speed of approximately $57 \mathrm{mph}$. This cycle deviated from the CFR defined UDDS for heavy-duty vehicles by the elimination of the first 20 seconds of idle [3]. The cycle covered 5.53 miles and called for fixed speeds at all times. Data evaluated for this cycle were collected by the TransLab and not by MEMS. This cycle was included for repeatability comparison purposes only. Vehicle speed for the UDDS as recorded during the Ford tractor test can be found in Figure 24.

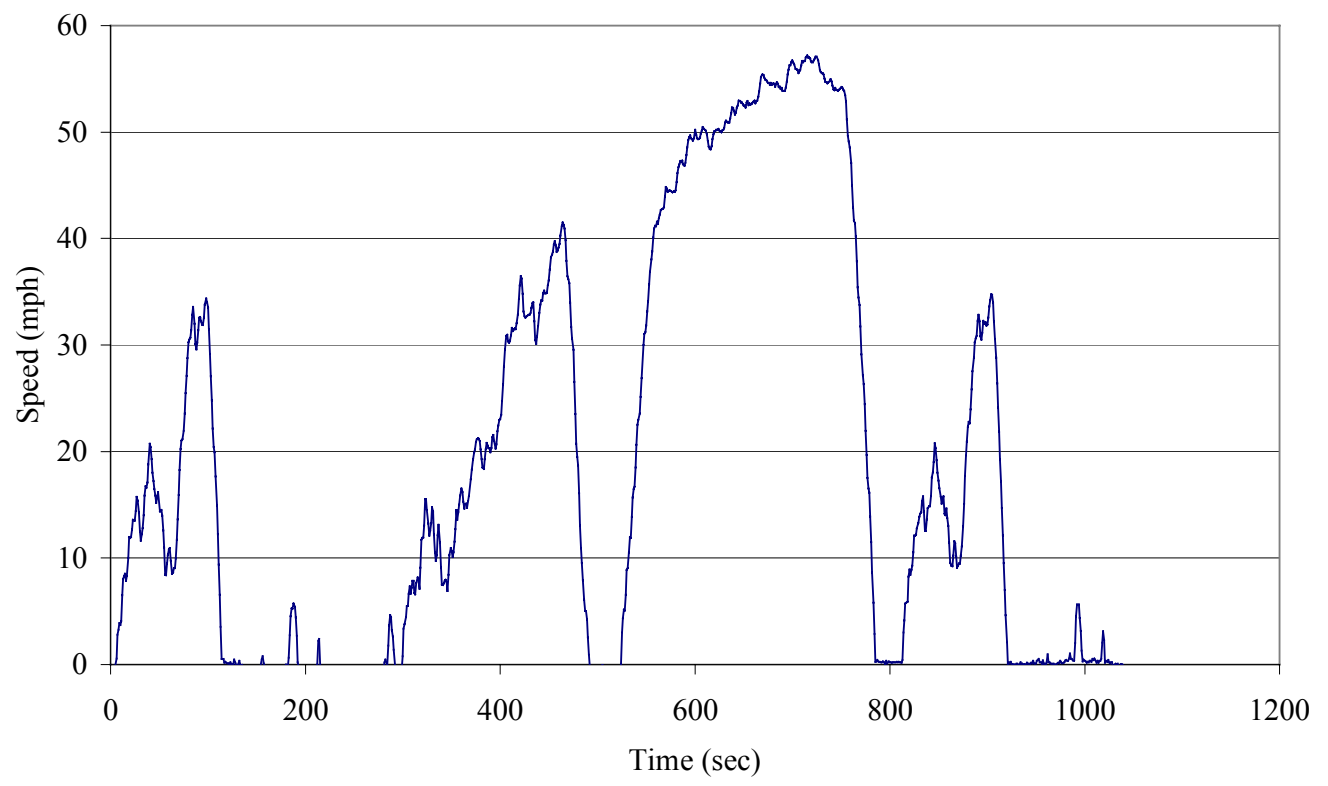

Figure 24: Vehicle speed for the UDDS

\subsubsection{CSHVR}

The City Suburban Highway Vehicle Route consisted of speeds less than $45 \mathrm{mph}$, with numerous starts and stops. The route contained portions of unrestrained full power acceleration, allowing vehicles with higher power to weight ratios to complete the route in less time than less powerful vehicles. Vehicle speed versus distance as recorded during the Sterling tractor test can be seen in Figure 25. Note that the graph fails to show zero speed because of the nature of the speed to distance conversion. Figure 26 shows 
vehicle speed and idle time from the same Sterling tractor test. TransLab and not MEMS collected data evaluated for this route.

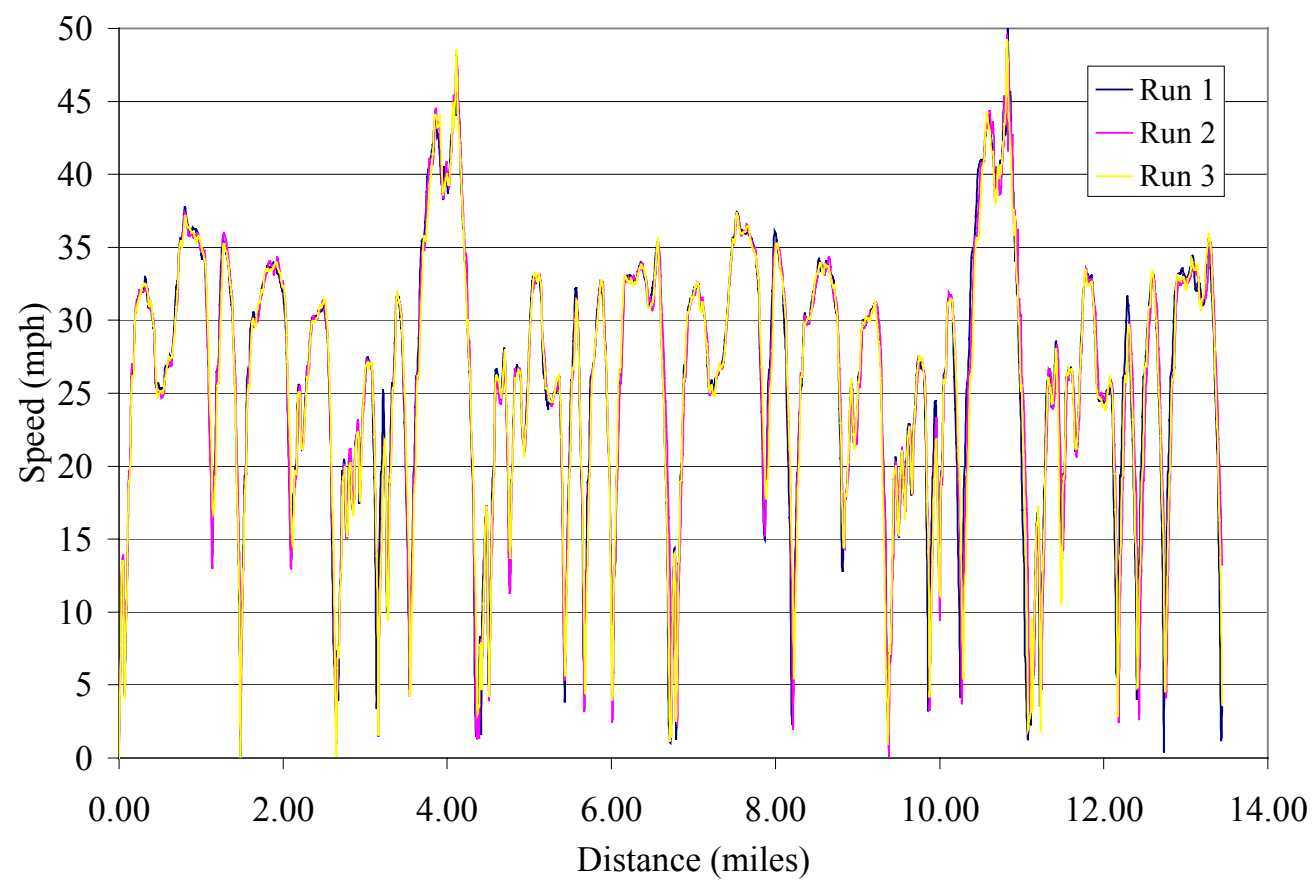

Figure 25: Speed versus distance for the CSHVR

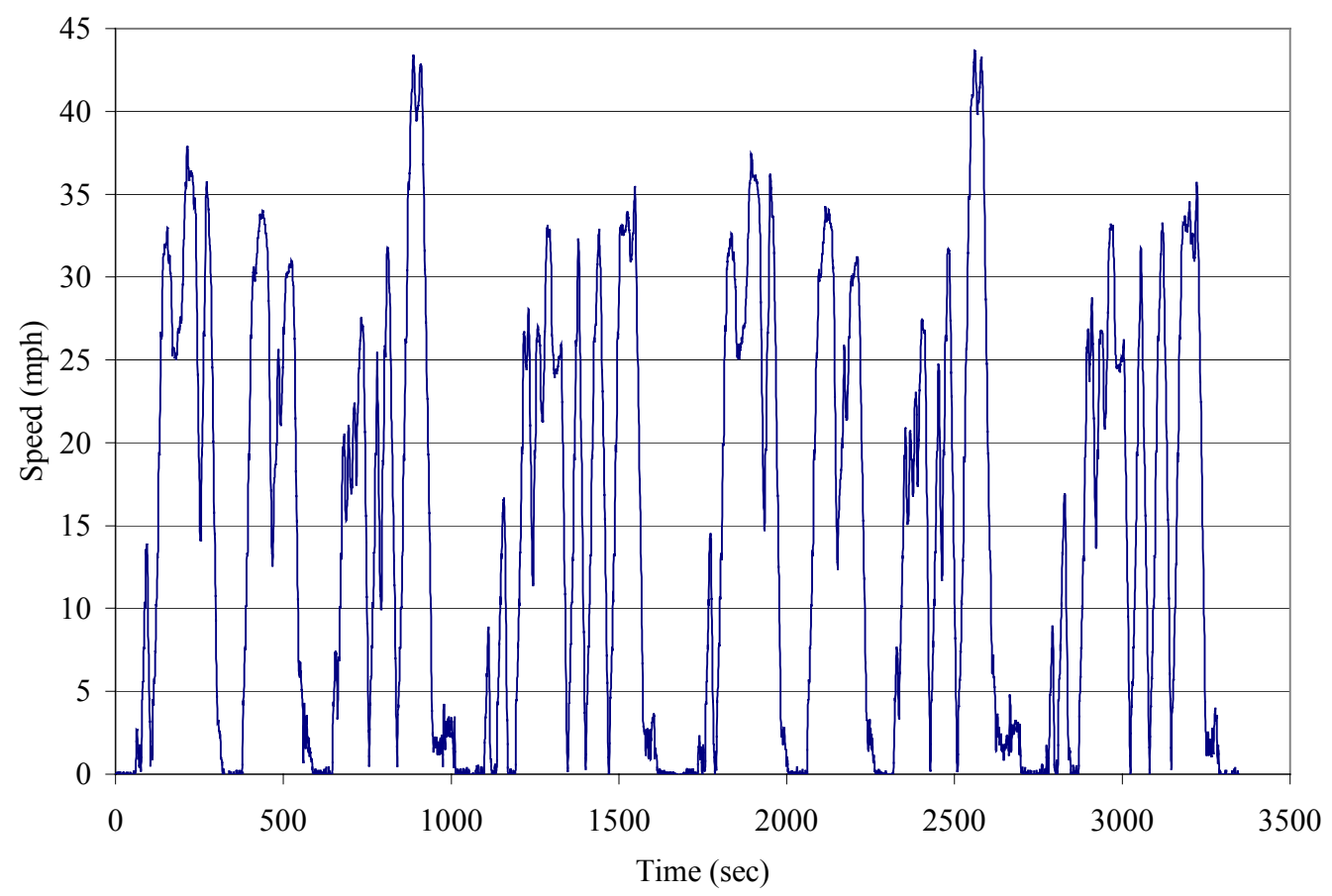

Figure 26: Speed versus time for the CSHVR 


\section{On-Road Route Data}

Data were recorded at $5 \mathrm{~Hz}$ and could easily be presented in time-specific graphs. Time-specific graphs show vehicle parameters or instantaneous emissions throughout the run. Time-specific run-to-run comparisons were difficult to compare for repeatability. If one vehicle was stopped at a traffic light and the second vehicle did not stop, then proceeding data varied drastically. This can be seen in Figure 27 where the vehicle stopped for extended periods during Run 1 and stopped for far shorter periods during Run 2 and Run 3. One can see that data between 1100 and 1400 seconds of Run 1 corresponded well with the data between 800 and 1200 seconds for Runs $2 \& 3$. This event occurred at the same location, but at considerably different times. It was apparent that data as a function of time were inadequate for proper run-to-run comparison. Table 6 shows driver, time, and day for MEMS \#12 over Sab2BM.

Table 6: Data for MEMS \#12 on Sab2BM

\begin{tabular}{|l|c|c|c|}
\cline { 2 - 4 } \multicolumn{1}{c|}{} & Run 1 & Run 2 & Run 3 \\
\hline Driver & Ron Jarrett & Jason England & Jason England \\
\hline Day & Thursday & Friday & Saturday \\
\hline Date & $8 / 21 / 2002$ & $9 / 19 / 2002$ & $9 / 20 / 2002$ \\
\hline Time & $4: 11: 46$ AM & $6: 14: 26$ PM & $9: 11: 56$ AM \\
\hline
\end{tabular}




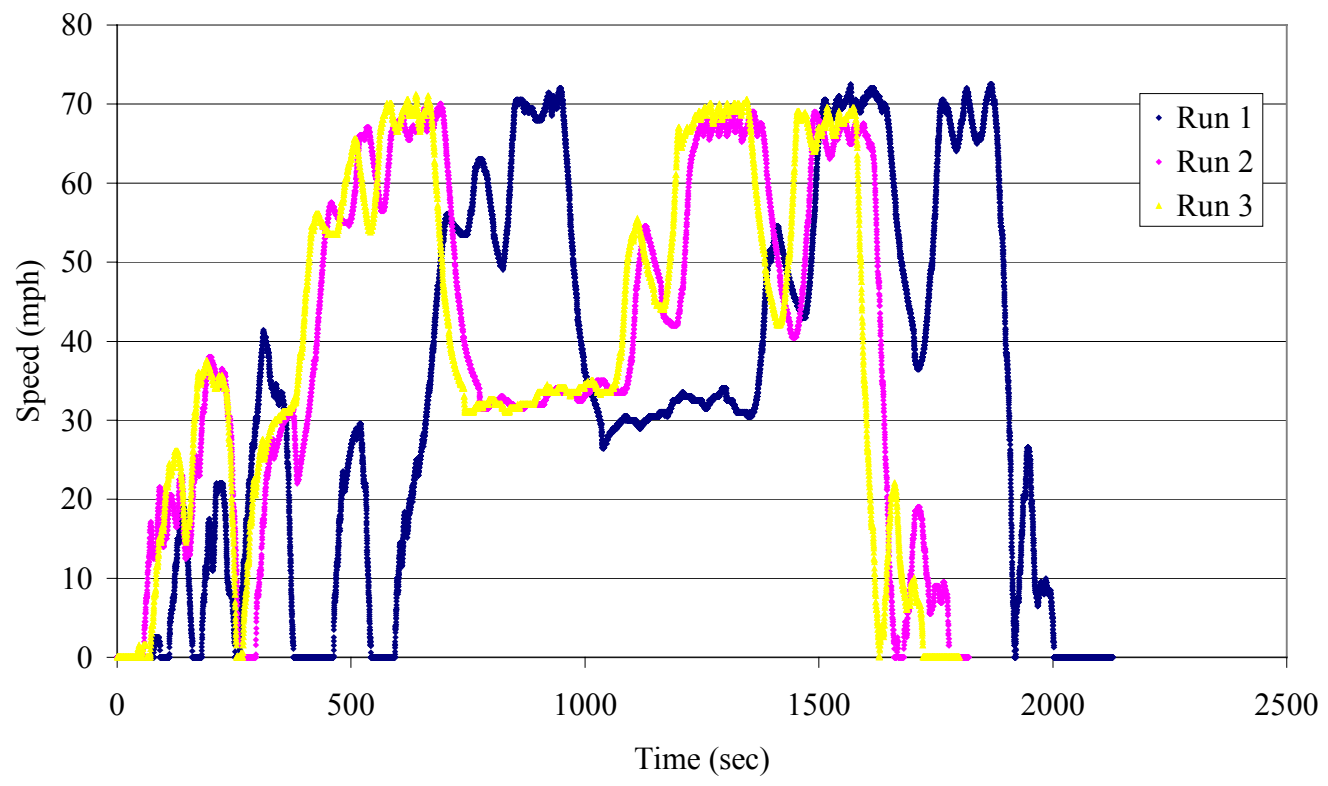

Figure 27: Time-based speed data for MEMS \#12 on Sab2BM

The data were much easier to compare visually when presented in distancespecific graphs. This can be seen in Figure 28. Vehicle stops did not affect distance traveled; therefore similar behavior was seen at a given distance, making comparison easier. From here onward, all presented data will have distance as the independent variable. Data regarding vehicle behavior and emissions that were collected and examined in this thesis were vehicle speed, elapsed time, gear (vehicle speed / engine speed), engine speed, engine torque, engine power, mass flow rate of $\mathrm{CO}_{2}(\mathrm{~g} / \mathrm{sec})$, mass flow rate of $\mathrm{NO}_{\mathrm{x}}(\mathrm{g} / \mathrm{sec})$, and NTE Zone activity. The methodology for the conversion to distance-based data can be found in Section 6.1.

The distance-based conversion resulted in the vehicle speed graph failing to account for complete stops or length of stops as seen in Figure 28. For this reason, time was examined. If a vehicle stopped for a long time in one run and not the next, this discrepancy was recognized on the time graph, as seen in Figure 29. One can see in Figure 29 that during Run 1, the vehicle stopped at two points (around 2.0 and 2.5 miles) for considerably longer than any other run. This was not reflected in the distance-based vehicle speed data, yet was deemed significant enough that the time comparison was 
found necessary. The time comparison was the only parameter examined that would account for idle time.

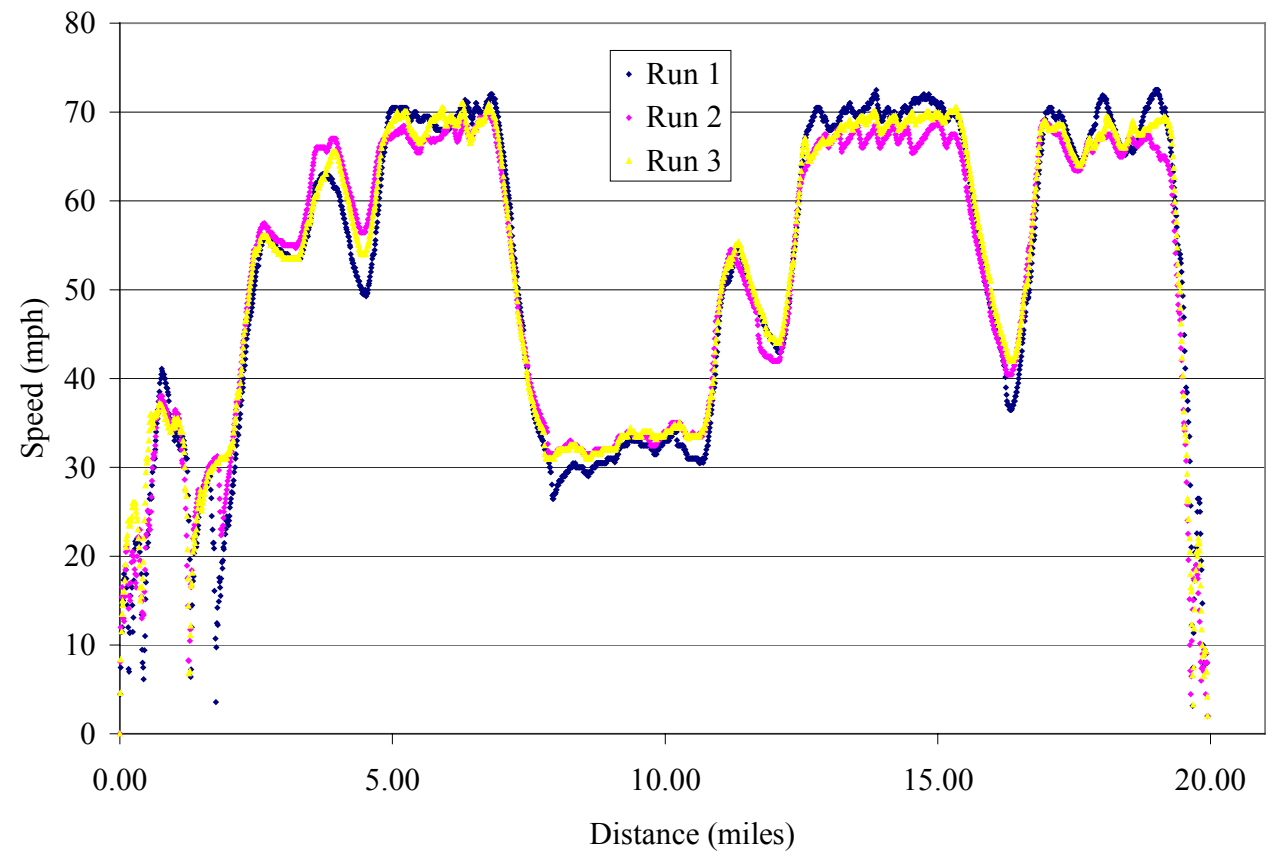

Figure 28: Distance-based vehicle speed data for MEMS \#12 on Sab2BM

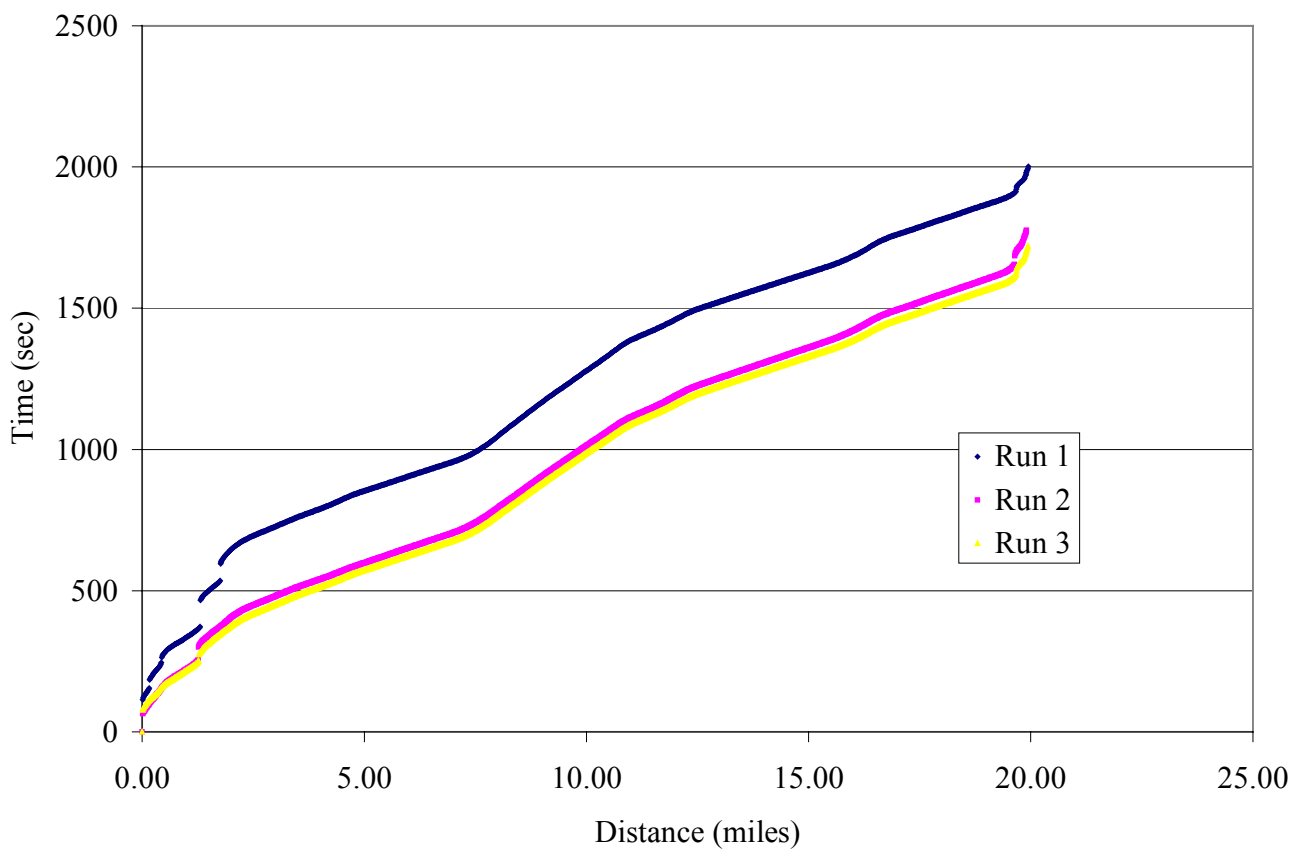

Figure 29: Distance-based elapsed time data for MEMS \#12 on Sab2BM 
Gear selection can be seen in Figure 30. The graph does not show actual gear, instead it displays the ratio of vehicle speed to engine speed which is proportional to gear ratio. This data gave insight into engine and driver behavior.

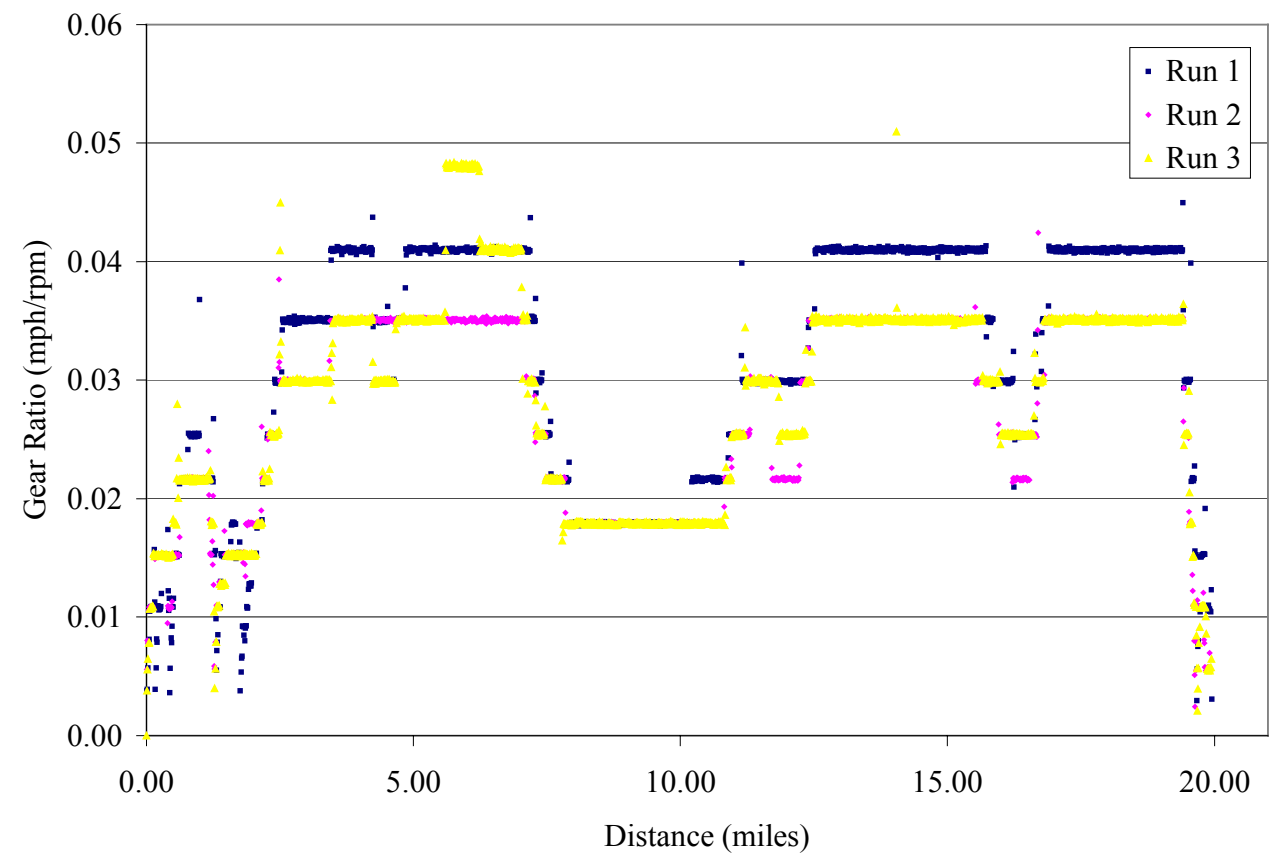

Figure 30: Distance-based gear ratio data for MEMS \#12 on Sab2BM

Engine speed, torque, and power are shown in Figure 32, Figure 33, and Figure 33. Engine speed had similar behavior for all three runs, with proportional differences stemming from gear usage. Torque also exhibited similar run-to-run behavior, with the majority of time spent at either full load or no load. Hills would increase the binary behavior of torque by requiring full load during the ascent and no load during the descent. Power, being a function of torque and speed, had similar behavior as torque, where most of the time was spent at the extremes, but maximum power varied with engine speed making it less binary. 


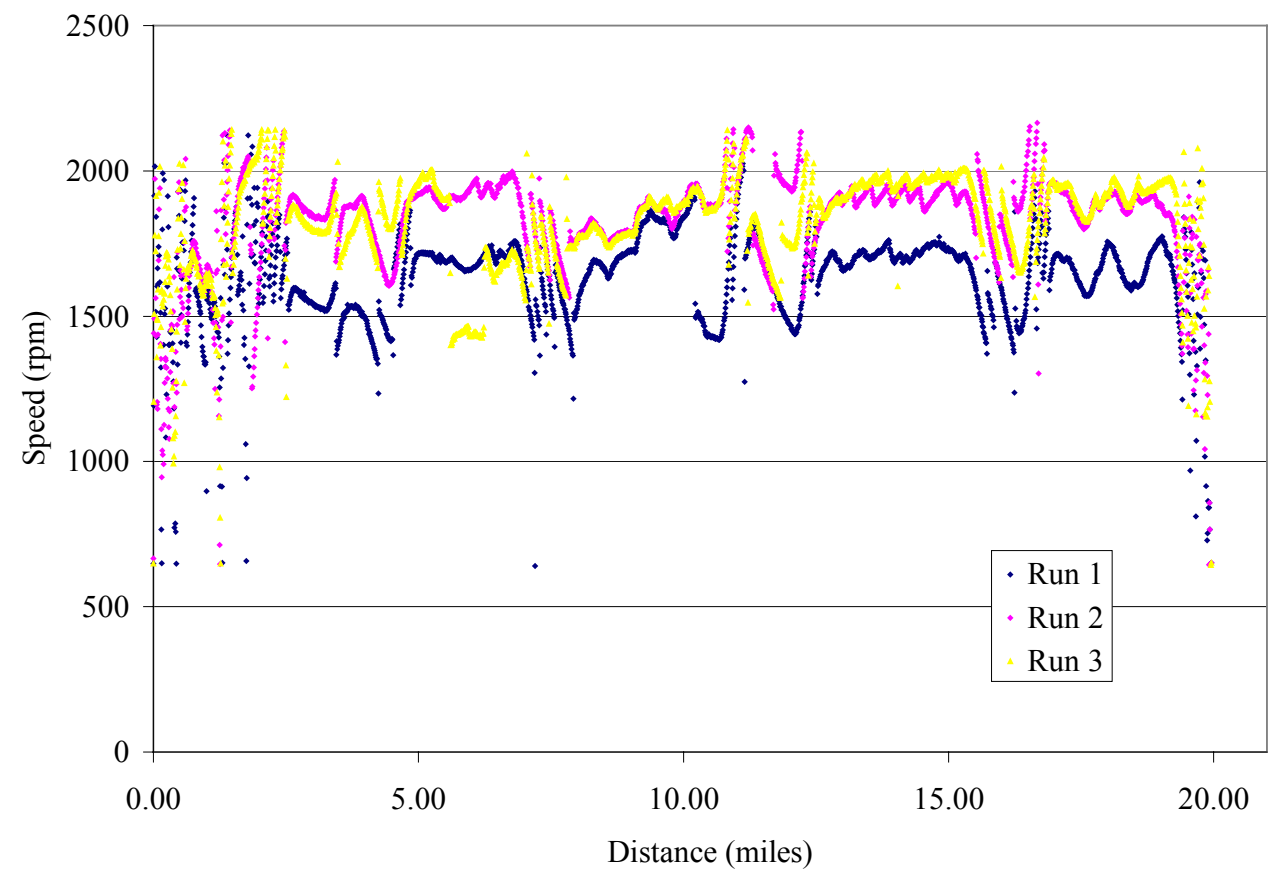

Figure 31: Distance-based engine speed data for MEMS \#12 on Sab2BM

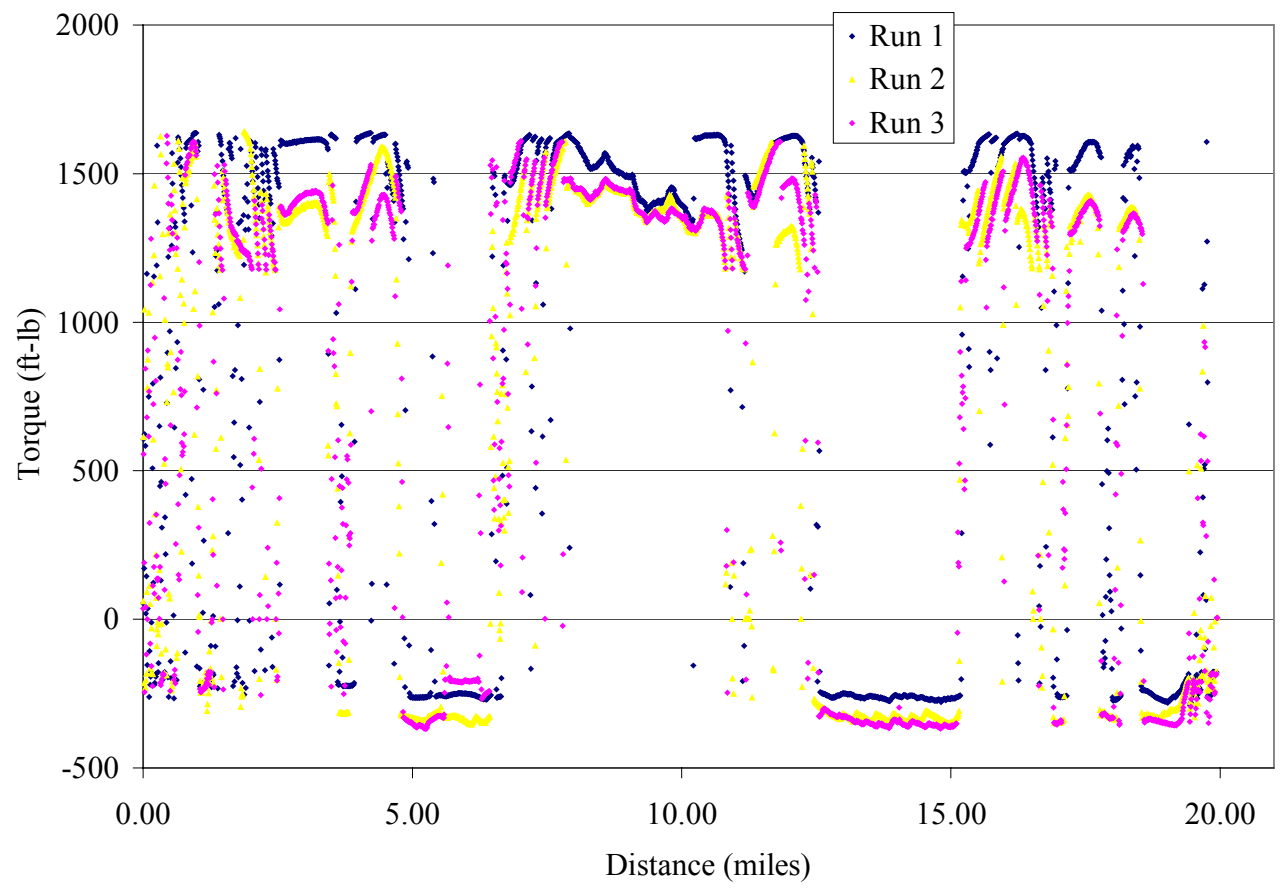

Figure 32: Distance-based engine torque data for MEMS \#12 on Sab2BM 


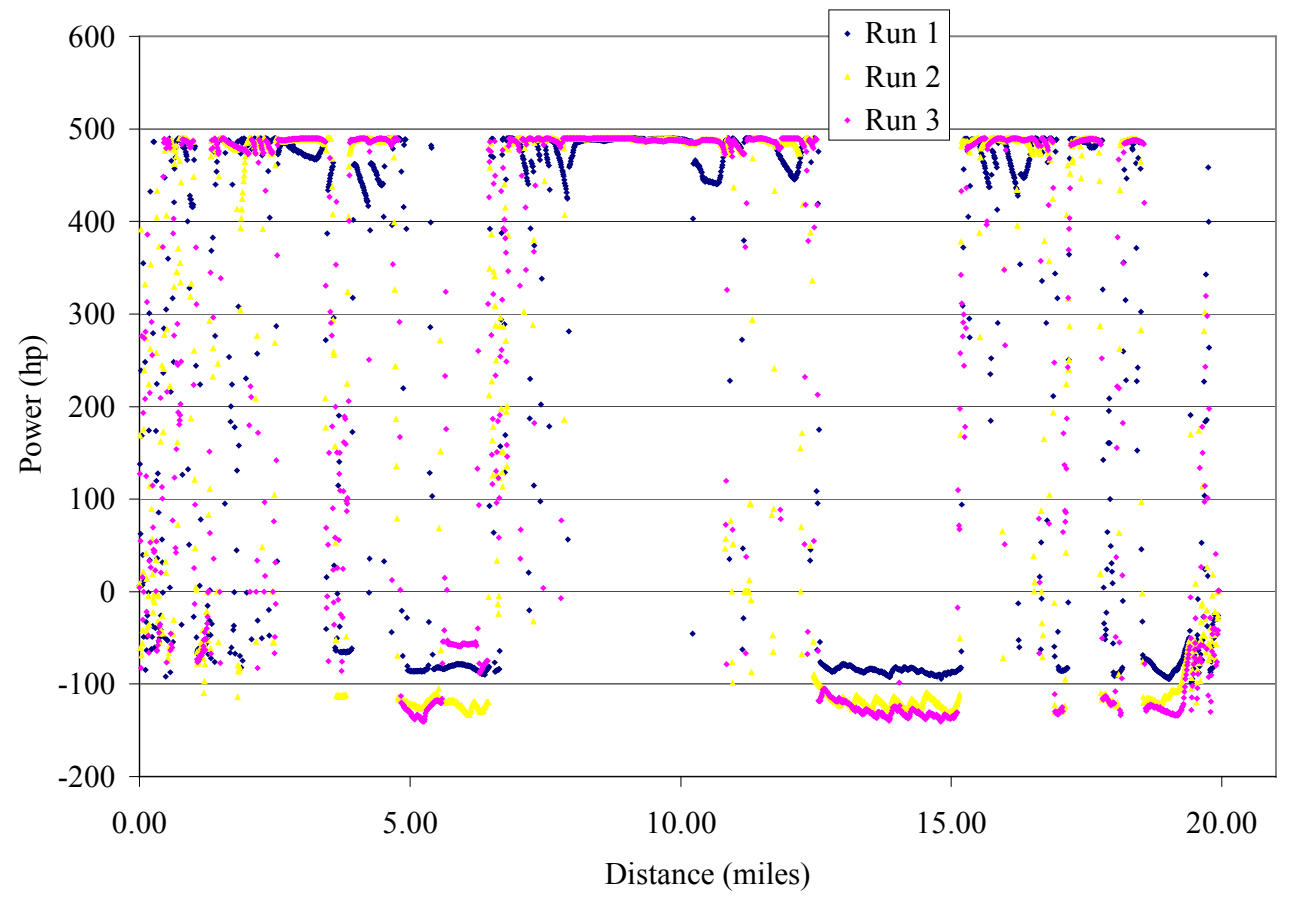

Figure 33: Distance-based engine power data for MEMS \#12 on Sab2BM

$\mathrm{NO}_{\mathrm{x}}$ and $\mathrm{CO}_{2}$ emissions data can be seen in Figure 34 and Figure 35. Data were reported as mass rates $(\mathrm{g} / \mathrm{sec})$ because brake-specific mass emissions are unreliable at light loads and would result in erroneous continuous comparisons. At very light loads, mass rate emissions become unreliable because concentrations are so low that they are hard to measure accurately. While it was possible to report emissions reliably in the NTE zone, it was the intent of the author to compare continuous vehicle behavior and not just NTE zone activity. The $\mathrm{CO}_{2}$ plot showed that mass flow rate varied at some points such as the 3 to 4 mile mark. Since almost the same amount of power was produced at this point, it appeared that during Run 1 the engine was operated more efficiently than the following runs. The $\mathrm{NO}_{\mathrm{x}}$ plot shows that mass rate emissions varied significantly, even though engine and vehicle behavior was similar. This most likely stemmed from offcycle behavior. 


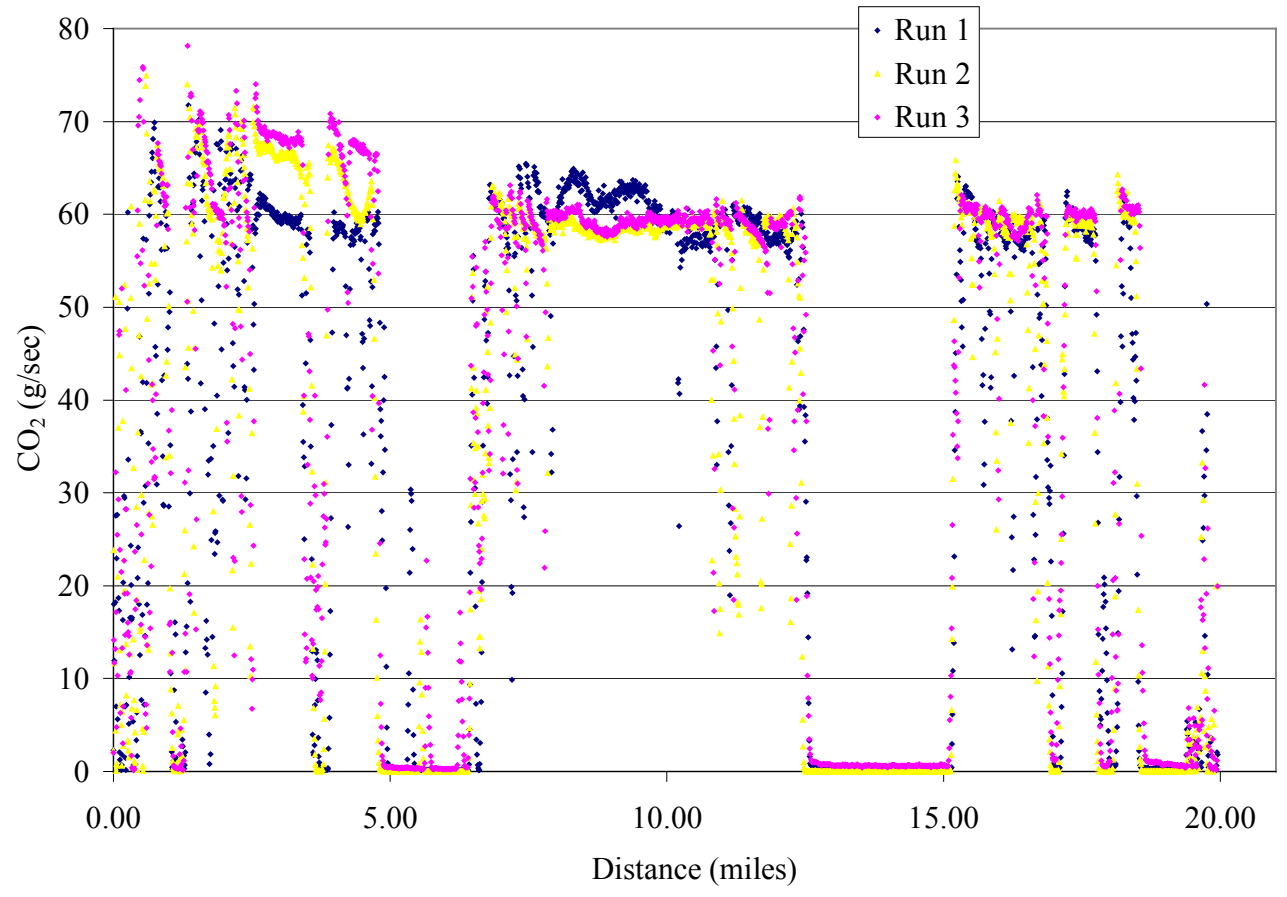

Figure 34: Distance-based $\mathrm{CO}_{2}$ emissions data for MEMS \#12 on Sab2BM

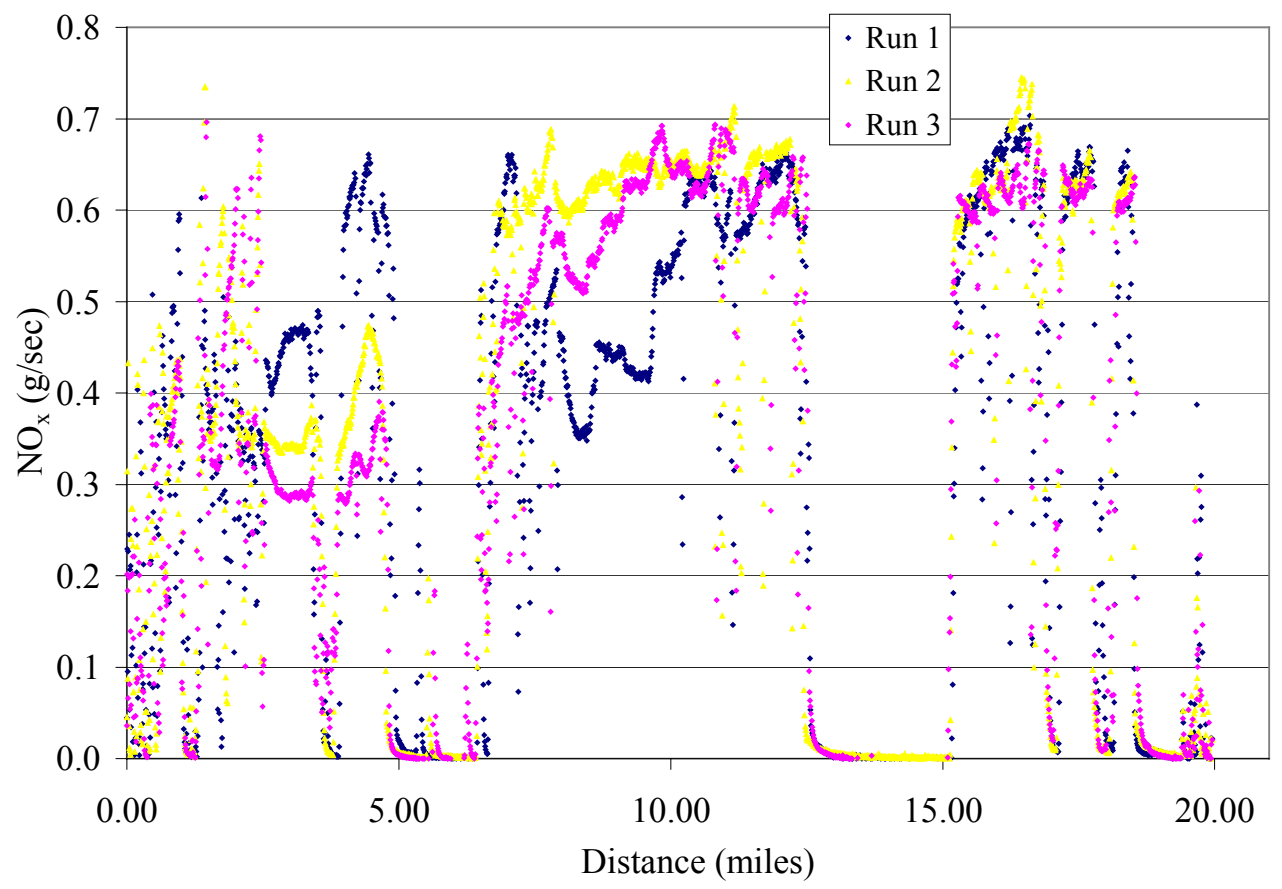

Figure 35: Distance-based NO $_{\mathrm{x}}$ emissions data for MEMS \#12 on Sab2BM

NTE Zone activity was the binary condition of the engine being or not being in the NTE Zone instantaneously. The data show numbers between zero and one, which resulted from the interpolation during the conversion to distance-based data. For easier 
viewing each run was multiplied by a different constant on the graph. This was only done for a visual comparison and not for the repeatability analysis. A description of the NTE zone can be found in Appendix A.

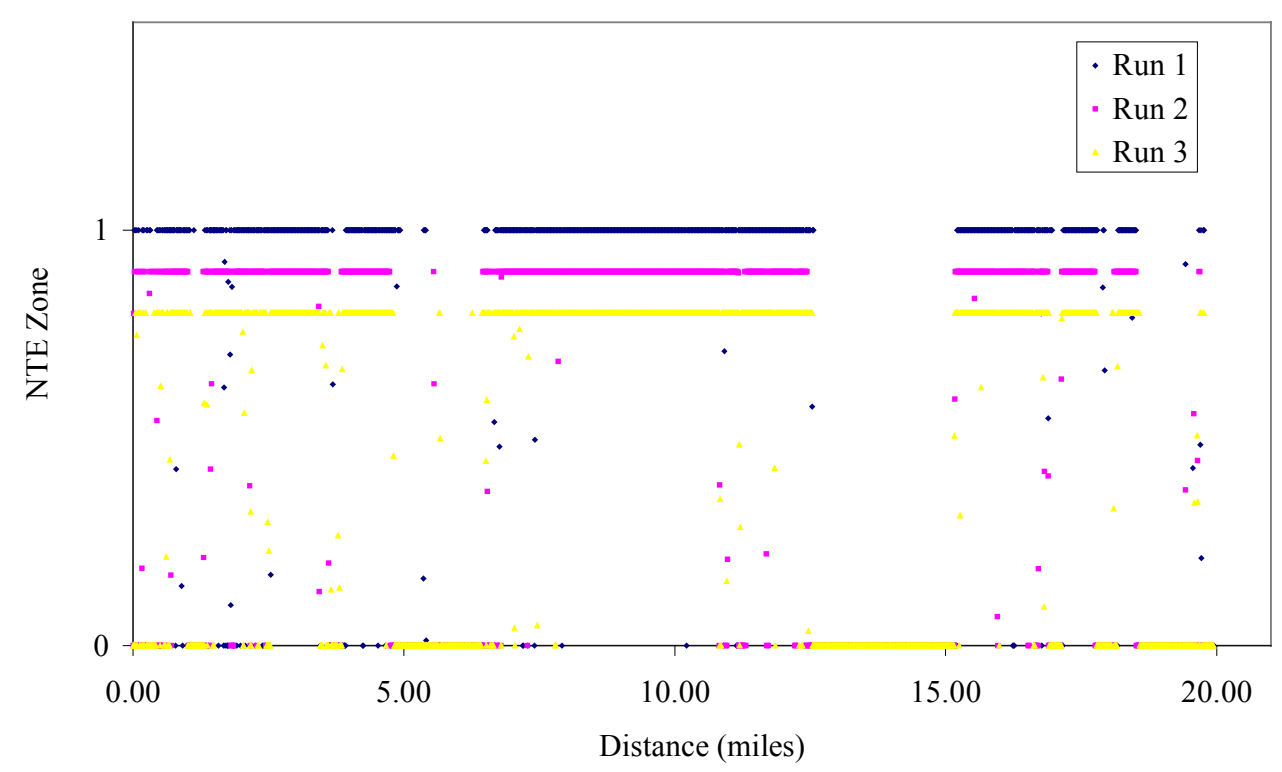

Figure 36: Distance-based NTE zone activity for MEMS \#12 on Sab2BM 


\section{Methodology}

\subsection{Distance-Specific Conversion}

The conversion from time-specific data to distance-specific data was made using the vehicle speed logged from the ECU. Vehicle distance traveled was calculated using Equation 3, where $\mathrm{D}_{\mathrm{c}}$ is the current distance in miles, $\mathrm{V}$ is the vehicle speed in mph, and $\mathrm{D}_{\mathrm{p}}$ is the previous distance in miles.

$$
\begin{gathered}
\text { Equation } 3 \\
D_{c}=D_{p}+\frac{V}{3600(s / h r)} * 0.2(s)
\end{gathered}
$$

An Excel Macro was written to identify the two consecutive data points that were before and after the instant at which the interval distance was reached. The values were then interpolated to find the value at the specific distance. A sample code for this can be found in Appendix B. The distance interval examined was 0.01 miles. This interval was chosen because it was small enough to capture transient behavior, yet not so small that it interpolates between the same data points more than once. An analysis of the distance interval can be found in Section 8.2.4.

\subsection{Multiple Dimension Linear Regression Analysis}

It was found necessary to compare multiple runs simultaneously with distance as the independent variable. Simple examinations could be done at each distance interval using coefficient of variance percent (COV\%) (Equation 4), standard deviation (Equation 5), or Student-T distribution (Equation 6, Equation 7, Equation 8). An example of this can be seen in Figure 37. This examination became problematic and inaccurate if the runs that were compared exhibited rapid change at slightly different locations. In Figure 37 the vehicle stopped during each run at a slightly different location near the 1.3-mile point, most likely due to traffic being backed up various distances from a traffic signal. While the vehicle exhibited very similar behavior, it still would create relatively large values for $\mathrm{COV} \%$, standard deviation, and student-t distribution. Pure localized statistical variation examination was not an accurate assessment of route repeatability. 


\section{Equation 4}

$$
C O V \%=\sqrt{\frac{n \Sigma y^{2}-(\Sigma y)^{2}}{n(n-1)}} /\left(\frac{\Sigma y}{n}\right)
$$

Equation 5

$$
\sigma_{y}=\sqrt{\frac{n \Sigma y^{2}-(\Sigma y)^{2}}{n(n-1)}}
$$

\section{Equation 6}

$$
T=\frac{\bar{Y}-\mu}{S_{n} / \sqrt{n}}
$$

\section{Equation 7}

$$
S_{n}^{2}=\frac{1}{n-1} \sum_{i=1}^{n}\left(Y_{i}-\bar{Y}\right)^{2}
$$

\section{Equation 8}

$$
\bar{Y}=\frac{\sum Y}{n}
$$

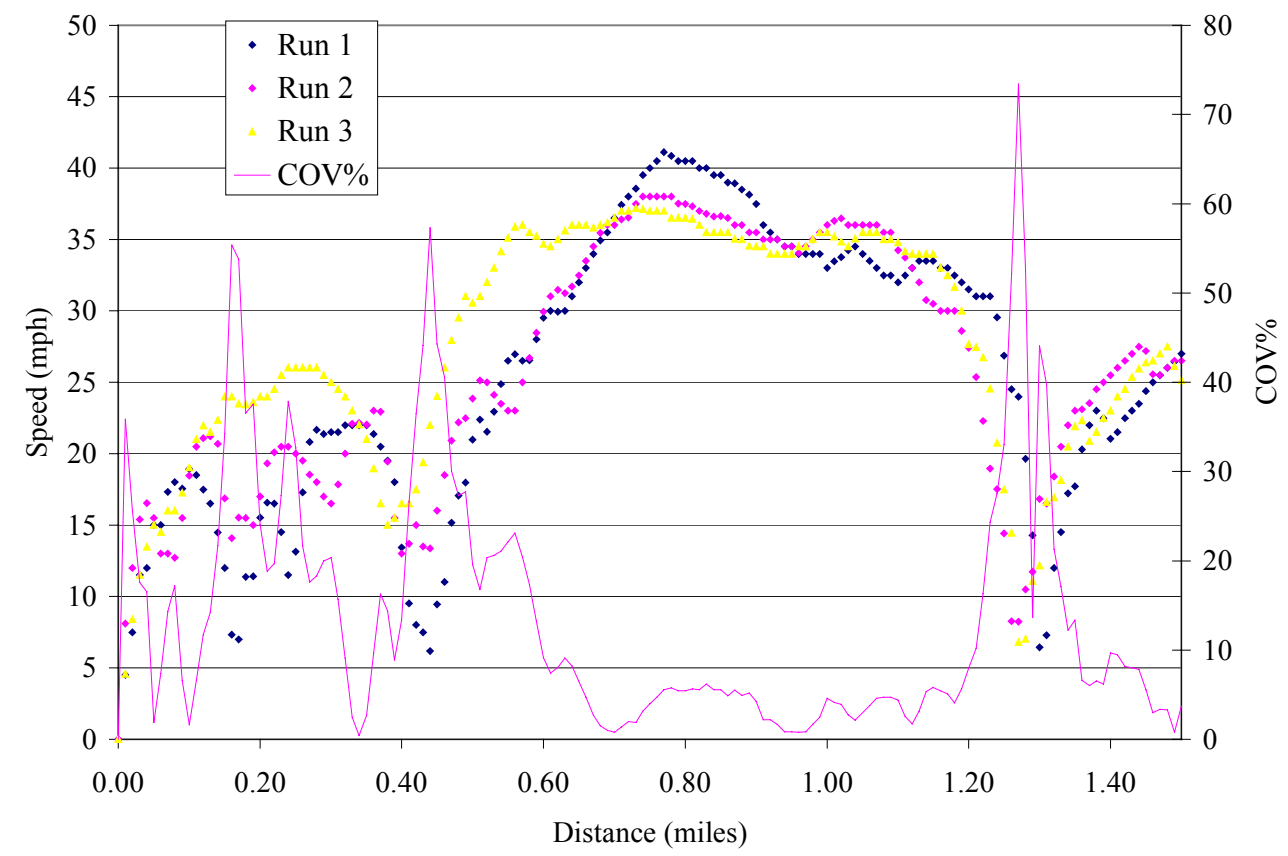

Figure 37: Detail of vehicle speed with instantaneous COV\% for MEMS \#12 over Sab2BM

Linear regression is very effective and common in two dimensions (as was used by McKain and Clark [19] when examining repeatability of chassis dynamometer cycles) and is used to validate the FTP. One would easily compare two runs by graphing a 
parameter, such as vehicle speed, at each distance interval as $\mathrm{X}$ and $\mathrm{Y}$ coordinates with Run 1 being on the $\mathrm{X}$-axis and Run 2 being on the Y-axis. One would find the coefficient of determination, or R-squared, using a "trendline." Typical linear regression using Microsoft $\subseteq$ Excel allows only for ordinate error examination, assuming the yvalues to be the dependent variable. This was appropriate for comparing a run to a trace, as in chassis and FTP testing, but inappropriate for run-to-run comparison because there was no dependent variable. Also the trendline found the best approximation of the relationship of dependent variable to the independent variable, which was not the case in this analysis.

The problem was solved by using an "exact line." The exact line went through the origin and had a slope of 1 . The points that fell on the line exhibited exact behavior from run to run. The error for a point was then found by calculating the shortest distance from the point to the exact line, dubbed "error distance." A "coefficient of repeatability" was found in place of the coefficient of determination, by first finding the intersection of the exact line and the error distance. The "exact distance" was the distance from this intersection of the exact line and the error distance line to the origin. The coefficient of repeatability was one minus the sum of the squared error distance over the sum of the squared exact distance as seen in Equation 9. A two dimensional graph of vehicle speed for two repeat runs using distance-based comparisons can be seen in Figure 38. For comparison purposes, a time-based analysis of two repeat runs can be see in Figure 39. Clearly repeatability is lower for time-based data.

\section{Equation 9}

$$
R^{2}=1-\frac{\sum \text { Error }^{2}}{\sum \text { Exact }^{2}}
$$




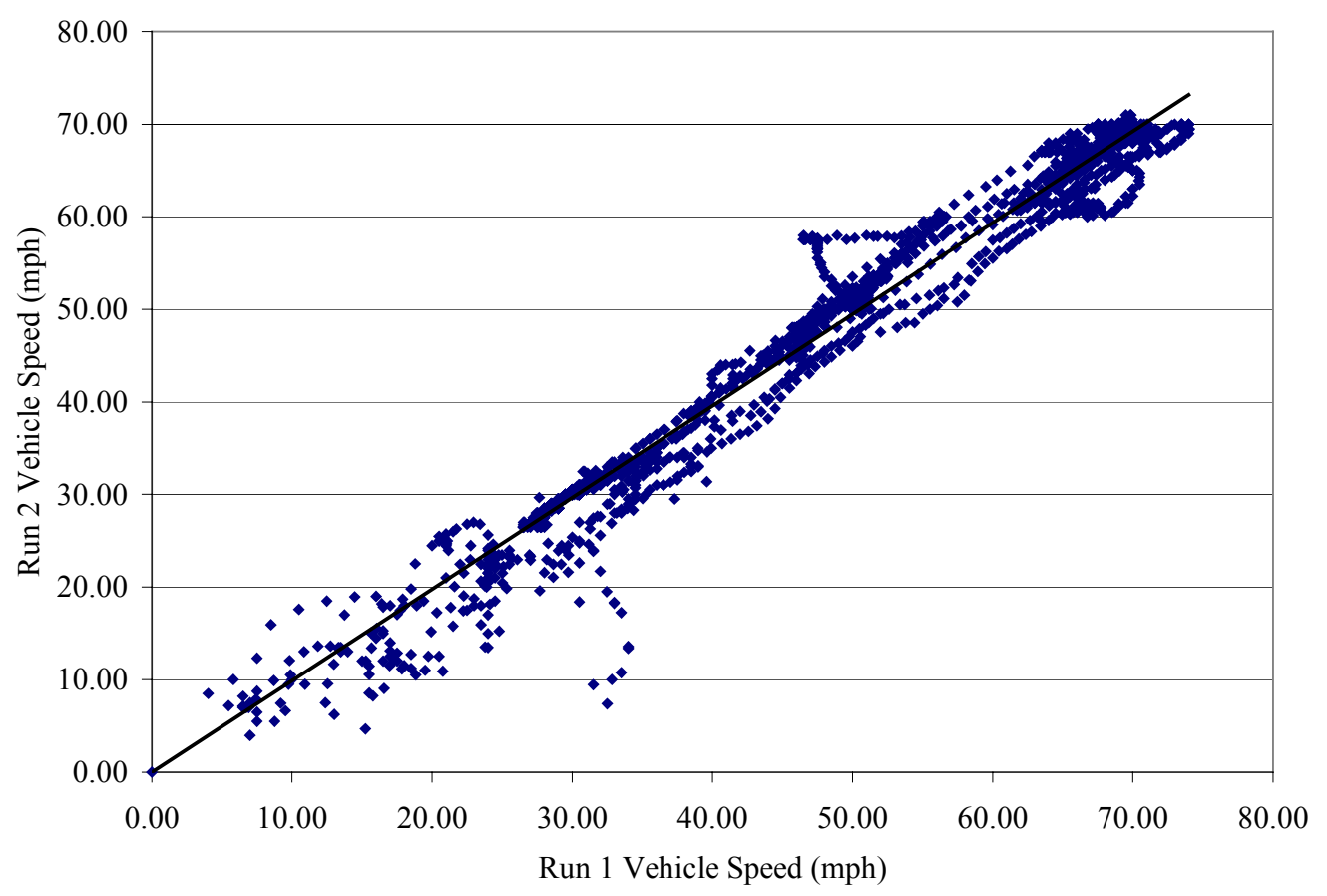

Figure 38: Vehicle speed as a function of distance for two repeat runs of MEMS \#8 on Sab2BM

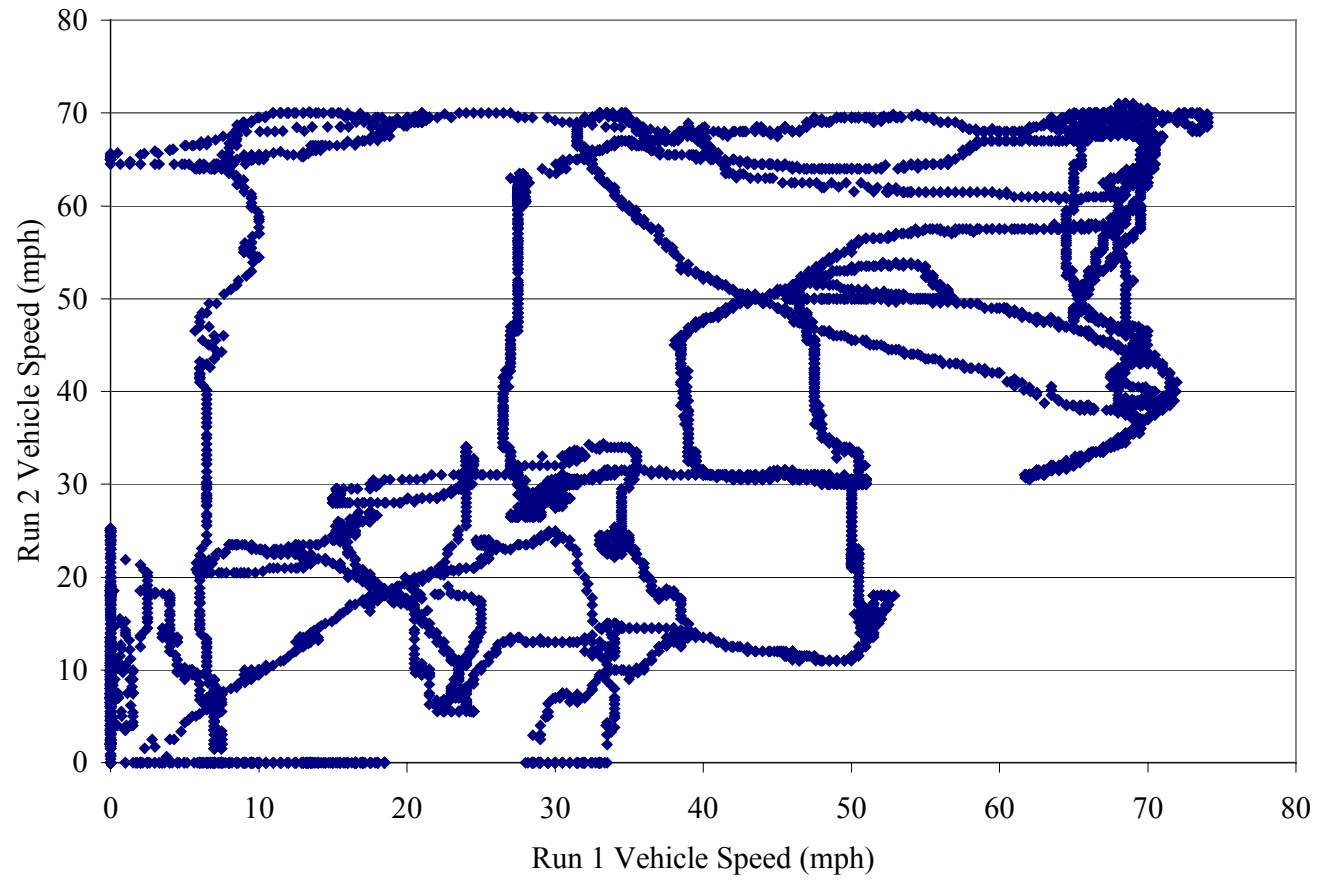

Figure 39: Vehicle speed as a function of time for two repeat of MEMS \#8 on Sab2BM

This same process was done for three or more runs using linear regression in a respective number of dimensions. This can be graphically depicted in the three dimensions, but becomes difficult to visualize with four or more. The process worked the 
same as the two dimensional version. Points were plotted in three (or more) dimensional space and the shortest distance from the point to the exact line, or error distance, was found. Error was calculated by finding the error distance and exact distance and using Equation 9. A graphical example of the error calculations can be seen in Figure 40, and a plot of data points in three-dimensional space can be found in Figure 41.

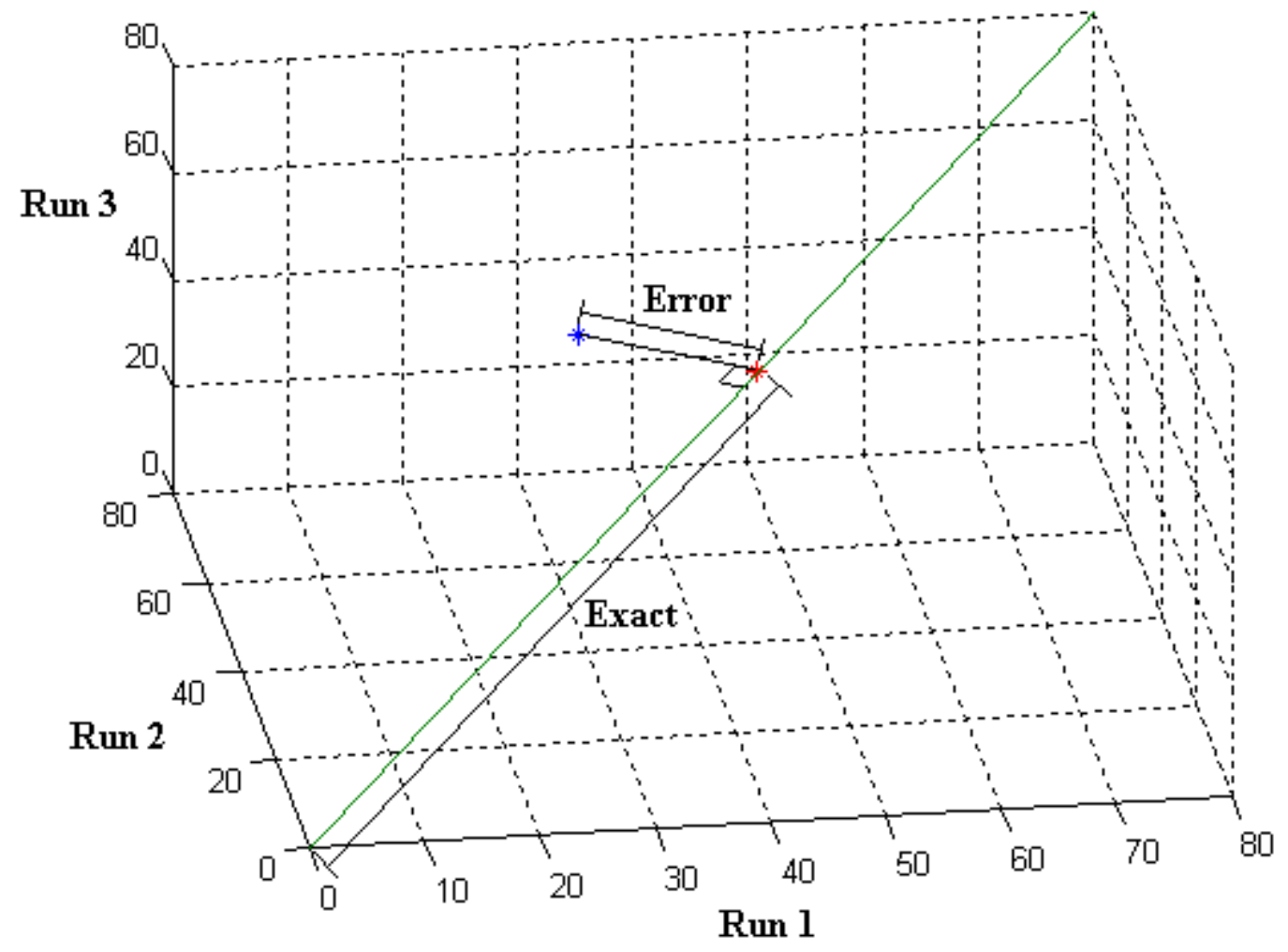

Vehicle Speed (mph) for all runs

Figure 40: Point plotted in three-dimensional space with error and ideal values 


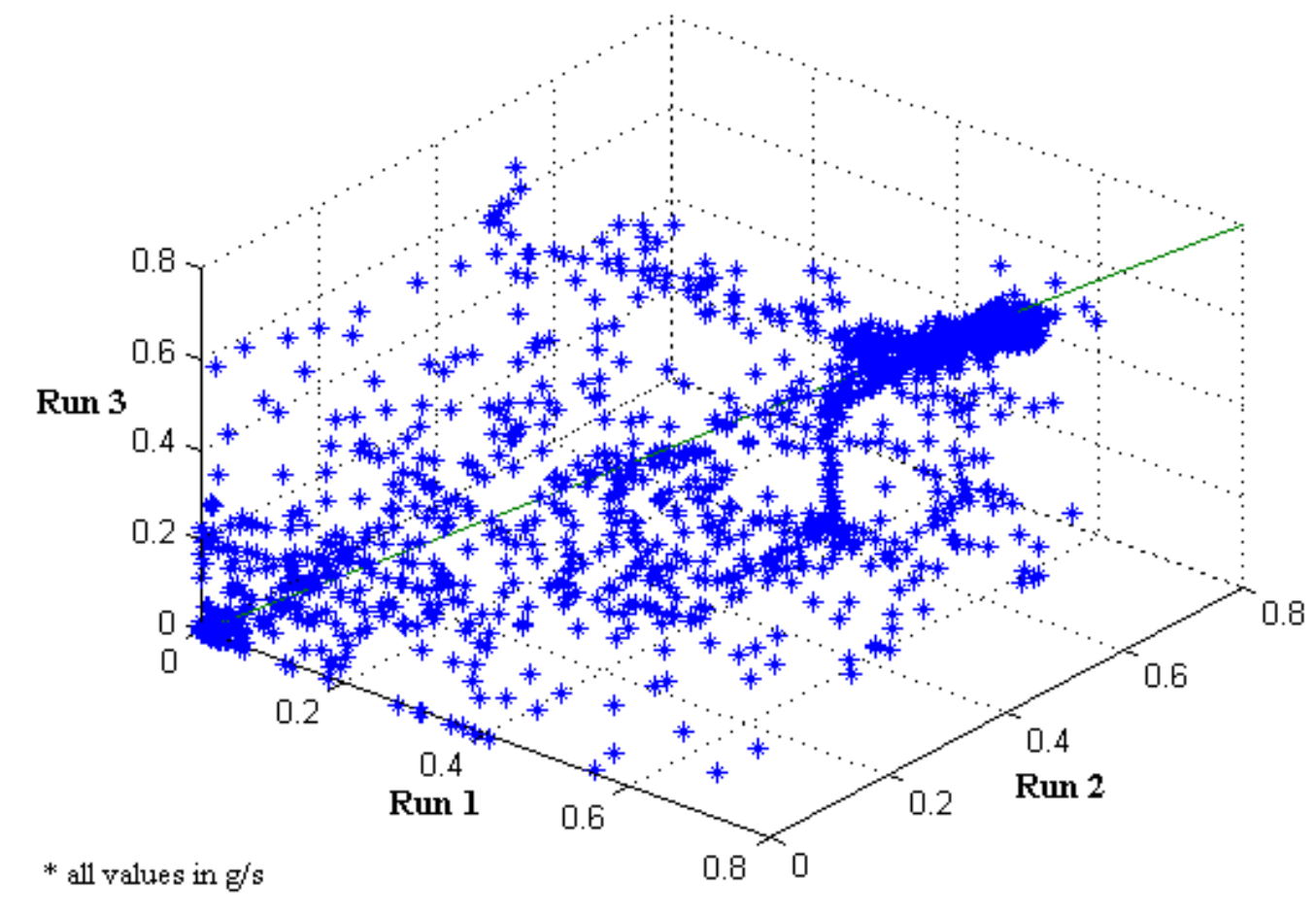

Figure 41: Three-dimensional plot of $\mathrm{NO}_{\mathrm{x}}$ data from three repeat runs of MEMS \#8 over the Sab2BM

This systems worked for more than three dimensions because magnitude of a higher (four or more) dimension vector can be calculated using similar methodology as two and three-dimensional vectors, despite human frailty of perception. To find the error distance and the exact distance, only magnitudes were necessary. The Excel Macro code for this can be found in Appendix C. This method has the same inherent problems as the $\mathrm{COV} \%$ comparison, in that the error values drastically increased during rapid changes at slightly different distance intervals, but it allowed for a conclusive value that was produced similarly to the common statistical coefficient of determination.

\subsection{Examples}

The multiple dimensional analysis was used to examine the differences between time and distance-based data. Time-based coefficients of repeatability values are shown in Table 7, and distance-based values are shown Table 8 (data for this route can be found 
in Figure 28 through Figure 35). It was apparent that distance-based comparison yielded much better results and appeared to be more representative of actual repeatability.

Table 7: Coefficients of repeatability for time-specific data of MEMS \#12 on Sab2BM

\begin{tabular}{|l|l|}
\hline Veh Speed & 0.868 \\
\hline Engine Speed & 0.972 \\
\hline Torque & 0.647 \\
\hline Power & 0.655 \\
\hline $\mathrm{CO}_{2}(\mathrm{~g} / \mathrm{sec})$ & 0.774 \\
\hline $\mathrm{NO}_{\mathrm{x}}(\mathrm{g} / \mathrm{sec})$ & 0.777 \\
\hline Distance & 0.978 \\
\hline
\end{tabular}

Table 8: Coefficients of repeatability for distance-specific data of MEMS \#12 on Sab2BM

\begin{tabular}{|l|l|}
\hline Vehicle Speed & 0.999 \\
\hline Engine Speed & 0.994 \\
\hline Torque & 0.933 \\
\hline Power & 0.936 \\
\hline $\mathrm{CO}_{2}(\mathrm{~g} / \mathrm{sec})$ & 0.968 \\
\hline $\mathrm{NO}_{\mathrm{x}}(\mathrm{g} / \mathrm{sec})$ & 0.960 \\
\hline Gear & 0.993 \\
\hline Time & 0.988 \\
\hline
\end{tabular}

Table 9: Total trip energy, $\mathrm{CO}_{2}$ emissions, and $\mathrm{NO}_{\mathrm{x}}$ emissions for MEMS \#12 on Sab2BM

\begin{tabular}{|c|c|c|}
\hline \multicolumn{2}{|l|}{ MEMS \#12 } & Sab2BM \\
\hline \multirow{2}{*}{$\begin{array}{c}\text { Total Energy } \\
\text { (bhp-hr) }\end{array}$} & Average & 137 \\
\cline { 2 - 3 } & COV\% & 2.1 \\
\hline \multirow{2}{*}{$\mathrm{CO}_{2}(\mathrm{~g} / \mathrm{mile})$} & Average & 3200 \\
\cline { 2 - 3 } & COV\% & 2.1 \\
\hline \multirow{2}{*}{$\mathrm{NO}_{\mathrm{x}}(\mathrm{g} / \mathrm{mile})$} & Average & 28.9 \\
\cline { 2 - 3 } & COV\% & 3.5 \\
\hline
\end{tabular}

$\mathrm{COV} \%$ for total trip power, $\mathrm{CO}_{2}$ emissions, and $\mathrm{NO}_{\mathrm{x}}$ emissions, as shown Table 9, were presented for comparison purposes and were not closely related to coefficients of repeatability. The integrated nature of total energy and average emissions did not account for instantaneous differences, unlike the coefficient of repeatability, which did account for instantaneous behavior. A detailed examination of the relationship of COV\% to the coefficient of repeatability can be found in Appendix G. Only very poor and inconsistent correlations could be found. 


\section{Repeatability of Current Testing Methods}

Chassis and engine dynamometer tests were examined for repeatability so that a better understanding for the methodology could be established. Engine dynamometer cycles, chassis dynamometer cycles, and chassis dynamometer routes were examined. Engine dynamometer data were examined separately for in-cell laboratory equipment and MEMS. These two systems collected data in series during engine testing.

\subsection{Engine Dynamometer Testing}

MEMS \#8 and MEMS \#12 had their engines removed from the vehicles and tested at WVU Engine Emissions Research Laboratory. The data collected from the laboratory over three consecutive tests were analyzed based on 3-dimensional linear regression. All results for engine testing were time-based. Both the FTP for MEMS \#8 (Table 10) and MEMS \#12 (Table 12) and the Sab2BM route for MEMS \#12 (Table 14) show high repeatability. The Sab2BM route was simulated as a cycle on the engine dynamometer using data previously collected from on-road testing. Information on cycle generation can be found elsewhere [14]. The respective total trip COV\% values can be found in Table 11, Table 13, and Table 15.

High coefficients of repeatability were to be expected because of the constrained conditions in which the tests were performed. Feedback controllers managed engine speed and torque, which therefore showed little variation from run to run. Torque had higher repeatability on the Sab2BM than on the FTP. This most likely resulted from the long periods of constant torque (either full load or zero load) for the Sab2BM route with less torque increase/decrease demands than the FTP. The high correlation suggested further examination of test cell data was not necessary.

Table 10: Coefficients of repeatability for MEMS \#8 dynamometer testing over the FTP

\begin{tabular}{|l|l|}
\hline Engine Speed & 1.000 \\
\hline Torque & 0.999 \\
\hline Power & 0.999 \\
\hline $\mathrm{CO}_{2}(\mathrm{~g} / \mathrm{sec})$ & 1.000 \\
\hline $\mathrm{NO}_{\mathrm{x}}(\mathrm{g} / \mathrm{sec})$ & 1.000 \\
\hline
\end{tabular}


Table 11: Total energy and brake-specific emissions values for MEMS \#8 engine over the FTP

\begin{tabular}{|l|c|c|c|}
\cline { 2 - 4 } \multicolumn{1}{c|}{} & $\mathrm{NO}_{\mathrm{x}}(\mathrm{g} / \mathrm{bhp}-\mathrm{hr})$ & $\mathrm{CO}_{2}(\mathrm{~g} / \mathrm{bhp}-\mathrm{hr})$ & $\mathrm{bhp}-\mathrm{hr}$ \\
\hline Average & 3.66 & 546 & 26.9 \\
\hline Std. Dev. & 0.0169 & 1.57 & 0.0200 \\
\hline COV\% & 0.461 & 0.288 & 0.0744 \\
\hline
\end{tabular}

Table 12: Coefficients of repeatability for MEMS \#12 over the FTP

\begin{tabular}{|l|l|}
\hline Engine Speed & 1.000 \\
\hline Torque & 0.997 \\
\hline Power & 0.999 \\
\hline $\mathrm{CO}_{2}(\mathrm{~g} / \mathrm{sec})$ & 1.000 \\
\hline $\mathrm{NO}_{x}(\mathrm{~g} / \mathrm{sec})$ & 1.000 \\
\hline
\end{tabular}

Table 13: Total energy and brake-specific emissions values for MEMS \#12 engine over the FTP

\begin{tabular}{|l|c|c|c|}
\cline { 2 - 4 } \multicolumn{1}{c|}{} & $\mathrm{NO}_{\mathrm{x}}(\mathrm{g} / \mathrm{bhp}-\mathrm{hr})$ & $\mathrm{CO}_{2}(\mathrm{~g} / \mathrm{bhp}-\mathrm{hr})$ & $\mathrm{bhp}-\mathrm{hr}$ \\
\hline Average & 3.67 & 555 & 30.4 \\
\hline Std. Dev. & 0.00404 & 0.990 & 0.0265 \\
\hline COV\% & 0.110 & 0.179 & 0.0870 \\
\hline
\end{tabular}

Table 14: Coefficients of repeatability for the dynamometer controlled Sab2BM route for MEMS $\# 12$

\begin{tabular}{|l|l|}
\hline Engine Speed & 1.000 \\
\hline Torque & 1.000 \\
\hline Power & 1.000 \\
\hline $\mathrm{CO}_{2}(\mathrm{~g} / \mathrm{sec})$ & 1.000 \\
\hline $\mathrm{NO}_{\mathrm{x}}(\mathrm{g} / \mathrm{sec})$ & 1.000 \\
\hline
\end{tabular}

Table 15: Total energy and brake-specific emissions values for MEMS \#12 engine over a simulated Sab2BM

\begin{tabular}{|l|c|c|c|}
\cline { 2 - 4 } \multicolumn{1}{c|}{} & $\mathrm{NO}_{\mathrm{x}}(\mathrm{g} / \mathrm{bhp}-\mathrm{hr})$ & $\mathrm{CO}_{2}(\mathrm{~g} / \mathrm{bhp}-\mathrm{hr})$ & $\mathrm{bhp}-\mathrm{hr}$ \\
\hline Average & 4.99 & 480 & 126.8 \\
\hline Std. Dev. & 0.0223 & 0.121 & 0.0611 \\
\hline COV\% & 0.447 & 0.025 & 0.0482 \\
\hline
\end{tabular}

While test cell data were very consistent, it was likely, yet not certain, that MEMS data would be similarly consistent. The MEMS data were examined for the same runs as the previously discussed test cell data. These data were taken when the engine was run in the test cell, with MEMS in parallel with the test cell laboratory. These data had to be 
time aligned to make a proper comparison because MEMS DAS was started and stopped manually, causing time variations between runs. For the FTP, repeatability was examined for the data between engine start and 1200 seconds after engine start. For the Sab2BM cycle, engine speed was graphically time aligned. Repeatability was high for both FTP runs and the Sab2BM run as seen in Table 16, Table 18, and Table 20. Corresponding total cycle COV\% values are shown in Table 17, Table 19, and Table 21. Both total cycle and instantaneous repeatability values were lower for MEMS data than test cell data.

Table 16: Coefficients of repeatability for MEMS \#8 using MEMS data over the FTP

\begin{tabular}{|l|l|}
\hline Engine Speed & 1.000 \\
\hline Torque & 0.999 \\
\hline Power & 0.999 \\
\hline $\mathrm{CO}_{2}(\mathrm{~g} / \mathrm{sec})$ & 0.995 \\
\hline $\mathrm{NO}_{\mathrm{x}}(\mathrm{g} / \mathrm{sec})$ & 0.982 \\
\hline
\end{tabular}

Table 17: Total energy and brake-specific emissions values for MEMS \#8 engine using MEMS data over the FTP

\begin{tabular}{|l|c|c|c|}
\cline { 2 - 4 } \multicolumn{1}{c|}{} & $\mathrm{NO}_{\mathrm{x}}(\mathrm{g} / \mathrm{bhp}-\mathrm{hr})$ & $\mathrm{CO}_{2}(\mathrm{~g} / \mathrm{bhp}-\mathrm{hr})$ & $\mathrm{bhp}-\mathrm{hr}$ \\
\hline Average & 3.60 & 604 & 27.5 \\
\hline Std. Dev. & 0.0766 & 1.86 & 0.0394 \\
\hline COV\% & 2.13 & 0.308 & 0.143 \\
\hline
\end{tabular}

Table 18: Coefficients of repeatability for MEMS \#12 over the FTP using MEMS data

\begin{tabular}{|l|l|}
\hline Engine Speed & 1.000 \\
\hline Torque & 0.999 \\
\hline Power & 0.999 \\
\hline $\mathrm{CO}_{2}(\mathrm{~g} / \mathrm{sec})$ & 0.997 \\
\hline $\mathrm{NO}_{\mathrm{x}}(\mathrm{g} / \mathrm{sec})$ & 0.993 \\
\hline
\end{tabular}

Table 19: Total energy and brake-specific emissions values for the MEMS \#12 engine over the FTP using MEMS data

\begin{tabular}{|l|c|c|c|}
\cline { 2 - 4 } \multicolumn{1}{c|}{} & $\mathrm{NO}_{\mathrm{x}}(\mathrm{g} / \mathrm{bhp}-\mathrm{hr})$ & $\mathrm{CO}_{2}(\mathrm{~g} / \mathrm{bhp}-\mathrm{hr})$ & $\mathrm{bhp}-\mathrm{hr}$ \\
\hline Average & 3.43 & 592 & 29.8 \\
\hline Std. Dev. & 0.1658 & 11.52 & 0.0384 \\
\hline COV\% & 4.83 & 1.947 & 0.129 \\
\hline
\end{tabular}


Table 20: Coefficients of repeatability for the MEMS \#12 engine over an in-cell simulated Sab2BM route using MEMS data

\begin{tabular}{|l|l|}
\hline Engine Speed & 1.000 \\
\hline Torque & 1.000 \\
\hline Power & 1.000 \\
\hline $\mathrm{CO}_{2}(\mathrm{~g} / \mathrm{sec})$ & 0.998 \\
\hline $\mathrm{NO}_{\mathrm{x}}(\mathrm{g} / \mathrm{sec})$ & 0.999 \\
\hline
\end{tabular}

Table 21: Total energy and brake-specific emissions values for the MEMS \#12 engine over an in-cell simulated Sab2BM route using MEMS data

\begin{tabular}{|l|c|c|c|}
\cline { 2 - 4 } \multicolumn{1}{c|}{} & $\mathrm{NO}_{\mathrm{x}}(\mathrm{g} / \mathrm{bhp}-\mathrm{hr})$ & $\mathrm{CO}_{2}(\mathrm{~g} / \mathrm{bhp}-\mathrm{hr})$ & $\mathrm{bhp}-\mathrm{hr}$ \\
\hline Average & 4.60 & 503 & 127 \\
\hline Std. Dev. & 0.0647 & 3.41 & 0.0803 \\
\hline COV\% & 1.41 & 0.679 & 0.063 \\
\hline
\end{tabular}

\subsection{Chassis Dynamometer Testing}

Heavy-duty chassis dynamometer emissions data were examined for repeatability over routes and cycles. The data were collected using West Virginia University's TransLab.

For the UDDS cycle, the test vehicle was a Ford tractor truck powered by a 1996 Cummins M11 280E and a 10-speed manual transmission. Repeatability was very high for hub speed and fairly high for gaseous emissions, but low for hub torque and power, as seen in Table 22. The driver, who used a graphical display to monitor speed, maintained speed very accurately. The driver had to adjust torque continually to maintain the proper speed. This action allowed for high correlation of speed, but low torque and power correlation. Even though $\mathrm{CO}_{2}$ is closely proportional to power, $\mathrm{CO}_{2}$ had much better repeatability. This resulted from the "smoothing" of $\mathrm{CO}_{2}$ as it linearly dispersed in the sample line, even though power had large instantaneous fluctuations. This can be seen in Figure 42, which shows substantial smoothing of $\mathrm{CO}_{2}$ compared to power during the Sterling tractor test. 
Table 22: Coefficients of repeatability for the Ford tractor over the UDDS

\begin{tabular}{|l|l|}
\hline Hub Speed & 1.000 \\
\hline Hub Torque & 0.716 \\
\hline Hub Power & 0.760 \\
\hline $\mathrm{CO}_{2}$ & 0.986 \\
\hline $\mathrm{NO}_{x}$ & 0.960 \\
\hline
\end{tabular}

Table 23: Total energy and brake-specific emissions values for the Ford tractor over the UDDS

\begin{tabular}{|l|c|c|c|}
\cline { 2 - 4 } \multicolumn{1}{c|}{} & $\mathrm{NO}_{\mathrm{x}}(\mathrm{g} / \mathrm{mile})$ & $\mathrm{CO}_{2}(\mathrm{~g} / \mathrm{mile})$ & $\mathrm{BTU} / \mathrm{mile}$ \\
\hline Average & 12.0 & 1600 & 20700 \\
\hline Std. Dev. & 0.300 & 36.0 & 464 \\
\hline COV\% & 2.30 & 2.20 & 2.20 \\
\hline
\end{tabular}

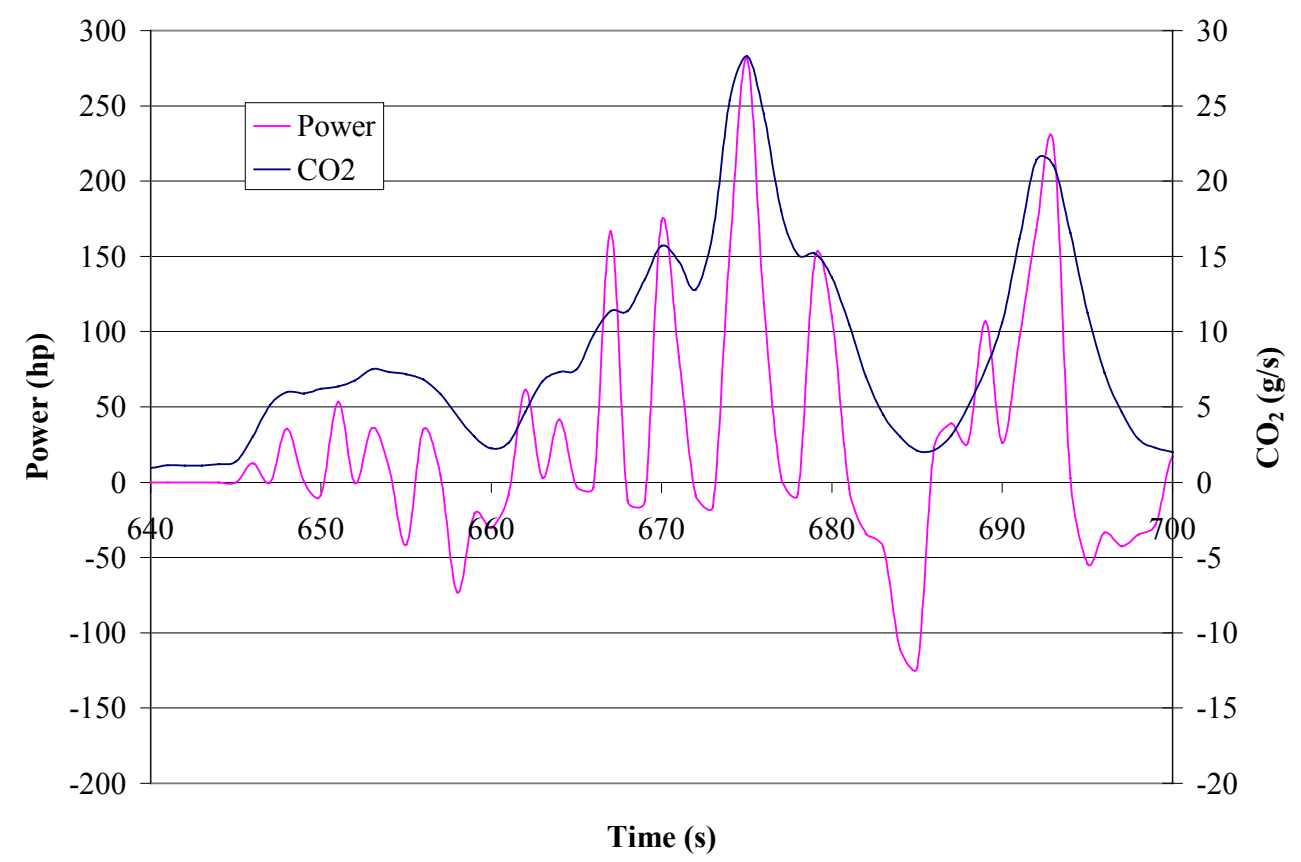

Figure 42: Detail of $\mathrm{CO}_{2}$ and power for the Sterling tractor test

Data were also examined over the CSHVR route. The test vehicle was a Sterling tractor with a 1998 Series 60 DDC engine and 10-speed transmission. A distancespecific examination was done for repeatability. Repeatability was found to be high for hub speed and $\mathrm{CO}_{2}$ emission. Torque, power, and $\mathrm{NO}_{\mathrm{x}}$ emissions have substantially lower repeatability as seen in Table 24. $\mathrm{NO}_{\mathrm{x}}$ probably had significantly lower repeatability than $\mathrm{CO}_{2}$, most likely because of off-cycle operation. 
Table 24: Coefficients of repeatability values for the Sterling tractor over the CSHVR

\begin{tabular}{|l|l|}
\hline Hub Speed & 0.998 \\
\hline Hub Torque & 0.723 \\
\hline Hub Power & 0.713 \\
\hline $\mathrm{CO}_{2}$ & 0.972 \\
\hline $\mathrm{NO}_{x}$ & 0.845 \\
\hline Time & 1.000 \\
\hline
\end{tabular}

Table 25: Total energy and brake-specific emissions values for the Sterling tractor over the CSHVR

\begin{tabular}{|l|c|c|c|}
\cline { 2 - 4 } \multicolumn{1}{c|}{} & $\mathrm{NO}_{\mathrm{x}}(\mathrm{g} / \mathrm{mile})$ & $\mathrm{CO}_{2}(\mathrm{~g} / \mathrm{mile})$ & $\mathrm{BTU} / \mathrm{mile}$ \\
\hline Average & 29.1 & 1960 & 25900 \\
\hline Std. Dev. & 0.600 & 62.0 & 822 \\
\hline COV\% & 2.20 & 3.20 & 3.20 \\
\hline
\end{tabular}

Speed was generally repeatable on chassis dynamometer tests for both cycles and routes as seen for the CSHVR in Figure 43. The driver could maintain the vehicle speed fairly accurately but had to dither the pedal to do so, as seen by power fluctuations in Figure 44. This transience caused the torque and power repeatability to drop substantially. Even though $\mathrm{CO}_{2}$ is closely proportional to power, the smoothing effect of the gas dispersion allowed $\mathrm{CO}_{2}$ to have higher repeatability.

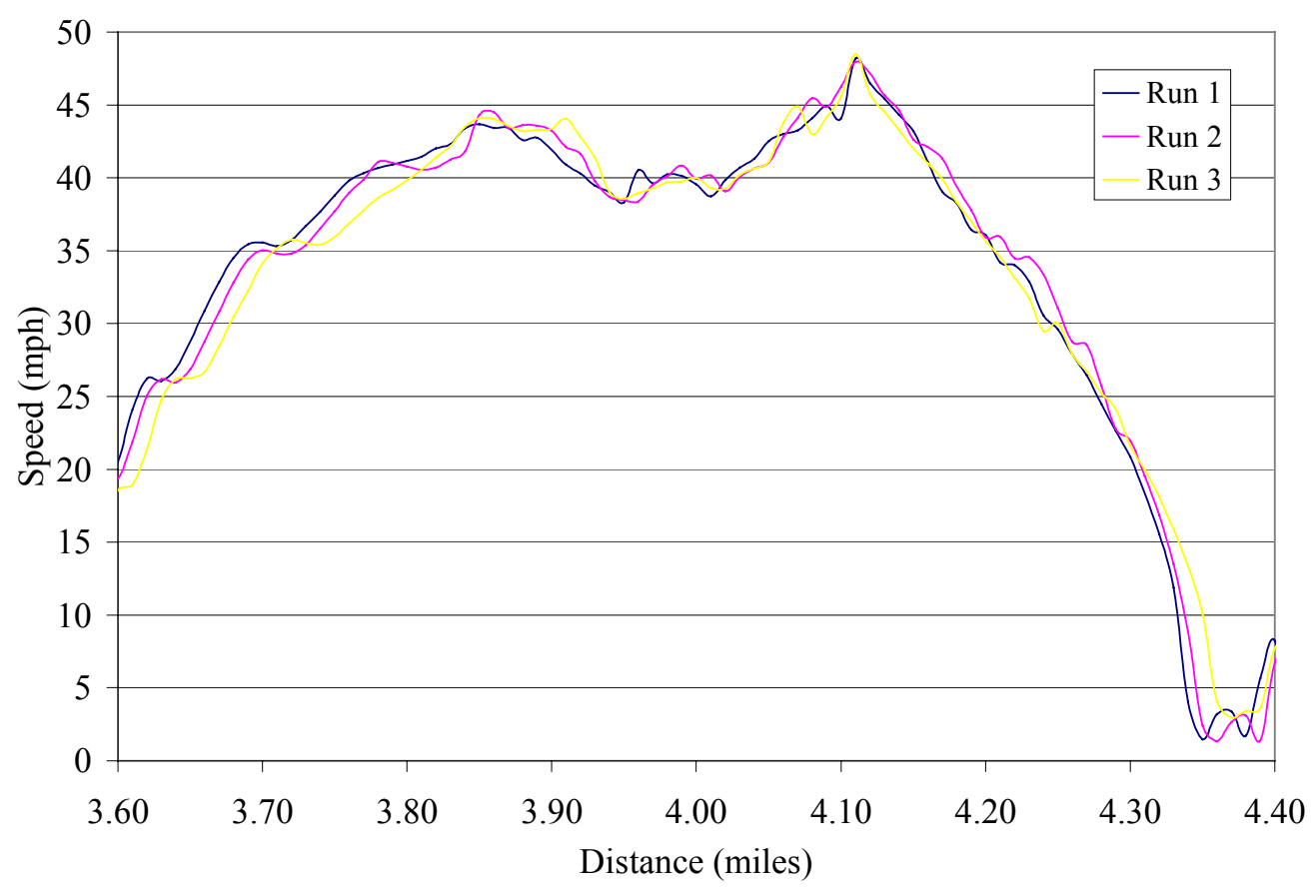

Figure 43: Detail of vehicle speed for the Sterling tractor over the CSHVR 


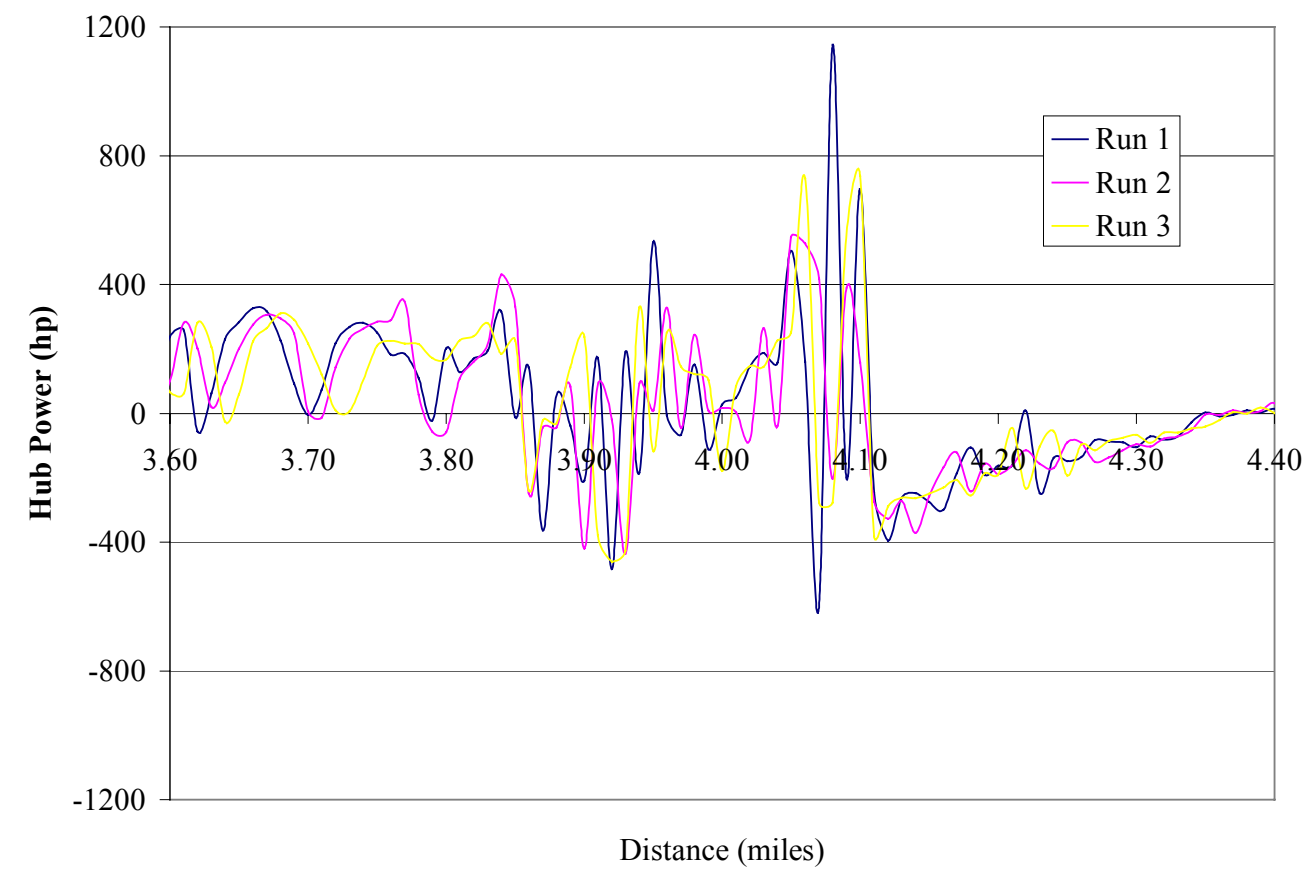

Figure 44: Detail of hub power for the Sterling tractor over the CSHVR

Chassis and engine dynamometer testing produced substantially different levels of repeatability. Chassis testing used human speed and torque control, which directly reduced torque repeatability and indirectly influenced emissions repeatability. This suggested that on-road testing, with human control and substantially more variables, could have low repeatability. On-road driving may require less pedal dithering by the driver, allowing for higher repeatability. 


\section{Repeatability of Vehicular Behavior and Emissions}

\subsection{Presentation of Data}

Data from four vehicles were compared on all routes that had at least two complete, reportable runs. Detailed discussion of influencing factors can be found below. Most vehicles exhibited similar behavior for a given parameter (this will be discussed in Section 8.2.4). Vehicle speed generally had high repeatability, with engine speed being slightly less repeatable. Torque and power exhibited low repeatability, resulting from the rapid fluctuations between their respective extreme limits. $\mathrm{CO}_{2}$ and $\mathrm{NO}_{\mathrm{x}}$, while fairly closely correlated to power, exhibited better repeatability than power because of the linear gas dispersion created a smoothing. $\mathrm{NO}_{\mathrm{x}}$, on average, had slightly lower repeatability than $\mathrm{CO}_{2}$ likely due to off-cycle operation. Time was fairly repeatable, which was to be expected since vehicle speed was repeatable. The only factor that would have prevented a 1:1 correlation of time and speed could have been length of stops. NTE Zone activity had a fairly wide range of repeatability. Average trip values for $\mathrm{CO}_{2}, \mathrm{NO}_{\mathrm{x}}$, and total trip energy were presented as well. Values presented in bold are equal to or less than 0.880 . These are the lowest $20 \%$ of calculated values and used to identify the parameters of lower repeatability.

\subsubsection{MEMS \#8}

Table 26: Coefficients of repeatability for MEMS \#8

\begin{tabular}{|l|c|c|c|c|c|c|c|c|}
\cline { 2 - 9 } \multicolumn{1}{c|}{} & Sab2BM & BM2Sab & Sab2SW & SW2Sab & PA1 & PA2 & PA3 & Average \\
\hline Vehicle Speed & 0.999 & 0.997 & 0.996 & 0.990 & 0.988 & 0.996 & 0.998 & 0.995 \\
\hline Engine Speed & 0.996 & 0.989 & 0.987 & 0.983 & 0.985 & 0.992 & 0.995 & 0.990 \\
\hline Torque & 0.930 & $\mathbf{0 . 5 9 4}$ & $\mathbf{0 . 8 4 2}$ & $\mathbf{0 . 7 9 8}$ & $\mathbf{0 . 7 8 6}$ & 0.890 & 0.934 & $\mathbf{0 . 8 2 5}$ \\
\hline Power & $\mathbf{0 . 9 2 9}$ & $\mathbf{0 . 4 4 7}$ & $\mathbf{0 . 8 1 5}$ & $\mathbf{0 . 7 3 5}$ & $\mathbf{0 . 7 8 8}$ & 0.893 & 0.934 & $\mathbf{0 . 7 9 2}$ \\
\hline $\mathrm{CO}_{2}(\mathrm{~g} / \mathrm{sec})$ & 0.963 & 0.946 & 0.931 & 0.909 & 0.882 & 0.934 & 0.961 & 0.932 \\
\hline $\mathrm{NO}_{\mathrm{x}}(\mathrm{g} / \mathrm{sec})$ & 0.957 & 0.951 & 0.922 & 0.895 & 0.872 & 0.937 & 0.954 & 0.927 \\
\hline Gear & 0.998 & 0.980 & 0.982 & 0.977 & 0.976 & 0.993 & 0.994 & 0.986 \\
\hline Time & 0.998 & 0.998 & 0.989 & 0.997 & 0.993 & 1.000 & 1.000 & 0.996 \\
\hline NTE Zone & 0.938 & 0.910 & 0.896 & $\mathbf{0 . 8 6 2}$ & $\mathbf{0 . 8 1 1}$ & $\mathbf{0 . 8 8 4}$ & 0.922 & 0.889 \\
\hline
\end{tabular}


Table 27: Average and COV\% values for total trip data for MEMS \#8

\begin{tabular}{|l|c|c|c|c|c|c|c|c|}
\hline \multicolumn{2}{|l|}{ MEMS \#8 } & Sab2BM & BM2Sab & Sab2SW & SW2Sab & PA1 & PA2 & PA3 \\
\hline \multirow{2}{*}{$\begin{array}{c}\text { Total Energy } \\
\text { (bhp-hr) }\end{array}$} & Average & 132 & 96.4 & 146 & 126 & 65.9 & 123 & 211 \\
\cline { 2 - 9 } & COV\% & 1.93 & 4.02 & 4.72 & 1.36 & 4.66 & 1.29 & 0.08 \\
\hline \multirow{2}{*}{$\mathrm{CO}_{2}(\mathrm{~g} / \mathrm{mile})$} & Average & 2750 & 1970 & 2100 & 1800 & 2420 & 2390 & 1770 \\
\cline { 2 - 9 } & COV\% & 0.962 & 3.69 & 4.96 & 3.44 & 5.73 & 1.89 & 1.64 \\
\hline \multirow{2}{*}{$\mathrm{NO}_{\mathrm{x}}(\mathrm{g} / \mathrm{mile})$} & Average & 36.4 & 26.1 & 29.0 & 24.4 & 28.3 & 27.3 & 26.1 \\
\cline { 2 - 9 } & COV\% & 15.2 & 3.42 & 9.12 & 5.26 & 7.23 & 1.83 & 6.91 \\
\hline
\end{tabular}

\subsubsection{MEMS \#10}

Table 28: Coefficients of repeatability for MEMS \#10

\begin{tabular}{|l|c|c|c|c|}
\cline { 2 - 5 } \multicolumn{1}{c|}{} & Motown & PA2 & PA3 & Average \\
\hline Vehicle Speed & 0.993 & 0.978 & 0.997 & 0.988 \\
\hline Engine Speed & 0.993 & 0.985 & 0.997 & 0.991 \\
\hline Torque & $\mathbf{0 . 8 5 6}$ & $\mathbf{0 . 7 7 6}$ & 0.894 & $\mathbf{0 . 8 3 5}$ \\
\hline Power & $\mathbf{0 . 8 5 3}$ & $\mathbf{0 . 7 7 3}$ & 0.883 & $\mathbf{0 . 8 2 8}$ \\
\hline $\mathrm{CO}_{2}(\mathrm{~g} / \mathrm{sec})$ & 0.925 & $\mathbf{0 . 8 6 7}$ & 0.947 & 0.907 \\
\hline $\mathrm{NO}_{\mathrm{x}}(\mathrm{g} / \mathrm{sec})$ & 0.918 & $\mathbf{0 . 8 3 3}$ & 0.940 & 0.886 \\
\hline Gear & 0.991 & 0.985 & 0.999 & 0.992 \\
\hline Time & 0.999 & 0.980 & 1.000 & 0.990 \\
\hline NTE Zone & $\mathbf{0 . 8 4 4}$ & $\mathbf{0 . 8 0 2}$ & $\mathbf{0 . 8 5 5}$ & $\mathbf{0 . 8 2 9}$ \\
\hline
\end{tabular}

Table 29: Average and COV\% values for total trip data for MEMS \#10

\begin{tabular}{|l|c|c|c|c|}
\hline \multicolumn{2}{|l|}{ MEMS \#10 } & PA2 & PA3 & Motown \\
\hline \multirow{2}{*}{$\begin{array}{c}\text { Total Energy } \\
\text { (bhp-hr) }\end{array}$} & Average & 53.5 & 103 & 48.7 \\
\cline { 2 - 5 } & COV\% & 0.306 & 4.76 & 18.0 \\
\hline \multirow{2}{*}{$\mathrm{CO}_{2}(\mathrm{~g} / \mathrm{mile})$} & Average & 1280 & 1080 & 1270 \\
\cline { 2 - 5 } & COV\% & 2.57 & 2.94 & 9.78 \\
\hline \multirow{2}{*}{$\mathrm{NO}_{\mathrm{x}}(\mathrm{g} / \mathrm{mile})$} & Average & 11.2 & 8.2 & 10.0 \\
\cline { 2 - 5 } & COV\% & 5.34 & 4.85 & 16.2 \\
\hline
\end{tabular}




\subsubsection{MEMS \#11}

Table 30: Coefficients of repeatability for MEMS \#11

\begin{tabular}{|l|c|c|c|c|c|}
\cline { 2 - 6 } \multicolumn{1}{c|}{} & Motown & PA1 & PA2 & PA3 & Average \\
\hline Vehicle Speed & 0.997 & 0.985 & 0.993 & 0.998 & 0.992 \\
\hline Engine Speed & 0.995 & 0.988 & 0.990 & 0.997 & 0.992 \\
\hline Torque & 0.889 & $\mathbf{0 . 8 2 8}$ & $\mathbf{0 . 8 4 6}$ & 0.930 & $\mathbf{0 . 8 6 8}$ \\
\hline Power & 0.897 & 0.841 & $\mathbf{0 . 8 6 2}$ & 0.926 & $\mathbf{0 . 8 7 6}$ \\
\hline $\mathrm{CO}_{2}(\mathrm{~g} / \mathrm{sec})$ & 0.943 & 0.898 & 0.908 & 0.960 & 0.922 \\
\hline $\mathrm{NO}_{\mathrm{x}}(\mathrm{g} / \mathrm{sec})$ & 0.952 & 0.910 & 0.909 & 0.948 & 0.922 \\
\hline Gear & 0.993 & 0.984 & 0.990 & 0.999 & 0.991 \\
\hline Time & 0.997 & 0.995 & 0.999 & 0.999 & 0.998 \\
\hline NTE Zone & $\mathbf{0 . 8 7 3}$ & $\mathbf{0 . 8 2 8}$ & $\mathbf{0 . 8 4 1}$ & 0.892 & $\mathbf{0 . 8 5 4}$ \\
\hline
\end{tabular}

Table 31: Average and COV\% values for total trip data for MEMS \#11

\begin{tabular}{|c|c|c|c|c|c|}
\hline \multicolumn{2}{|l|}{ MEMS \#11 } & PA1 & PA2 & PA3 & Motown \\
\hline \multirow{2}{*}{$\begin{array}{c}\text { Total Energy } \\
\text { (bhp-hr) }\end{array}$} & Average & 27.6 & 52.2 & 99.6 & 51.7 \\
\cline { 2 - 6 } & COV\% & 2.98 & 3.22 & 2.86 & 4.13 \\
\hline \multirow{2}{*}{$\mathrm{CO}_{2}(\mathrm{~g} /$ mile) $)$} & Average & 1320 & 1410 & 1220 & 1530 \\
\cline { 2 - 6 } & COV\% & 1.81 & 6.76 & 2.39 & 8.71 \\
\hline \multirow{2}{*}{$\mathrm{NO}_{x}(\mathrm{~g} /$ mile) $)$} & Average & 13.1 & 12.3 & 9.69 & 11.9 \\
\cline { 2 - 6 } & COV\% & 4.74 & 4.97 & 5.22 & 5.28 \\
\hline
\end{tabular}

\subsubsection{MEMS \#12}

Table 32: Coefficients of repeatability for MEMS \#12

\begin{tabular}{|l|c|c|c|c|c|c|c|c|}
\cline { 2 - 9 } \multicolumn{1}{c|}{} & Sab2BM & BM2Sab & Sab2SW & SW2Sab & PA1 & PA2 & PA3 & Average \\
\hline Vehicle Speed & 0.999 & 0.988 & 0.997 & 0.998 & 0.987 & 0.984 & 0.996 & 0.993 \\
\hline Engine Speed & 0.994 & 0.992 & 0.989 & 0.993 & 0.988 & 0.987 & 0.992 & 0.991 \\
\hline Torque & 0.933 & 0.901 & 0.895 & 0.886 & $\mathbf{0 . 7 2 1}$ & $\mathbf{0 . 7 8 4}$ & $\mathbf{0 . 8 4 7}$ & $\mathbf{0 . 8 5 2}$ \\
\hline Power & 0.936 & 0.900 & 0.888 & 0.885 & $\mathbf{0 . 7 4 0}$ & $\mathbf{0 . 7 9 9}$ & $\mathbf{0 . 8 5 2}$ & $\mathbf{0 . 8 5 7}$ \\
\hline $\mathrm{CO}_{2}(\mathrm{~g} / \mathrm{sec})$ & 0.968 & 0.945 & 0.935 & 0.936 & 0.859 & 0.884 & 0.909 & 0.919 \\
\hline $\mathrm{NO}_{\mathrm{x}}(\mathrm{g} / \mathrm{sec})$ & 0.960 & 0.916 & 0.925 & 0.919 & $\mathbf{0 . 8 5 6}$ & $\mathbf{0 . 8 6 9}$ & 0.907 & 0.908 \\
\hline Gear & 0.993 & 0.984 & 0.994 & 0.993 & 0.976 & 0.981 & 0.990 & 0.987 \\
\hline Time & 0.988 & 0.997 & 0.986 & 1.000 & 0.996 & 0.986 & 0.996 & 0.993 \\
\hline NTE Zone & 0.938 & 0.898 & 0.897 & 0.893 & $\mathbf{0 . 7 2 4}$ & $\mathbf{0 . 7 7 9}$ & $\mathbf{0 . 8 3 3}$ & $\mathbf{0 . 8 5 2}$ \\
\hline
\end{tabular}


Table 33: Average and COV\% values for total trip data for MEMS \#12

\begin{tabular}{|l|c|c|c|c|c|c|c|c|}
\hline \multicolumn{2}{|l|}{ MEMS \#12 } & Sab2BM & BM2Sab & Sab2SW & SW2Sab & PA1 & PA2 & PA3 \\
\hline \multirow{2}{*}{$\begin{array}{c}\text { Total Energy } \\
\text { (bhp-hr) }\end{array}$} & Average & 137 & 99.1 & 150 & 132 & 61 & 113 & 206 \\
\cline { 2 - 9 } & COV\% & 2.06 & 2.86 & 3.33 & 2.25 & 3.23 & 1.68 & 1.85 \\
\hline \multirow{2}{*}{$\mathrm{CO}_{2}(\mathrm{~g} /$ mile) $)$} & Average & 3200 & 2450 & 2460 & 2160 & 2670 & 2530 & 1850 \\
\cline { 2 - 9 } & COV\% & 2.13 & 2.25 & 1.38 & 1.09 & 5.89 & 3.56 & 4.53 \\
\hline \multirow{2}{*}{$\mathrm{NO}_{x}$ (g/mile) $)$} & Average & 28.9 & 20.1 & 23.3 & 19.4 & 18.9 & 22.0 & 20.0 \\
\cline { 2 - 9 } & COV\% & 3.47 & 4.03 & 1.36 & 6.85 & 11.4 & 5.68 & 4.63 \\
\hline
\end{tabular}

\subsection{Examination of Influencing Factors}

\subsubsection{Vehicle}

Test vehicles examined in this thesis varied significantly. MEMS \# 10 and \#11 were automatic transmission school busses. MEMS \#8 and \#12 were tractor trucks with different numbers of gears and different power ratings. Individual vehicle repeatability results can be seen in Table 34. Vehicles that were more similar were presented side-byside for easier comparison.

Table 34: Vehicle and repeatability

\begin{tabular}{|l|c|c|c|c||c|}
\cline { 2 - 6 } \multicolumn{1}{c|}{} & MEMS\#8 & MEMS\#12 & MEMS\#10 & MEMS\#11 & Average \\
\hline Vehicle Speed & 0.995 & 0.993 & 0.990 & 0.993 & 0.993 \\
\hline Engine Speed & 0.990 & 0.991 & 0.992 & 0.992 & 0.991 \\
\hline Torque & $\mathbf{0 . 8 2 5}$ & $\mathbf{0 . 8 5 2}$ & $\mathbf{0 . 8 4 2}$ & $\mathbf{0 . 8 7 3}$ & $\mathbf{0 . 8 4 8}$ \\
\hline Power & $\mathbf{0 . 7 9 2}$ & $\mathbf{0 . 8 5 7}$ & $\mathbf{0 . 8 3 6}$ & 0.881 & $\mathbf{0 . 8 4 2}$ \\
\hline $\mathrm{CO}_{2}(\mathrm{~g} / \mathrm{sec})$ & 0.932 & 0.919 & 0.913 & 0.927 & 0.923 \\
\hline $\mathrm{NO}_{\mathrm{x}}(\mathrm{g} / \mathrm{sec})$ & 0.927 & 0.908 & 0.897 & 0.930 & 0.915 \\
\hline Gear & 0.986 & 0.987 & 0.992 & 0.992 & 0.989 \\
\hline Time & 0.996 & 0.993 & 0.993 & 0.998 & 0.995 \\
\hline NTE Zone & 0.889 & $\mathbf{0 . 8 5 2}$ & $\mathbf{0 . 8 3 4}$ & $\mathbf{0 . 8 5 9}$ & $\mathbf{0 . 8 5 8}$ \\
\hline \hline Average & 0.926 & 0.928 & 0.921 & 0.938 & 0.928 \\
\hline
\end{tabular}

Vehicle speed repeatability varied little from vehicle to vehicle. Engine speed repeatability also varied little, but vehicles with automatic transmissions exhibited slightly better repeatability than vehicles with manual transmissions, on average. Engine torque and power had the widest distribution in repeatability. This most likely resulted from the rapid power and torque fluctuations that cause instantaneous unrepeated activity. 
The automatic transmission vehicles had better repeatability for the gear comparison than the manual transmission vehicles. This could result both from the driver's inability to select the gear and/or from the fewer gears in the automatic transmission vehicles. An unlocked or locked torque converter could reduce gear repeatability, but this behavior either was consistent from run to run or had little effect.

A noticeable difference existed between MEMS \#10 and \#11. These were nearly identical vehicles that exhibited differing degrees of repeatability. This may have resulted from the method of testing. The vehicles were often tested together with MEMS \#10 following MEMS \#11. This perhaps resulted in the second driver acting more aggressively during acceleration and/or braking. This is discussed in more detail in Section 8.2.3.

A further examination of repeatability was conducted by comparing different vehicles over the same route. It is difficult to conclude if the vehicle or driver had a greater influence on results. If runs existed for each vehicle that had the same driver, these were selected for comparison. Otherwise, the first run was selected arbitrarily. Only one run was compared for each vehicle with.

MEMS \#10 and \#11 had good repeatability over the same route as shown in Table 35. This most likely resulted from the vehicles being identical and that one followed the other over some of the tested routes. The Morgantown route had the same driver for both vehicles while the PA2 route did not. MEMS \#8 and \#12 exhibited much lower repeatability over the same route, as seen in Table 36. The two vehicles varied substantially in torque, power, and gear ratio. The fact that parameters were examined in absolute amplified the differences. This created an inherent difference between two vehicles even if behavior is similar. For example, if one vehicle produces $1600 \mathrm{ft}-\mathrm{lb}$ and the other produces $1400 \mathrm{ft}-\mathrm{lb}$ during the $5 \%$ grade on Sab2BM, then the vehicles produce instantaneous errors, even though they are operating in the same respective range. Dimensionless torque comparison would most likely have increased the calculated repeatability values, but this would have incorrectly analyzed the $1400 \mathrm{ft}-\mathrm{lb}$ and the 1600 $\mathrm{ft}-\mathrm{lb}$ as equal. 
All four vehicles were compared over PA2, as seen in Table 37. Repeatability was low when the repeatability of the four vehicles was compared to the separate repeatability of the school busses and tractor trucks.

Table 35: Coefficients of repeatability for MEMS \#10 vs. MEMS \#11 over two routes

\begin{tabular}{|l|c|c|}
\hline MEMS\#10 vs. MEMS\#11 & Motown & PA2 \\
\hline Vehicle Speed & 0.997 & 0.995 \\
\hline Engine Speed & 0.995 & 0.991 \\
\hline Torque & 0.907 & $\mathbf{0 . 8 4 7}$ \\
\hline Power & 0.908 & $\mathbf{0 . 8 5 7}$ \\
\hline $\mathrm{CO}_{2}(\mathrm{~g} / \mathrm{sec})$ & 0.946 & 0.908 \\
\hline $\mathrm{NO}_{\mathrm{x}}(\mathrm{g} / \mathrm{sec})$ & 0.954 & 0.912 \\
\hline Gear & 0.995 & 0.991 \\
\hline Time & 0.999 & 0.999 \\
\hline NTE Zone & 0.897 & $\mathbf{0 . 8 5 3}$ \\
\hline
\end{tabular}

Table 36: Coefficients of repeatability for MEMS \#8 vs. MEMS \#12 over two routes

\begin{tabular}{|l|c|c|}
\hline MEMS\#8 vs. MEMS\#12 & Sab2BM & PA2 \\
\hline Vehicle Speed & 0.998 & 0.984 \\
\hline Engine Speed & 0.996 & 0.987 \\
\hline Torque & 0.939 & $\mathbf{0 . 8 3 5}$ \\
\hline Power & 0.936 & $\mathbf{0 . 8 3 5}$ \\
\hline $\mathrm{CO}_{2}(\mathrm{~g} / \mathrm{sec})$ & 0.956 & 0.901 \\
\hline $\mathrm{NO}_{\mathrm{x}}(\mathrm{g} / \mathrm{sec})$ & 0.956 & 0.885 \\
\hline Gear & 0.996 & 0.975 \\
\hline Time & 0.998 & 0.994 \\
\hline NTE Zone & 0.950 & $\mathbf{0 . 8 2 6}$ \\
\hline
\end{tabular}


Table 37: Coefficients of repeatability for MEMS \#8, MEMS \#10, MEMS \#11, and MEMS \#12 over PA2

\begin{tabular}{|l|c|c|c|c|c|c|c|}
\hline \multicolumn{1}{|c|}{ PA2 } & $\begin{array}{c}\text { MEMS\#8 vs. } \\
\text { MEMS\#10 vs. } \\
\text { MEMS\#11 vs. } \\
\text { MEMS\#12 }\end{array}$ & $\begin{array}{c}\text { MEMS\#10 } \\
\text { vs. } \\
\text { MEMS\#11 }\end{array}$ & $\begin{array}{c}\text { MEMS\#8 } \\
\text { vs. } \\
\text { MEMS\#12 }\end{array}$ & $\begin{array}{c}\text { MEMS } \\
\# 8\end{array}$ & $\begin{array}{c}\text { MEMS } \\
\# 12\end{array}$ & $\begin{array}{c}\text { MEMS } \\
\# 10\end{array}$ & $\begin{array}{c}\text { MEMS } \\
\# 11\end{array}$ \\
\hline Veh. Speed & 0.984 & 0.995 & 0.984 & 0.996 & 0.984 & 0.978 & 0.993 \\
\hline Eng. Speed & 0.972 & 0.991 & 0.987 & 0.992 & 0.987 & 0.985 & 0.990 \\
\hline Torque & $\mathbf{0 . 7 0 8}$ & $\mathbf{0 . 8 4 7}$ & $\mathbf{0 . 8 3 5}$ & 0.890 & $\mathbf{0 . 7 8 4}$ & $\mathbf{0 . 7 7 6}$ & $\mathbf{0 . 8 4 6}$ \\
\hline Power & $\mathbf{0 . 7 3 3}$ & $\mathbf{0 . 8 5 7}$ & $\mathbf{0 . 8 3 5}$ & 0.893 & $\mathbf{0 . 7 9 9}$ & $\mathbf{0 . 7 7 3}$ & $\mathbf{0 . 8 6 2}$ \\
\hline $\mathrm{CO}_{2}(\mathrm{~g} / \mathrm{sec})$ & $\mathbf{0 . 8 2 9}$ & 0.908 & 0.901 & 0.934 & 0.884 & 0.867 & 0.908 \\
\hline $\mathrm{NO}_{\mathrm{x}}(\mathrm{g} / \mathrm{sec})$ & $\mathbf{0 . 7 9 7}$ & 0.912 & 0.885 & 0.937 & $\mathbf{0 . 8 6 9}$ & $\mathbf{0 . 8 3 3}$ & 0.909 \\
\hline Gear & 0.964 & 0.991 & 0.975 & 0.993 & 0.981 & 0.985 & 0.990 \\
\hline Time & 0.989 & 0.999 & 0.994 & 1.000 & 0.986 & 0.980 & 0.999 \\
\hline NTE Zone & $\mathbf{0 . 7 8 9}$ & $\mathbf{0 . 8 5 3}$ & $\mathbf{0 . 8 2 6}$ & $\mathbf{0 . 8 8 4}$ & $\mathbf{0 . 7 7 9}$ & 0.802 & $\mathbf{0 . 8 4 1}$ \\
\hline Average & $\mathbf{0 . 8 6 3}$ & 0.928 & 0.914 & 0.947 & 0.895 & 0.887 & 0.927 \\
\hline
\end{tabular}

\subsubsection{Route}

The effects of routes on repeatability can be seen in Table 38. All vehicles were averaged for each route.

Table 38: Comparison of route repeatability

\begin{tabular}{|l|c|c|c|c|c|c|c|c||c|}
\cline { 2 - 10 } \multicolumn{1}{c|}{} & Motown & Sab2BM & BM2Sab & Sab2SW & SW2Sab & PA1 & PA2 & PA3 & Average \\
\hline Veh. Sp. & 0.995 & 0.999 & 0.992 & 0.997 & 0.994 & 0.987 & 0.988 & 0.997 & 0.994 \\
\hline Eng. Sp. & 0.994 & 0.995 & 0.991 & 0.988 & 0.988 & 0.987 & 0.989 & 0.995 & 0.991 \\
\hline Torque & $\mathbf{0 . 8 7 2}$ & 0.931 & $\mathbf{0 . 7 4 7}$ & $\mathbf{0 . 8 6 9}$ & $\mathbf{0 . 8 4 2}$ & $\mathbf{0 . 7 7 8}$ & $\mathbf{0 . 8 2 4}$ & 0.901 & $\mathbf{0 . 8 4 6}$ \\
\hline Power & $\mathbf{0 . 8 7 5}$ & 0.932 & $\mathbf{0 . 6 7 3}$ & $\mathbf{0 . 8 5 1}$ & $\mathbf{0 . 8 1 0}$ & $\mathbf{0 . 7 8 9}$ & $\mathbf{0 . 8 3 2}$ & 0.899 & $\mathbf{0 . 8 3 3}$ \\
\hline $\mathrm{CO}_{2}(\mathrm{~g} / \mathrm{s})$ & 0.934 & 0.966 & 0.946 & 0.933 & 0.923 & $\mathbf{0 . 8 8 0}$ & 0.898 & 0.944 & 0.928 \\
\hline $\mathrm{NO}_{\mathrm{x}}(\mathrm{g} / \mathrm{s})$ & 0.935 & 0.959 & 0.933 & 0.924 & 0.907 & $\mathbf{0 . 8 8 0}$ & 0.887 & 0.937 & 0.920 \\
\hline Gear & 0.992 & 0.995 & 0.982 & 0.988 & 0.985 & 0.978 & 0.987 & 0.996 & 0.988 \\
\hline Time & 0.998 & 0.993 & 0.998 & 0.987 & 0.999 & 0.995 & 0.991 & 0.999 & 0.995 \\
\hline NTE Zone & $\mathbf{0 . 8 5 8}$ & 0.938 & 0.904 & 0.897 & 0.878 & $\mathbf{0 . 7 8 8}$ & $\mathbf{0 . 8 2 7}$ & $\mathbf{0 . 8 7 5}$ & $\mathbf{0 . 8 7 1}$ \\
\hline \hline Average & 0.939 & 0.968 & 0.907 & 0.937 & 0.925 & 0.896 & 0.914 & 0.949 & 0.929 \\
\hline
\end{tabular}

The MEMS test routes differed substantially and it was to be expected that repeatability would vary from route to route. Repeatability was highest for the Sab2BM route. As discussed earlier, this route had several long, steep grades where engine power was the limiting factor. During the majority of a climb, the vehicle would not stray far 
from the peak power state. This reduced rapid torque and power fluctuations for a large part of the route, which in turn, improved engine torque and power, as well as $\mathrm{NO}_{\mathrm{x}}$ and $\mathrm{CO}_{2}$ repeatability. Also, gear, engine speed, and vehicle speed generally behaved consistently over these climbs.

BM2Sab also included portions of steep, long, uphill grades but not as extensive as the grades during the Sab2BM route. BM2Sab exhibited lower repeatability than Sab2BM because of low repeatability of torque and power. Torque and power repeatability was occasionally artificially reduced by numerical error associated with the inferring of torque while operating the engine near maximum speed. One driver consistently operated at this point, reducing repeatability for the BM2Sab route. The effects of the driver on repeatability will be discussed in the next section.

PA1 was the most urban route. It contained many traffic lights and possibly had the greatest number of varying traffic conditions because it was the most urban. Not surprisingly it had the lowest repeatability. PA2 included some urban roads and some freeway driving. This resulted in increased repeatability, most likely due to the lower variance on freeways. PA3 was mostly freeway driving. The freeway driving allowed for more consistent operation, which was shown by the higher average repeatability.

Sab2SW and SW2Sab have similar driving conditions to PA3. There are rolling hills but no substantial grades over extended distances. This was reflected in the repeatability by PA3, Sab2SW, and SW2Sab having similar repeatability values. PA3, Sab2SW, and SW2Sab were less repeatable than Sab2BM. This supports the hypothesis that the limiting factors of a long hill climb greatly increase repeatability during mostly unconstrained operation. Sab2SW and SW2Sab again had the same driver who operated the engine near maximum speed. This resulted in lower repeatability of torque and power due to numerical errors.

The Morgantown route included urban, suburban, and freeway driving. This route was found to be more repeatable than were PA1, PA2, and PA3. This could result from the lower levels of traffic found in Morgantown. The route was found to be comparable to the Sab2SW and SW2Sab in repeatability. This was of interest because more time was spent in urban areas for the Morgantown route than for Sab2SW or SW2Sab. This could result from the distance-specific comparison. While most of the 
time was spent in urban areas, the majority of the distance was on freeways. The distance-based methodology biased the data toward higher repeatability even though most of the operation was during lower repeatability.

\subsubsection{Driver}

The driver could potentially affect repeatability. While most runs were fairly consistent and many vehicles were tested by the same driver over a given route, there were a few exceptions. Over the Sab2BM route, a different driver tested MEMS \#8 for the fourth run. This driver exhibited behavior different from the previous driver. This can be seen by the vehicle speed graph as shown in Figure 45 and the repeatability values in Table 39. This driver tended to climb the grade using too low a gear. The engine was operated at speeds above peak power until it started to cut fueling. The engine no longer produced peak power during the climb. This behavior was inconsistent with previous runs, causing repeatability to be reduced on average for the run and individually for torque and power. This same behavior caused numerical errors to significantly affect inferred torque values as seen at the 5 to 7 mile and 13 to 15 mile intervals in Figure 46.

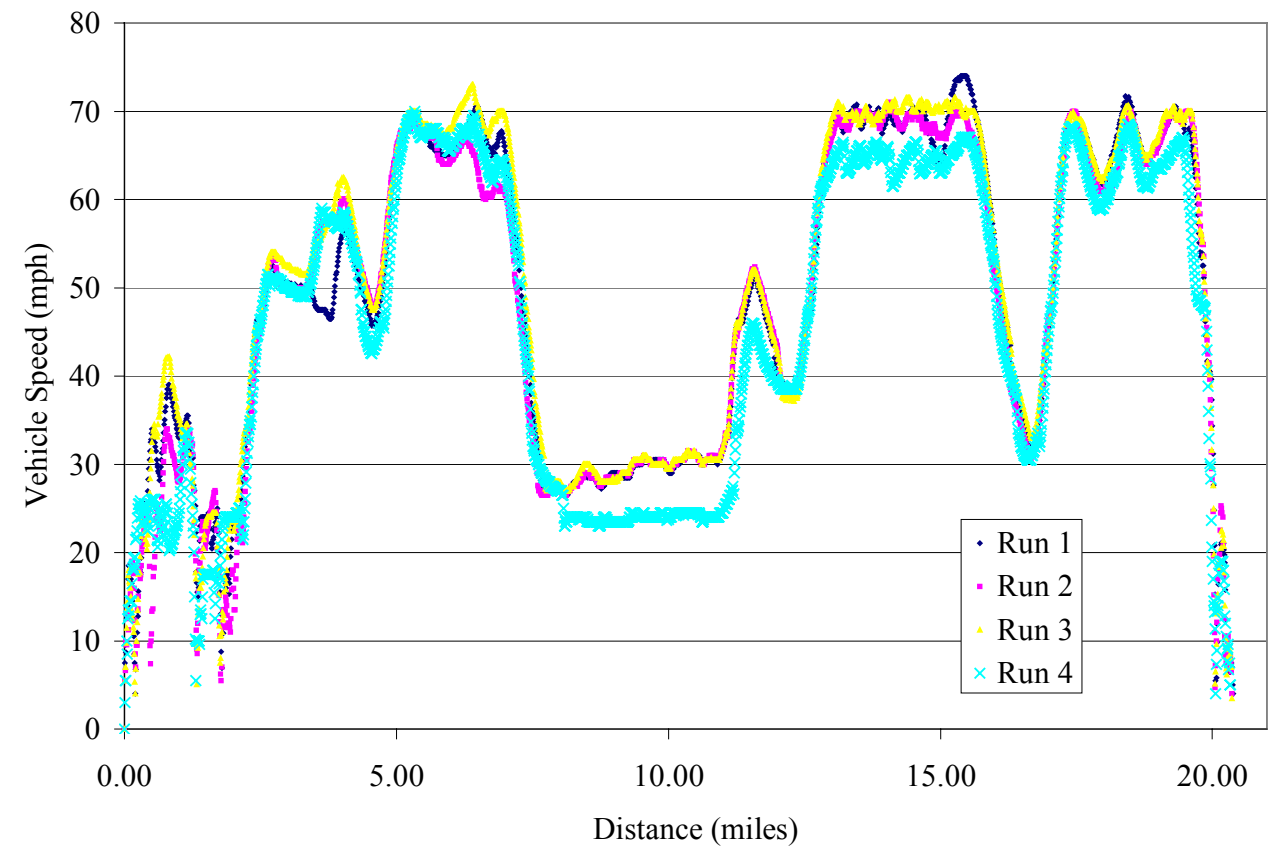

Figure 45: Vehicle speed for four runs for MEMS \#8 over Sab2BM 


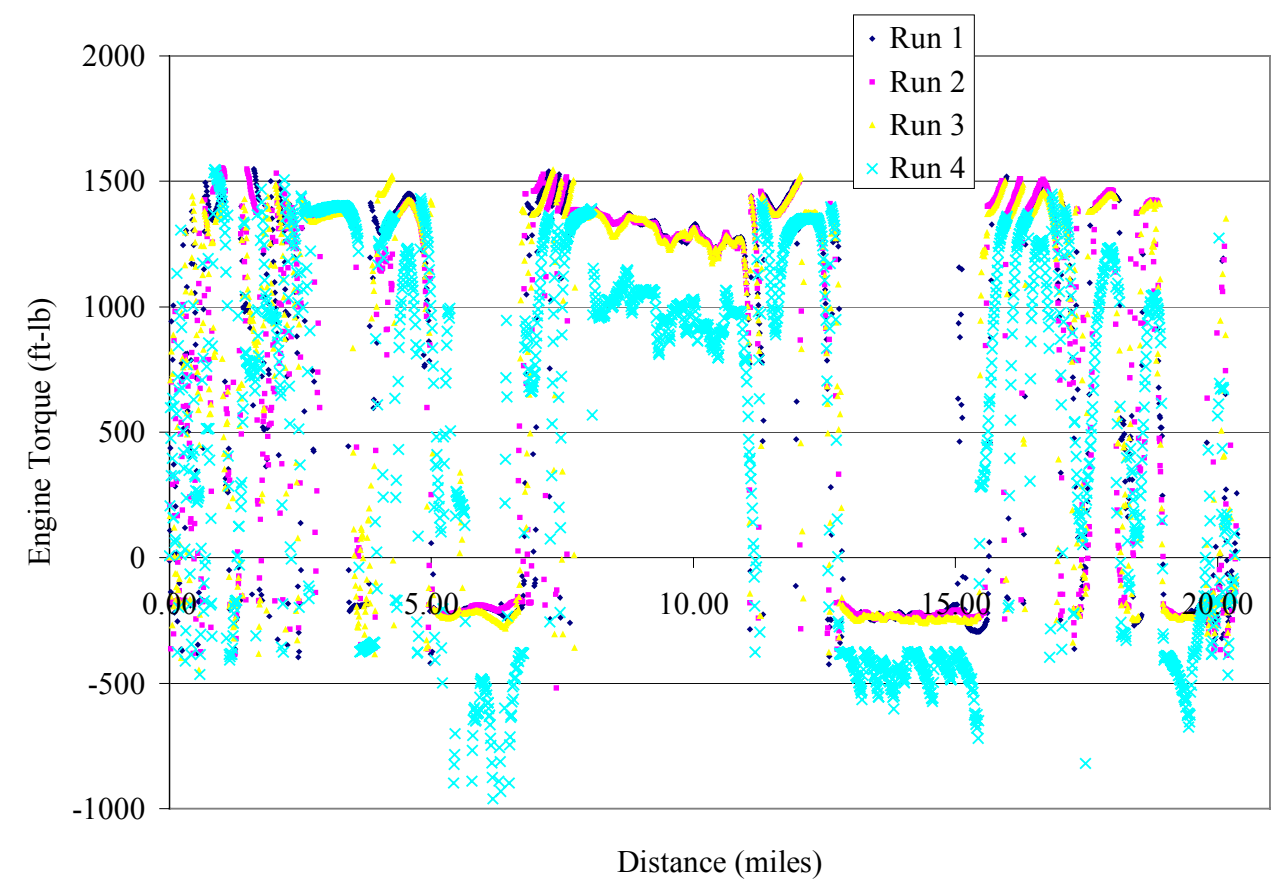

Figure 46: Engine torque for four runs for MEMS \#8 over Sab2BM

Table 39: Coefficients of repeatability for MEMS \#8 over Sab2BM for three and four runs

\begin{tabular}{|l|c|c|}
\cline { 2 - 3 } \multicolumn{1}{c|}{} & $3-\mathrm{D}$ & $4-\mathrm{D}$ \\
\hline Vehicle Speed & 0.999 & 0.998 \\
\hline Engine Speed & 0.996 & 0.990 \\
\hline Torque & 0.930 & $\mathbf{0 . 8 7 7}$ \\
\hline Power & 0.929 & $\mathbf{0 . 8 4 8}$ \\
\hline $\mathrm{CO}_{2}(\mathrm{~g} / \mathrm{sec})$ & 0.963 & 0.960 \\
\hline $\mathrm{NO}_{x}(\mathrm{~g} / \mathrm{sec})$ & 0.957 & 0.955 \\
\hline Gear & 0.998 & 0.986 \\
\hline Time & 0.998 & 0.997 \\
\hline NTE Zone & 0.938 & 0.940 \\
\hline Average & 0.968 & 0.950 \\
\hline
\end{tabular}

Further evidence for the reduction in repeatability when more than one driver was used can be seen for MEMS \#12 over BM2Sab. There were two drivers that each completed two consecutive runs. Driver A had less experience and exhibited lower repeatability than did driver B. Individually each driver exhibited better repeatability than their combined efforts as seen in Table 40. 
Table 40: Coefficients of repeatability for MEMS \#12 over BM2Sab

\begin{tabular}{|l|c|c|c|}
\cline { 2 - 4 } \multicolumn{1}{c|}{} & 4 Runs & Driver A & Driver B \\
\hline Vehicle Speed & 0.990 & 0.991 & 0.999 \\
\hline Engine Speed & 0.994 & 0.995 & 0.998 \\
\hline Torque & 0.922 & 0.918 & 0.954 \\
\hline Power & 0.922 & 0.918 & 0.952 \\
\hline $\mathrm{CO}_{2}(\mathrm{~g} / \mathrm{sec})$ & 0.958 & 0.955 & 0.975 \\
\hline $\mathrm{NO}_{\mathrm{x}}(\mathrm{g} / \mathrm{sec})$ & 0.931 & 0.956 & 0.970 \\
\hline Gear & 0.931 & 0.988 & 0.999 \\
\hline Time & 0.998 & 0.999 & 0.999 \\
\hline NTE Zone & 0.921 & 0.918 & 0.950 \\
\hline Average & 0.952 & 0.960 & 0.977 \\
\hline
\end{tabular}

A similar event occurred over the Sab2SW route. MEMS \#8 completed five runs, two by driver A and three by driver C. Driver A exhibited much better repeatability than did Driver C, as seen in Table 41. The reduced repeatability found for torque and power during driver C's runs was compounded by significant numerical error that occurred at high engine speed and low load. Only driver $\mathrm{C}$ operated in this range. If these parameters were disregarded, driver $\mathrm{C}$ still had lower repeatability for the remaining parameters.

Table 41: Coefficients of repeatability for MEMS \#8 over Sab2SW

\begin{tabular}{|l|c|c|c|}
\cline { 2 - 4 } \multicolumn{1}{c|}{} & 5 Runs & Driver A & Driver C \\
\hline Vehicle Speed & 0.990 & 0.999 & 0.989 \\
\hline Engine Speed & 0.989 & 0.997 & 0.994 \\
\hline Torque & $\mathbf{0 . 7 5 0}$ & 0.932 & $\mathbf{0 . 7 5 2}$ \\
\hline Power & $\mathbf{0 . 7 0 8}$ & 0.929 & $\mathbf{0 . 7 1 4}$ \\
\hline $\mathrm{CO}_{2}(\mathrm{~g} /$ sec $)$ & 0.920 & 0.960 & 0.927 \\
\hline $\mathrm{NO}_{x}(\mathrm{~g} / \mathrm{sec})$ & 0.912 & 0.957 & 0.920 \\
\hline Gear & 0.976 & 0.998 & 0.989 \\
\hline Time & 0.990 & 1.000 & 0.993 \\
\hline NTE Zone & $\mathbf{0 . 8 7 9}$ & 0.936 & 0.888 \\
\hline Average & 0.901 & 0.968 & 0.907 \\
\hline
\end{tabular}

Other effects that resulted from driver behavior can be seen in the lower repeatability of MEMS \#10 when compared to MEMS \#11. As previously mentioned, MEMS \#10 followed MEMS \#11 for several of the tests. It is likely that the "chase" driver behaved more aggressively to insure that he maintained a constant distance from 
the vehicle in front. This could very likely be the same effect that caused low torque and power repeatability in chassis testing. Instead of following a speed trace, the driver followed another vehicle, which required the same response and produced similar results. Evidence for this can be seen in Figure 47 and Figure 48. One can see that vehicle speed fluctuated more for MEMS \#10 than MEMS \#11. Engine torque had even greater fluctuations. The driver for MEMS \#10 aggressively adjusted the throttle causing torque to vary much more than on MEMS \#11. This behavior significantly reduced repeatability. It is likely that similar behavior could have occurred if a MEMS vehicle followed a non-MEMS vehicle, either intentionally or coincidentally. This condition reflected another variable of on-road testing.

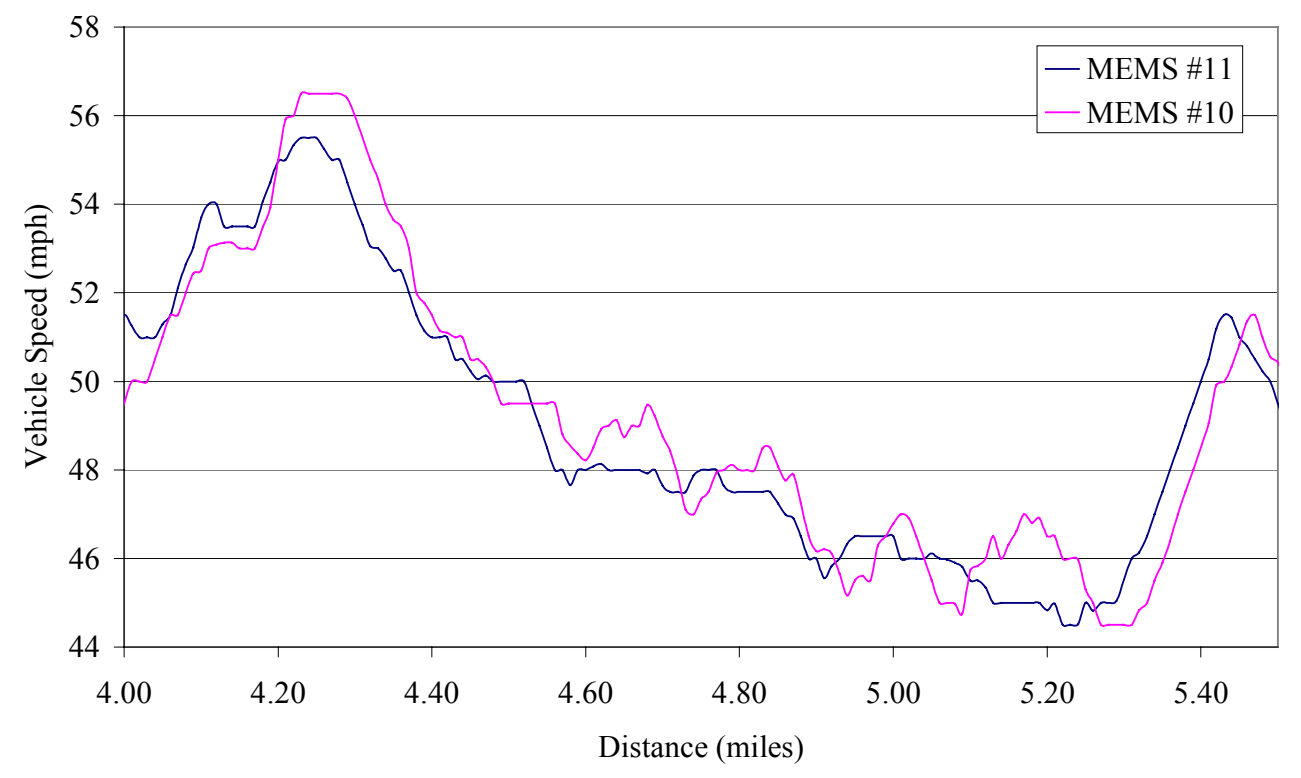

Figure 47: Detail of vehicle speed for MEMS \#10 and MEMS \#11 over PA1 


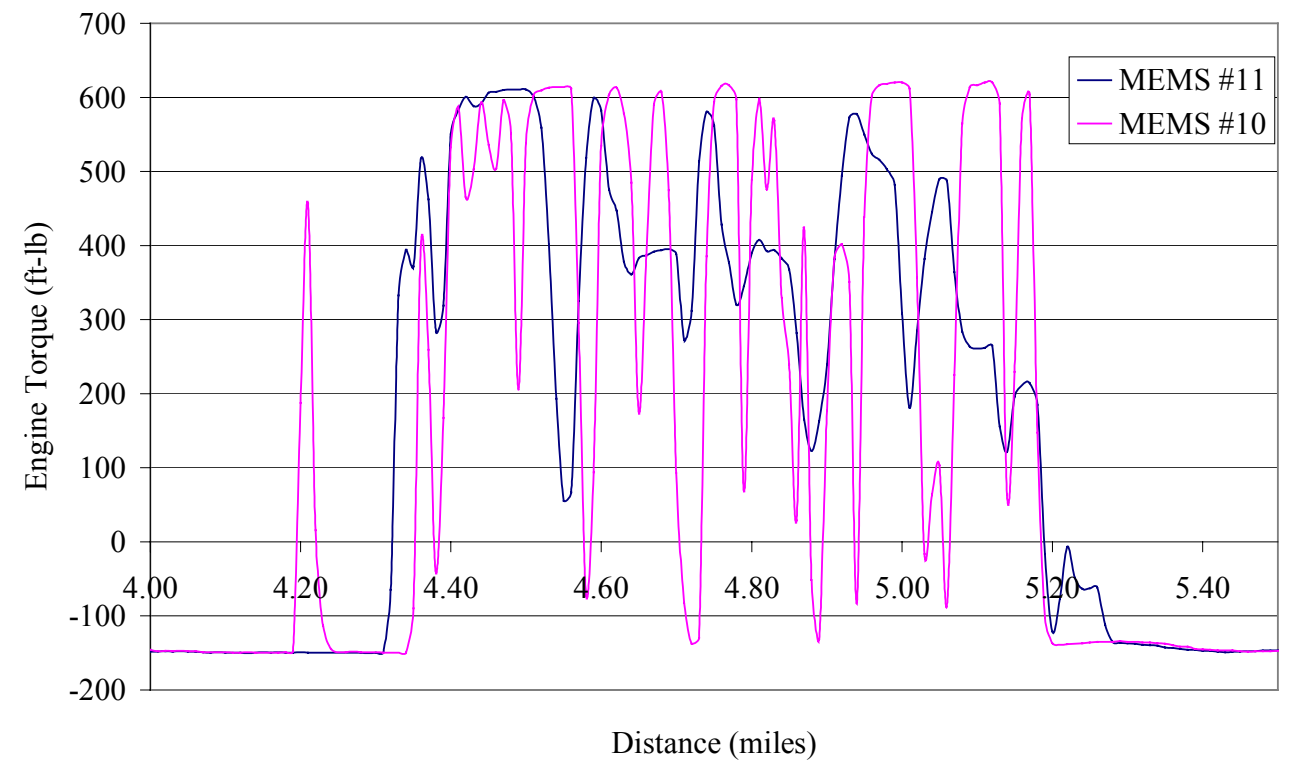

Figure 48: Detail of engine torque for MEMS \#10 and MEMS \#11 over PA1

The effects of driver on repeatability were significant. These effects could possibly be reduced but that would change the fundamentals of on-road testing. The goal of on-road testing was to examine actual in-use emissions including the variables that influence in-use behavior. Any effort to minimize these variables would change the tests so that they less accurately reflect in-use behavior.

\subsubsection{Methodology}

Each parameter usually had similar repeatability when compared to other parameters for a given vehicle. NTE zone activity, torque, and power have the lowest repeatability and the lowest time constants. $\mathrm{CO}_{2}$ and $\mathrm{NO}_{\mathrm{x}}$ had better repeatability than torque or power, but less than vehicle speed or gear selection. Gear, engine speed, vehicle speed, and time had the highest repeatability. The differences of repeatability for the different parameters can be related to time constants. Vehicle speed would take several minutes to go from zero to the maximum value. Torque could go from minimum to maximum on the order of a few seconds. $\mathrm{CO}_{2}$ and $\mathrm{NO}_{\mathrm{x}}$ have a greater time constant than torque because of the response time of the analyzers and axial gas dispersion. NTE zone activity is apt to have the lowest time constant because of its binary nature. 
The methodology may in itself present values that bias certain conditions. The randomness of the data had little influence on the results if there was a strong offset in the positive or negative direction. Random data may have seemingly high correlation if the data have a high offset. This allows for a relationship between the ratio of the range of random values and the amount of offset. For example, random values with a range of one can be placed at different offsets of $0,+2$, and -2 . This has resulted in calculated repeatability values to be $-0.9825,0.9862$, and 0.9863 . This can be seen in Figure 49 , Figure 50, and Figure 51. The relationship of coefficient of repeatability versus range/offset can be seen in Figure 52. It is necessary to consider the effect of the methodology on the results when analyzing repeatability.

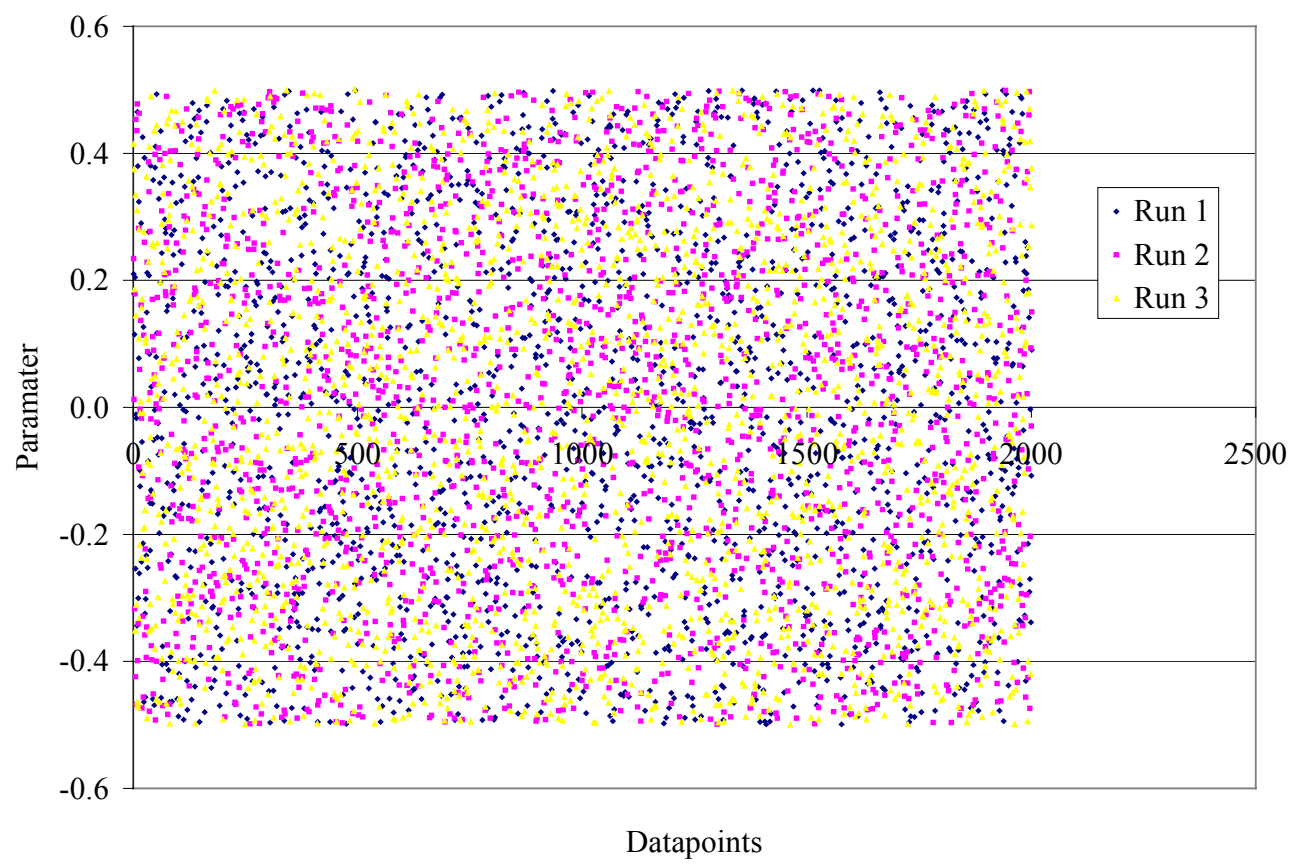

Figure 49: Random points with a range of one and an offset of zero 


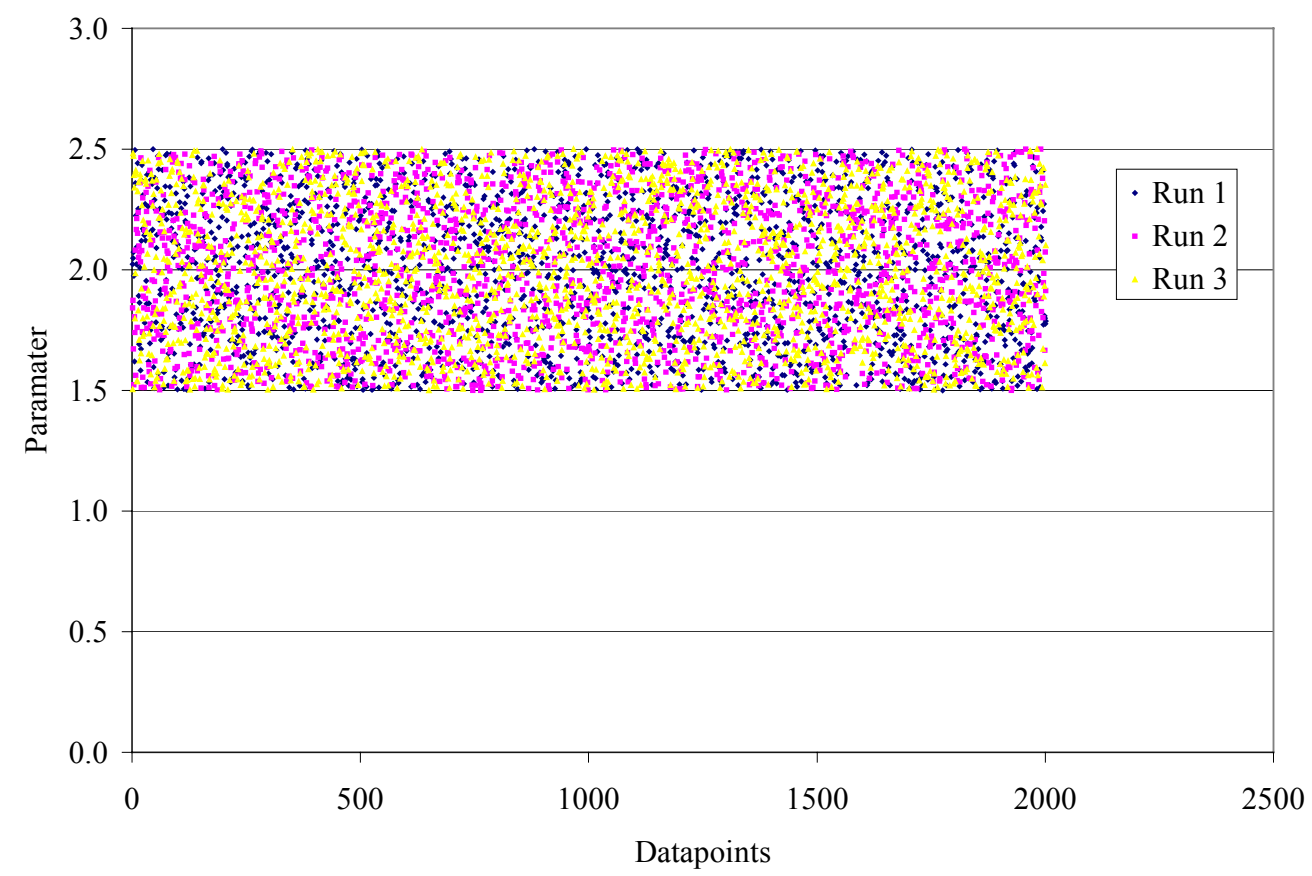

Figure 50: Random points with a range of one and an offset of two

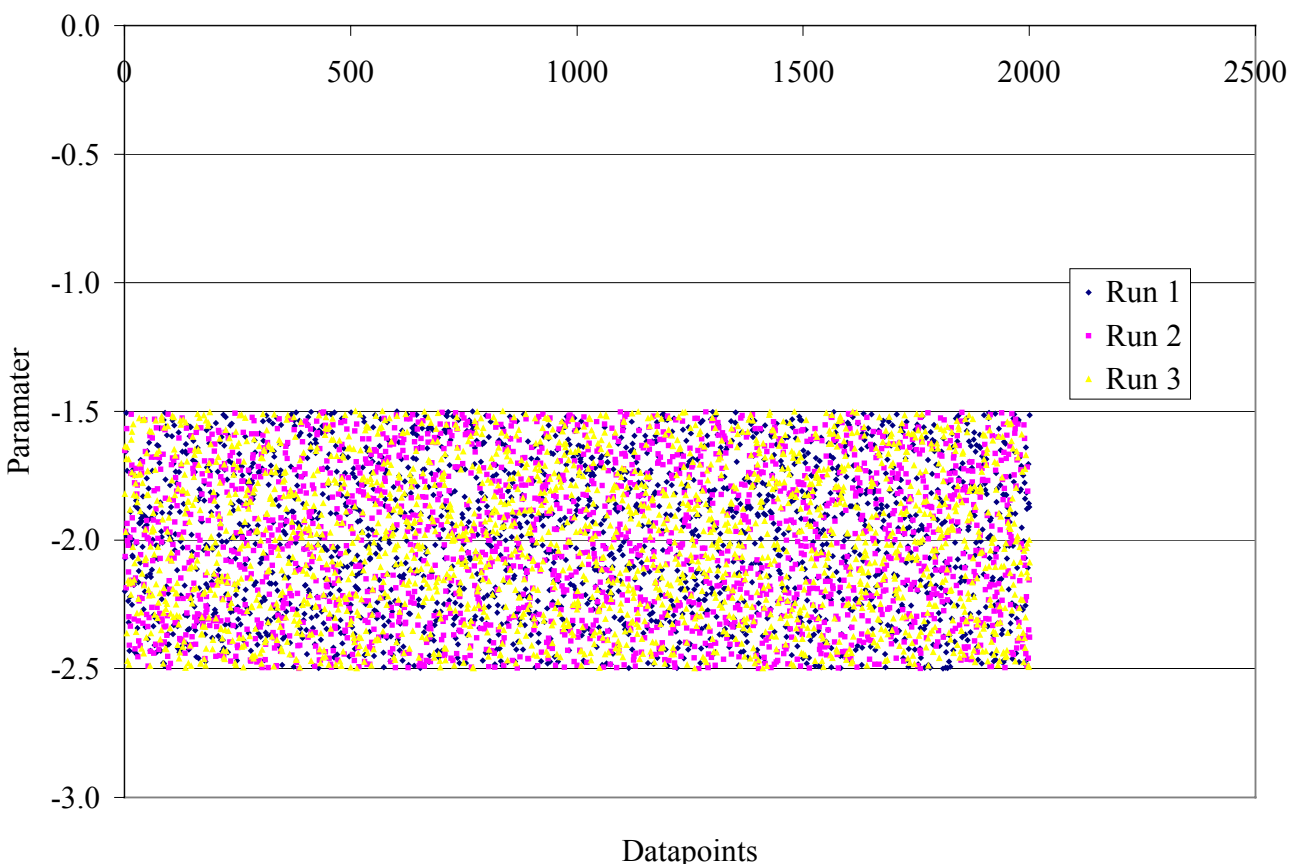

Figure 51: Random points with a range of one and an offset of negative two 


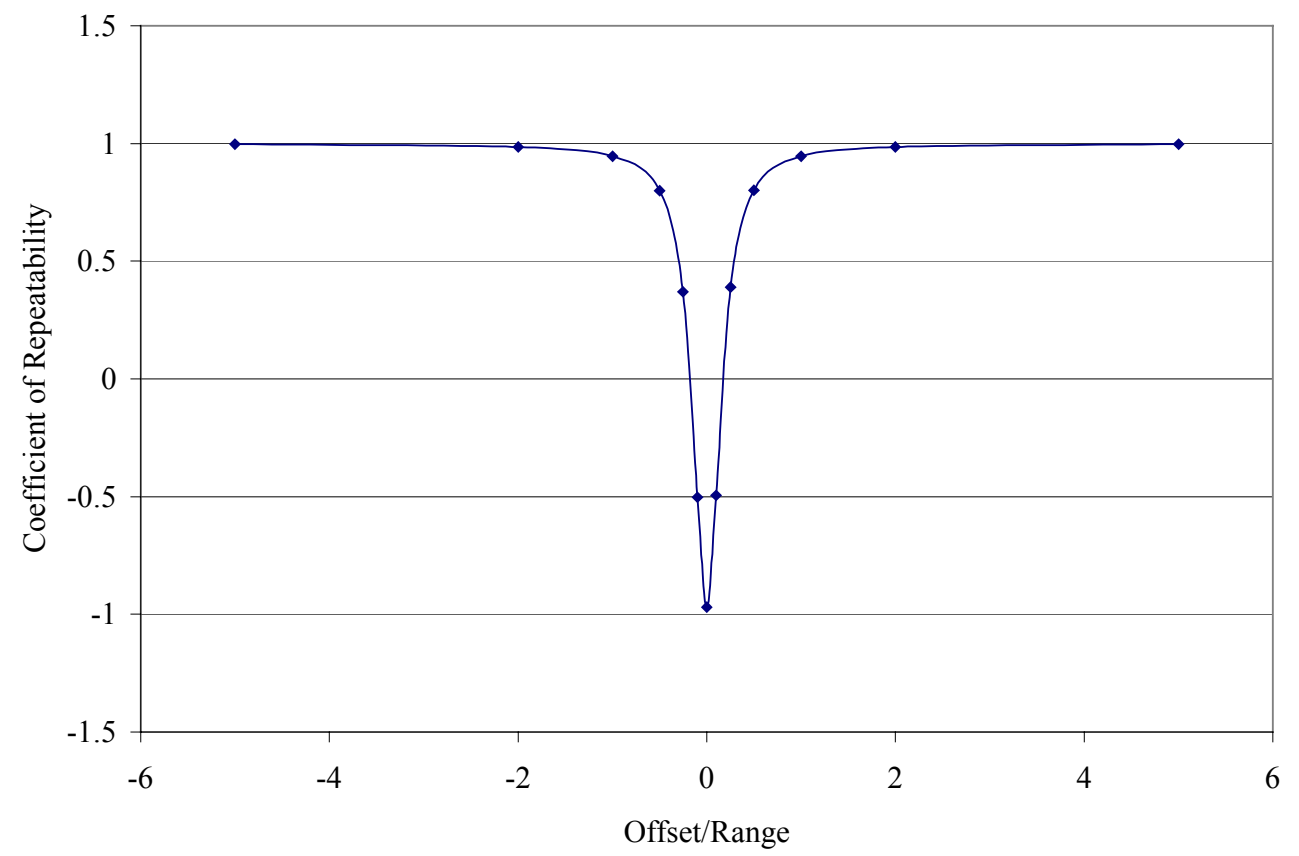

Figure 52: The relationship of offset/range to coefficient of repeatability

This can influence repeatability analysis as follows. A given engine speed has a minimum value of approximately 600 and a maximum 2100. This gives an approximate offset of 1350 and a range of 1500 , or an offset/range ratio of 0.9 . Torque can fluctuate over a greater range with maximum values of 1600 and minimum values of -400 with a range of 2000, while having a lower offset of 600 . This would have an offset/range ratio of 0.3. If engine speed and engine torque were completely random, engine speed would produce a coefficient of repeatability value of 0.8 and engine torque would produce approximately 0.4. During normal driving this engine speed window would be further reduced, further increasing the coefficient of repeatability. Torque would often fluctuate between its extreme during normal operation, causing it to have an even lower coefficient of repeatability.

It is necessary to insure that the methodology properly analyzes multiple runs. It would be inappropriate if a three-run comparison could never have a better repeatability than a two-run comparison or vice versa. The number of routes analyzed affected the coefficient of repeatability in the following manner. If two runs were first examined and a third run fell within the first two or within a few percentage points of the first two, then 
repeatability was increased. If the third parameter did not fall close to within the first two, repeatability decreased. An example of this can be found in Table 42 and Figure 53. Nine sets of four "runs" were examined, with three remaining constant and one varied. The 2-D analysis analyzed only the first two runs, the 3-D analyzed the first three runs, and the 4-D analyzed all four runs. All values are shown with greater precision because the runs were considered ideal and exact.

Table 42: Effects of multiple runs on coefficient of repeatability

\begin{tabular}{|c|c|c|c|c|c|c|}
\hline Run 1 & Run 2 & Run 3 & Run 4 & 2-D & 3-D & 4-D \\
\hline 100 & 60 & 90 & 110 & 0.93750 & 0.95840 & 0.95679 \\
\hline 100 & 70 & 90 & 110 & 0.96886 & 0.97929 & 0.97443 \\
\hline 100 & 80 & 90 & 110 & 0.98765 & 0.99177 & 0.98615 \\
\hline 100 & 90 & 90 & 110 & 0.99723 & 0.99745 & 0.99277 \\
\hline 100 & 100 & 90 & 110 & 1.00000 & 0.99762 & 0.99500 \\
\hline 100 & 110 & 90 & 110 & 0.99773 & 0.99333 & 0.99346 \\
\hline 100 & 120 & 90 & 110 & 0.99174 & 0.98543 & 0.98866 \\
\hline 100 & 130 & 90 & 110 & 0.98299 & 0.97461 & 0.98107 \\
\hline 100 & 140 & 90 & 110 & 0.97222 & 0.96143 & 0.97107 \\
\hline
\end{tabular}

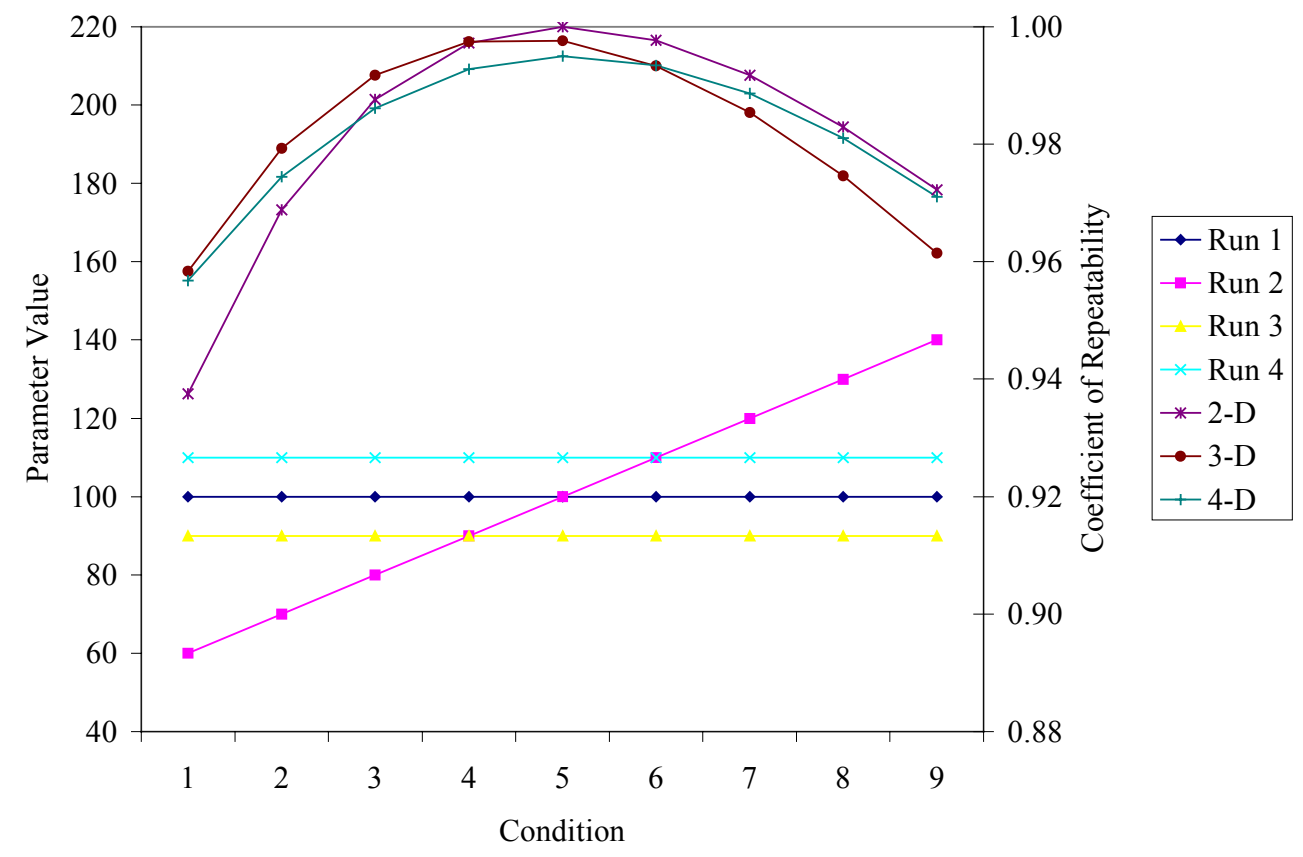

Figure 53: Effects of multiple runs on coefficient of repeatability 
Further examination of the methodology shows that reducing the distance interval had little effect on coefficient of repeatability, but increasing the interval reduced repeatability. PA1 and PA3 were examined for MEMS \#12 over 0.1-, 0.5-, 0.01-, and 0.005-mile intervals. The results are presented in Figure 54 and Figure 55. Very little difference was found for parameters that changed relatively slowly, such as vehicle speed, or had little transience, such as gear. Parameters that had substantial transience, such as torque, power, and NTE zone, showed better repeatability as the distance interval was shortened.

As the interval became smaller, the coefficient of repeatability reached a plateau. The selected distance interval of 0.01-miles appeared to be on this plateau as shown for NTE zone, torque, and power in Figure 55. It appeared that the time constants of the more transient parameters were fully recognized by examining this interval. If the distance interval was further reduced, below 0.005-miles, than the conversion to distance based algorithm would interpolate between the same two data points more than once if vehicle speed were high, as suggested in Figure 56.

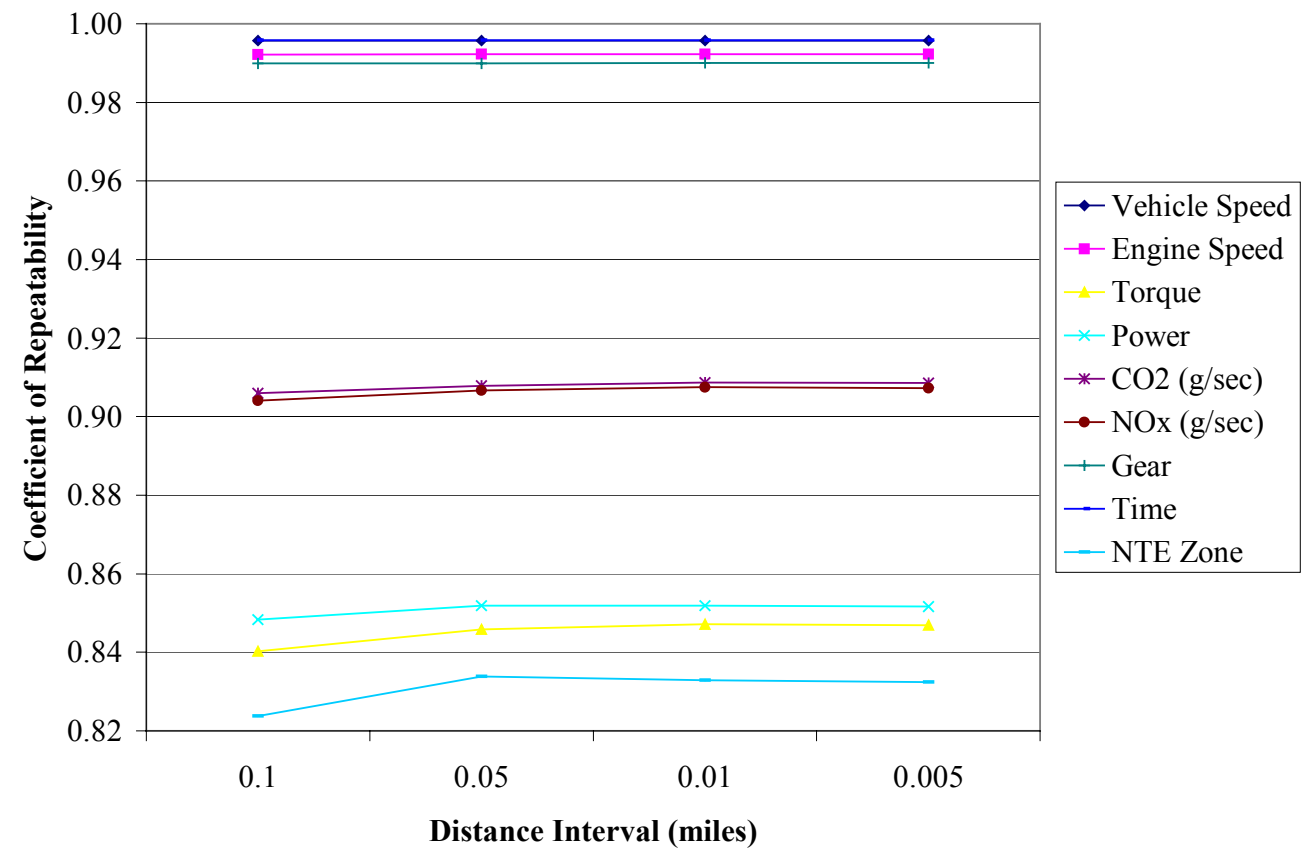

Figure 54: Effects of discretization adjustments for MEMS \#12 over PA3 


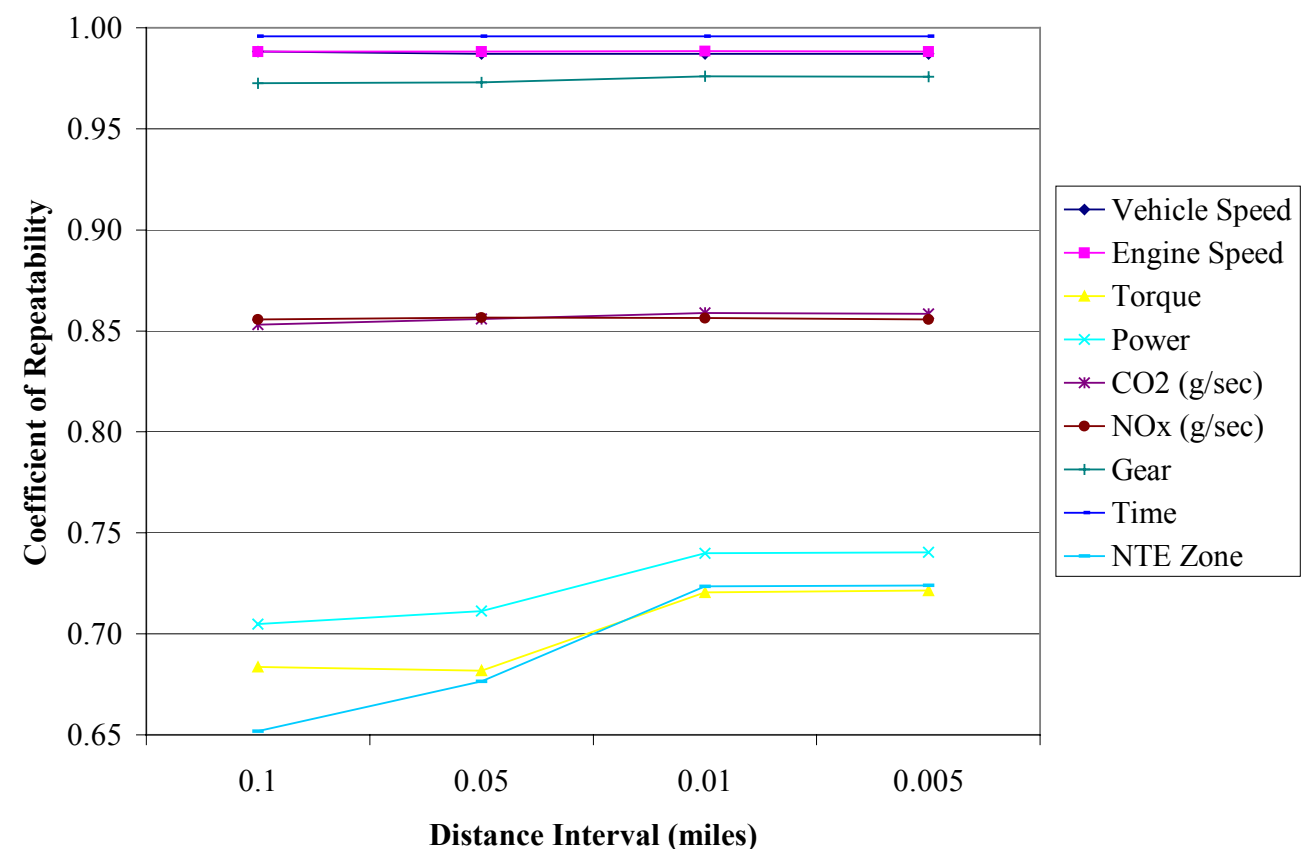

Figure 55: Effects of discretization adjustments for MEMS \#12 over PA1

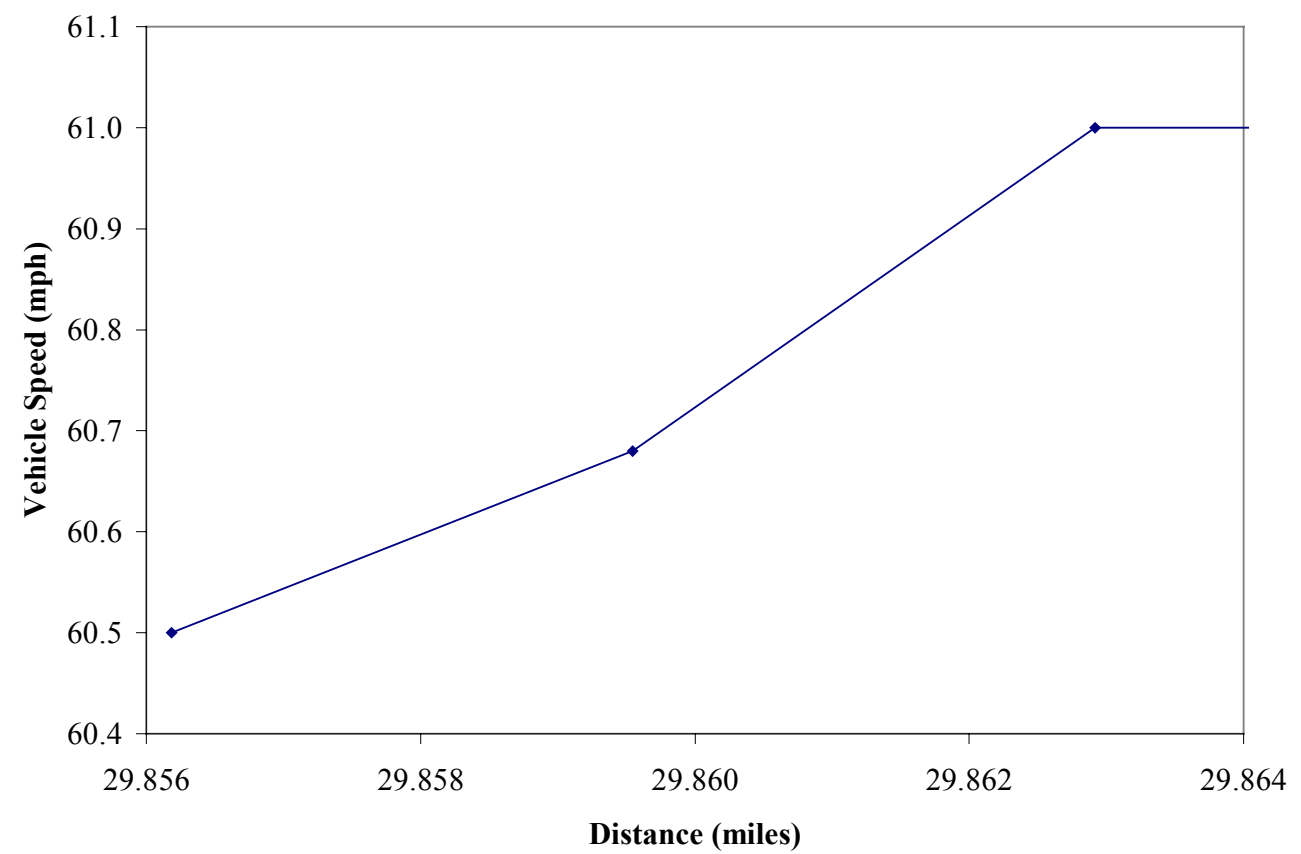

Figure 56: Detail of time-based vehicle speed for MEMS \#12 over PA3 


\section{Examination of MEMS Routes with Respect to FTP}

Examination of on-road routes with respect to the FTP allows researchers to know how well actual in-use emissions should compare to the FTP. Some current inventory models use FTP data to estimate vehicular lifetime and/or distance-specific emissions. The present examination was conducted only with MEMS \#8 and \#12, because these were the only vehicles examined in this thesis that were engine dynamometer tested. All routes tested with these vehicles were examined, which includes all routes except Morgantown. MEMS routes were design to include little idle and have extensive NTE zone operation, criteria that differ from the FTP.

\subsection{MEMS FTP versus Actual FTP}

There is a significant difference between the actual defined FTP and the data collected using MEMS. This stems from the FTP being defined numerical set points with no direct consideration of engine dynamics, such as turbocharger lag and inertia. Throughout the FTP, the test engine was not required to meet set points exactly, but had to fall within limits set by the CFR. A comparison of the behavior exhibited by a pseudoengine following the FTP exactly and an actual engine tested over the FTP where data were collected using MEMS, shows that the two were quite different. The behavior of an ideal engine following the defined set points was referred to as FTP (ideal), and the actual data collected by MEMS were referred to as FTP (MEMS). Figure 57 shows the FTPdefined set points and the actual operation of a tested engine. Figure 58 shows a detailed version of the same, where one can see that the actual engine attempts to meet the trace but does not succeed exactly. This was probably the result of turbocharger lag, where full torque was not produced until the turbocharger reached steady-state operation [28]. Figure 59 and Figure 60 show rate of change of engine speed and rate of change of engine torque, respectively.

It is evident that the ideal FTP focuses almost $50 \%$ of the time at constant engine speed and over $40 \%$ of the time at constant engine torque (including idle for both cases). The actual engine would sometimes fluctuate over $10 \mathrm{rpm}$ and over $5 \mathrm{ft}-\mathrm{lb}$ at idle causing the engine to exceed the respective window of steady-state operation. Also, the actual engine would sometimes increase torque gradually, while the ideal FTP would have 
reached the set torque and be at a steady-state. Because of these discrepancies, it was found best to compare the FTP values from the actual test as recorded by MEMS, allowing for highest consistency of conditions.

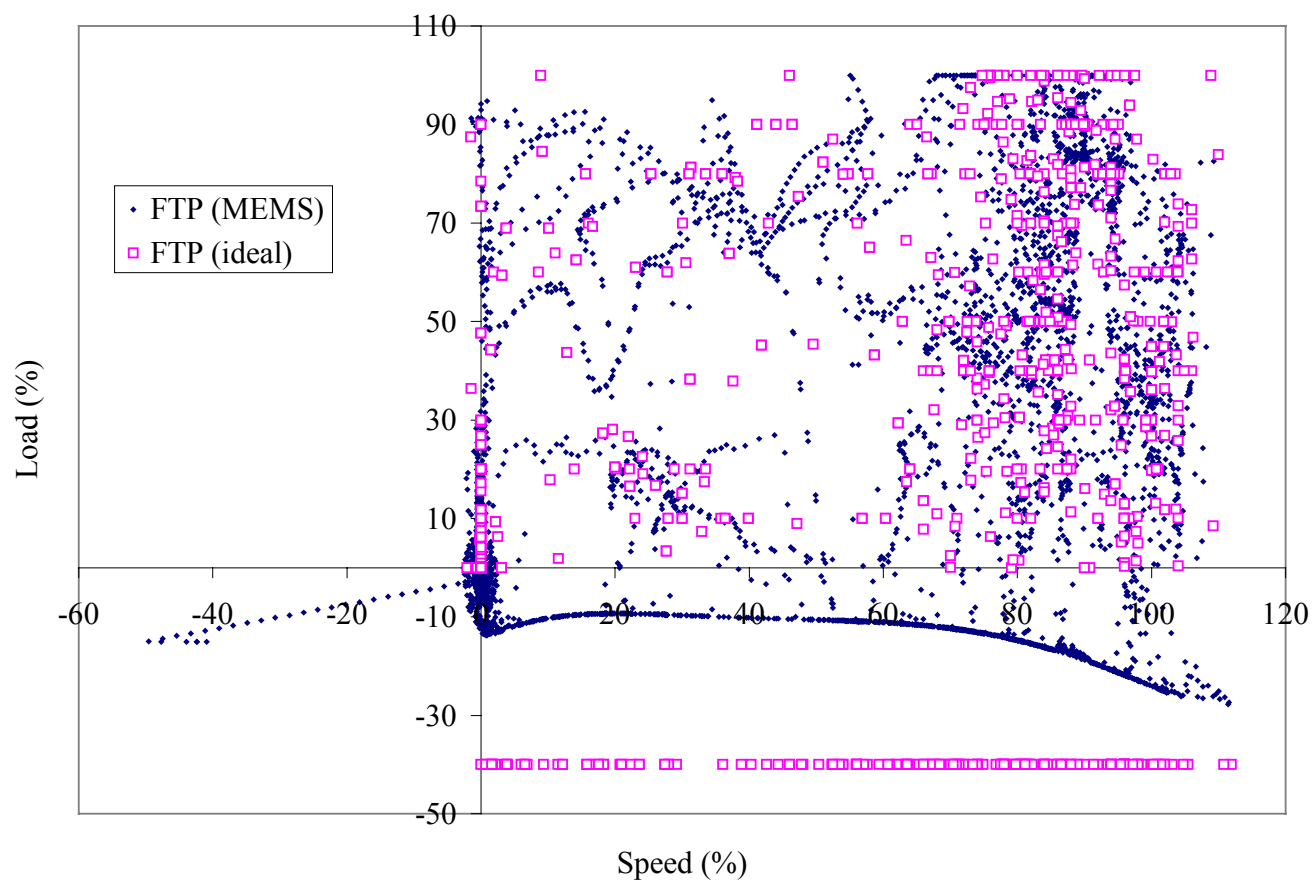

Figure 57: FTP tested and defined percent speed and load set points for MEMS \#8

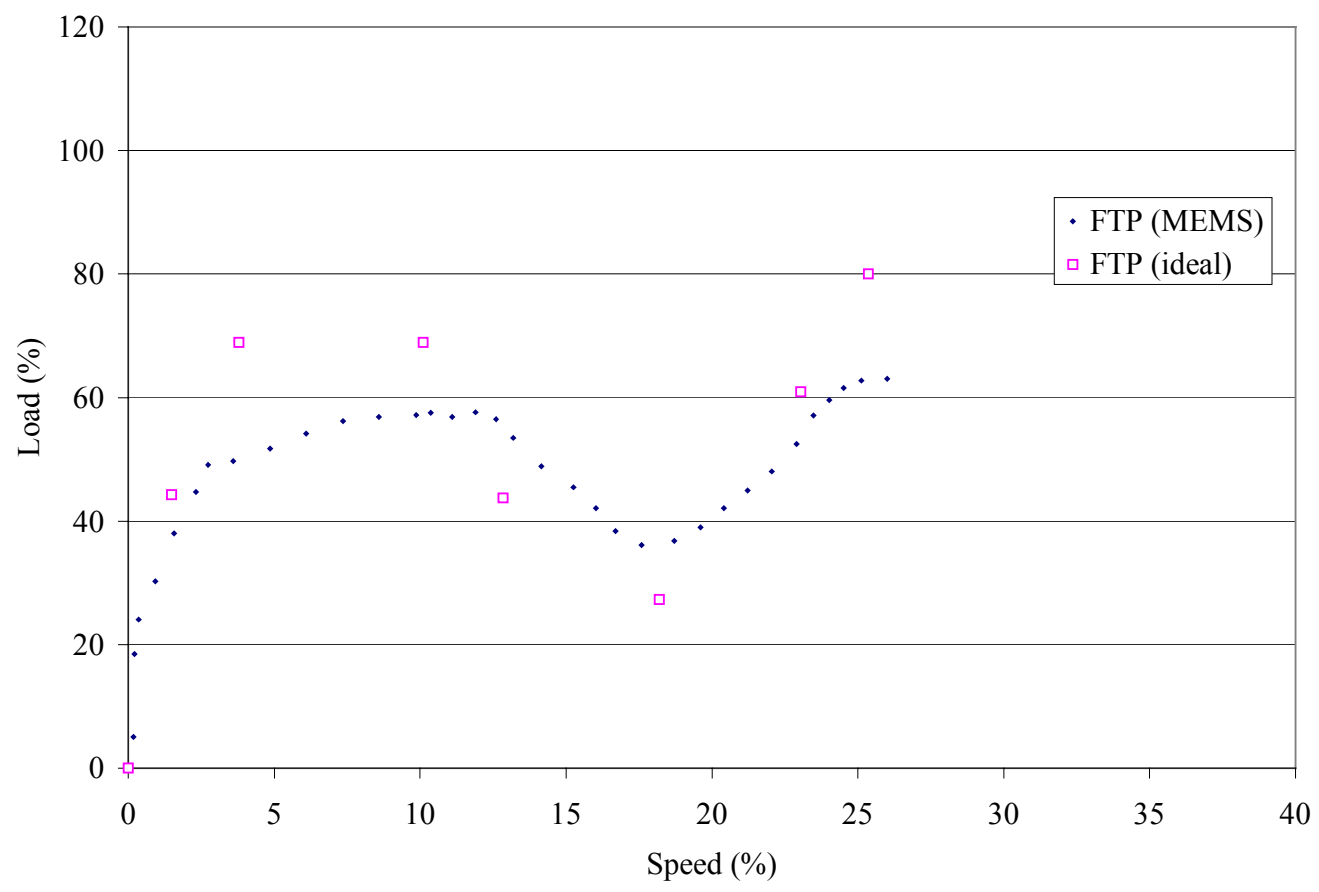

Figure 58: Detail of actual engine speed and torque for MEMS \#8 and FTP-defined set points 


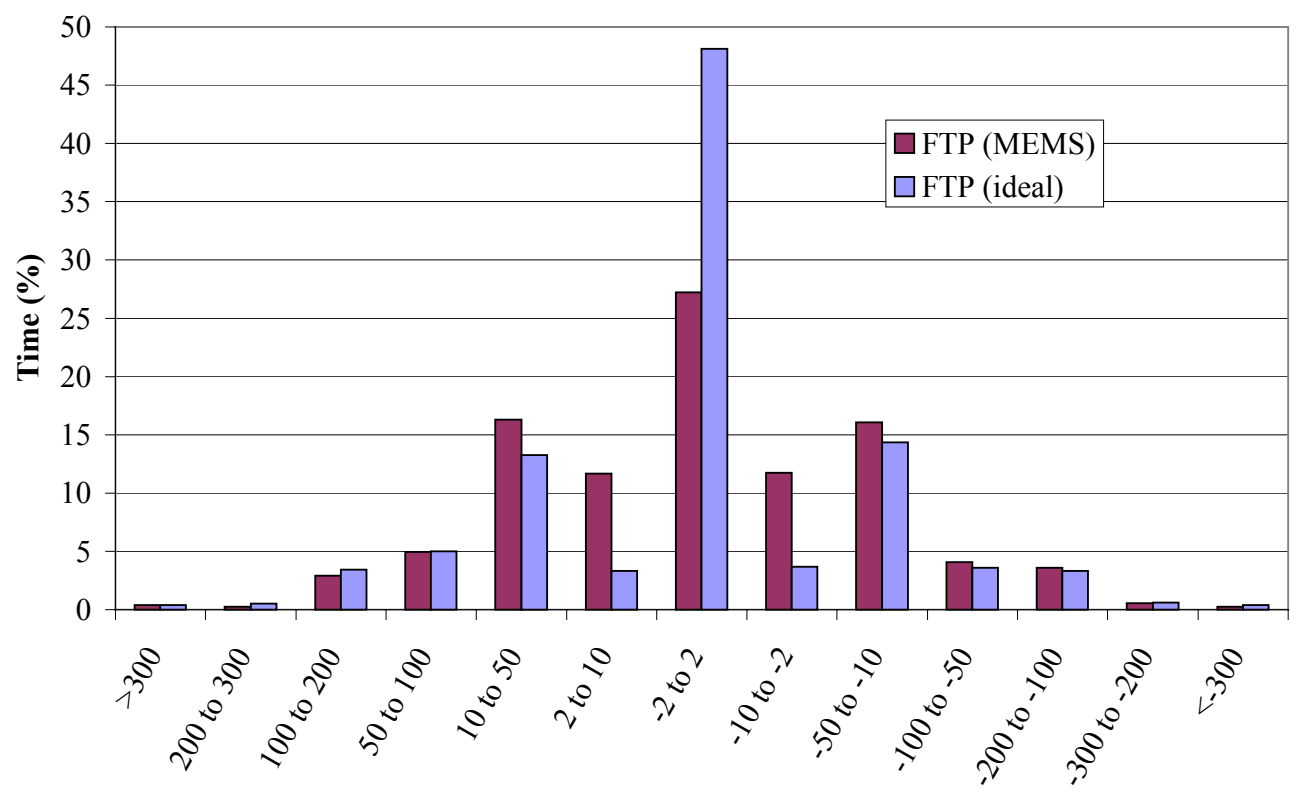

Rate of Change in Speed (rpm/s)

Figure 59: Rate of change of engine speed for actual and ideal engines over the FTP

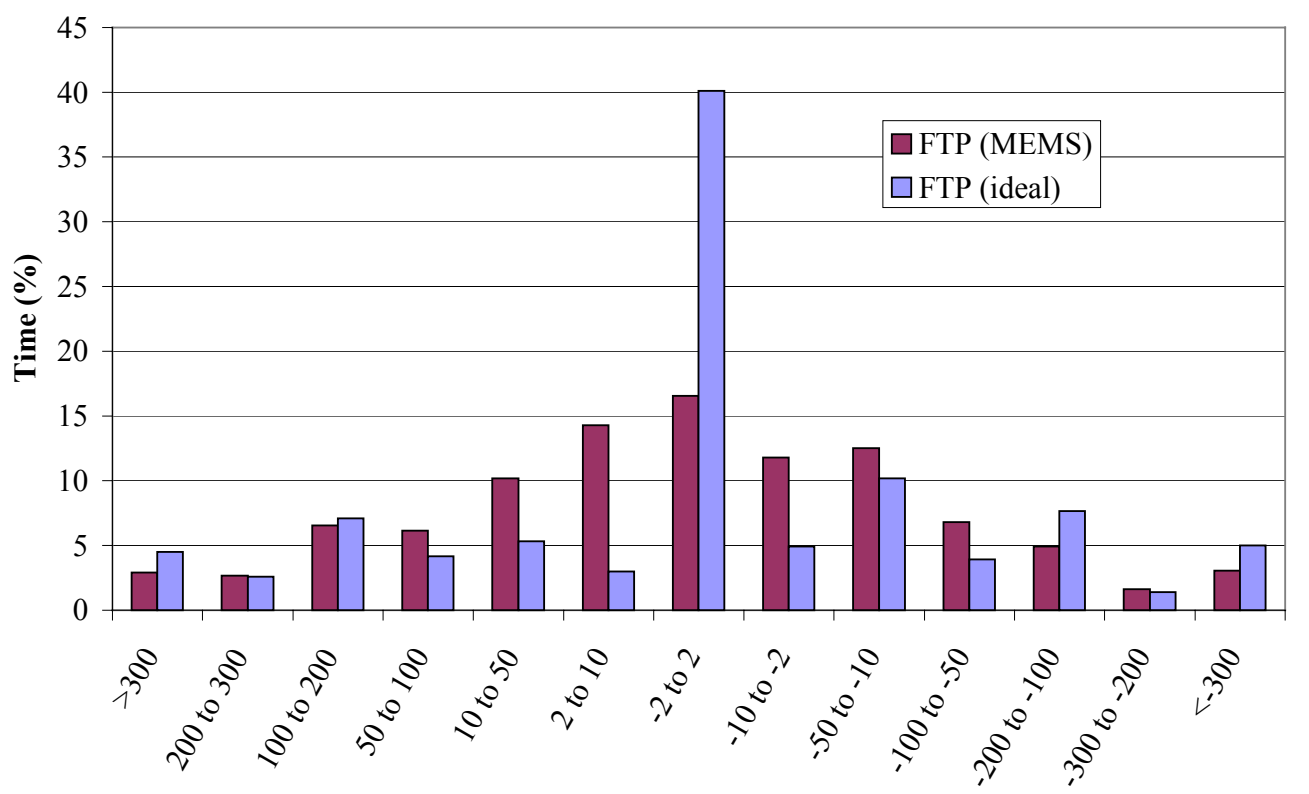

Rate of Change in Torque (ft-lb/s)

Figure 60: Rate of change of engine torque for actual and ideal engines over the FTP 


\subsection{Methodology for FTP/On-Road Route Comparison}

There are several key differences between the on-road routes and the federal test procedure. On-road data were reduced using the manufacturers' supplied lug curves, while in-cell testing data were reduced using a tested lug curve. The manufacturersupplied curve most likely was less accurate than a tested curve due to engine wear, fuel variations, ambient conditions, and/or other uncontrollable parameters such as multiple engine maps. For in-cell testing, a lug curve was made for each engine tested. This allowed for a much more accurate inference of torque and power [23]. The use of different lug curves most likely increased differences between the in-cell FTP and onroad routes. Both FTP and on-road route data were examined at $5 \mathrm{~Hz}$. The previous discretization for the repeatability study no longer applies.

To analyze properly the correlation between the FTP and on-road routes, the previously discussed multidimensional comparison was no longer possible. Visual comparison of torque and load set points give one an idea of how well the on-road cycle represents the FTP, as seen in Figure 61. One can see that there were several areas where the FTP did not operate, but the on-road cycle did. This visual comparison does not statistically represent the amount of time spent in each area, and therefore a better comparison was necessary.

An examination of torque distribution and speed distribution quantify differences of the FTP from on-road routes. These show how much time the route or FTP were at a given speed or load. The torque and speed distribution was averaged for a given vehicle on each route. Examples of these can be seen for MEMS \#8 over Sab2BM in Figure 62 and Figure 63. One can see that the on-road vehicle spent a large amount of time at full load and no load, as opposed to the FTP, which had engine load distribution spread out much more evenly. The engine operated at higher speeds (above 100\%) and spent far less time at $0 \%$ speed on-road than for the FTP.

A more comprehensive analysis was conducted using bubble charts that show the time spent at each speed/load point as seen in Figure 64. When the engine was operated over the FTP, it spent far more time at idle than it did when operated over on-road routes. Also the high-load, high-speed operation is reiterated with this presentation. The large 
FTP bubble represents idle and has been offset so that the respective on-road route bubble can be displayed.

An analysis of engine dynamics further contrasted the differences between onroad routes and the FTP. In Figure 65 and Figure 66 one can see the rate of change in speed and the rate of change in torque for the FTP and the Sab2BM route. One can see that these parameters differ significantly from the on-road route and the FTP. The onroad route had more steady-state torque operation and less steady-state speed operation than the FTP. It is interesting to note that the on-road route had more operation at the rate of change of torque and speed extremes than did the FTP.

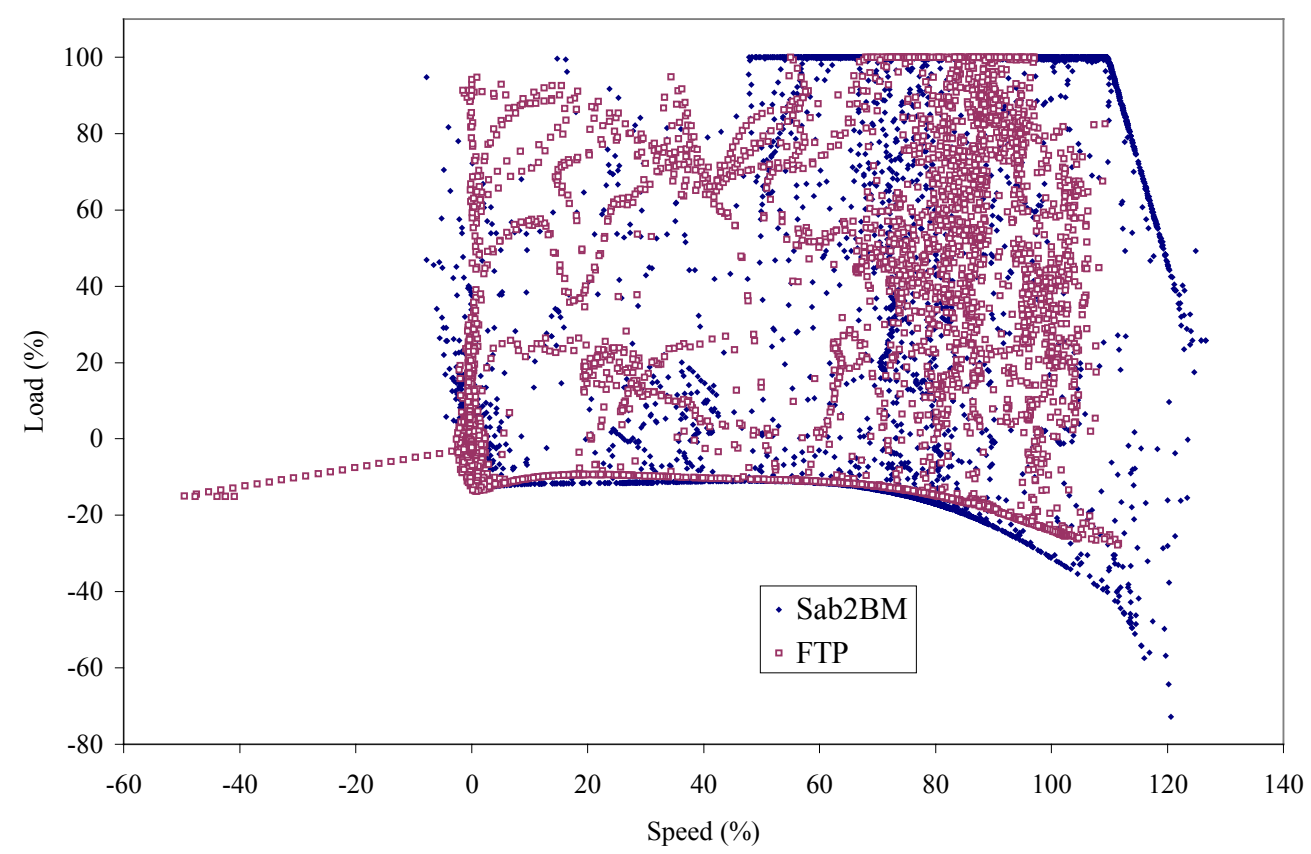

Figure 61: Speed and load for the FTP and Run 1 of Sab2SW for MEMS \#8 


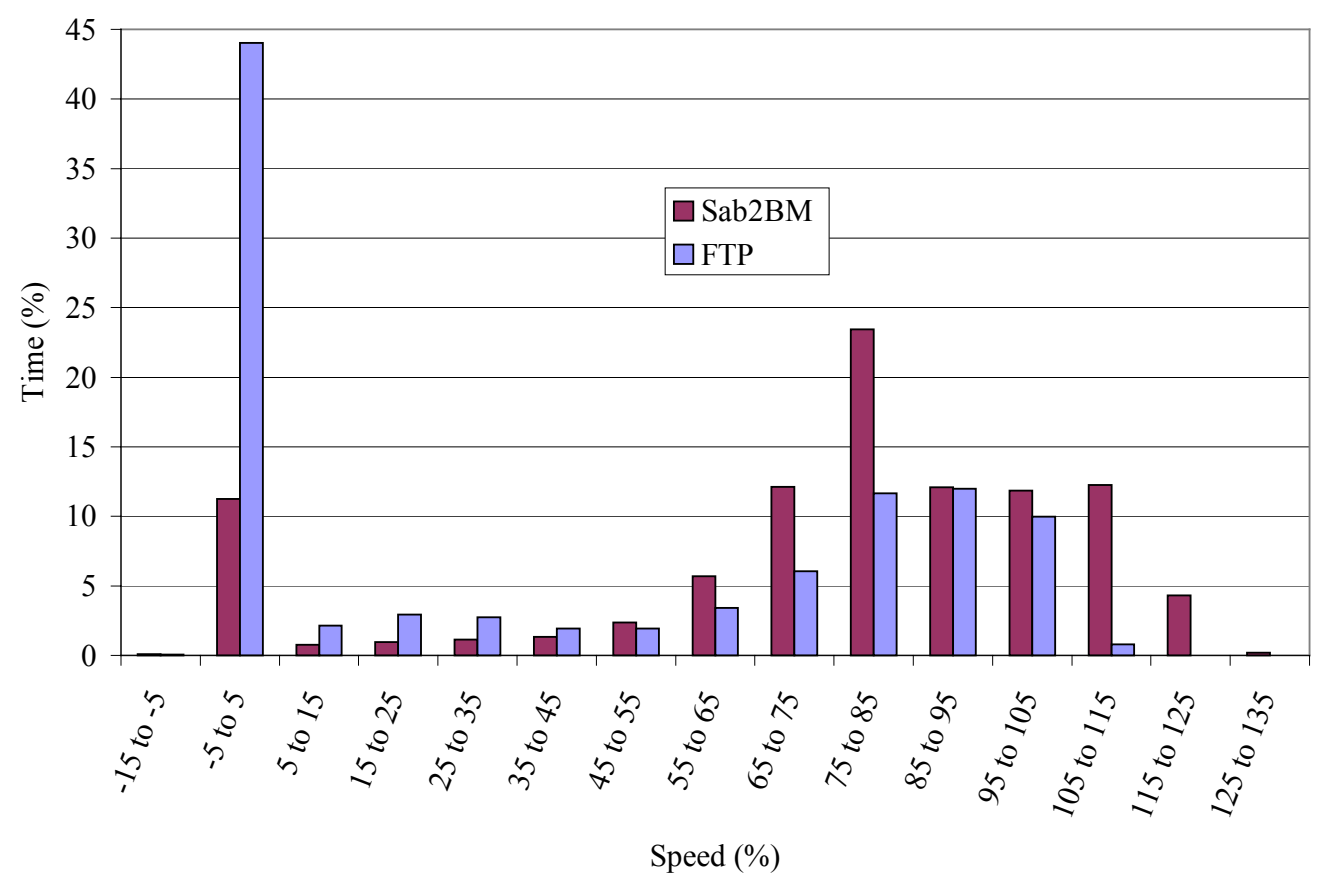

Figure 62: Percent engine speed distribution for Sab2BM and the FTP for MEMS \#8

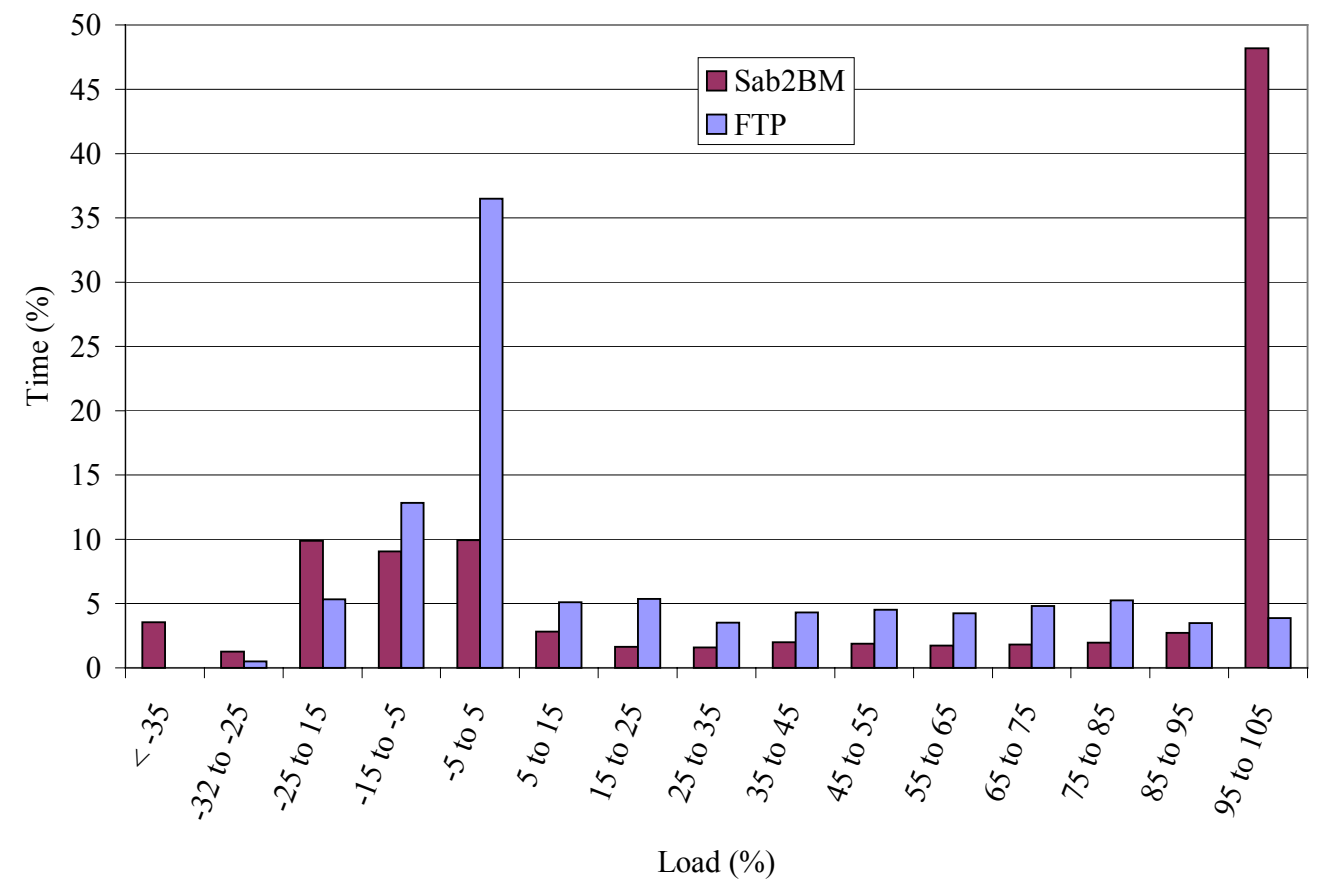

Figure 63: Percent engine torque distribution for Sab2BM and the FTP for MEMS \#8 


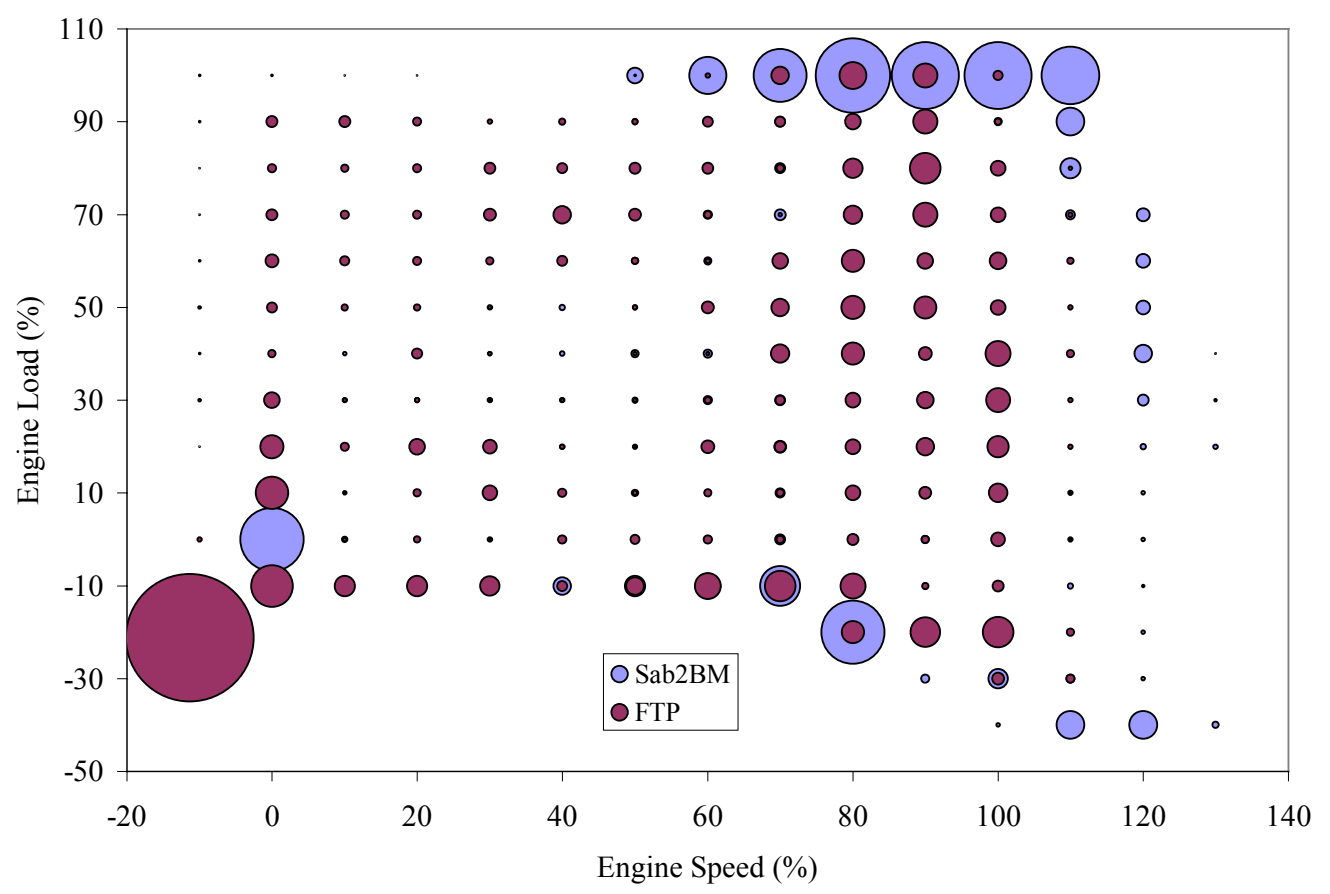

Figure 64: Bubble chart of speed and load distribution for Sab2BM and the FTP for MEMS \#8

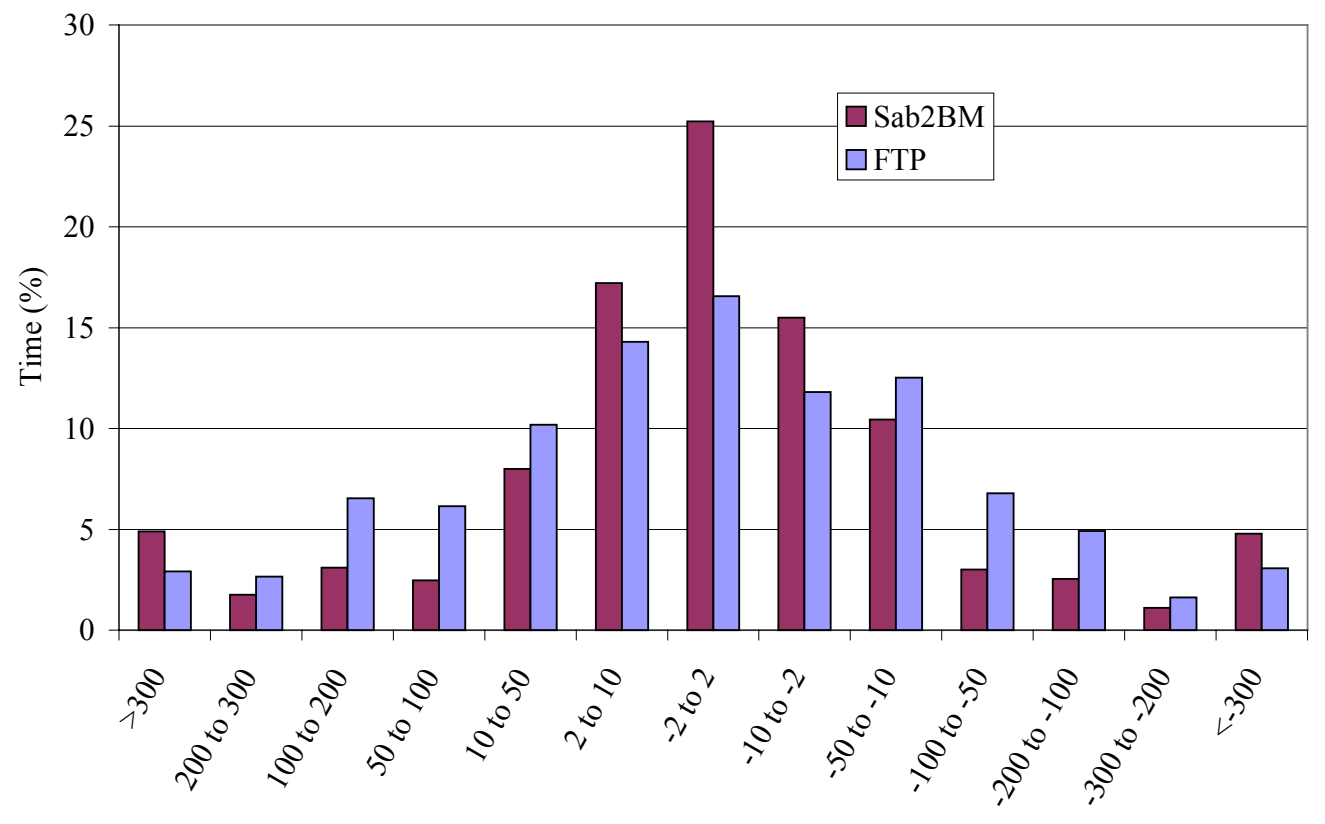

Rate of Change in Torque (ft-lb/s)

Figure 65: Rate of Change in torque distribution for Sab2BM and FTP for MEMS \#8 


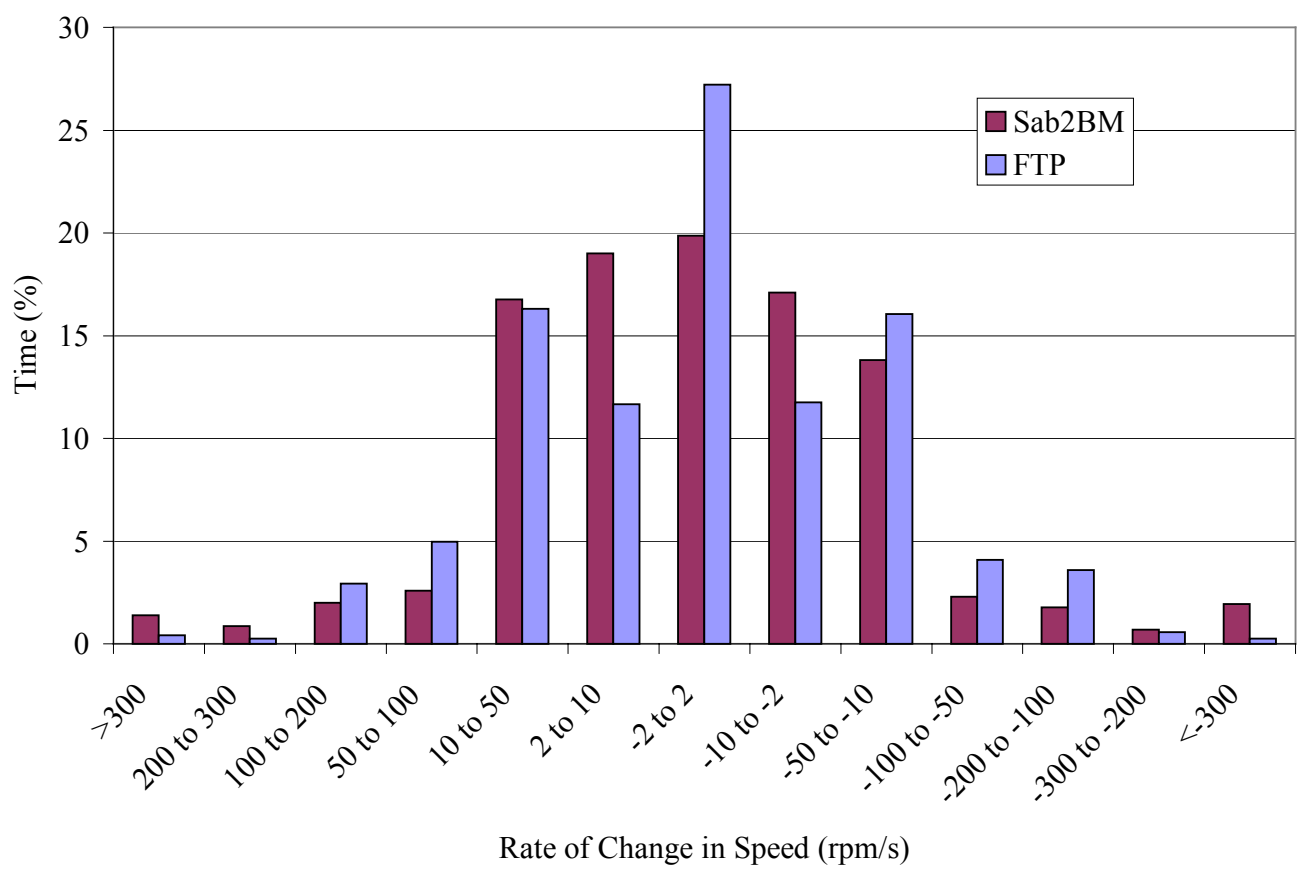

Figure 66: Rate of change in engine speed distribution for MEMS \#8 over Sab2BM and the FTP

Furthermore, a "degree of variation" was defined to give one an idea to what extent the on-road route varied from the FTP. To calculate this, the difference was found between the on-road engine behavior and the FTP engine behavior for each bubble on Figure 64 and each bar on Figure 62, Figure 63, Figure 65, and Figure 66. The variance of the differences was found for each group. The variance of the difference for speed distribution was 101.22, for torque distribution 198.59, for combined speed and torque distribution 6.5, for rate of change of torque distribution 13.29, and for rate of change of speed 13.30. The average of the variances was 66.52. The higher the value, the less the route was representative of the FTP.

Because variance is a function of the square of a value, the degree of variation can be large if several bins contain relatively large values. To put these values in perspective, the degree of variation was found between the MEMS \#8 FTP and MEMS \#12 FTP from MEMS data. These are shown in Table 43. Results for the study are summarized for all routes after both vehicles were averaged in Table 44 .

Before these values can be analyzed, a brief description of the values was necessary. The bins varied in size and were selected so that both large and small engine 
behavior fluctuations were recognized. If the route operated close to the edge of one of these bins and the FTP operated in the neighboring bin, the two could be exhibiting very similar behavior yet show very different results. This may occur during on-road testing if accessory loading was heavy during idle. The engine may be loaded enough that the operation were recorded in a different bin, making similar operation appear quite different. This problem is typical with discretization.

Combined torque and speed distribution used a two-dimensional plot with bins, at each $10 \%$ torque and speed increment. This produced 225 bins, some of which contained no actual engine operation. This caused many values to have zero difference between the FTP value and on-road route value. This in turn reduced the overall variance for the comparison. The other four parameters that were considered had far fewer bins, allowing one extreme operating point to have greater effect on the final variance. The speed distribution and torque distribution had 15 bins each, and the rate of change in speed and rate of change in torque had 13 bins each.

Table 43: Variances between MEMS \#8 and MEMS \#12 for each examined parameter

\begin{tabular}{|l|l|}
\hline Torque Dist. & 5.99 \\
\hline Speed Dist. & 0.05 \\
\hline Torq. \& Speed Dist. & 0.20 \\
\hline Change Torque Dist. & 8.26 \\
\hline Change Speed Dist. & 1.47 \\
\hline Average & 3.20 \\
\hline
\end{tabular}

Table 44: Degree of variation for all routes

\begin{tabular}{|l|c|c|c|c|c|c|c|}
\cline { 2 - 8 } \multicolumn{1}{c|}{} & Sab2BM & BM2Sab & Sab2SW & SW2Sab & PA1 & PA2 & PA3 \\
\hline Torque Dist. & 165 & 143 & 151 & 163 & 70.8 & 45.2 & 168 \\
\hline Speed Dist. & 101 & 103 & 98.2 & 126 & 71.5 & 49.2 & 181 \\
\hline Torq. \& Speed Dist. & 5.33 & 5.17 & 4.34 & 5.30 & 2.72 & 1.76 & 6.51 \\
\hline Change Torque Dist. & 14.2 & 15.3 & 11.3 & 11.5 & 16.1 & 22.4 & 26.4 \\
\hline Change Speed Dist. & 19.0 & 14.3 & 22.5 & 27.3 & 15.0 & 9.23 & 30.9 \\
\hline Average & 61.0 & 56.1 & 57.5 & 66.6 & 35.2 & 25.6 & 82.6 \\
\hline
\end{tabular}

\subsection{Routes and the FTP}

The degree of variation for all the examined parameters and for each route and vehicle can be seen in Table 45, Table 46, Table 46, Table 47, Table 48, Table 49, Table 50, and Table 51. Numbers presented in bold are less than one standard deviation below 
the average value and numbers presented in italics are greater than one standard deviation above the average value. One can see that wide differences existed for each parameter and each route. This was to be expected because of the more transient nature of the FTP when compared to MEMS on-road routes. All MEMS routes had extensive regions of operation at full load, primarily resulting from vehicle acceleration and hills, whereas the FTP has very little.

Table 45: FTP and Sab2BM comparison

\begin{tabular}{|l|c|c|c|}
\cline { 2 - 4 } \multicolumn{1}{c|}{} & MEMS \#8 & MEMS \#12 & Average \\
\hline Torque Dist. & 199 & 132 & 165 \\
\hline Speed Dist. & 101 & 101 & 101 \\
\hline Torq. \& Speed Dist. & 6.18 & 4.48 & 5.33 \\
\hline Change Torque Dist. & 13.3 & 15.1 & 14.2 \\
\hline Change Speed Dist. & 13.3 & 24.8 & 19.0 \\
\hline Average & 66.5 & 55.5 & 61.0 \\
\hline
\end{tabular}

Table 46: FTP and BM2Sab comparison

\begin{tabular}{|l|c|c|c|}
\cline { 2 - 4 } \multicolumn{1}{c|}{} & MEMS \#8 & MEMS \#12 & Average \\
\hline Torque Dist. & 122 & 163 & 143 \\
\hline Speed Dist. & 99 & 107 & 103 \\
\hline Torq. \& Speed Dist. & 5.63 & 4.71 & 5.17 \\
\hline Change Torque Dist. & $\mathbf{7 . 1}$ & 23.5 & 15.3 \\
\hline Change Speed Dist. & 14.8 & 13.7 & 14.3 \\
\hline Average & 49.7 & 62.5 & 56.1 \\
\hline
\end{tabular}

Table 47: FTP and Sab2SW comparison

\begin{tabular}{|l|c|c|c|}
\cline { 2 - 4 } \multicolumn{1}{c|}{} & MEMS \#8 & MEMS \#12 & Average \\
\hline Torque Dist. & 170 & 132 & 151 \\
\hline Speed Dist. & 95.1 & 101 & 98 \\
\hline Torq. \& Speed Dist. & 4.20 & 4.48 & 4.34 \\
\hline Change Torque Dist. & $\mathbf{7 . 5}$ & 15.1 & 11.3 \\
\hline Change Speed Dist. & 20.1 & 24.8 & 22.5 \\
\hline Average & 59.5 & 55.5 & 57.5 \\
\hline
\end{tabular}


Table 48: FTP and SW2Sab comparison

\begin{tabular}{|l|c|c|c|}
\cline { 2 - 4 } \multicolumn{1}{c|}{} & MEMS \#8 & MEMS \#12 & Average \\
\hline Torque Dist. & 146 & 180 & 163 \\
\hline Speed Dist. & 117 & 135 & 126 \\
\hline Torq. \& Speed Dist. & 4.82 & 5.78 & 5.30 \\
\hline Change Torque Dist. & $\mathbf{5 . 3}$ & 17.6 & 11.5 \\
\hline Change Speed Dist. & 27.4 & 27.1 & 27.3 \\
\hline Average & 60.1 & 73.1 & 66.6 \\
\hline
\end{tabular}

Table 49: FTP and PA1 comparison

\begin{tabular}{|l|c|c|c|}
\cline { 2 - 4 } \multicolumn{1}{c|}{} & MEMS \#8 & MEMS \#12 & Average \\
\hline Torque Dist. & 77.3 & $\mathbf{6 4 . 3}$ & 70.8 \\
\hline Speed Dist. & 72.6 & 70.4 & 71.5 \\
\hline Torq. \& Speed Dist. & 2.90 & $\mathbf{2 . 5 3}$ & $\mathbf{2 . 7 2}$ \\
\hline Change Torque Dist. & 16.9 & 15.4 & 16.1 \\
\hline Change Speed Dist. & 12.5 & 17.4 & 15.0 \\
\hline Average & 36.4 & $\mathbf{3 4 . 0}$ & 35.2 \\
\hline
\end{tabular}

Table 50: FTP and PA2 comparison

\begin{tabular}{|l|c|c|c|}
\cline { 2 - 4 } \multicolumn{1}{c|}{} & MEMS \#8 & MEMS \#12 & Average \\
\hline Torque Dist. & $\mathbf{4 4 . 2}$ & $\mathbf{4 6 . 2}$ & $\mathbf{4 5 . 2}$ \\
\hline Speed Dist. & $\mathbf{4 7 . 0}$ & $\mathbf{5 1 . 5}$ & $\mathbf{4 9 . 2}$ \\
\hline Torq. \& Speed Dist. & $\mathbf{1 . 6 0}$ & $\mathbf{1 . 9 1}$ & $\mathbf{1 . 7 6}$ \\
\hline Change Torque Dist. & $\mathbf{3 1 . 1}$ & 13.7 & 22.4 \\
\hline Change Speed Dist. & $\mathbf{3 . 8 8}$ & 14.6 & $\mathbf{9 . 2 3}$ \\
\hline Average & 25.6 & 25.6 & 25.6 \\
\hline
\end{tabular}

Table 51: FTP and PA3 comparison

\begin{tabular}{|l|c|c|c|}
\cline { 2 - 4 } \multicolumn{1}{c|}{} & MEMS \#8 & MEMS \#12 & Average \\
\hline Torque Dist. & 192 & 144 & 168 \\
\hline Speed Dist. & 197 & 165 & 181 \\
\hline Torq. \& Speed Dist. & 6.72 & 6.30 & 6.51 \\
\hline Change Torque Dist. & 26.0 & 26.7 & 26.4 \\
\hline Change Speed Dist. & 32.5 & 29.3 & 30.9 \\
\hline Average & 91.0 & 74.2 & 82.6 \\
\hline
\end{tabular}

The differences between the on-road routes and the FTP can be seen through an examination of a few key factors. The CFR defined FTP idles 36.5\% of the time, 
operates above $95 \%$ load $2.9 \%$ of the time, and operates over $105 \%$ engine speed $0.9 \%$ of the time. The tested FTP was fairly close to these values, but not exactly.

The on-road routes differed substantially as seen in Table 52, Table 53, and Table 54. MEMS on-road routes contained far less time at idle and far more time at high-load operation. Also vehicles driven on MEMS routes were often operated at much higher engine speeds than common on the FTP. This behavior caused the routes to vary from the FTP. The routes that exhibited behavior that matched the FTP the closest were also those that had the lowest degree of variation for the above analysis.

Table 52: Percent idle time for on-road routes and the FTP

\begin{tabular}{|l|c|c|}
\cline { 2 - 3 } \multicolumn{1}{c|}{} & MEMS \#8 & MEMS \#12 \\
\hline Sab2BM & 8.61 & 12.1 \\
\hline BM2Sab & 7.88 & 10.4 \\
\hline Sab2SW & 10.9 & 9.85 \\
\hline SW2Sab & 7.19 & 5.46 \\
\hline PA1 & 13.4 & 15.7 \\
\hline PA2 & 20.3 & 18.2 \\
\hline PA3 & 2.10 & 2.06 \\
\hline \hline Average & 10.1 & 10.5 \\
\hline Tested FTP & 34.7 & 35.1 \\
\hline Defined FTP & 36.5 & 36.5 \\
\hline
\end{tabular}

Table 53: Percent time spent at greater than $95 \%$ load for on-road routes and the FTP

\begin{tabular}{|l|c|c|}
\cline { 2 - 3 } \multicolumn{1}{c|}{} & MEMS \#8 & MEMS \#12 \\
\hline Sab2BM & 48.2 & 52.3 \\
\hline BM2Sab & 30.1 & 36.8 \\
\hline Sab2SW & 45.0 & 32.5 \\
\hline SW2Sab & 38.4 & 38.4 \\
\hline PA1 & 26.3 & 17.1 \\
\hline PA2 & 22.2 & 13.9 \\
\hline PA3 & 43.9 & 32.6 \\
\hline \hline Average & 36.3 & 31.9 \\
\hline Tested FTP & 3.87 & 2.96 \\
\hline Defined FTP & 2.92 & 2.92 \\
\hline
\end{tabular}


Table 54: Percent time spent over $105 \%$ engine speed for on-road routes and the FTP

\begin{tabular}{|l|c|c|}
\cline { 2 - 3 } \multicolumn{1}{c|}{} & MEMS \#8 & MEMS \#12 \\
\hline Sab2BM & 16.8 & 30.2 \\
\hline BM2Sab & 23.2 & 27.4 \\
\hline Sab2SW & 16.9 & 10.6 \\
\hline SW2Sab & 18.4 & 9.93 \\
\hline PA1 & 6.57 & 17.6 \\
\hline PA2 & 4.48 & 12.7 \\
\hline PA3 & 1.51 & 5.73 \\
\hline \hline Average & 12.6 & 16.3 \\
\hline Tested FTP & 0.80 & 0.72 \\
\hline Defined FTP & 0.92 & 0.92 \\
\hline
\end{tabular}

Even though the engine tested over the FTP operated for considerable portions of the test at conditions where the engine on the on-road routes operated less, an examination of the bubble charts like the one in Figure 64 revealed that the FTP, for the most part, covered the same engine operating ranges as the on-road routes. Yet, the onroad routes differed by often operating at higher engine speeds. The maximum engine speed set by the CFR-defined FTP was 111.9\% [3]. The MEMS \#8 engine would begin to reduce fueling $110 \%$ but would continue to fuel until 127\%. The MEMS \#12 engine would start to cut fueling at $126 \%$ and would continue to fuel until $129 \%$. MEMS \#12 was operated at higher engine speeds more often because the engine could operate at full load in this range. This allowed for much higher operating ranges than tested on the FTP.

The FTP as examined using MEMS data at $5 \mathrm{~Hz}$ contained a few areas with no operation in the middle of the operating range. For example, the MEMS \#8 FTP never operated at $40 \%$ speed and $50 \%$ torque. MEMS \#8 operated in this bin for PA2 for $0.16 \%$, but some other routes never operated at this point. The MEMS \#12 FTP never operated at $40 \%$ speed and $40 \%$ torque, but every on-road route did.

The FTP also operated at low-speed and high-load, a region where only a few of the on-routes operated consistently. PA2 operated in this region the most, which was most likely a reflection of stop and go driving where low-speed, high-load was necessary for launching the vehicle. For MEMS \#12, there were no bins in which no on-road route operated but the FTP did. For MEMS \#8 the FTP operated at an engine speed of $-10 \%$ 
for a total of $0.08 \%$ of the time where the on-road routes never operated. This amount of time was considered insignificant to affect any emissions results. 


\section{Conclusions and Recommendations}

\subsection{Route Repeatability}

A study was conducted to examine the repeatability of on-road routes for emissions testing of heavy-duty diesel vehicles. Repeatability was examined for each vehicle over all tested routes using a revised form of linear regression in multiple dimensions. Factors that influence repeatability were examined, including vehicle, route, driver, and methodology with reference to the parameter examined.

The vehicle had little influence on repeatability. There appears to be no direct correlation for number of gears and repeatability, unless the two automatic transmission vehicles are not considered. MEMS \#8 and \#12 had unsynchronized 10 and 18 speed manual transmissions, respectively, which presented the correlation that the more gears the lower the repeatability. Other conditions could have also caused this result, such as power to weight ratio or driver behavior. MEMS \#12 was more powerful than MEMS \#8 suggesting that the lower power to weight ratio increased repeatability. This theory was supported by the high repeatability of the Sab2BM route where extensive full power operation appeared to increase repeatability as discussed below. There appeared to be no real difference between repeatability based on transmission type or GVWR.

The route on which the vehicle was tested significantly influenced repeatability. Routes with extensive urban driving, such as PA1, exhibited the lowest repeatability. As the amount of highway-like driving increased, the route become more repeatable as seen with PA3, Sab2SW, and SW2Sab. The greatest repeatability stemmed from routes with extensive hill climbs that required periods of full torque operation, such as Sab2BM and BM2Sab.

Repeatability was affected by individual drivers and between different drivers. When examining MEMS \#8, repeatability for the first three repeat runs was noticeably better than a repeatability analysis that included the forth run, where a different driver

operated the vehicle, suggesting that changing drivers reduced repeatability. The testing of MEMS \#12 on BM2Sab supported this. Here two different drivers each completed two separate runs and both drivers had higher repeatability individually than combined. MEMS \#10 was tested while following MEMS \#11 for a significant portion of the tests. 
MEMS \#10 exhibited significantly lower repeatability than MEMS \#11, suggesting that either the driver of MEMS \#10 or the test method of one vehicle following another reduced repeatability.

The strongest variance in repeatability was in the parameter examined. Torque and power consistently exhibited the lowest repeatability while vehicle speed, time, and gear exhibited the highest repeatability. The low repeatability of torque and power resulted from sudden, severe fluctuations of the respective parameter. If a driver shifted at a given location during the first run and on the second run shifted fifty yards past the given location, then the methodology analyzed the behavior as grossly different while in actuality it was quite consistent. This may cause vehicle speed, time, and even gear to appear repeatable during shifts, while torque and power fluctuated greatly. Engine speed may fluctuate, but not nearly as extensively as torque and power. This resulted from the nature of instantaneous analysis. An integrated analysis may have eliminated some of these problems but this poses new problems as discussed later.

To better understand the factors influencing the repeatability of a vehicle, route, or driver, one would need to study a larger sample. For this thesis, four vehicles were examined over four routes that included eight separate legs. It was difficult to establish which factors were influencing repeatability. One cannot be certain if the driver of MEMS \#10 caused lower repeatability or if the test method of one vehicle following the other was to blame. Also, it was impossible to establish with certainty if the difference of power to weight ratio, the difference in the number of gears, and/or the driver affected the difference of repeatability between MEMS \#8 and \#12. One cannot establish with certainty if manual or automatic transmissions showed higher or lower repeatability. All of these factors could only be known by extensively examining a larger database of onroad route tests. It would also be beneficial to examine vehicles with higher power-toweight ratios. These would have less binary-like engine operation most likely affecting repeatability.

Different methodology may improve the understanding of repeatability. As previously discussed, the methodology failed to account for behavior exhibited by a vehicle during Run 1, that occurred at a similar, but not exact location over Run 2. An examination could be conducted where every data point of Run 1 is compared to the 
closest data point of Run 2. This would allow an event such as an instantaneous drop in power during Run 1 to be compared to a similar event a small distance apart in Run 2 instead of behavior exhibited at that set distance. Yet new problems arise. The values must be weighted somehow for the parameter and the distance. An initial thought would be to make the values dimensionless. This would make a one-mile distance between the two runs change weighting based on route length, which may or may not be ideal. Other questions arise such as, would each and every point of Run 1 have to have an error calculated with respect to a separate point in Run 2, or could the error for several points in Run 1 be compared to the same point in Run 2? Also, each point of a run would have to be compared to all other points of all runs at each distance interval, which is a time and processor-intensive task. A different methodology that accounts for similar behavior at different distances would require extensive definitions.

Integrated routes would account for similar behavior a small distance apart on repeated runs. An examination of coefficient of repeatability for integrated routes revealed that early behavior had a much greater influence on overall repeatability than late behavior. This method may work for the average of COV\% or other methodology. Integrated data would create new problems when considering aftertreatment, which will most likely be found on diesel trucks in the future. Most aftertreatment devices use temperature-dependent catalysts that require hot exhaust gas to reach "light off" temperature. The order of engine behavior could have a significant effect on emissions. Engine operation that would heat the catalyst shortly after a cold start could reduce net emissions compared to a similar operation that failed to heat the catalyst. Integrated engine operating data would notice less of a difference from early or late behavior that caused the catalyst to reach light off temperature.

It is likely that further examinations of route repeatability will be conducted. As on-road tests become more common, the need for understanding the consistency of repeated test increases. The comparison of new engine technologies over on-road routes would require a form of validation for researchers. This study and methodology may aide these analyses. 


\subsection{Comparison of On-Road Routes to the FTP}

A comparison between on-road routes and the FTP was conducted. Examinations were made for engine speed distribution, engine torque distribution, combined engine speed and torque distribution, rate-of-change in engine speed distribution, and rate of change in engine torque distribution where each parameter was binned. To evaluate the difference between the binned values of the on-road route and the FTP, the variance of the difference was found for each examination. The on-road routes were compared to the MEMS FTP data as tested and not to the actual CFR-defined FTP data in order to minimize variables.

A visual comparison of the bins showed that the FTP was significantly different from the MEMS on-road routes in speed and torque distribution. When compared to the MEMS on-road routes, the FTP consistently over-represented idle and underrepresented higher engine speeds. For the MEMS routes, the vehicle only idled at traffic stops or at the start and end of each run; the idle of the FTP is probably more representative of a delivery truck that makes periodic stops for extended periods of time. The FTP also distributed load over broad operating ranges while the on-road routes had a large portion of their operation at no-load or full-load.

Moreover, MEMS on-road routes were designed to have little idle and extensive operation in the NTE zone, causing the routes to differ from the FTP. Using the methodology as previously described, routes with extensive highway driving varied the most from the FTP. For all routes, the on-road behavior consistently had higher engine speed operation and more full load operation than the FTP. PA3 had the greatest difference from the FTP. PA3 operated at full load almost $45 \%$ of the time while the FTP operated at full load for less than 5\% of the time. PA2 was most like the FTP. PA2 had more idle time and less full load operation than other MEMS routes and had the closest rate of change in speed and rate of change in torque correlation to the FTP. PA1 had slightly lower correlation to the FTP than PA2 but was next closest. BM2Sab, Sab2SW, Sab2BM, and SW2Sab were about equally well correlated, but much less so than PA1.

Improvements can be made with the FTP and on-road route comparison. The separate torque distribution and speed distribution could be eliminated, with the combined torque and speed distribution accounting for this behavior. The combined 
torque and speed distribution could also be weighted in the comparison to other examined parameters so that it has more overall effect on the final rating. Further improvements could include using the same lug curve for FTP and on-road data. Also, a larger database of on-road route data could be compared to the FTP to support or dispute the findings presented herein.

Again, the use of aftertreatment would not be represented in this analysis. For temperature-dependent aftertreatment, the order of engine behavior would have a net effect on emissions results. This analysis did not examine if any behavior that would heat a catalyst to light-off temperature occurred early or late for either the FTP or the on-road routes.

The comparison of on-road routes to the FTP can increase the understanding of some current emissions models. The coefficient of variation as defined herein can only provide a rough comparison of between on-road behavior and FTP testing. As on-road emissions testing becomes more commonplace, the possibility that emissions certification will occur on-road becomes more feasible. This may eliminate the need for comparing on-road engine behavior to the FTP, but currently, the knowledge will increase our understanding of emissions. 


\section{References}

1. Lloyd, A. C. and Cackette, T. A., "Diesel Engines: Environmental Impact and Control," Journal of the Air \& Waste Management Association, June 2001, Vol. 51, pp 809-847, Pittsburgh, PA, 2001.

2. U.S. Environmental Protection Agency, "Health Assessment Document for Diesel Engine Exhaust," Prepared by the National Center for Environmental Assessment, for the Office of Transportation and Air Quality; EPA/600/8-90/057F, Washington, DC, May 2002.

3. "Code of Federal Regulations," CFR 40, Part 86, Office of the Federal Register National Archives and Records Administration, Washington, DC, 1998.

4. Air Resources Board, "Changes in California's EMFAC Vehicle Emissions Model," Hypertext 7 January 2003, < http://www.arb.ca.gov/planning/sip/emfac2002/encl_a.pdf $>$ Sacramento, California, 2002.

5. Nine, R. D., Clark, N. N., Daley, J. J., and Atkinson, C. M., "Development of a Heavy-Duty Chassis Dynamometer Driving Route," Proceedings of the Institution Mechanical Engineers, Volume 213, Part D, pp 561-574, London, England, 1999.

6. Gautam, M., Clark, N. N., Thompson, G. J., Carder, D. K., and Lyons, D. W., "Evaluation of Mobile Monitoring Technologies for Heavy-Duty Diesel-Powered Vehicle Emissions," Phase I Report, Submitted to the Settling Heavy-Duty Diesel Engine Manufacturers by West Virginia University, Morgantown, WV, March, 2000.

7. Gautam, M., Clark, N. N., Thompson, G. J., Carder, D. K., and Lyons, D. W., "Development of In-Use Procedures for Heavy-Duty Diesel Powered Vehicle Emissions," Phase II Report, Submitted to the Settling Heavy-Duty Diesel Engine Manufacturers by West Virginia University, Morgantown, WV, March, 2000.

8. Gautam, M., Clark, N. N., Thompson, G. J., Carder, D. K., Riddle, W. C., and Lyons, D. W., "Evaluation of In-Use Heavy-Duty Vehicle Emissions Using the Mobile Emissions Measurement System (MEMS)," Phase III Report, Submitted to the Settling Heavy-Duty Diesel Engine Manufacturers by West Virginia University, Morgantown, WV, December, 2002.

9. "Notice of Filing of Consent Decree Under the Clean Air Act," Federal Register, Vol. 63, No. 212, Office of the Federal Register, National Archives and Records Administration, Washington DC, November 3, 1998.

10. Ecopoint Inc., "Emissions Standards: USA; Heavy-Duty Truck and Bus Engines," Hypertext 7 July 2003, < http://www.dieselnet.com/standards/us/hd.html\#pre04 > Bramalea, ON, Canada, 2003. 
11. Shundoh, S., Komori, M., Tsujimura, K., and Kobayashi, S., "NO Reduction from Diesel Combustion Using Pilot Injection with High Pressure Fuel Injection," SAE Paper 920461, SAE International, Warrendale, PA, 1992.

12. Kern, J. M., Inventory and Prediction of Heavy-Duty Diesel Vehicle Emissions, M.S. Thesis, Department of Mechanical and Aerospace Engineering, West Virginia University, Morgantown, WV, 2000.

13. Weaver, C. S. and Balam-Almanza, M. V., "Development of the 'RAVEM' RideAlong Vehicle Emission Measurement System for Gaseous and Particulate Emissions," SAE Paper No. 2001-01-3644, SAE International, Warrendale, PA, 2001.

14. Gibble, J. C., Comparison of Heavy-Duty Diesel Engine Emissions Between an OnRoad Route and Engine Dynamometer Simulated On-Road Cycle, M.S. Thesis, Department of Mechanical and Aerospace Engineering, West Virginia University, Morgantown, WV, 2000.

15. Hawirko, J. D. and Checkel, M. D., "Quantifying Vehicle Emission Factors for Various Ambient Conditions using an On-Road, Real-Time Emissions System," SAE Paper 2003-01-0301, SAE International, Warrendale, PA, 2003.

16. Hawirko, J. D. and Checkel, M. D., "Real-Time, On-Road Measurement of Driving Behavior, Engine Parameters and Exhaust Emissions," SAE Paper 2002-01-1714, SAE International, Warrendale, PA, 2002.

17. Kihara, N., Tsukamoto, T., Matsumoto, K., Ishida, K., Kon, M., and Murase, T., "Real-time On-board Measurement of Mass Emissions of NOx, Fuel Consumption, Road Load, and Engine Output for Diesel Vehicles," SAE Paper 2000-01-1141, SAE International, Warrendale, PA, 2000.

18. Ikonen, M., Westerholm, M., and Nylund, N., "Emission and Fuel Consumption Measurements for Transit Buses Running on Gaseous Fuels Using a Mobile Measurement System," SAE Paper 2001-01-3638, SAE International, Warrendale, PA, 2001.

19. McKain, D. L. and Clark, N. N, "Speed and Power Regressions for Quality Control of Heavy Duty Chassis Vehicle Dynamometer Research," SAE Paper 1999-01-0614, SAE International, Warrendale, PA, 1999.

20. Noguchi, S., Konishi, T., Ogawa, Y., and Ishida, K., "Evaluating the Performance of Automatic Driving System for Use on Chassis Dynamometers," SAE Paper 920253, SAE International, Warrendale, PA, 1992.

21. Traver M. L., Tennant, C. J., McDaniel, T. I., McConnell, S. S., Bailey, B. K., and Maldonado, H., "Interlaboratory Cross-Check of Heavy-Duty Vehicle Chassis Dynamometers," SAE Paper 2002-01-2879, SAE International, Warrendale, PA. 2002. 
22. Riddle, W. C., Design and Evaluation of the Emissions Measurement Components for a Heavy-Duty Diesel Powered Vehicle Mobile Emissions Measurement System (MEMS), M.S. Thesis, Department of Mechanical and Aerospace Engineering, West Virginia University, Morgantown, WV, 2001.

23. Thompson, G. J., Clark, N. N., Gautam, M., Carder, D. K., and Lyons, D. W., "Inference of Torque and Power from Heavy-Duty Diesel Engines for On-Road Emissions Monitoring," SAE Paper 2002-01-0614, SAE International, Warrendale, PA, 2002.

24. Chan, L., Carlson, D. H., and John J. H., "Evaluation and Application of a Portable Tailpipe Emissions Measurement Apparatus for Field Use," SAE Paper No. 921647, SAE International, Warrendale, PA, 1992.

25. Human, D. M. and Ullman, T. L., "Development of an I/M Short Emissions Test for Buses," SAE Paper No. 920727, SAE International, Warrendale, PA, 1992.

26. Kwon, Y., Mann, N., Rickeard, D. J., Haugland, R., Ulvund, K. A., Kvinge F., and Wilson, G., "Fuel Effects on Diesel Emissions-A New Understanding," SAE Paper 2001-01-3522, SAE International, Warrendale, PA, 2001.

27. Mann, N., Kvinge, F., and Wilson, G., "Diesel Fuel Effects on Emissions-Towards a Better Understanding," SAE Paper 982486, SAE International, Warrendale, PA, 1998.

28. Bane, B. R., A Comparison of Steady State and Transient Emissions from a HeavyDuty Diesel Engine," M.S. Thesis, Department of Mechanical and Aerospace Engineering, West Virginia University, Morgantown, WV, 2002. 


\section{Appendix A: Not-to-Exceed Zone Description}

NTE--Not-to-Exceed Control Area is defined by the consent decree [9] as:

The $15 \%$ ESC Speed is calculated using the formula $n_{10}+0.15\left(n_{h i}-\right.$ $\mathrm{n}_{\mathrm{lo}}$ ), where $\mathrm{n}_{\mathrm{lo}}$ and $\mathrm{n}_{\mathrm{hi}}$ are the low and high engine speeds defined in Annex III, Appendix 1, Section1.1 of the earlier referenced December 3, 1997 Proposal of the Commission of the European Union. (Note: $\mathrm{n}_{10}$ is the lowest engine speed where $50 \%$ of full power can be achieved. $\mathrm{n}_{\mathrm{hi}}$ is the highest speed where $70 \%$ of full power can be achieved. [3])

The area below $30 \%$ of the maximum power value produced by the engine is excluded from the Not-to-Exceed Control Area. In addition, the area defined in either (a) or (b) below, as applicable, is excluded from the Not-to-Exceed Control Area for PM

a) To the right of the line from $30 \%$ of maximum torque or $30 \%$ of maximum power (whichever is greater) at the B speed to $70 \%$ of maximum power at $100 \%$ speed $\left(\mathrm{n}_{\mathrm{hi}}\right)$ if the C speed is below $2400 \mathrm{rpm}$ (See Figure 67).

b) To the right of the line from $30 \%$ of maximum torque or $30 \%$ of maximum power (whichever is greater) at the $\mathrm{B}$ speed to $50 \%$ power at $2400 \mathrm{rpm}$ to $70 \%$ of maximum power at $100 \%$ speed (nhi) if the $\mathrm{C}$ speed is above 2400 rpm. (See Figure 68).

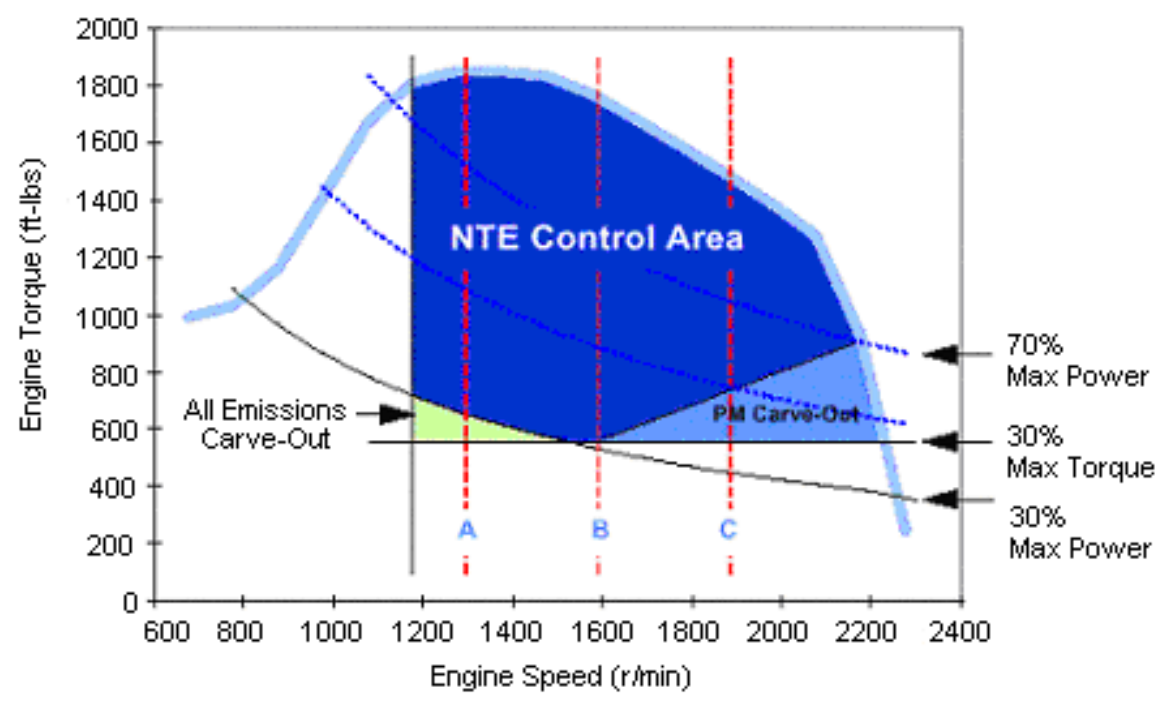

Figure 67: NTE Control Area [9] 


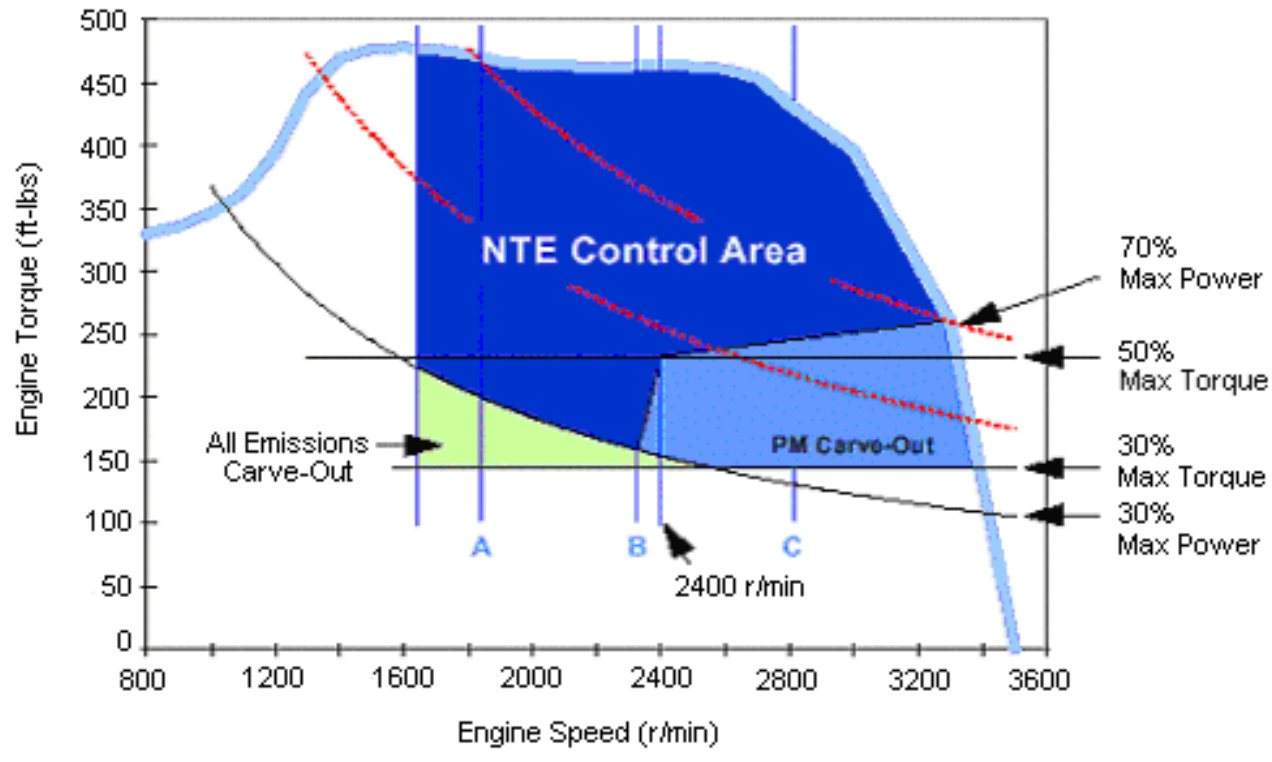

Figure 68: NTE Control Area [9] 


\section{Appendix B: Converting Data to Distance-Based Program}

Sub distancespecificalgorythm1()

' This Excel Macro was written to convert data as a function of time to data as a 'function of distance. The macro examines the calculated distances and if the current 'examined distance and the previous distance overlap the 0.01-mile interval than the 'previous and current values are interpolated in relation to the distance. This new values 'are recorded in a new column

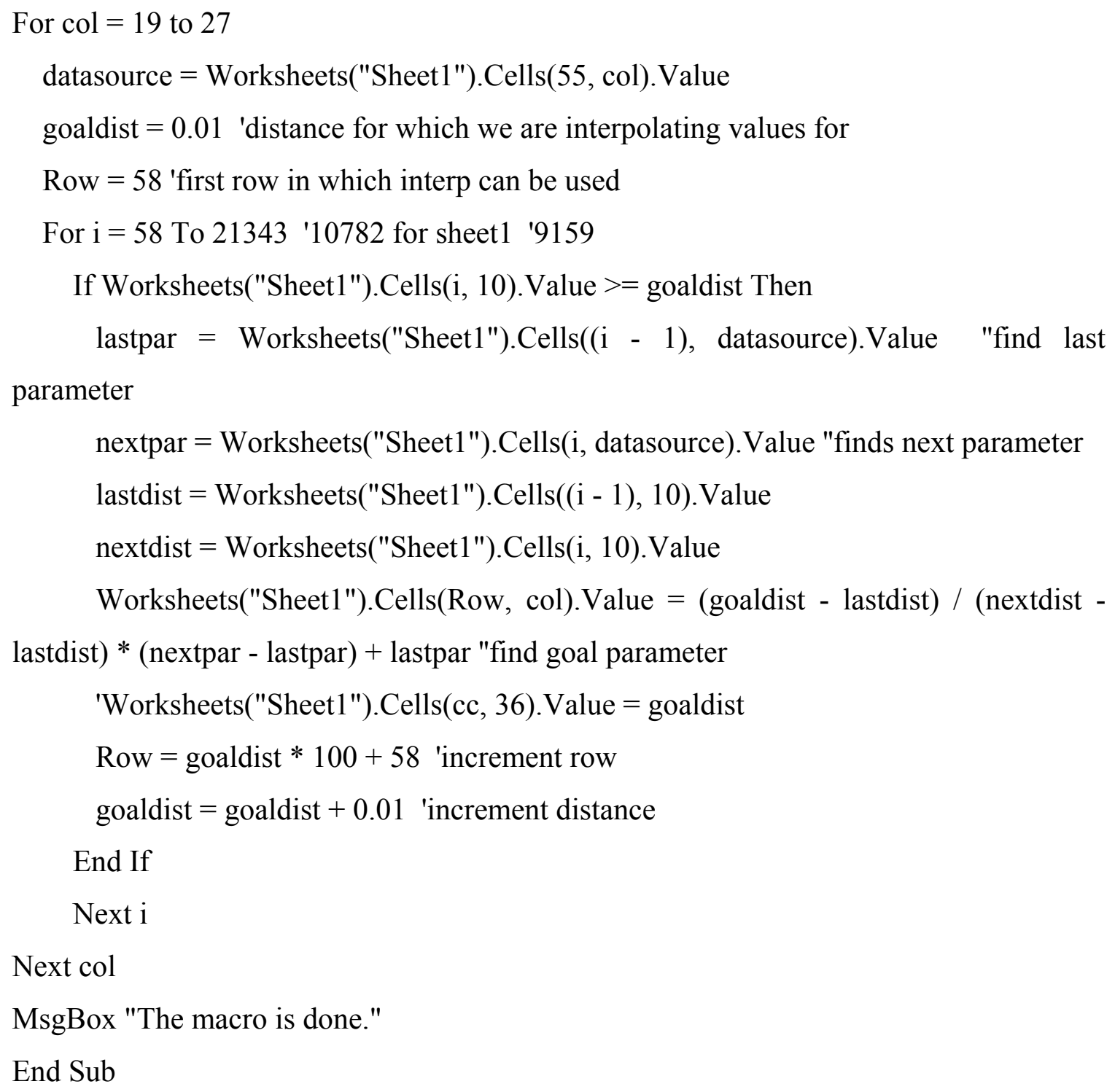




\section{Appendix C: 3-Dimensional Linear Regression Program}

This Excel Macro was written to find the R-squared valued for 3-dimensional linear regression using an "exact line".

Sub error3d()

' error3d Macro

' Macro recorded 6/24/2003 by Axel Radermacher

' Macro to find error of points using a 3d version of linear regression

' where at every distance interval the values are considered a point in $3 \mathrm{~d}$ (possible $4 \mathrm{~d}$ ) space called PointC

' trendline is set to an ideal angle where all points would be if runs are identical

' trendline is from $(0,0,0)$ called linepointA to $(100,100,100)$ called linepointB in $3 \mathrm{~d}$ space

' the error is the distance the point is from the "trendline" when the errorline and trendline are perpendicular

'trendline and error line intersect at point $\mathrm{D}$

'line from A to D is called idealline because this is where the datapoint would exist had the runs been identical

$$
\begin{aligned}
& \text { linepointA } 1=0 \\
& \text { linepointA2 }=0 \\
& \text { linepointA3 }=0 \\
& \text { linepointB1 }=100 \\
& \text { linepointB2 }=100 \\
& \text { linepointB3 }=100
\end{aligned}
$$

'For col = 19 To 24 Step 1 'column 25 is g/bhphr and it has NaN

$$
\begin{aligned}
& \text { col }=26 \\
& \text { sumerror }=0 \\
& \text { sumideal }=0
\end{aligned}
$$




$$
\begin{gathered}
\text { For Row }=58 \text { To } 2052 \text { Step } 1 \\
\text { pointC } 1=\text { Worksheets("Sheet1").Cells(Row, col).Value } \\
\text { pointC2 }=\text { Worksheets("Sheet2").Cells(Row, col).Value } \\
\text { pointC2 }=\text { Worksheets("Sheet3").Cells(Row, col).Value } \\
\text { pointC3 }=\text { Worksheets("Sheet4").Cells(Row, col).Value }
\end{gathered}
$$

' because the points on the "exact" line are always the same these equations are used

$$
\text { Line } \mathrm{AB}=(\text { linepointB } 1 \wedge 2+\operatorname{linepointB} 2 \wedge 2+\operatorname{linepointB} 3 \wedge 2)^{\wedge} 0.5
$$$$
\text { Line } \mathrm{AC}=\left(\text { pointC } 1^{\wedge} 2+\operatorname{pointC}^{\wedge} \wedge 2+\operatorname{pointC}^{\wedge} \wedge 2\right)^{\wedge} 0.5
$$$$
\text { LineBC1 = pointC1 - linepointB1 }
$$$$
\text { LineBC2 }=\text { pointC2 - linepointB2 }
$$$$
\text { LineBC3 }=\text { pointC3 - linepointB3 }
$$$$
\text { LineBC }=(\operatorname{LineBC} 1 \wedge 2+\operatorname{LineBC} 2 \wedge 2+\operatorname{LineBC} 3 \wedge 2)^{\wedge} 0.5
$$

' $\mathrm{S}=$ semiperimeter

$$
\mathrm{S}=(\text { Line } \mathrm{AB}+\text { Line } \mathrm{AC}+\mathrm{LineBC}) / 2
$$

, $\mathrm{t}=$ area of triangle

$$
\begin{aligned}
& \mathrm{t}=(\mathrm{s} *(\mathrm{~s}-\text { Line } \mathrm{AB}) *(\mathrm{~s}-\text { LineAC }) *(\mathrm{~s}-\text { LineBC })) \wedge 0.5 \\
& \text { distError }=2 * \mathrm{t} / \text { LineAB }
\end{aligned}
$$

' line from $\mathrm{A}$ to $\mathrm{D}$, idealline

$$
\begin{aligned}
& \text { ideal }=\left(\operatorname{LineAC}^{\wedge} 2-\operatorname{distError}^{\wedge} 2\right)^{\wedge} 0.5 \\
& \text { sumerror }=\text { sumerror }+\operatorname{distError}^{\wedge} 2 \\
& \text { sumideal }=\text { sumideal }+\operatorname{ideal}^{\wedge} 2
\end{aligned}
$$

\section{Next Row}

$$
\mathrm{r}=1 \text { - sumerror / sumideal }
$$

Worksheets("3d error").Cells(2, col - 18).Value $=r$

'Next col

End Sub 


\section{Appendix D: Repeatability Results}

Table 55: Repeatability analysis of MEMS vehicle over Morgantown route.

\begin{tabular}{|l|c|c||c|}
\hline & MEMS\#10 & MEMS\#11 & Average \\
\hline Vehicle Speed & 0.993 & 0.997 & 0.995 \\
\hline Engine Speed & 0.993 & 0.995 & 0.994 \\
\hline Torque & $\mathbf{0 . 8 5 6}$ & 0.889 & $\mathbf{0 . 8 7 2}$ \\
\hline Power & $\mathbf{0 . 8 5 3}$ & 0.897 & $\mathbf{0 . 8 7 5}$ \\
\hline $\mathrm{CO}_{2}(\mathrm{~g} / \mathrm{sec})$ & 0.925 & 0.943 & 0.934 \\
\hline $\mathrm{NO}_{\mathrm{x}}(\mathrm{g} / \mathrm{sec})$ & 0.918 & 0.952 & 0.935 \\
\hline Gear & 0.991 & 0.993 & 0.992 \\
\hline Time & 0.999 & 0.997 & 0.998 \\
\hline NTE Zone & $\mathbf{0 . 8 4 4}$ & $\mathbf{0 . 8 7 3}$ & $\mathbf{0 . 8 5 8}$ \\
\hline \hline Average & 0.930 & 0.948 & 0.939 \\
\hline
\end{tabular}

Table 56: Repeatability analysis of MEMS vehicle over Sab2BM route.

\begin{tabular}{|l|c|c||c|}
\hline & MEMS\#8 & MEMS\#12 & Average \\
\hline Vehicle Speed & 0.999 & 0.999 & 0.999 \\
\hline Engine Speed & 0.996 & 0.994 & 0.995 \\
\hline Torque & 0.930 & 0.933 & 0.931 \\
\hline Power & 0.929 & 0.936 & 0.932 \\
\hline $\mathrm{CO}_{2}(\mathrm{~g} / \mathrm{sec})$ & 0.963 & 0.968 & 0.966 \\
\hline $\mathrm{NO}_{\mathrm{x}}(\mathrm{g} / \mathrm{sec})$ & 0.957 & 0.960 & 0.959 \\
\hline Gear & 0.998 & 0.993 & 0.995 \\
\hline Time & 0.998 & 0.988 & 0.993 \\
\hline NTE Zone & 0.938 & 0.938 & 0.938 \\
\hline \hline Average & 0.968 & 0.968 & 0.968 \\
\hline
\end{tabular}


Table 57: Repeatability analysis of MEMS vehicle over BM2Sab route.

\begin{tabular}{|l|c|c||c|}
\hline & MEMS\#8 & MEMS\#12 & Average \\
\hline Vehicle Speed & 0.997 & 0.988 & 0.992 \\
\hline Engine Speed & 0.989 & 0.992 & 0.991 \\
\hline Torque & $\mathbf{0 . 5 9 4}$ & 0.901 & $\mathbf{0 . 7 4 7}$ \\
\hline Power & $\mathbf{0 . 4 4 7}$ & 0.900 & $\mathbf{0 . 6 7 3}$ \\
\hline $\mathrm{CO}_{2}(\mathrm{~g} / \mathrm{sec})$ & $\mathbf{0 . 9 4 6}$ & 0.945 & 0.946 \\
\hline $\mathrm{NO}_{\mathrm{x}}(\mathrm{g} / \mathrm{sec})$ & 0.951 & 0.916 & 0.933 \\
\hline Gear & 0.980 & 0.984 & 0.982 \\
\hline Time & 0.998 & 0.997 & 0.998 \\
\hline NTE Zone & 0.910 & 0.898 & 0.904 \\
\hline \hline Average & 0.868 & 0.947 & 0.907 \\
\hline
\end{tabular}

Table 58: Repeatability analysis of MEMS vehicle over Sab2SW route.

\begin{tabular}{|l|c|c||c|}
\hline & MEMS\#8 & MEMS\#12 & Average \\
\hline Vehicle Speed & 0.996 & 0.997 & 0.997 \\
\hline Engine Speed & 0.987 & 0.989 & 0.988 \\
\hline Torque & $\mathbf{0 . 8 4 2}$ & 0.895 & $\mathbf{0 . 8 6 9}$ \\
\hline Power & $\mathbf{0 . 8 1 5}$ & 0.888 & $\mathbf{0 . 8 5 1}$ \\
\hline $\mathrm{CO}_{2}(\mathrm{~g} / \mathrm{sec})$ & 0.931 & 0.935 & 0.933 \\
\hline $\mathrm{NO}_{\mathrm{x}}(\mathrm{g} / \mathrm{sec})$ & 0.922 & 0.925 & 0.924 \\
\hline Gear & 0.982 & 0.994 & 0.988 \\
\hline Time & 0.989 & 0.986 & 0.987 \\
\hline NTE Zone & 0.896 & 0.897 & 0.897 \\
\hline \hline Average & 0.929 & 0.945 & 0.937 \\
\hline
\end{tabular}

Table 59: Repeatability analysis of MEMS vehicle over SW2Sab route.

\begin{tabular}{|l|c|c||c|}
\hline & MEMS\#8 & MEMS\#12 & Average \\
\hline Vehicle Speed & 0.990 & 0.998 & 0.994 \\
\hline Engine Speed & 0.983 & 0.993 & 0.988 \\
\hline Torque & $\mathbf{0 . 7 9 8}$ & 0.886 & $\mathbf{0 . 8 4 2}$ \\
\hline Power & $\mathbf{0 . 7 3 5}$ & 0.885 & $\mathbf{0 . 8 1 0}$ \\
\hline $\mathrm{CO}_{2}(\mathrm{~g} / \mathrm{sec})$ & 0.909 & 0.936 & 0.923 \\
\hline $\mathrm{NO}_{\mathrm{x}}(\mathrm{g} / \mathrm{sec})$ & 0.895 & 0.919 & 0.907 \\
\hline Gear & 0.977 & 0.993 & 0.985 \\
\hline Time & 0.997 & 1.000 & 0.999 \\
\hline NTE Zone & 0.862 & 0.893 & 0.878 \\
\hline \hline Average & 0.905 & 0.945 & 0.925 \\
\hline
\end{tabular}


Table 60: Repeatability analysis of MEMS vehicle over PA1 route.

\begin{tabular}{|l|c|c|c||c|}
\hline & MEMS\#8 & MEMS\#12 & MEMS\#11 & Average \\
\hline Vehicle Speed & 0.988 & 0.987 & 0.985 & 0.987 \\
\hline Engine Speed & 0.985 & 0.988 & 0.988 & 0.987 \\
\hline Torque & $\mathbf{0 . 7 8 6}$ & $\mathbf{0 . 7 2 1}$ & $\mathbf{0 . 8 2 8}$ & $\mathbf{0 . 7 7 8}$ \\
\hline Power & $\mathbf{0 . 7 8 8}$ & $\mathbf{0 . 7 4 0}$ & $\mathbf{0 . 8 4 1}$ & $\mathbf{0 . 7 8 9}$ \\
\hline $\mathrm{CO}_{2}(\mathrm{~g} / \mathrm{sec})$ & 0.882 & $\mathbf{0 . 8 5 9}$ & 0.898 & $\mathbf{0 . 8 8 0}$ \\
\hline $\mathrm{NO}_{\mathrm{x}}(\mathrm{g} / \mathrm{sec})$ & $\mathbf{0 . 8 7 2}$ & $\mathbf{0 . 8 5 6}$ & 0.910 & $\mathbf{0 . 8 8 0}$ \\
\hline Gear & 0.976 & 0.976 & 0.984 & 0.978 \\
\hline Time & 0.993 & 0.996 & 0.995 & 0.995 \\
\hline NTE Zone & $\mathbf{0 . 8 1 1}$ & $\mathbf{0 . 7 2 4}$ & $\mathbf{0 . 8 2 8}$ & $\mathbf{0 . 7 8 8}$ \\
\hline \hline Average & 0.898 & 0.872 & 0.917 & 0.896 \\
\hline
\end{tabular}

Table 61: Repeatability analysis of MEMS vehicle over PA2 route.

\begin{tabular}{|l|c|c|c|c||c|}
\hline & MEMS\#8 & MEMS\#12 & MEMS\#10 & MEMS\#11 & Average \\
\hline Vehicle Speed & 0.996 & 0.984 & 0.978 & 0.993 & 0.988 \\
\hline Engine Speed & 0.992 & 0.987 & 0.985 & 0.990 & 0.989 \\
\hline Torque & 0.890 & $\mathbf{0 . 7 8 4}$ & $\mathbf{0 . 7 7 6}$ & $\mathbf{0 . 8 4 6}$ & $\mathbf{0 . 8 2 4}$ \\
\hline Power & 0.893 & $\mathbf{0 . 7 9 9}$ & $\mathbf{0 . 7 7 3}$ & $\mathbf{0 . 8 6 2}$ & $\mathbf{0 . 8 3 2}$ \\
\hline $\mathrm{CO}_{2}(\mathrm{~g} / \mathrm{sec})$ & 0.934 & 0.884 & $\mathbf{0 . 8 6 7}$ & 0.908 & 0.898 \\
\hline $\mathrm{NO}_{\mathrm{x}}(\mathrm{g} / \mathrm{sec})$ & 0.937 & $\mathbf{0 . 8 6 9}$ & $\mathbf{0 . 8 3 3}$ & 0.909 & 0.887 \\
\hline Gear & 0.993 & 0.981 & 0.985 & 0.990 & 0.987 \\
\hline Time & 1.000 & 0.986 & 0.980 & 0.999 & 0.991 \\
\hline NTE Zone & 0.884 & $\mathbf{0 . 7 7 9}$ & $\mathbf{0 . 8 0 2}$ & $\mathbf{0 . 8 4 1}$ & $\mathbf{0 . 8 2 7}$ \\
\hline \hline Average & 0.947 & 0.895 & 0.887 & 0.927 & 0.914 \\
\hline
\end{tabular}

Table 62: Repeatability analysis of MEMS vehicle over $P A 3$ route.

\begin{tabular}{|l|c|c|c|c||c|}
\hline & MEMS\#8 & MEMS\#12 & MEMS\#10 & MEMS\#11 & Average \\
\hline Vehicle Speed & 0.998 & 0.996 & 0.997 & 0.998 & 0.997 \\
\hline Engine Speed & 0.995 & 0.992 & 0.997 & 0.997 & 0.995 \\
\hline Torque & 0.934 & $\mathbf{0 . 8 4 7}$ & 0.894 & 0.930 & 0.901 \\
\hline Power & 0.934 & $\mathbf{0 . 8 5 2}$ & 0.883 & 0.926 & 0.899 \\
\hline $\mathrm{CO}_{2}(\mathrm{~g} / \mathrm{sec})$ & 0.961 & 0.909 & 0.947 & 0.960 & 0.944 \\
\hline $\mathrm{NO}_{\mathrm{x}}(\mathrm{g} / \mathrm{sec})$ & 0.954 & 0.907 & 0.940 & 0.948 & 0.937 \\
\hline Gear & 0.994 & 0.990 & 0.999 & 0.999 & 0.996 \\
\hline Time & 1.000 & 0.996 & 1.000 & 0.999 & 0.999 \\
\hline NTE Zone & 0.922 & $\mathbf{0 . 8 3 3}$ & $\mathbf{0 . 8 5 5}$ & 0.892 & $\mathbf{0 . 8 7 5}$ \\
\hline \hline Average & 0.966 & 0.925 & 0.946 & 0.961 & 0.949 \\
\hline
\end{tabular}




\section{Appendix E: Speed/Load Distribution Program}

The following Excel Macro was used to find the time distribution at speed/load set points for the comparison of routes to the FTP.

Sub bubblechart1()

' bubblechart Macro

' Macro recorded 7/11/2003 by Axel Radermacher

' Macro finds the $\%$ time spent at each speed load point to display in bubble chart.

rowout $=57$

"Worksheets("Sheet1").Cells(51, 12).Formula = "=max(A:A)"

For engspeedset $=-10$ To 130 Step 10

For engloadset $=-40$ To 100 Step 10

$$
\begin{aligned}
& \text { Count }=0 \\
& \text { For Row }=57 \text { To } 22000 \\
& \quad \text { engspeed }=\text { Worksheets("Sheet1").Cells(Row, 12).Value } \\
& \text { engload }=\text { Worksheets("Sheet1").Cells(Row, 13).Value }
\end{aligned}
$$

If engload $=$ "" Then

$$
\text { maxtime }=\text { Worksheets("Sheet1").Cells(Row - 1, 1).Value }
$$$$
\text { Row }=22001
$$

End If

If engload $<-40$ Then

If engloadset $=-40$ Then

If engspeed $=$ engspeedset Then

$$
\text { Count }=\text { Count }+1
$$

End If

End If

End If 


$$
\begin{gathered}
\text { If engspeed }=\text { engspeedset Then } \\
\text { If engload }=\text { engloadset Then } \\
\text { Count }=\text { Count }+1
\end{gathered}
$$

End If

\title{
End If
}

Next Row

\begin{abstract}
Value $=$ Count $/($ maxtime $* 5) * 100$
Worksheets("Sheet1").Cells(rowout, 15).Value = engspeedset

Worksheets("Sheet1").Cells(rowout, 16).Value = engloadset

Worksheets("Sheet1").Cells(rowout, 17).Value = Value

rowout $=$ rowout +1
\end{abstract}

Next engloadset

Next engspeedset

End Sub 


\section{Appendix F: COV\% and Coefficient of Repeatability Comparison}

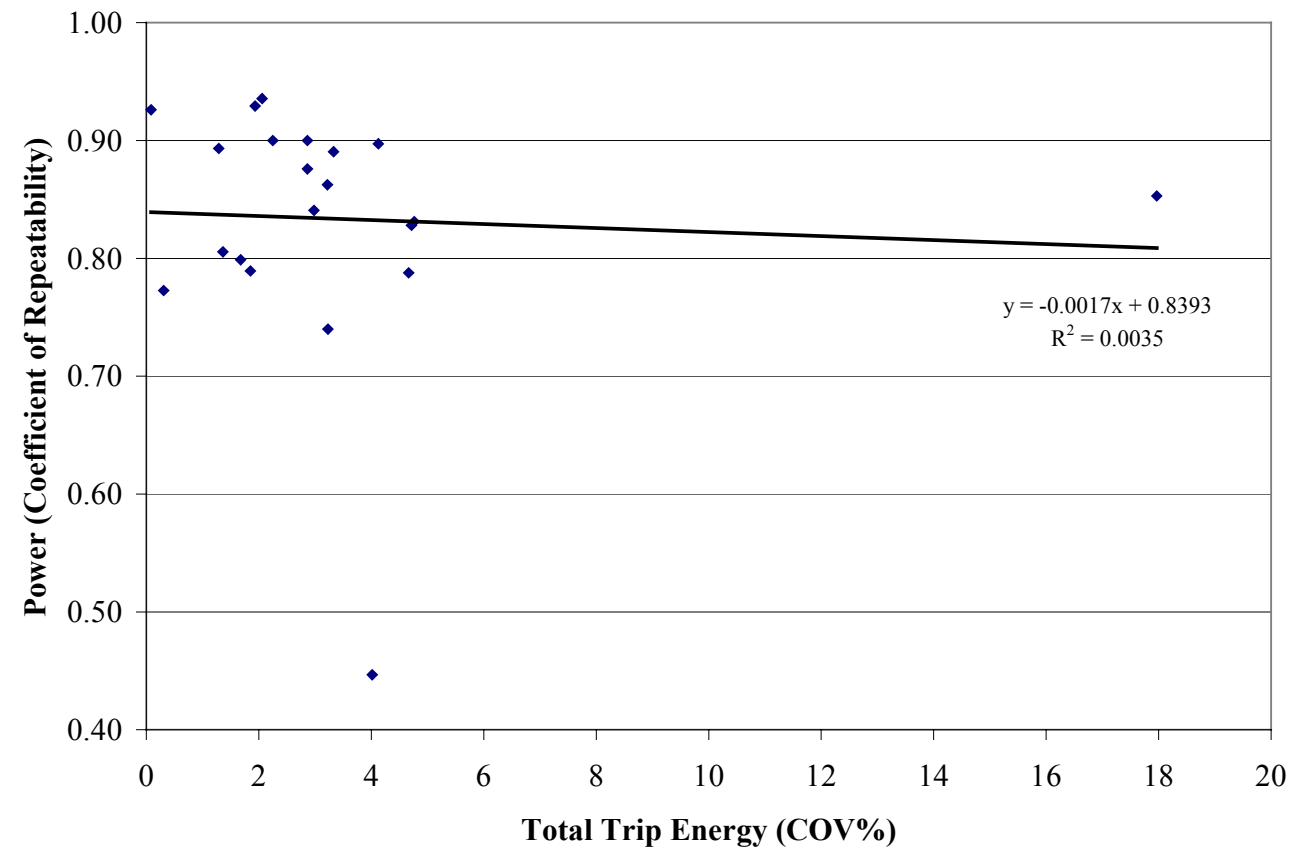

Figure 69: Comparison of COV\% for total trip energy (bhp-hr) and power coefficient of repeatability.

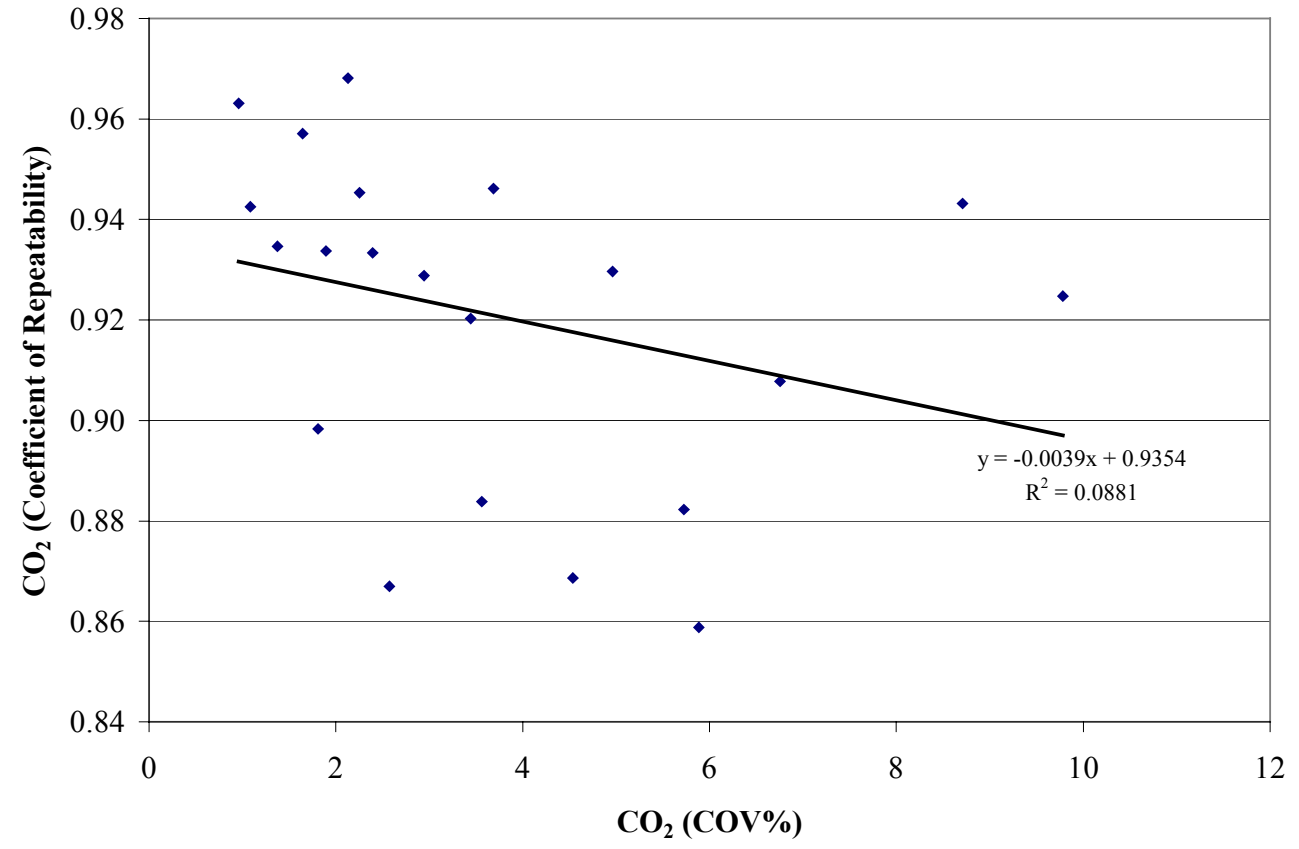

Figure 70: Comparison of $\mathrm{COV} \%$ for $\mathrm{CO}_{2}(\mathrm{~g} / \mathrm{mile})$ to $\mathrm{CO}_{2}$ coefficient of repeatability. 


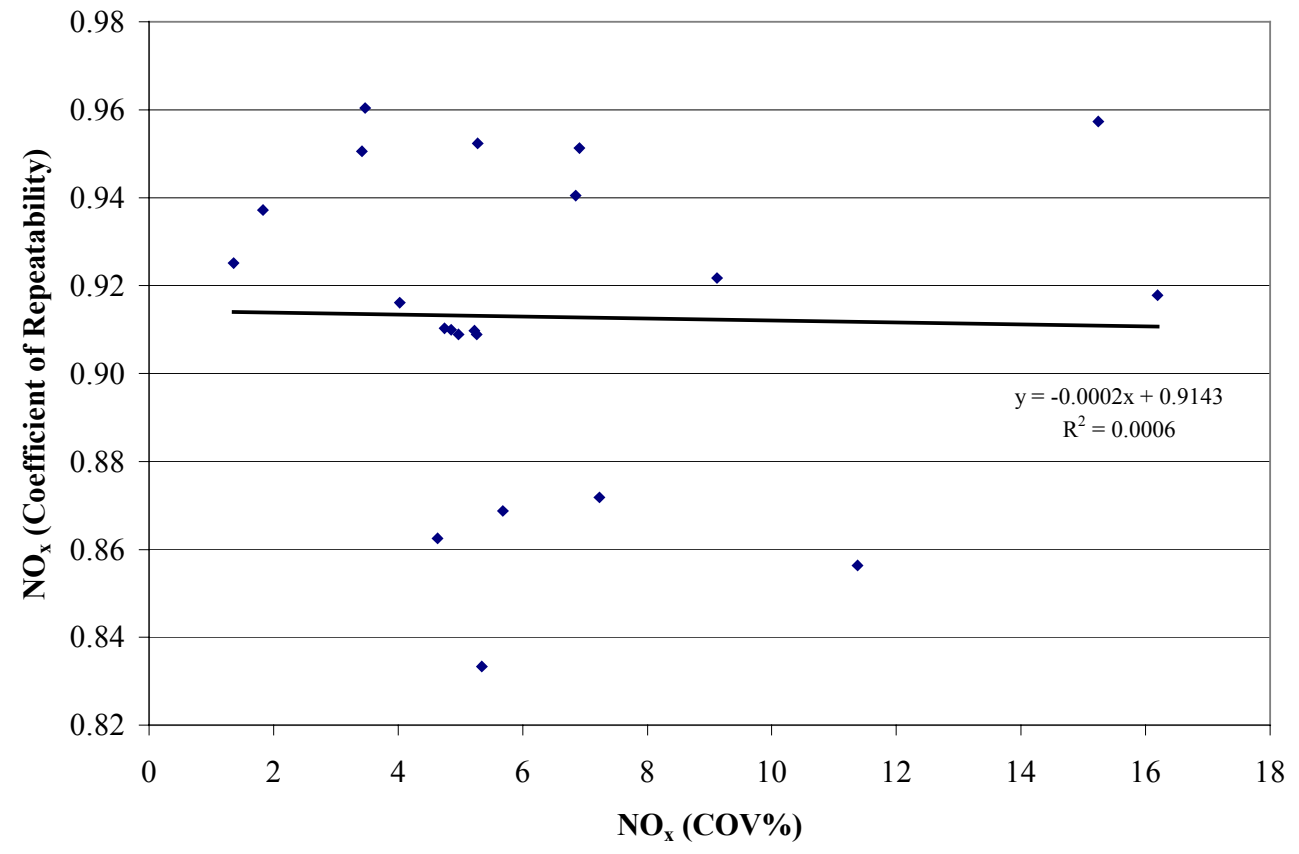

Figure 71: Comparison of $\mathrm{COV} \%$ for $\mathrm{NO}_{\mathrm{x}}(\mathrm{g} / \mathrm{mile})$ to $\mathrm{NO}_{\mathrm{x}}$ coefficient of repeatability. 